\title{
The multi-scale interaction between the atmosphere, cryosphere and extreme topography in High Mountain Asia
}

De multi-schaal interactie tussen de atmosfeer, cryosfeer en de extreme topografie in het Aziatisch hooggebergte

(met een samenvatting in het Nederlands)

\section{PROEFSCHRIFT}

ter verkrijging van de graad van doctor aan de Universiteit Utrecht op gezag van de rector magnificus, prof. dr. H.R.B.M. Kummeling, ingevolge het besluit van het college voor promoties in het openbaar te verdedigen op vrijdag 20 november 2020 des middags te 12.45 uur

door

Pleun Neeltje Jacobien Bonekamp

geboren op 5 oktober 1992 te Oss 


\section{Promotoren:}

Prof. dr. W.W. Immerzeel

Prof. dr. ir. M.F.P. Bierkens

This research was funded by the European Research Council (ERC) under the European Union Horizon 2020 Research and Innovation program (Grant no. 676819) 
PhD thesis

\title{
The multi-scale interaction between the atmosphere, cryosphere and extreme topography in High Mountain Asia
}

\author{
Pleun Bonekamp
}

Utrecht 2020

Faculty of Geosciences

Utrecht University 


\section{Promotoren:}

Prof. dr. W.W. Immerzeel

Prof. dr. ir. M.F.P. Bierkens

Examination committee:

Prof. dr. M.R. van den Broeke

Utrecht University, The Netherlands

Prof. dr. H.J. Fowler

Newcastle University, United Kingdom

Prof. dr. B.J.M.M. van den Hurk

VU University Amsterdam, The Netherlands

Prof. dr. F. Pellicciotti

Swiss Federal Institute for Forest, Snow and Landscape Research, Switzerland

Prof. dr. I. Stiperski

Innsbruck University, Austria

ISBN: 978-90-6266-584-6

Published by Faculty of Geosciences of Utrecht University, the Netherlands in:

Utrecht Studies in Earth Sciences (ISSN 2211-4335)

Printed by Ipskamp Drukkers B.V., Enschede, The Netherlands

Correspondence to Pleun Bonekamp, pleunbonekamp@gmail.com

On the cover: Schematic overview of snow and rain processes in complex terrain (P.N.J. Bonekamp)

\section{(c) (1) $\Theta \Theta$ \\ BY NC ND}

(C) 2020 Pleun N.J. Bonekamp

This work is licenced under Creative Commons Attribution-NonCommercialNoDerivatives 4.0 International Licence (https://creativecommons.org/licenses/bync-nd/4.0/).

Chapters 2 to 5 and Appendices are based on final author versions of published articles, (C) by Pleun N.J. Bonekamp and co-authors. More information and citation suggestions are provided at the beginning of these chapters. 
Climate is what you expect - weather is what you get

R.A. Heinlen 



\section{Contents}

$\begin{array}{ll}\text { Summary } & 1\end{array}$

$\begin{array}{ll}\text { Samenvatting } & 5\end{array}$

1. Introduction 9

1.1 Background and importance of glaciers in HMA . . . . . . . . . . . 10

1.2 Climate of HMA . . . . . . . . . . . . . . . . . . . . . . 11

1.2.1 Synoptic scale . . . . . . . . . . . . . . . . . . . . 11

1.2.2 Catchment-scale . . . . . . . . . . . . . . . 12

1.2 .3 Micro-scale . . . . . . . . . . . . . . . . . 13

1.3 Glaciers in HMA . . . . . . . . . . . . . . . . . . . . . . . . . 13

1.3.1. Glaciers types . . . . . . . . . . . . . . . . . . . . . . 13

1.3.2. The glacier surface energy balance . . . . . . . . . . . . . . . . . . 14

1.3.3. Karakoram Anomaly . . . . . . . . . . . . . . . . . . . . . . . . . 14

1.4 Climate change in HMA . . . . . . . . . . . . . . . . . . . . 16

1.4.1 Observed changes . . . . . . . . . . . . . . . . 16

1.4 .2 Projected changes . . . . . . . . . . . . . . . . . . 16

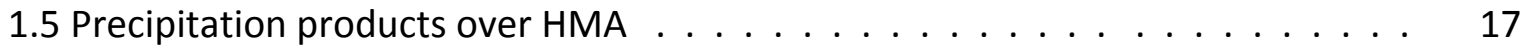

1.6 Atmospheric modelling . . . . . . . . . . . . . . . . . . . . 18

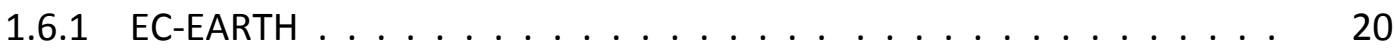

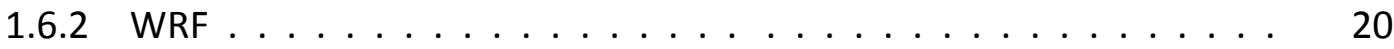

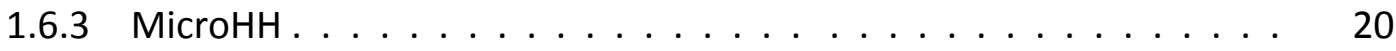

1.6.4 Glacier representation in atmospheric models . . . . . . . . . . 21

1.7 Research objectives and thesis outline . . . . . . . . . . . . . . . 22

2. Using 3D turbulence-resolving simulations to understand the impact of surface 25 properties on the energy balance of a debris-covered glacier

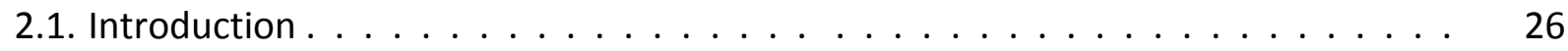

2.2. Methods . . . . . . . . . . . . . . . . . . . . . . . . 29

2.2.1. Study area . . . . . . . . . . . . . . . . . . . . . . 29

2.2.2. Field measurements . . . . . . . . . . . . . . . . . . 29

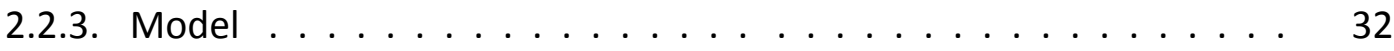

2.2.4. Boundary conditions . . . . . . . . . . . . . . . . 34

2.2.5. Vertical profile . . . . . . . . . . . . . . . . 35

2.2.6. Experiments . . . . . . . . . . . . . . . . 35 


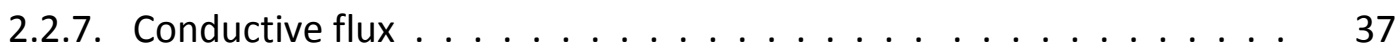

2.3. Results 38

2.3.1. Spatial distribution of LHF and SHF. . . . . . . . . . . . . . 38

2.3.1.1. Surface roughness . . . . . . . . . . . . . . 38

2.3.1.2. Surface temperature . . . . . . . . . . . . . . 40

2.3.1.3. Surface specific humidity . . . . . . . . . . . . 41

2.3.1.4. Spatial variation of elevation, surface temperature and 41 specific humidity

2.3.2. Vertical distribution of temperature, wind and specific humidity. . . 41

2.3.3. Spatial analysis . . . . . . . . . . . . . . . . . 46

2.3.3.1. Debris . . . . . . . . . . . . . . . . 46

2.3.3.2. Ice cliff . . . . . . . . . . . . . . . . . . . 47

2.3.3.3. AWS measurement comparison . . . . . . . . . . . 47

2.3.4. Surface energy balance . . . . . . . . . . . . . . . . . 48

2.3.5. Ice cliff analysis . . . . . . . . . . . . . . . . . . 51

2.4. Sensitivity to Reynolds number . . . . . . . . . . . . . . . . . . . 53

2.5. Limitations . . . . . . . . . . . . . . . . . . . . . . . . . . . . . 54

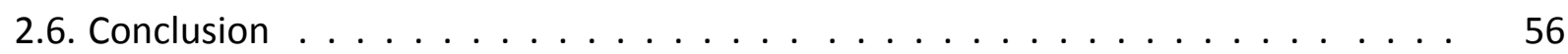

3. The Impact of Spatial Resolution, Land Use, and Spinup Time on Resolving Spatial 59 Precipitation Patterns in the Himalayas

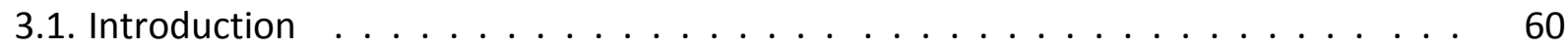

3.2. Methods ........................... 62

3.2.1. Study area . . . . . . . . . . . . . . . . . . . . 62

3.2.2. Simulation period and measurements . . . . . . . . . . 63

3.2.3. Model . . . . . . . . . . . . . . . . . . . . . . . 64

3.2.4. Numerical experiments. . . . . . . . . . . . . . . . . . . 65

3.2.5. Statistical evaluation. . . . . . . . . . . . . . . . . 66

3.2.6. Snow correction factor . . . . . . . . . . . . . . . . . . . . 67

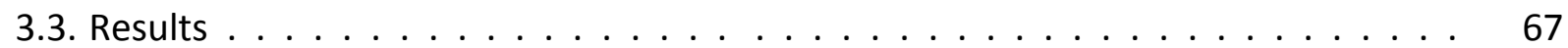

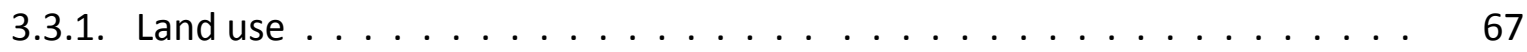

3.3.2. Spin up time . . . . . . . . . . . . . . . . . 68

3.3.3. Spatial resolution . . . . . . . . . . . . . . . . . . . 71

3.3.4. Optimal model configuration. . . . . . . . . . . . . . . . . . 76

3.3.5. Correction for under-catch of snow. . . . . . . . . . . . . . . . 78

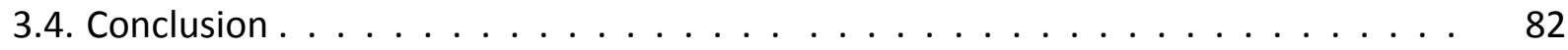


4. Contrasting Meteorological Drivers of the Glacier Mass Balance Between the 85 Karakoram and Central Himalaya

4.1. Introduction . . . . . . . . . . . . . . . . . . . . 86

4.2. Methods . . . . . . . . . . . . . . . . . . . . . . . . . 87

4.2.1. Study area . . . . . . . . . . . . . . . . . . . 87

4.2.2. Model ......................... 88

4.2.3. Glacier mass balance . . . . . . . . . . . . . . . . . . . . . . . 89

4.3. Results . . . . . . . . . . . . . . . . . . . . . . . . 91

4.3.1. Precipitation temperature and wind . . . . . . . . . . . . . 91

4.3.2. Origin of precipitation events . . . . . . . . . . . . . . . 92

4.3.3. Glacier energy balance . . . . . . . . . . . . . . . . . . . . . . . . . 97

4.3.4. Glacier surface mass balance . . . . . . . . . . . . . . . . . . . . . . . 100

4.4. Discussion . . . . . . . . . . . . . . . . . . . . . . . 102

4.4.1. Model performance . . . . . . . . . . . . . . . . . . . . . . 102

4.4.2. WRF caveats . . . . . . . . . . . . . . . . . . . . . 104

4.4.3. Climate sensitivity . . . . . . . . . . . . . . . . . . . 105

4.5. Conclusion . . . . . . . . . . . . . . . . . . . . 106

5. Shifts in meteorological extremes in High-Mountain Asia using large ensemble 109 modelling

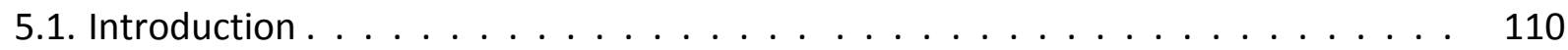

5.2. Methods . . . . . . . . . . . . . . . . . . . . . . . 111

5.2.1. Climate indicators . . . . . . . . . . . . . . . . . . 113

5.3. Results and discussion . . . . . . . . . . . . . . . . . . . . . 114

5.3.1. Performance of EC-Earth in HMA . . . . . . . . . . . . . . . . . . . . . . . 114

5.3.2. Changes in mean monthly temperature and precipitation . . . . . . . . . . 116

5.3.3. Return periods of temperature and precipitation . . . . . . . . . . . . . . 120

5.3.4. Mountain relevant climate indicators . . . . . . . . . . . . . . . . . . . . 122

5.3.5. DT sensitivity per region for the relevant indicators . . . . . . . . . . . 126

5.4. Conclusion . . . . . . . . . . . . . . . . . . . . . . . 128

6. Synthesis 131

6.1. How do turbulent fluxes drive the energy exchange on debris-covered glaciers? . . 132

6.2. Orographic-climate interactions at catchment scale . . . . . . . . . . . . . . . . . 134

6.3. Meteorological drivers of the Karakoram anomaly . . . . . . . . . . . . . . . . . . 135

6.4. Climate change impacts on meteorological extremes . . . . . . . . . . . . . . 137

6.5. Recommendations and outlook . . . . . . . . . . . . . . . . . . 138

6.5.1. Observations versus models . . . . . . . . . . . . . . . . . . . 138 
6.5.2. Small-scale process understanding . . . . . . . . . . . . . . . . . 139

6.5.3. Computational advances . . . . . . . . . . . . . . . . . . . . . . 140

6.5.4. High-resolution insights in coarser resolution models . . . . . . . . . . . . . 141

6.5.5. Integrated approach . . . . . . . . . . . . . . . . . . . . . . 141

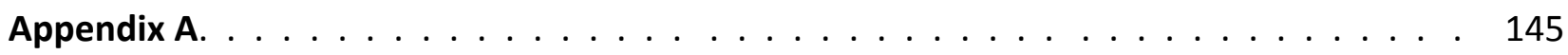

Appendix B . . . . . . . . . . . . . . . . . . . . . . . . 147

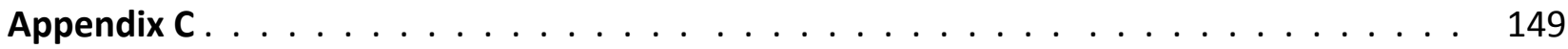

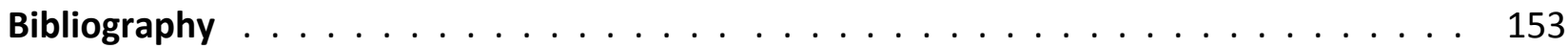

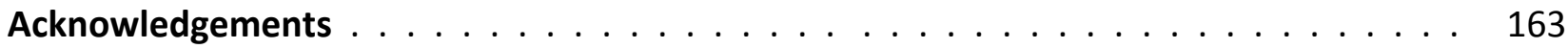

About the author $\ldots \ldots \ldots \ldots \ldots \ldots$

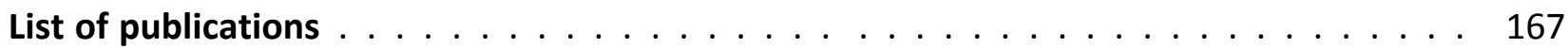

Selected conference abstracts $\ldots \ldots \ldots \ldots \ldots$

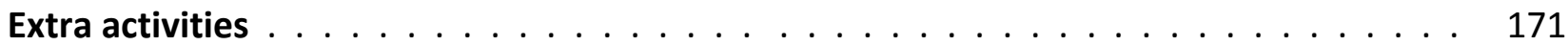




\section{Summary}

Atmospheric processes control hydrological processes (e.g. precipitation), and cryospheric processes (e.g. the glacier surface energy balance), and are key to understanding our changing climate (e.g. weather extremes). However, atmospheric processes in high mountain environments are not well understood, as measurements are scarce due to the inaccessibility of the terrain, while operational models and remote sensing products have too coarse a resolution to resolve the complex topography. Atmospheric modelling therefore plays an important role in improving the understanding of the water cycle at high altitude and in complex terrain.

The main objective of this thesis is to advance the knowledge of high-altitude climate dynamics, from micro to synoptic scales, with a special focus on high-altitude precipitation and the interaction between the atmosphere, the extreme topography and the cryosphere in High Mountain Asia. The objective is achieved by analysing four cases at different spatial resolutions with a variety of atmospheric model codes. The MicroHH model code is used for turbulent resolving simulations to investigate turbulent fluxes on a debris-covered glacier. The WRF model code is used to investigate the effect of surface boundary conditions and to perform a climate assessment for the Central Himalayas and Karakoram region. Finally, a large ensemble of the ECEARTH model runs is used to investigate weather extremes in High Mountain Asia for different climates.

At the micro-scale the effect of turbulent fluxes on the surface energy balance of a debriscovered glacier is unravelled by DNS (Direct Numerical Simulation) at $1 \mathrm{~m}$ resolution with the novel MicroHH model code. The effects of surface properties of debris on the spatial distribution of micro meteorological variables, such as wind fields, moisture and temperature are investigated with sensitivity tests. Subsequently, how these properties drive the turbulent fluxes and eventually the conductive heat flux for a debris-covered glacier are investigated. Results show that turbulent fluxes can decrease the energy available for melt at the debris surface during daytime by $40 \%$ and act as a sink of energy, while on ice cliffs turbulent fluxes enhance the energy for melt by $51 \%$ and are therefore a contributor to melt. As a result, ice cliffs become - in combination with low albedo - melt hot spots.

At catchment scale the effects of spatial resolution on patterns of precipitation, wind speed and temperature are studied with the WRF model and compared to measurements. The effects of 
spatial resolution, spin-up time and land use on near-surface meteorological variables, are studied. It is shown that modelling at sub-kilometre scale results in more realistic amounts and patterns of precipitation in complex terrain. This suggests that future modelling studies in complex terrain should consider sub-kilometre grids or parameterizations in order to more accurately resolve local meteorological variability. The sensitivity of these meteorological variables to spin-up time is larger in summer than during winter, and is not linear. The impact of land use on precipitation is more pronounced during the summer. This is through the way it affects the latent heat flux.

Glaciers In the Karakoram and Kunlun Shan ranges are in equilibrium or even gaining mass, which is in sharp contrast with the negative mass balances in the rest of High Mountain Asia. At regional scale, meteorological drivers of this Karakoram anomaly are investigated by a novel multi-year high-resolution comparative study with WRF. The accumulation and melt dynamics differ by its contrasting seasonal and altitudinal distribution of snowfall and surface energy balance components. Glaciers in the Karakoram are more sensitive to long-wave radiation from clouds, and summer snow events are important drivers of the surface energy balance because of their effect on the surface albedo. It is shown that the understanding of glacier mass balance anomalies requires quantification and insight into subtle shifts in the energy balance and accumulation regimes at high altitude, and that the sensitivity of glaciers to climate change is regionally variable.

A regional assessment in High Mountain Asia of climate indicators at large scale is addressed in relation to temperature and precipitation (positive degree days, accumulated precipitation, preand post- monsoon precipitation), their sensitivity to temperature change and the change in return periods of extreme temperature and precipitation in a climate that has warmed first by $2^{\circ} \mathrm{C}$ and then by $3^{\circ} \mathrm{C}$. Data is analysed for three large (2000 year) ensembles of present day climate and for both a $2^{\circ} \mathrm{C}$ and $3^{\circ} \mathrm{C}$ warmer world produced with the EC-EARTH model. Strong seasonal and regional differences in temperature and precipitation change exist between a $2^{\circ} \mathrm{C}$ and $3^{\circ} \mathrm{C}$ warmer world. A $2^{\circ} \mathrm{C}$ warmer world shows a fairly homogeneous response, while distinct differences between regions are present in a $3^{\circ} \mathrm{C}$ warmer world. Differences between wet and dry seasons are amplified in monsoon-dominated regions with drier winters and wetter monsoon periods in the future compared to present-day climate. The return periods of extreme temperature and precipitation events decrease in a warmer climate, and in general lowfrequency events change more than less frequent events. Overall, the largest changes in climate indicators can be found in the Hindu Kush and Himalaya. East Himalaya is by far the most affected 
region, where changes in 7 out of 8 climate indicators are greater than anywhere in HMA. The increase in weather extremes will affect the number and intensity of natural hazards. Our results are of great importance for climate change adaptation strategies in HMA.

Computational advances open opportunities to model weather and climate at very high resolution. However, two main challenges remain: how to combine high-resolution insights into coarser resolution models and how to establish the direct coupling with glacio-hydrological models. High-resolution models can now be used as a stand-alone, operational model or as a validation tool for coarser models. Future research should focus on the benefits of very highresolution models compared to coarser models and an ideal resolution and complexity should be found for different purposes. Additionally, the increase in computational power enables the use of large ensemble modelling to gain insight into the uncertainty of the outcomes. In order to also gain insight into model uncertainty, unity in the set-up of future large ensembles is preferred.

This thesis shows that atmospheric modelling is a valuable tool to investigate the current state and future fate of cryospheric features in mountainous environments. Advances in atmospheric modelling are seen to play an important role in improving the understanding of the water cycle in high altitudes and complex terrain. Future research should aim for a more integrated approach between meteorology, glaciology and hydrology. This will result in a better interpretation of the impacts of climate change on the hydrological cycle and on cryospheric change. This would improve our understanding of current climate, advance climate and hydrological projections for the future, and would directly benefit the quality of climate change adaptation strategies in mountainous environments. 


\section{Samenvatting}

Atmosferische processen hebben grote invloed op hydrologische processen (bv. neerslag), cryosferische processen (bv de energiebalans van het gletsjeroppervlak) en zijn essentieel om het veranderende klimaat, bijvoorbeeld extreme weersomstandigheden, te begrijpen. Echter, de atmosferische processen in hooggebergten worden momenteel nog niet volledig begrepen, omdat metingen schaars zijn vanwege de ontoegankelijkheid van het gebied; en operationele modellen en satelliet producten een te grove resolutie hebben om de complexe topografie representatief weer te geven. Atmosferisch modelleren speelt daarom een belangrijke rol in het verbeteren van het begrijpen van de waterkringloop op grote hoogte en in complex terrein.

Het belangrijkste doel van dit proefschrift is om de kennis over klimaatdynamica op grote hoogte te vergroten van de micro- tot de mesoschaal, met speciale aandacht voor neerslag op grote hoogte en de interactie tussen de atmosfeer, de extreme topografie en de cryosfeer in het Aziatisch hooggebergte. Dit doel wordt bereikt door vier cases met verschillende ruimtelijke schalen te analyseren met verschillende atmosferische modellen. De MicroHH-modelcode wordt gebruikt om turbulente fluxen op een puingletsjer te onderzoeken. De WRF-modelcode wordt gebruikt om het effect van randvoorwaarden te onderzoeken en om te analyseren welke meteorologische variabelen van belang zijn voor de aangroei en smelt van gletsjers in twee klimatologisch contrasterende valleien in de Himalaya en Karakoram respectievelijk. Tenslotte wordt gebruik gemaakt van een groot ensemble van runs met het EC-EARTH-model om het voorkomen van extreme weersomstandigheden in het Aziatisch hooggebergte onder verschillende (toekomstige) klimaten te onderzoeken.

Op microschaal wordt het effect van turbulente fluxen op de energiebalans van een puingletsjer ontrafeld door deze te simuleren met DNS (Direct Numerical Simulation) op een resolutie van 1 meter met MicroHH. De effecten van de eigenschappen van puin op de ruimtelijke verdeling van meteorologische variabelen, zoals windvelden, vocht en temperatuur worden onderzocht met gevoeligheidstesten. Vervolgens wordt onderzocht hoe die turbulente fluxen de netto energie balans beïnvloeden. Onze resultaten tonen aan dat turbulente fluxen de energie die beschikbaar is voor smelt aan het oppervlak overdag met $40 \%$ kan verminderen en daarom kan fungeren als een bron van energie, terwijl turbulente fluxen op ijskliffen deze energie juist met $51 \%$ versterken en daarom bijdragen aan een versnelde smelt. Het resultaat is dat ijskliffen -in combinatie met hun lage albedo- smelt hotspots zijn. 
Op vallei-schaal zijn de effecten van de ruimtelijke resolutie, spin-up tijd en landgebruik op ruimtelijke patronen in neerslag, windsnelheid en temperatuur bestudeerd met het WRF-model en vergeleken met observaties. Aangetoond is dat atmosferisch modelleren op sub-kilometer schaal resulteert in realistischere neerslaghoeveelheden en -patronen in complex terrein en dit suggereert dat toekomstige modelstudies rekening zouden moeten houden met een resolutie kleiner dan 1 kilometer om de lokale meteorologische variabiliteit nauwkeurig op te lossen. De gevoeligheid van meteorologische variabelen op de spin-up tijd is groter in de zomer dan in de winter en is niet lineair. Landgebruik beïnvloedt voornamelijk de neerslaghoeveelheden in de zomer doordat dit de latente warmtestroom rechtstreeks beïnvloed.

In de Karakoram- en Kunlun Shan-regios zijn gletsjers in evenwicht of neemt de massa zelfs toe, wat in contrast staat met het massaverlies van gletsjers in de rest van het Aziatisch hooggebergte. Op regionale schaal zijn meteorologische factoren van dit afwijkende gedrag onderzocht met een meerjarige, hoge resolutie simulatie van WRF. Ik laat zien dat de accumulatie en smeltdynamiek van gletsjers in de Karakoram verschillen door de contrasterende seizoens- en hoogteverdeling van sneeuwval en door verschillen in energiebalans componenten. Gletsjers in de Karakoram zijn gevoeliger voor langgolvige straling van wolken en tevens voor sneeuwval in de zomer, omdat sneeuw het oppervlakte albedo verhoogt en daarom de energie beschikbaar voor het smelten verlaagt. In deze thesis wordt aangetoond dat om afwijkingen in de massabalans van gletsjers te begrijpen, kwantificering van en inzicht in subtiele veranderingen in de energiebalans en accumulatie regimes op grote hoogte vereist is en dat de gevoeligheid van gletsjers voor klimaatverandering regionaal variabel is.

Op meso-schaal is een regionale analyse van klimaatindicatoren gedaan voor het Aziatisch hooggebergte met betrekking tot temperatuur en neerslag (positieve graaddagen, geaccumuleerde neerslag, (pre- en post-) moesson neerslag), hun gevoeligheid voor temperatuurverandering en de verandering van de herhalingstijd van extreme temperatuur en neerslag in een 2 en $3{ }^{\circ} \mathrm{C}$ warmer klimaat. Drie grote ensembles van 2000 jaar in het huidige klimaat en in een $2{ }^{\circ} \mathrm{C}$ en $3{ }^{\circ} \mathrm{C}$ warmere wereld, gemaakt met het EC-EARTH-model zijn geanalyseerd. Er bestaan sterke seizoensafhankelijke en regionale verschillen in temperatuur- en neerslagverandering tussen een $2{ }^{\circ} \mathrm{C}$ en $3{ }^{\circ} \mathrm{C}$ warmere wereld. Veranderingen in een $2{ }^{\circ} \mathrm{C}$ warmere wereld zijn vrijwel homogeen, terwijl duidelijke verschillen tussen regio's aanwezig zijn in een $3{ }^{\circ} \mathrm{C}$ warmere wereld. In moesson gedomineerde regio's worden de huidige verschillen tussen natte en droge seizoenen versterkt door een nog drogere winter en juist nattere moessonperiode in de toekomst. 
De herhalingstijd van extreme temperatuur- en neerslaggebeurtenissen wordt korter in een warmer klimaat, en in het algemeen veranderen zeldzame gebeurtenissen meer dan de frequentere gebeurtenissen. De grootste veranderingen in klimaatindicatoren zijn te vinden in de Hindu Kush en Himalaya. De oostkant van de Himalaya laat het sterkste effect zien, en de veranderingen van zeven van de acht klimaatindicatoren zijn in deze regio het grootst in vergelijking met alle andere regio's het Aziatisch hooggebergte. De toename in extreme weersomstandigheden zal het aantal en de intensiteit van natuurlijke rampen beïnvloeden. Onze resultaten zijn daarom van groot belang in de adaptatiestrategieën voor klimaatverandering in Azië.

De toename in computerrekenkracht biedt kansen om het weer en klimaat op een zeer hoge resolutie te modelleren. Er blijven echter twee grote uitdagingen bestaan: hoe deze hogeresolutie-inzichten geïntegreerd kunnen worden in modellen met een grovere resolutie en hoe deze direct gekoppeld kunnen worden aan glacio-hydrologische modellen. Hogeresolutiemodellen kunnen momenteel gebruikt worden als een op zichzelf staand, operationeel model of als validatietool voor de grovere resolutie modellen. Toekomstig onderzoek moet de voordelen van hoge-resolutiemodellen in vergelijking met grovere modellen vaststellen zodat de ideale resolutie en complexiteit gevonden kan worden voor verschillende modeldoeleinden. Hiernaast maakt de toename van rekenkracht het mogelijk om grote model ensembles te creëren om inzicht te krijgen in de onzekerheid van de uitkomsten. Om ook inzicht te krijgen in de modelonzekerheid zouden toekomstige ensembles met andere klimaatmodellen dezelfde set-up up moeten hebben.

Dit proefschrift laat zien dat atmosferisch modelleren een waardevolle toevoeging is om de huidige toestand en toekomstige veranderingen van de cryosfeer in bergachtige omgevingen te onderzoeken. Vooruitgang in atmosferische modellering speelt daarom een belangrijke rol bij het verbeteren van het begrip van de waterkringloop op grote hoogte en in complex terrein. Toekomstig onderzoek zou moeten streven naar een meer geïntegreerde benadering tussen meteorologie, glaciologie en hydrologie zodat de hydrologische cyclus beter begrepen wordt en cryosferische veranderingen als gevolg van klimaatverandering beter in kaart worden gebracht. Dit zou ons begrip van het huidige klimaat vergroten; de klimaat- en hydrologische projecties voor de toekomst verbeteren; en adaptatiestrategieën ondersteunen om de gevolgen van klimaatverandering in bergachtige gebieden het hoofd te bieden. 


\section{1}

Introduction

A quarter of the earth's surface is covered by mountains (Kapos et al., 2000), supplying fresh water to 1.6 billion people worldwide (Immerzeel et al., 2020). Fresh water is unevenly distributed across the planet, with problems of distribution and sharing manifesting for more than 5000 years (Gleick, 1993). Water conflicts are now getting ever more common as fresh water, a primary basic need, becomes even scarcer. Water is therefore also called the new oil (Robins and Fergusson, 2014). Water regions are generally not bounded by national borders, and this complicates geopolitical negations (Gleick, 1993). Examples are reduced water availability in downstream areas by upstream damming, water extraction or water pollution (i.e. Lundqvist and Falkenmark, 2000).

Although the height of the largest mountain peak on earth (Mount Everest, $8.8 \mathrm{~km}$ ) is not even $0.1 \%$ of the earth's radius (6371 km), mountains have a profound influence on the global climate. This is because the bulk of the planet's atmospheric mass (75\%) is located in the lowest layer of the earth's atmosphere (the troposphere), and contains $99 \%$ of the total water vapour. The thickness of this layer varies dependent on its geographical location but, globally averaged, the troposphere is 13 kilometres thick and thus of the same order of magnitude as the elevations in high-altitude mountain ranges.

Mountains are generally defined as "substantial elevations of the Earth's crust above sea level which result in localized disruptions to climate, drainage, soils, plants and animals" (Goudie, 1985). The earth's major mountain ranges have a typical longitudinal dimension of 1000 kilometres (e.g. the Alps, Andes, Himalayas, and the Rockies) which act as natural flow barriers. 
Mountains generate precipitation as they force the air mass upwards, decreasing the water holding capacity of air. This results in climatic regions that are often bounded by mountain ranges with wet climates often found on the windward slopes of the mountains, while dry climates can be found in the lee of mountain ranges. A clear example of this is the tropical climate in Nepal and the arid Tibetan Plateau in Asia. The distinction between the two climatic zones is clearly visible on satellite imagery. The orientation of mountains in relation to the main wind direction is important in defining a clear distinction between the climatic regions.

Mountain ranges both precipitate moisture and have a large water buffering capacity - and are therefore often referred to as water towers (Immerzeel et al., 2020; Viviroli et al., 2007). Water can be stored at high altitudes in solid form as glaciers, snow and permafrost or in liquid form as ground water. Stored water will be released back to the hydrological cycle at different time scales. Glaciers, for example, provide water in dry seasons (Marzeion et al., 2014) while permafrost can persist for decades (Hiyama et al., 2013).

\subsection{Background and importance of glaciers in HMA}

The High Mountains of Asia (HMA) contain roughly one hundred thousand glaciers with a total glacier area of almost $100.000 \mathrm{~km}^{2}$ (RGI Consortium, 2017). After Greenland and Antarctica this is the largest reservoir of stored fresh water and therefore HMA is often referred to as Third Pole (Qiu, 2008). Glaciers in HMA provide fresh water to ten major rivers in this region and 800 million people are dependent on its water resources for food supply, energy generation and domestic use (Pritchard, 2019). This water use is projected to increase due to both population growth and an increase in welfare and living standards (Wester et al., 2019)

Climate change will affect glaciers and therefore water availability by changing the accumulation and ablation through changes in precipitation and in temperature. This immediately stresses the need for an interdisciplinary approach involving both the atmospheric and cryospheric sciences to properly understand and predict the cryospheric response to climate change.

For rivers dependent on glacier runoff, melting glaciers are projected to first increase river discharge through increased melt water, followed by a future reduction in river discharge once this melt has resulted in a decrease in glacier volume (Huss and Hock, 2018; Immerzeel et al., 2013; Shea et al., 2015). In rivers less dependent on glacier runoff, changes in pre-monsoon and monsoon precipitation will be major drivers of changes in future river runoff (Lutz et al., 2014). High Mountain Asia is a region of high interest due to the population density in combination with 
a high vulnerability to climate change. A detailed understanding of the behaviour of glaciers in HMA is required to plan adaptations to climate change.

\subsection{Climate of HMA}

High Mountain Asia includes the mountain ranges of the Himalaya, Karakoram, Pamir, Hindu Kush, Tien Shan, and the Tibetan Plateau. These mountain ranges influence the climate at different scales. The synoptic scale circulations define the general climate but smaller catchmentscale and micro-scale processes define the final and local climate (Barros et al., 2004). The main feedbacks between the topography and climate are discussed in the following paragraphs.

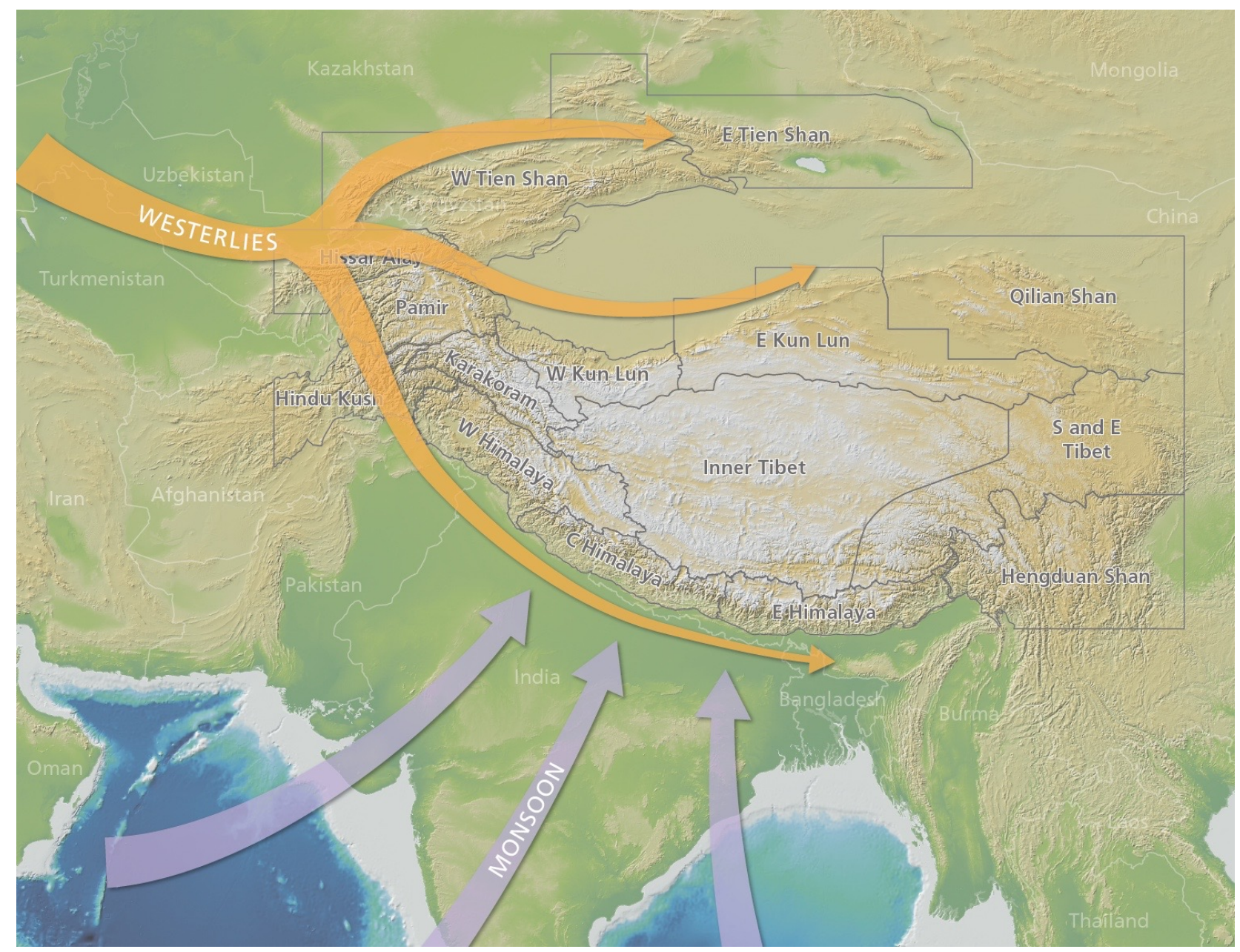

Figure 1.1: Overview of the main mountain ranges, climate systems and rivers in High Mountain Asia (Markus, 2020)

\subsubsection{Synoptic scale}

At the synoptic scale the climate is dominated by Westerly winds and by the Indian monsoon (Figure 1.1). The importance of the Westerlies decreases to the East, while that of the monsoon decreases to the West (Bookhagen and Burbank, 2010). Westerlies have a seasonal shift (south- 
north movement) and varying intensity (Kuang and Zhang, 2005). In the Karakoram up to twothird of the precipitation falls as snow during winter (Hewitt, 2005), while in the Himalayas $80 \%$ of the precipitation falls during summer (Ghosh et al., 2009).

The monsoon starts in June and transports warm and moist air northwards from the equator, leading to high temperatures and high precipitation amounts from June to September. This air interacts with the two-step topography and results in two precipitation geographical peaks corresponding to the topography (Bookhagen and Burbank, 2010). Consequently, there is a clear south-north decrease in precipitation, where regions north of the orographic barriers receive very little precipitation. The accumulated annual precipitation at the foot of the Himalayas can be over 3 metres, while at the Tibetan Plateau this is generally less than 0.5 metres (Maussion et al., 2014).

\subsubsection{Catchment scale}

Valleys are of great importance in the transport of water vapour up to the higher-elevated parts of High Mountain Asia, acting as a conduit in the supply of precipitation to these higher altitudes (Bookhagen and Burbank, 2010). Catchment-scale processes (order of tens of kilometres) are mainly driven by solar radiation and topography. During the day the sun heats the surface and causes air to rise (slope winds or anabatic winds), while during the night radiative cooling causes air to descend down the slopes (katabatic winds; see Figure 1.2). The term katabatic wind is also often used to describe smaller scale downward glacier winds, which generally develop during the day and are caused by the cold ice surface that cools the atmosphere. Valley winds are more developed and occur in a thicker layer (20-200m) than found for night-time katabatic winds (3$100 \mathrm{~m})$. This is because stable stratification restrains turbulent exchange between the surface and atmosphere (Zardi and Whiteman, 2013).
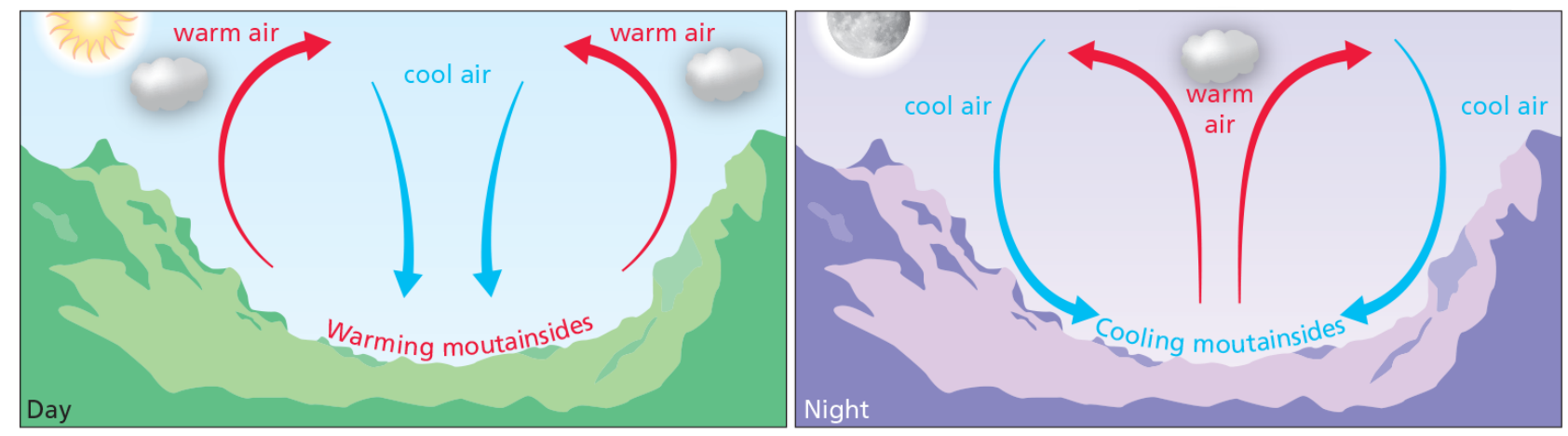

Figure 1.2: Typical day time and night time valley-circulations (Markus, 2020) 
At the valley scale the topography plays an important role with the air forced upwards due to the valley-circulations, causing clouds to form (Figure 1.2). Variation in cloud cover and precipitation can lead to differences in local climate within a catchment, potentially causing relatively dry and wet areas between or within catchments. The local climate may influence the glacier mass balance directly by affecting the snow accumulation and surface energy balance and should be carefully considered when making glacier mass balance projections

\subsubsection{Micro-scale}

Small-scale meteorological processes regulate micro-scale climate (in the order of metres) such as heat transport between the surface and atmosphere caused by turbulence. Turbulence can be represented by eddies and can be measured with an eddy covariance system taking high frequency measurements of horizontal and vertical wind speeds, air pressure, temperature and humidity. With these measurements the sensible and latent heat flux can be determined. Surface characteristics influence the heat exchange between the surface and atmosphere. Surface roughness, surface type and surface moisture are examples of factors that influence the microclimate of an area.

In summary, synoptic scale processes provide the boundary conditions for radiation, wind and moisture. Valley scale processes drive the local weather through the heating and cooling of the surface, the development of valley winds, and the formation of clouds due to the rising of warm air. At the micro scale the surface energy balance is influenced by turbulent processes, which depend on the surface temperature, roughness and moisture conditions. To gain a holistic insight in mountain weather patterns and how they interact with the cryosphere, it is essential to address all three scales and their interactions.

\subsection{Glaciers in HMA}

\subsubsection{Glacier types}

Mountain glaciers are characterized by two different surface types: clean ice glaciers and debriscovered glaciers. In the case of clean ice glaciers, glacier ice is directly exposed to the atmosphere, while debris on top of the glacier tongue forms the connection between the ice and atmosphere. This debris originates from erosion and deposition of the surrounding terrain and varies from silt to large boulders (Miles et al., 2017; Van Woerkom et al., 2019). The main effect of this debris is a higher surface temperature which influences the surface energy balance by emitting more longwave radiation and also receiving extra longwave radiation from its surrounding terrain (Steiner et al., 2015). Debris also increases the surface roughness, enhancing 
the energy exchange between the surface and atmosphere. Additionally, debris comprises an unsaturated surface that influences the conduction of heat through the debris material.

Debris decreases the glacier's albedo and thus increases the absorption of solar radiation. A thin layer of debris enhances the melt rate, while in the case of a thick debris layer the insulating effects are dominant and lead to decreased melt (Östrem, 1959). However, more recent observations show similar thinning rates for both clean ice and debris-covered glaciers (e.g. Gardelle et al., 2013; Kääb et al., 2012; Nuimura et al., 2017). This phenomenon has been referred to as the 'debris-cover anomaly' (Pellicciotti et al., 2015). Two explanations are proposed; first, the emergence velocity of debris-covered glacier tongues is lower, which can result in similar thinning rates even with lower melt rates (Anderson and Anderson, 2016). Secondly, supra-glacial features such as ice cliffs and ice ponds can accelerate glacier melt (Buri and Pellicciotti, 2018; Immerzeel et al., 2014a; Miles et al., 2018; Sakai et al., 2000; Steiner et al., 2019).

\subsubsection{Glacier surface energy balance}

A glacier is in steady state when the accumulation is equal to the ablation. Melt (M), is the main ablation component, and is driven by a positive surface energy flux, which can be approximated by:

$M=Q_{S W_{\_} \text {in }}-Q_{S W_{-} \text {out }}+Q_{l w_{-} \text {in }}-Q_{L W_{-} \text {out }}+Q_{H}+Q_{L}$

Where $Q_{s w_{-} \text {in }}$ and $Q_{s w_{-} \text {out }}$ are the shortwave incoming and outgoing radiation respectively, $Q_{L w_{-} \text {in }}$ and $Q_{L w_{-} \text {out }}$ the longwave incoming and outgoing radiation, $Q_{H}$ the sensible heat flux, and $Q_{L}$ the latent heat flux. Modelling or measuring the spatio-temporal variation in the glacier surface energy balance components gives insight in the total glacier surface energy balance and the importance of specific terms. The surface energy balance is an important component in the understanding of atmospheric exchange processes over complex terrain (De Wekker et al., 2018). The complexity of the specific individual components varies with resolution and will be discussed in relevant individual chapters in this thesis.

\subsubsection{Karakoram anomaly}

The Karakoram anomaly is the phenomenon of irregular behaviour of glaciers in the Karakoram region, where glaciers are stable or slightly gaining in mass, in contrast to diminishing glaciers in other parts of HMA (Figure 1.3). The Karakoram anomaly was firstly described by Hewitt (2005) 
and later confirmed by larger scale geodetic studies (Brun et al., 2017; Gardelle et al., 2012; Kääb et al., 2012) that extended the Karakoram region to the Eastern Pamir Kunlun Shan region.

Several explanations have been proposed for the Karakoram anomaly, including a difference in glacier response (Sakai and Fujita, 2017) and change in climatic forcing. The latter includes more winter precipitation (Forsythe et al., 2017), a change in seasonality (Kapnick et al., 2014), summer cooling (Fowler and Archer, 2005) and intensified irrigation that enhances local circulation patterns (de Kok et al., 2018). See Farinotti et al. (2020) for a recent overview.

A disadvantage of geodetic or observational studies is that they quantify only glacier surface height changes and devote limited attention to the actual drivers of this change. Meteorological observations show, for example, a cooling in summer - but this can also be a result of the Karakoram anomaly due to more snow and an expanded glacier surface, instead of a direct driver of the glacier surface increase (Fowler and Archer, 2006).

It is unknown whether this anomalous behaviour is temporary or systematic; this can be studied with atmospheric modelling. More generally, in order to improve our understanding of the cryospheric response to climate change, we need to gain further insight into several atmospherecryosphere feedbacks at different scales. Atmospheric modelling studies may provide these necessary insights.

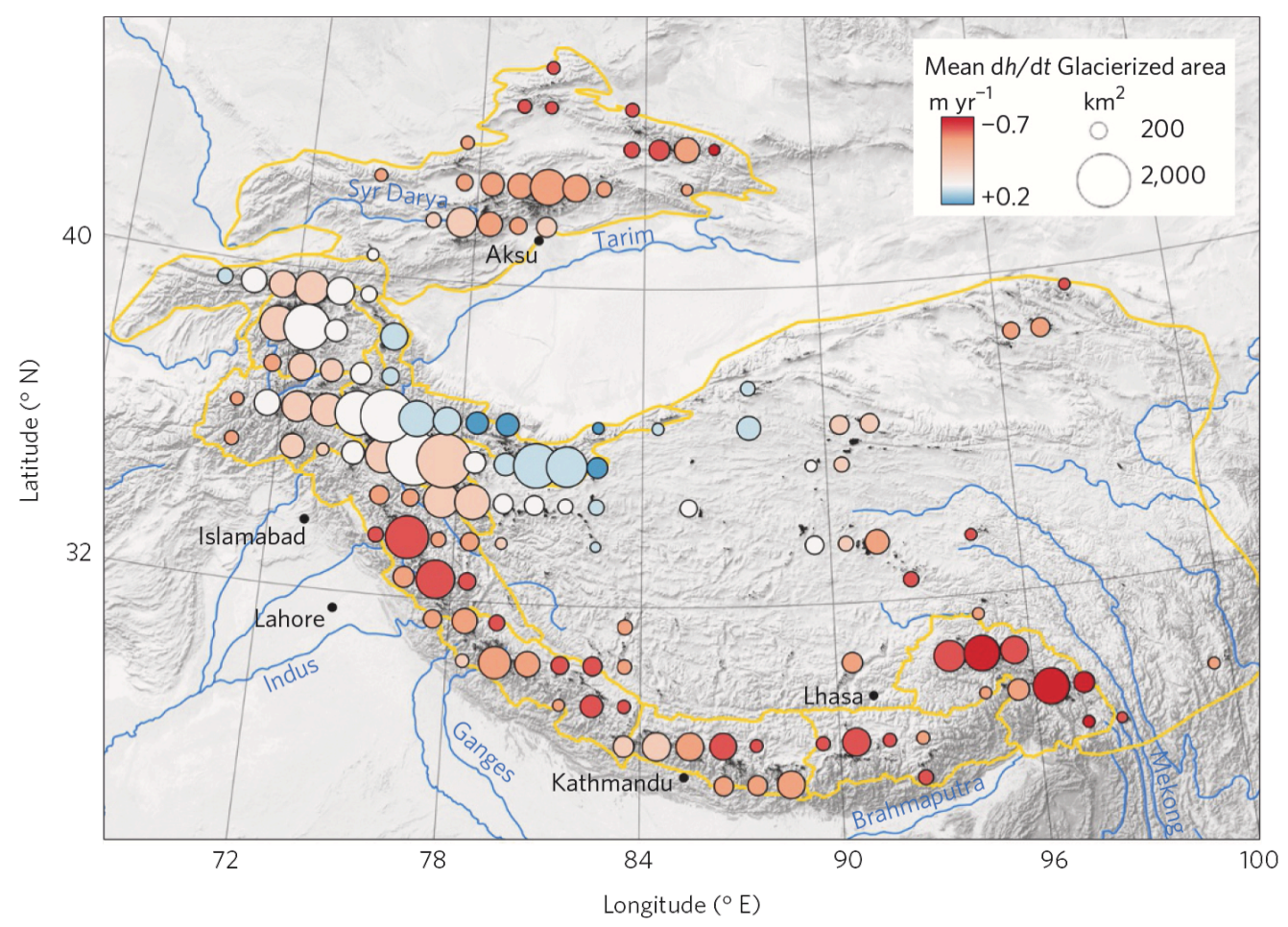

Figure 1.3: Glacier surface elevation changes in HMA over the period 2001-2016 (Brun et al., 2017) 


\subsection{Climate change in HMA}

\subsubsection{Observed changes}

HMA is sensitive to climate change. During the last decades HMA temperatures have risen faster than the global average (Liu and Chen, 2000), a phenomena known as elevation dependent warming (Pepin et al., 2015). Possible causes are: snow albedo and surface-based feedbacks; water vapour changes and latent heat release; surface water vapour and radiative flux changes; surface heat loss and temperature change; and aerosols (Pepin et al., 2015).

Currently, glaciers in HMA are retreating rapidly and under 1.5 degrees of global warming, compared to preindustrial greenhouse gas concentration and temperature levels, $36 \%$ of the glacier ice volume would be lost (Kraaijenbrink et al., 2017). This has large implications for regional water supply, and therefore regional water management. In the near future, a small increase in river flow during the summer months is expected together with increased flow in other seasons, while in the more distant future a decrease in summer flow and a stronger increase in flows in other months can be expected as the glaciers diminish (Lutz et al., 2016a). Extreme river discharge are projected to occur more often and intensify, which may have large implications for floods in the Indus region (Lutz et al., 2016b).

\subsubsection{Projected changes}

The Indus Basin strongly depends on glacier melt water and downstream water demands are high. $60 \%$ of the total irrigation requirement in the Indus basin originates from mountain snow and glacier melt during the pre-monsoon (Biemans et al., 2019). Lutz et al. (2016a) show water availability projections in year 2100 to range from $-15 \%$ to $+60 \%$; this is mainly caused by uncertainties in precipitation in this region as a consequence of climate change.

The CMIP5 models project, on average, slightly wetter summers in the Himalaya and HinduKush Himalaya in the $21^{\text {st }}$ century, while winter precipitation is projected to remain statistically stable (Palazzi et al., 2015). However predicting future climate in HMA is not straightforward and current climate models find it difficult to simulate the climate in HMA because of the role played by various processes at different scales (lacono et al., 2008; Palazzi et al., 2015). First, global circulation models are of too coarse a resolution $( \pm 50-100 \mathrm{~km})$ to resolve the steep topography, resulting in an underestimation of orographic lifting and consequent incorrect location of precipitation (Christensen et al., 2007). Second, parameterizations of unresolved processes are key to the correct simulation of the climate. Convective processes, for example, are identified as a major limitation in future projections of GCMs, since different atmospheric scales are involved 
in this process (Stevens and Bony, 2013). The existing convection parameterization schemes in GCMs are the main source of uncertainty when simulating precipitation, and all have different complexity and physical assumptions (classes of hydrometeors, using single or double moments; Arakawa, 2004).

\subsection{Precipitation products over HMA}

Unravelling climate dynamics at high-altitude, and precipitation patterns in particular, is one of the largest quests in understanding greater Himalayan hydrology (Immerzeel et al., 2015). The main input for hydrological models is precipitation data, and existing data sets have strong limitations in mountainous areas. Immerzeel et al. (2015) found, for example, that the water balance in HMA can only be closed if the local precipitation is, on average, double what was previously thought. Identifying the best precipitation product in HMA is not possible due to the lack of field observations, the complex topography, and different meteo-climatic regimes (Palazzi et al., 2013).

For highly heterogeneous regions, such as HMA, a coarse model resolution or coarse input data is unable to simulate hydrology or climate adequately, as many processes are misrepresented. So, for example, the smoothing of the topography results in both too little precipitation and a shift in precipitation patterns (Cannon et al., 2017). Additionally, coarse scale surface inputs (e.g. temperature, soil moisture) cannot represent glaciers and their feedbacks (Kotlarski et al., 2010).

Surface (point) observations to validate precipitation datasets are generally sparse in HMA, while these are almost entirely absent in the western HMA. Point observations are sparse, provide very limited spatial coverage, and are generally of low data quality. Snow measurements are especially sparse (and therefore uncertain), due to the undercatch of snow, and the occurrence of snow bridging on pluviometers (Groisman and Legates, 1994; Thériault et al., 2012). In a few wellequipped research catchments in the Himalayas, a relatively dense network of meteorological stations (automatic weather stations, pluviometers, tipping buckets) and hydrological stations (runoff measurements) can be found (Immerzeel et al., 2014; Salerno et al., 2015). In 2019, National Geographic installed the highest AWS $(8400 \mathrm{~m})$ on Earth on Mount Everest. This was in order to get more insight into high-altitude meteorology and is exceptional in that it offers the possibility of measuring the sub-tropical jet stream at this altitude (National Geographic, 2019).

Reanalysis data sets use satellite observations for data assimilation. In HMA the reanalysis data set ERA-Interim (Dee et al., 2011) is often used, since precipitation amounts have the best 
agreement of current available reanalyses with observations or satellite precipitation data sets (Palazzi et al., 2013). ERA-Interim over-estimates precipitation when compared to other gridded data sets and satellite products, yet it is in closest agreement with observations. It is likely that the satellite data sets have problems with the detection of snow. ERA-Interim was replaced by the higher resolution ERA5 data set in 2019 (ECMWF, 2019). Its higher resolution has meant that precipitation patterns and amounts are now better resolved than they were when using ERAInterim. A inter-comparison study by Copernicus (2017) shows that ERA5 gives increased precipitation amounts in steep terrain in High Mountain Asia when compared to ERA-Interim and is therefore even more distinct than ERA-Interim.

Besides reanalysis data sets, several other types of gridded precipitation data sets are available: 1. rain-gauge based collections (CRU, APHRODITE, GPCC), 2. satellite data sets (TRMM), 3. a raingauge and satellite combined product (GPCP), and 4. data output from climate models. A disadvantage of all gridded data sets is the coarse spatial resolution, which is only useful for large scale studies (Palazzi et al., 2013).

\subsection{Atmospheric modelling over HMA}

As observations are scarce and only provide information for a single point, modelling becomes a necessary tool to obtain spatial data, especially in heterogeneous terrain. Model resolution generally is a trade-off between the scale, the desired simulation period and the amount of computational time. The model resolution needs to be appropriate to resolve the process of interest. For example, to model large-scale circulation a resolution in the order of tens of kilometres is needed and to model valley-scale processes in the order of kilometres. It is not appropriate to model the East Indian monsoon at 100-metre resolution, or to model turbulent fluxes with a general circulation model.

General circulation models (GCM's) are among the most coarse climate models that couple atmosphere, cryosphere and land surface models, and solve fluid dynamic equations globally in a three-dimensional grid (see Figure 1.4). Sub-grid processes, such as convection are represented by parameterizations. The higher the resolution, the more processes are resolved explicitly in the model and model outcomes rely less on parameterizations. Direct numerical simulations (DNS) are located at the other end of the spectrum and fully solve the Navier-Stokes equations without the need for parameterizations. Between GCM's and DNS many other types of models are present with different degrees of sub-grid parameterizations (i.e. regional climate models and nested weather models). A standard method to represent sub-grid processes in coarser 
resolution models is not straightforward and corresponding uncertainties are unknown (Maraun et al., 2010).

Small-scale processes cannot be represented accurately in large-scale atmospheric models, because many of these processes take place at a smaller scale than the model grid resolution and it is computationally too expensive to run at a higher spatial resolution. Examples are the representation of cloud convection or turbulences, which are too expensive to resolve explicitly. Parameterizations obtained from higher resolution data are used to quantify the behaviour at coarser scale (e.g. temperature lapse rates, occurrence or formation of cloud presence).

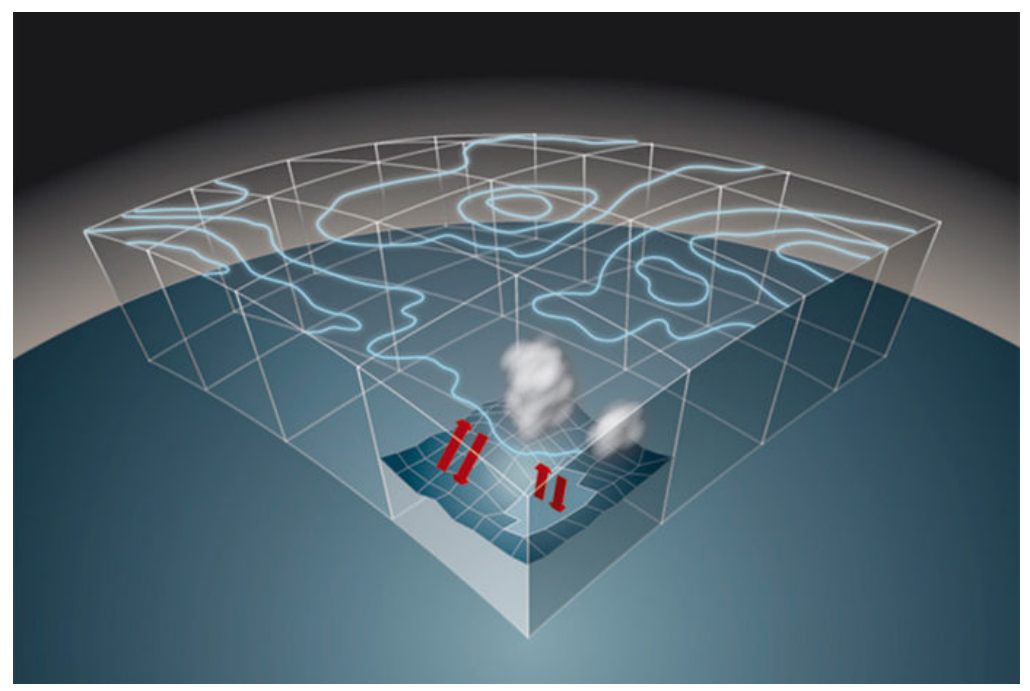

Figure 1.4: GCM model grid overview and representation of sub-grid processes (ECMWF, 2017).

One way of obtaining high-resolution data from coarse resolution data is through the application of dynamical or statistical downscaling. Statistical downscaling uses the relation between largescale meteorological variables, such as pressure, with local variables, such as wind speed, to downscale coarse resolution runs. Dynamical downscaling is the method of forcing a higher resolution model with coarser resolution data at its boundaries in order to simulate the climate at higher resolution. This is often done with regional models that are forced by global (coarse) data. A limitation is that this is computationally expensive when smaller scales become important, whereas the smallest scales (e.g. turbulence) still need to be parameterized. High-resolution modelling at different scales is therefore important in understanding the importance of smallscale processes and how to incorporate these into coarser resolution models.

High-resolution atmospheric (and other) models also need high-quality and high-resolution input data. However, the effect of the quality of surface boundary conditions is poorly known and the effect of correct land use classification will be investigated in this thesis. In this thesis several models will be used to simulate the weather at different scales in HMA. EC-EARTH is used for 
region-wide analysis, WRF for catchment modelling, and MicroHH for micro-scale modelling. These models are briefly discussed below:

\subsubsection{EC-EARTH}

EC-EARTH is a global Earth system model (Hazeleger et al., 2012) based on the numerical weather prediction system of the ECMWF (European Centre for Medium-Range Weather Forecasts). It includes an interactive atmosphere, ocean and sea ice coupling (including the poles). The atmospheric model is run on 1.125 degrees spatial resolution and has 62 vertical atmospheric layers (Hazeleger et al., 2012), with its lowest model level at 30 meter above the surface. ECEARTH is part of the Coupled Model Intercomparison Project Phase 5 and 6 (Taylor et al., 2012). It is used extensively for various climate topics and the simulated climate shows good agreement in HMA (Palazzi et al., 2013).

\subsubsection{WRF}

WRF, the Weather and Research and Forecasting model (Skamarock et al., 2008), is an open access numerical weather prediction model. It contains several schemes for surface, planetary boundary layer, radiation, cumulus and microphysics, which can be selected by the user. The model can run at any desired spatial resolution and has options for data nudging. Data nudging is a form of data assimilation and is often used in weather models by relaxation of the model outcome to observations (Hoke and Anthes, 1976). WRF has been used in HMA at different scales. Maussion et al. (2014) designed the High Asia Reanalysis (HAR) data set with WRF at $30 \mathrm{~km}$ and $10 \mathrm{~km}$ resolution. They showed that dynamical downscaling of coarse data sets reveals regional dynamics and is important for the formation of, for example, precipitation. At smaller scales $(1 \mathrm{~km})$ Collier and Immerzeel (2015) investigated the spatial and seasonal patterns of meteorological fields over the Langtang catchment. Many other studies exist and show this model is a useful tool to investigate catchment-scale meteorology (i.e. Cannon et al., 2016; Collier et al., 2013; Mölg and Kaser, 2011; Norris et al., 2018). Insight from high-resolution atmospheric data input will improve the local accuracy of impact studies (Collier and Immerzeel, 2015; Potter et al., 2018).

\subsubsection{MicroHH}

MicroHH is designed for Direct Numerical Modelling (DNS) and Large-Eddy Simulation (LES) of turbulent flows in the atmosphere based on computational fluid dynamics code (Heerwaarden et al., 2017). DNS explicitly solves all length scales in the atmospheric flow, while LES uses parameterizations for the smallest length scales in the atmosphere and is therefore computationally less expensive than DNS. This model can resolve flows from several centimetres to several hundreds of metres. It has been used successfully in the modelling of katabatic flows 
and nocturnal low-level jets (Fedorovich and Shapiro, 2009; Umphrey et al., 2017). This model has recently been adjusted to cater for heterogeneous surface boundary conditions (surface temperature and surface specific humidity) and allows for inhomogeneous terrain, both of which features are of great importance for (debris-covered) glacier modelling in HMA.

\subsubsection{Glacier representation in atmospheric models}

Glaciers affect the atmosphere through surface temperature, albedo and roughness. Due to their distinct properties, clean ice glaciers and debris-covered glaciers affect the overlying atmosphere in very different ways. Clean ice glaciers generally have a colder surface than the atmosphere, a high albedo, and low roughness length. These properties have a positive effect on air stability and limit ice-atmosphere turbulent exchange. The surface of debris-covered glaciers is quite different in that they are covered with lower albedo rocks and boulders, which warm during day and normally become warmer than the atmosphere. This enhances the instability of the air above the glacier and, together with the higher surface roughness, causes increased turbulent exchange and mixing of the atmosphere.

In atmospheric models, glaciers are generally modelled implicitly by the land-surface model. Each glacier pixel is defined by a (fixed) surface temperature, albedo and moisture content. Depending on the complexity of the model the depth and characteristics of the soil layer may also be taken into account (i.e. ECMWF, 2007; Heerwaarden et al., 2017; Skamarock et al., 2008). The most advanced method to model glaciers in an atmospheric model is to couple an atmospheric model to a physically-based climatic mass balance (CMB) modelling system such that it includes glacier CMB feedbacks to the atmosphere (Collier et al., 2013). This ensures two-way coupling effects between the glacier surface and atmosphere. A disadvantage of this framework is that this specific model coupling needs to be updated manually for every new version of either the atmospheric or glacier model.

In MicroHH the surface temperature, surface specific humidity, and the topography of the domain define the surface conditions. In WRF, the NOAH-MP scheme is used as the land-surface scheme (in this thesis). In this scheme clean ice glaciers have an albedo of 0.70 , a soil moisture availability of $95 \%$, surface emissivity $95 \%$, roughness length of $0.001 \mathrm{~m}$, and surface heat capacity of $910^{30} \mathrm{Jm}^{-3} \mathrm{~K}^{-1}$. Debris is not represented in the WRF model. In the case of EC-EARTH, clean ice glaciers and snow areas are based on the Global Land Cover Characteristics (GLCC; Loveland et al., 2000) data set. The glacier class is defined as a vegetation-free gridcell with a surface roughness length of $1.310^{-3}$ (momentum) and $1.310^{-4}$ (heat), and with albedo ranging between 0.5 and 0.85 depending on the snow age (ECMWF, 2007). 


\subsection{Research objective and thesis outline}

From the above it is evident that there are a number of major research challenges regarding the understanding of the weather and climate dynamics in HMA. At the smallest scales this relates, for example, to the interaction between a glacier surface and the atmosphere. At the catchment scale understanding how large-scale circulation interacts with the steep terrain, and how precipitation is formed and distributed, is a major challenge. Within the HMA region, there are strong differences in the drivers of the mass balance, e.g. the energy balance and snowfall. Quantifying these regional differences can provide important clues in explaining anomalous glacier behaviour in HMA. Finally, in the longer term and at the largest scale, little is known about how climate change may impact weather extremes. Atmospheric modelling can make an important contribution to overcoming these challenges at different spatial scales.

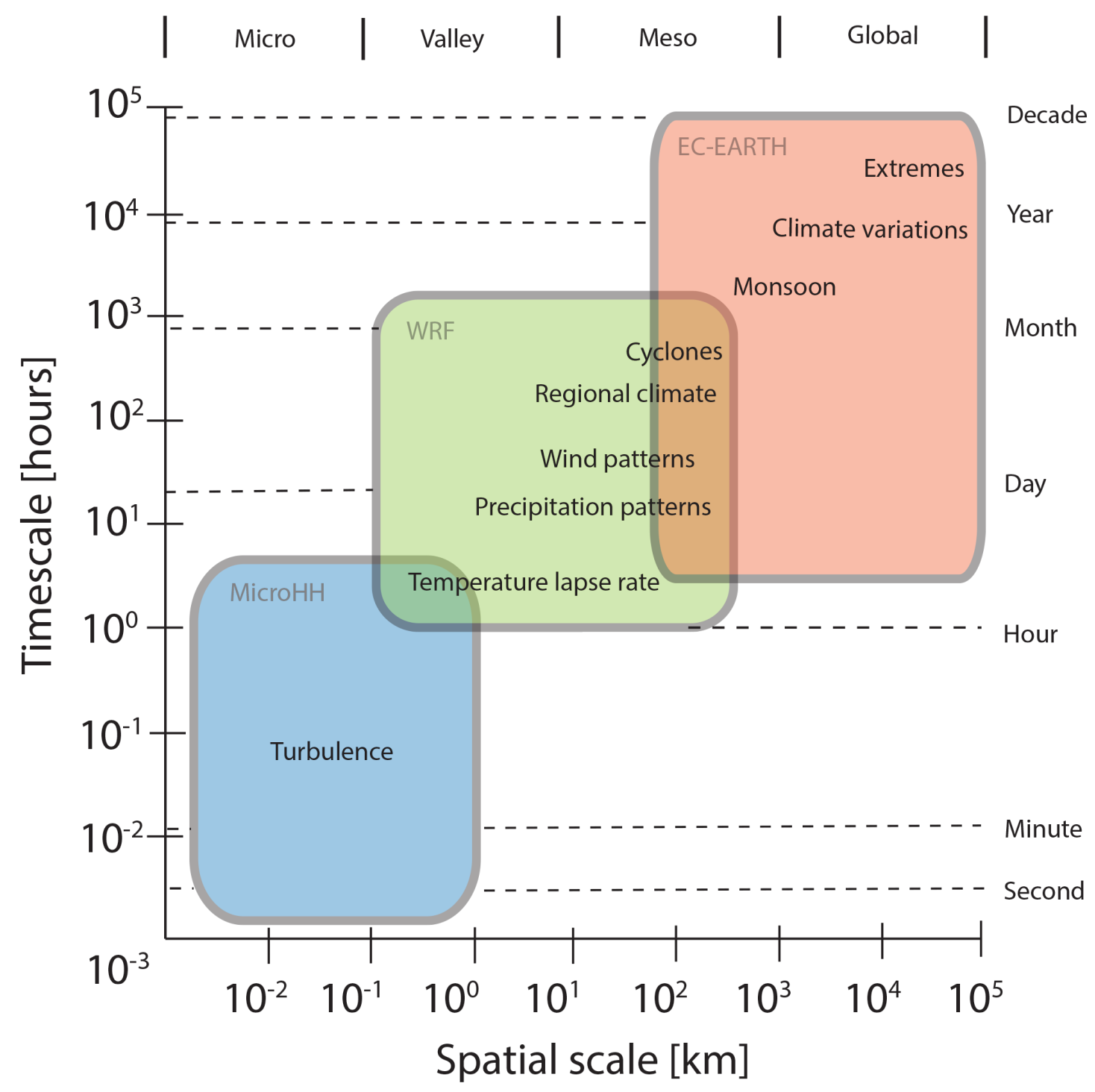

Figure 1.5: Overview of scales and corresponding models used in this thesis. 
In Figure 1.5 the different scales and models used in this thesis are shown conceptually. It is shown that processes which occur at the smallest spatial scales coincide with shortest time scales and that processes which occur at large spatial scale have the longest time scales. For example, turbulence is a phenomenon in the order of metres and seconds, while climate variations take place over thousands of kilometres and have a time span of multiple years. Each of the scales mentioned in Figure 1.5 can be best resolved by tailored model codes or models, which are indicated by the coloured rectangles.

In this thesis I aim to address the above-mentioned research gaps to better understand how climate controls key glacio-hydrological processes in high-altitude catchments at different scales. Here, the focus is on high-altitude precipitation and glacier melt dynamics. The main objective of this thesis is:

To advance the knowledge of high-altitude climate dynamics from micro to synoptic scales, with a special focus on high-altitude precipitation and the interaction between the atmosphere, cryosphere and extreme topography.

I have selected four case studies, ranging from micro to synoptic scales, on which I elaborate in this thesis. The corresponding research questions are:

1. How do turbulent fluxes drive the energy exchange on debris-covered glaciers?

The contribution of debris-covered glaciers to the hydrological budget is largely unknown. In order to quantify glacier melt, first the glacier surface energy balance should be known in more detail. A Direct Numerical Simulation (DNS) performed on Lirung glacier at $1 \mathrm{~m}$ spatial resolution allows us to investigate micro-scale processes and feedbacks on debris. The effect of a heterogeneous topography, surface temperature and surface specific humidity on turbulent fluxes and subsequently on the conductive heat flux is determined, and the surface energy balance then quantified.

2. What is the orography-climate interaction at catchment scale, and how do boundary conditions influence the outcome?

As current precipitation data sets lack detailed information due to their coarse resolution, ERA-Interim data is dynamically downscaled with the WRF model to 500 metres to assess the interaction between valley scale circulation patterns and atmosphere-cryosphere feedbacks. A specific focus is given to the effect of topography on spatial precipitation 
patterns at catchment scale, along with the effects of surface boundary conditions on local meteorological conditions.

3. What are the meteorological drivers of the Karakoram anomaly?

In order to understand the anomalous behaviour of glaciers in the Karakoram and Kunlun Shan region, the WRF model is set up for two contrasting regions in the central Himalaya and Karakoram at $1 \mathrm{~km}$ resolution. The seasonal differences are explored and the mechanisms of the differences in surface energy balance are discussed.

4. How does climate change influence the (regional) meteorological extremes in HMA?

Weather extremes will change due to climate change, however detailed analyses are absent in HMA. A large model ensemble of 2000 members allows us to explicitly model extreme events, and to perform a thorough analysis on glacier climate change indicators, such as melt days and winter precipitation.

These research questions focus on specific clear gaps in the glaciological and atmospheric research in HMA. A full chapter is dedicated to each of the four research questions (chapters 2 to 5). In Chapter 6 the results of my research are synthesized and put into broader perspective, including recommendations for future research. 


\section{Using 3D turbulence-resolving simulations to understand the impact of surface properties on the energy balance of a debris-covered glacier}

Debris-covered glaciers account for almost one fifth of the total glacier ice volume in High Mountain Asia, however their contribution to the total glacier melt remains uncertain and the drivers controlling this melt are still largely unknown. Debris influences the properties (e.g. albedo, thermal conductivity, roughness) of the glacier surface and thus the surface energy balance and glacier melt. In this study we have used sensitivity tests to assess the effect of surface properties of debris on the spatial distribution of micro-meteorological variables such as wind fields, moisture and temperature. Subsequently we investigated how those surface properties drive the turbulent fluxes and eventually the conductive heat flux of a debris-covered glacier. We simulated a debris-covered glacier (Lirung Glacier, Nepal) at a $1 \mathrm{~m}$ resolution with the MicroHH model, with boundary conditions retrieved from an automatic weather station (temperature, wind and specific humidity) and UAV flights (digital elevation map and surface temperature). The model was validated using eddy covariance data. A sensitivity analysis was then performed to provide insight into how heterogeneous surface variables control the glacier microclimate. Additionally, we show that ice cliffs are local melt hot spots, and that turbulent fluxes and local heat advection amplify

Chapter published as:

P.N.J. Bonekamp, C.C. van Heerwaarden, J.F. Steiner, W.W. Immerzeel, 2020, Using 3D turbulence-resolving simulations to understand the impact of surface properties on the energy balance of a debris-covered glacier, The Cryosphere, 14,1611-1632 
spatial heterogeneity on the surface. The high spatial variability of small-scale meteorological variables suggests that point based station observations cannot be simply extrapolated to an entire glacier. These outcomes should be considered in future studies for a better estimation of glacier melt in High Mountain Asia.

\subsection{Introduction}

Glaciers in High Mountain Asia (HMA) act as a fresh water supply for millions of people living downstream, and this supply will change due to global warming (Lutz et al., 2013; Wester et al., 2019). Debris-covered glaciers account for $18 \%$ of the total glacier ice volume in High Mountain Asia, however the exact melt processes of these glaciers are still unknown and their contribution to the total glacier melt remains uncertain (Kraaijenbrink et al., 2017).

Debris-covered glacier surfaces differ from clean ice glaciers - with surface temperatures that can exceed the melting point considerably, a higher topographic variability and the possibility of an unsaturated surface. Debris influences the surface energy balance and therefore glacier melt by influencing the properties (e.g. albedo, thermal conductivity) of the glacier surface (Reid and Brock, 2010). Due to the albedo effect glacier ablation is generally enhanced by debris thickness smaller than a few centimetres, while it decreases exponentially with thickening debris due to ice insulation (Östrem, 1959).

The energy exchange between the (debris-covered) glacier surface and atmosphere is determined by small-scale meteorological conditions, rather than large-scale weather patterns (Sauter and Galos, 2016). Heterogeneous surface conditions affect the microclimate resulting in large spatial differences in energy balance components (Reid and Brock, 2010). For example, daytime surface temperatures can range between melting point (ice and water) and $27.5{ }^{\circ} \mathrm{C}$ due to inhomogeneous surface heating and variable debris thickness (Kraaijenbrink et al., 2018; Steiner and Pellicciotti, 2016) and the surface roughness length ranges from $\sim 0.005 \mathrm{~m}$ (gravel) to $\sim 0.5 \mathrm{~m}$ (boulders; Miles et al., 2017). Local melt hot spots generally exist on the surface of a debris-covered glacier in the form of ice cliffs and supraglacial ponds (Buri et al., 2016a; Miles et al., 2016), causing highly heterogeneous ablation rates. However, it is not entirely understood how those ice cliffs and ponds form, evolve and disappear. While the cut-and-closure of englacial drainage systems is likely to be an important driver (Benn et al., 2017; Miles et al., 2017b), and the interaction between cliffs and ponds is an important process (Miles et al., 2017b; Steiner et al., 2019), heterogeneous meteorological forcing over the debris surface may also play a major role (Buri and Pellicciotti, 2018). The influence of spatial variability, and especially with respect to 
turbulent exchange in the atmosphere has, however, not previously been investigated.

Currently there are several methods to model the melt of a debris-covered glacier spatially, including a multilayer energy balance model (Fyffe et al., 2014; Reid and Brock, 2010) as well as specifically for surface features on debris cover (Buri et al., 2016b; Miles et al., 2018) and a fully coupled atmosphere-glacier mass balance model (Collier et al., 2013), with the latter including two-way debris-atmosphere feedbacks. However these approaches remain limited in their scope as they cannot adequately address the spatial and temporal distribution of surface and meteorological variables. This is because atmospheric field observations on debris-covered tongues are limited to only a few field locations in the Himalaya (Lejeune et al., 2013; Ragettli et al., 2013; Rounce et al., 2015; Steiner et al., 2018), the Karakoram (Mihalcea et al., 2008) and the Tien Shan (Yao et al., 2014). All of these studies cover relatively short time spans ranging from days to multiple months. Extrapolating point measurements remains a challenge when it comes to debris-covered glaciers, as measurements from a single weather station are not representative of the complex, inhomogeneous terrain. In a situation where there is large spatial variation, a high-resolution modelling approach can give important new insights into the coupling and interaction between the surface and the atmosphere (Mott et al., 2014).

Turbulent fluxes can play a substantial role in the surface energy balance of debris-covered glaciers (Rounce et al., 2015; Steiner et al., 2018). These fluxes are often calculated using the bulk method, where the sensible and latent heat fluxes are related to the temperature and moisture gradients between the atmosphere and surface respectively. However, the bulk method assumes atmospheric stability and a constant surface roughness, which is not valid over debris-covered glacier surfaces (Steiner et al., 2018). Steiner et al. (2018) found, for example, that bulk methods overestimate turbulent heat fluxes.

High-resolution turbulent resolving simulations offer a means of gaining insight into the microclimate of a debris-covered glacier (i.e. wind, humidity and temperature fields). Turbulence can be simulated by two techniques: LES (Large Eddy simulations) and DNS (Direct Numerical simulations). The difference between these simulations is the treatment of the smallest scales in the flow; LES uses a sub-grid parameterization while DNS resolves these explicitly. DNS at atmospheric viscosity is computationally unfeasible. It is, however, not always necessary to resolve all scales, as many flow characteristics become independent of the Reynolds number at much larger values for the viscosity than that of the atmosphere. In this paper, we build on this property (see Appendix A). One could also refer to this approach as 'LES with a constant eddy viscosity'. 
Large-eddy simulations (LES) studies have been conducted for clean-ice glaciers, focussing on katabatic winds and sensible heat fluxes (e.g. Axelsen \& Dop 2009; Axelsen \& van Dop 2009; Sauter \& Peter Galos 2016). LES often implies a simplification of reality, such as a flat terrain and horizontally homogeneous meteorological conditions (Axelsen and Dop, 2009), though simulations can give insight into fundamental processes. LES ignores the smallest length scales of turbulence and can be used if the behaviour of those scales can be described as a function of the resolved structures in the simulation. In order to also resolve the smallest length scales, direct numerical simulation (DNS) should be used.

Both DNS and LES have advantages and drawbacks for the simulation of atmospheric turbulent flows. Generally, it is assumed LES represents high Reynolds numbers well, while DNS is only correct if all scales in the flow are resolved. However, as shown by Moin and Mahesh, (1998), it is in many cases unnecessary to resolve the flow up to the Kolmogorov scale, as many of the statistics of turbulent flows become independent of the Reynolds number at Reynolds numbers far less than the atmospheric Reynolds number This is proven for convective boundary layers in the atmosphere (Heerwaarden and Mellado, 2016), turbulent channel flow (e.g. Moser et al., 1999; Schultz and Flack, 2013), Ekman flow (Spalart, 2009), and stable atmospheric boundary layers (Ansorge and Mellado, 2016). Additionally, Dimotakis, (2000) has delivered clear guidelines on estimating whether turbulence is fully developed. We are converging to that situation in this study as we show that only a marginal part of the total variance is missed and the most relevant results are independent of the Reynolds number.

Applying LES combined with wall models in complex terrain is questionable. The Monin-Obukhov Similarity Theory (MOST) that is used to compute the interaction with the wall has already been demonstrated invalid over simple slopes (Nadeau et al., 2013). Wall modelling on the faces of non-horizontal objects is an unsolved challenge, as all assumptions of the MOST break down. With no alternative is available, MOST is often used nonetheless. The consequences of this are potentially harder to estimate and interpret than those of moderate Reynolds numbers in the application of DNS.

The drivers of heterogeneous melt patterns on debris-covered glaciers, and the role turbulent fluxes play, are not well understood. In this study the impact of surface properties (roughness, surface temperature and surface moisture) of debris on the spatial distribution of small-scale meteorological variables, such as wind fields, moisture and temperature, and subsequently the turbulent fluxes and conductive heat flux, is investigated for the Lirung Glacier (Nepal) using a 
DNS model with constant eddy viscosity and a spatial resolution of $\sim 1 \mathrm{~m}$. Observational data are used as boundary conditions, which include a high-resolution DEM (digital elevation map) and thermal imagery, retrieved from UAV (unmanned aerial vehicle) flights. We show the impact of heterogeneous surface conditions and we show that turbulent fluxes are an important contributor to the energy balance of ice cliffs. This is the first high-resolution study for a debriscovered glacier that investigates the effects of debris on meteorological variables using a turbulent fluxes resolving model. This study improves our understanding of the processes of debris-glacier melt, and will lead to a better understanding of the contribution of debris glacier melt to current river discharges, and how this will change in future.

\subsection{Methods}

\subsubsection{Study area}

Lirung Glacier is a debris-covered glacier in the Langtang catchment located 50 kilometres North of Kathmandu (Nepal; Figure 2.1). The Langtang catchment has an area of approximately 560 $\mathrm{km}^{2}$, of which $30 \%$ is glacierized. One fourth of all the Langtang glaciers are debris-covered. Lirung Glacier itself is $3.5 \mathrm{~km}$ long and on average $500 \mathrm{~m}$ wide (Immerzeel et al., 2014a) and ranges in elevation from $4000 \mathrm{~m}$ to $7132 \mathrm{~m}$ a.s.l.. The surface is highly heterogeneous and debris is composed of a range of textures from silt to gravel to boulders (Miles, 2017). The average gradient of the tongue is approximately two degrees and debris thickness ranges from 0.1 to 2.0 $m$ (McCarthy et al., 2017). This area is influenced during the summer months by the Indian summer monsoon, which provides $70 \%$ of the annual precipitation. (Immerzeel et al., 2014b). The winters are relatively dry and precipitation generally occurs only during a few cyclonic events (Bonekamp et al., 2019; Collier and Immerzeel, 2015).

\subsubsection{Field measurements}

AWS data on the glacier (Figure 2.1) is used for model validation (air temperature, wind speed, relative humidity and incoming and outgoing short- and longwave radiation). For this study we only use the measurements between 10:30 - 11:30 LT on 12 October 2016 (10-minute average; Steiner et al. (2018)). The sensible and latent heat fluxes are derived from high frequency measurements $(10 \mathrm{~Hz})$ of fluctuations in temperature, humidity and wind speed with the IRGASON eddy covariance (EC) system (5-minute average). The footprint of the EC-system depends on its sensor orientation, wind speed and direction (Steiner et al., 2018) and complicates the direct comparison between measurements and simulation. We used the footprint as described in Steiner et al. (2018) and determined the weighted contribution of each model pixel within the footprint area to the flux observation at the AWS site to ensure a fair comparison with the measurements. 


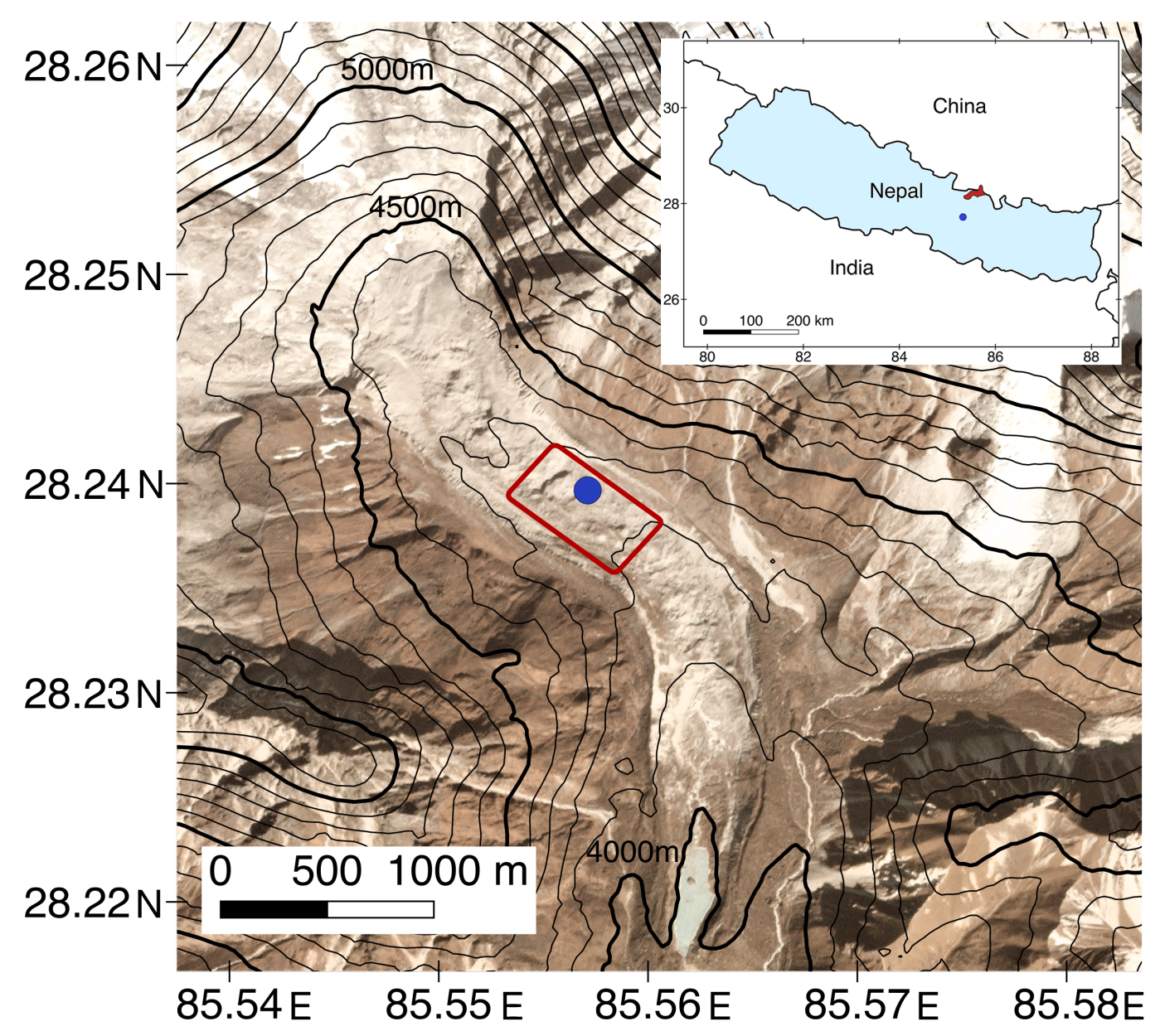

Figure 2.1: Lirung Glacier with the microHH domain (red contour) and the location of the AWS (blue point). The background image is a Planet image from 9 December 2018 (Planet Team, 2017). The inset shows the Langtang catchment (red) and its location in Nepal. 

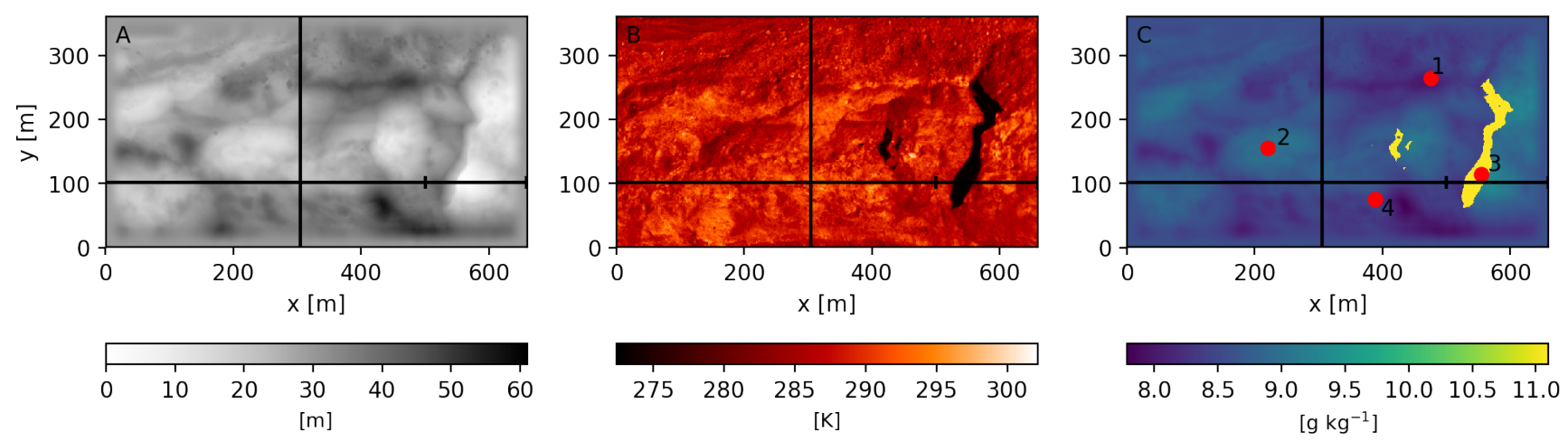

Figure 2.2: Boundary conditions used in MicroHH: the DEM (A), surface temperature (B) and surface specific humidity $(C)$. Black lines $(A-C)$ indicate the locations of the vertical cross sections used in Figure 2.5-2.7. The vertical cross section used in Figure 2.9 is a subset of the cross section $(x=500-660, y=102)$. Its start and end points are indicated by small vertical lines. Red points indicate the locations used in Figure 2.8 (1=dry debris, 2=wet debris, 3=ice cliff and 4=AWS).

The high resolution DEM is based on the structure-from-motion workflow using optical imagery retrieved on 9 October 2016 (13:00 LT) and resampled to $1 \mathrm{~m}$ resolution for further use (Figure 2.2A) (Immerzeel et al., 2014a; Kraaijenbrink et al., 2016). A resolution of 1 metre is the highest possible spatial resolution we could achieve given the constraints of computational power and input data. In Appendix A we show that the spatial resolution of 1 metre is sufficient to capture the characteristics of the flow and that increasing the resolution will not improve the information derived. The surface temperature (12 October 2016 11:00 LT) was retrieved with the UAV thermal infrared camera and is bias corrected (Kraaijenbrink et al., 2018). We use only a subset of the UAV data in this research, since the domain is constrained by the intersect of the optical and thermal flight extent, and the domain should be rectangular in the model. The DEM of the domain is detrended, rotated to the main wind direction, and smoothed at the boundaries in order to connect the outer left pixels with the outer right pixels of the domain to allow for periodic boundaries. Periodic boundary conditions presume that the fluxes exiting the domain are used as influx in the next time step. This allows us to investigate processes and feedbacks solely in the domain, as larger forcings are excluded. We include only the glacier surface in the domain and not the surrounding moraines. The final extent of the domain is $660 \times 361 \mathrm{~m}$, the final detrended topography ranges from 0 to 57 metres, and the surface temperature ranges from $273.1 \mathrm{~K}$ (ice cliff at melting point) to $302.2 \mathrm{~K}$ with an average of $282.2 \mathrm{~K}$. The corresponding potential temperature is $331.3 \mathrm{~K}$. In total $2 \%$ of the domain is covered with ice cliffs and is representative for glaciers in the Langtang catchment as the ice cliff glacier average is found to be between 1.4 and 3.4\% (Steiner et al., 2019). 


\subsubsection{Model}

The MicroHH model (Heerwaarden et al., 2017) is a computational fluid dynamics model designed to simulate turbulent flows in the atmosphere through direct numerical simulation (DNS) and large eddy simulation (LES). We use MicroHH as a DNS model with a constant eddy viscosity, which effectively renders a LES with the most primitive eddy viscosity model possible. MicroHH can be run in parallel and is made for efficient computations. The configuration of the model makes allowance for heterogeneous surface boundary conditions such as topography, surface temperature and surface specific humidity. We give a brief description of the model below. More details can be found in Heerwaarden et al. (2017).

MicroHH solves the conservation equations of mass, momentum and energy under the Boussinesq approximation. The model assumes constant density with altitude, thus simplifying the governing equations substantially. The conservation of mass is thereby reduced to the conservation of volume in Einstein summation:

$\frac{\partial u_{i}}{\partial x_{i}}=0$

$u_{i}$ are components of the velocity vector $(v, v, w)$ and $x_{i}$ is the position of the vector $(x, y, z)$. The thermodynamics are a relation between fluctuations of virtual potential temperature $\left(\vartheta_{v}^{\prime}\right)$ and density $\left(\rho^{\prime}\right)$ under the Boussinesq approximation by:

$\frac{\vartheta_{v}^{\prime}}{\vartheta_{v 0}}=-\frac{\rho^{\prime}}{\rho_{0}}$

with $\vartheta_{v 0}$ the reference virtual potential temperature and $\rho_{0}$ the reference density. The conservation of momentum is formulated as:

$\frac{\partial u_{i}}{\partial t}=-\frac{\partial u_{i} u_{j}}{\partial x_{j}}-\frac{1}{\rho_{0}} \frac{\partial p^{\prime}}{\partial x_{i}}+\delta_{i 3} g \frac{\theta_{v}^{\prime}}{\theta_{v 0}}+v \frac{\partial^{2} u_{i}}{\partial x_{j}^{2}}+F_{i}$

where $\delta$ is the Kronecker delta, $v$ the kinematic viscosity, $g$ the gravity constant $\left(9.81 \mathrm{~m} \mathrm{~s}^{-2}\right)$ and $\mathrm{F}_{\mathrm{i}}$ the external forces originating from, for example, large scale forcings. We used moist dynamics in our simulations and this implies that the liquid water potential temperature $\theta_{l}$ is the conserved variable in the energy conservation equation. 
$\theta_{l} \approx \theta-\frac{L_{v}}{c_{p} \Pi} q_{l}$

with $L_{v}$ the latent heat of vaporization $\left(2.510^{6} \mathrm{~kJ} \mathrm{~kg}^{-1}\right), c_{p}$ the specific heat of dry air $\left(1002 \mathrm{~kJ} \mathrm{~kg}^{-1}\right)$,

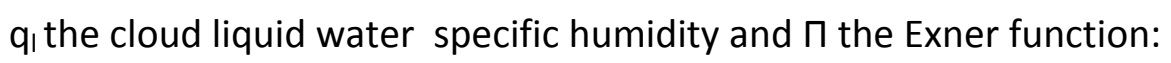

$\Pi=\left(\frac{p}{p_{00}}\right)^{R_{d} / c_{p}}$

with $p$ the actual pressure, $p_{00}$ the reference pressure $(1000 \mathrm{hPa})$ and $R_{d}$ the gas constant for dry $\operatorname{air}\left(287.058 \mathrm{~J} \mathrm{~kg}^{-1} \mathrm{~K}^{-1}\right)$.

The conservation of energy is defined by:

$\frac{\partial \theta_{l}}{\partial t}=-\frac{1}{\rho_{0}} \frac{\partial \rho_{0 u_{j}} \theta_{l}}{\partial x_{j}}+\kappa_{\theta} \frac{\partial^{2} \theta_{l}}{\partial x_{j}^{2}}+\frac{\theta_{l 0}}{\rho_{0} c_{p} T_{0}} Q$.

The density of dry air $\left(\rho_{0}\right)$ is measured via the eddy covariance system and is set to $0.75 \mathrm{~kg} \mathrm{~m}^{-3}$, $\kappa_{\theta}$ is the thermal diffusivity for heat, and chosen commensurate with the Reynolds number in order to stay close to the Prandtl number of the atmosphere (Section. 2.4), and Q the external heat source or sink. $T_{0}$ is the reference temperature profile.

MicroHH provides output of the 3D variables (total specific moisture, liquid potential temperature and the $u$ and $v$ components of the wind) at desired cross sections parallel along the axes $x, y, z$. The accumulated temperature $\left(\left.t h\right|_{\text {flux }}\right)$ and moisture fluxes $\left(\mathrm{qt}_{\text {flux }}\right)$ are given at the surface of a grid cell and should be divided by the surface area of that cell to obtain the flux in W $\mathrm{m}^{-2}$. Therefore the fluxes are converted to a sensible heat flux (SHF) and latent heat flux (LHF) by:

$S H F=\rho \cdot t h l_{\text {flux }} \cdot c_{p}$,

and

$L H F=\rho \cdot q t_{f l u x} \cdot L_{v}$,

where thl flux and $\mathrm{qt}_{\text {flux }}$ are the diffusive fluxes perpendicular to the surface and are directly dependent on the temperature and moisture gradient between the surface and the atmosphere. 


\subsubsection{Boundary conditions}

The bottom boundary condition for the velocity components is set to a Dirichlet no-slip condition (zero velocity at this interface) and the top boundary condition is a Neumann free slip condition (velocity gradient). Random noise is added to the flow in order to add turbulence and is applied to the wind vectors $u$ and $v$ with an amplitude of $0.1 \mathrm{~m} \mathrm{~s}^{-1}$. Preferably the viscosity of the atmosphere is used in the simulations, however, this is not computationally feasible in our simulations. Therefore we chose the lowest possible eddy viscosity and checked the results for convergence (Section 2.4). The Prandtl number $\left(v / \kappa_{\theta}, 2\right.$ and 1.2 for the two Reynolds numbers), is chosen such that it remains close to the value of the atmosphere (0.71). This approach follows earlier direct numerical simulation studies of the atmosphere (e.g. Van Heerwaarden et al., 2014; Mellado, 2012). In the vicinity of unity, the flow characteristics are insensitive to the exact value of the Prandtl number (Ahlers et al., 2009). A second order spatial discretization scheme is used. A buffer zone of the upper hundred metres is used for numerical stability and the state values decrease exponentially to the top boundary. The boundary conditions at the DEM surface are Dirichlet boundary conditions and can be prescribed spatially for specific humidity and surface temperature. In our experiments the surface temperature is set to values measured by the UAV. The specific humidity is not measured spatially by the UAV, although the spatial variability of the relative humidity $(\mathrm{RH})$ is made dependent on the topography to indicate dry higher elevated areas and wetter depressions by:

$R H=R H_{0}-0.26 \cdot \mathrm{DEM}$,

with $\mathrm{RH}_{0}=85 \%$ at the lowest point and $\mathrm{RH}=70 \%$ at the highest point of the $\mathrm{DEM}$ - and an average of $\mathrm{q}=8.6 \mathrm{~g} \mathrm{~kg}^{-1}$. This approximation follows the reasoning that melt water entrained in the debris accumulates in depressions. Additionally, finer grained debris from wash outs tends to be found in depressions, resulting in a higher surface retention capacity. At the site location of the AWS the relative humidity (measured at $3.1 \mathrm{~m}$ ) is $66 \%$ and with this relationship we assume the surface is everywhere moister than the atmosphere. The relative humidity at the AWS location during the morning varied from $54 \%$ to $100 \%$ over time, which is typical of general diurnal variability (Steiner et al., 2018). We assume a spatially constant saturation vapour pressure in the domain, based on the air temperature measured by the AWS. Using Tetens' Formula:

$e_{S}=0.61078 \cdot e^{\frac{17.27 \cdot T}{(T+237.3)}}$

we calculated the spatial variable specific humidity as: 
$q=\frac{\mathrm{RH}}{100 \%} \cdot 0.622 \frac{\mathrm{e}_{\mathrm{s}}}{\mathrm{p}}$.

In order to implement the DEM in MicroHH, ghost cells below the surface are included for interpolation at the surface following the immersed boundary technique as described by Tseng and Ferziger (2003). This method allows for fast computation and senses the presence of the boundary condition of the extrapolated values below the complex surface. The ghost cells themselves are excluded from all analysis and are only needed for model performance. The lateral boundary conditions are periodic, such that air flowing out of one side of the domain will enter on the opposite side and act as a lateral boundary condition. The domain can therefore be interpreted as an infinite iteration of the prescribed domain.

\subsubsection{Vertical profile}

MicroHH is initialized with vertical profiles of liquid potential temperature $\left(\frac{\mathrm{d} \theta_{l}}{\mathrm{dz}}\right)$, specific humidity $\left(\frac{\mathrm{dq}}{\mathrm{dz}}\right)$ and wind $\left(\frac{d u}{\mathrm{dz}}\right)$. The large-scale pressure force is prescribed by the geostrophic flow components $U_{g}$ and $V_{g}$. Profiles of the wind vectors are taken from ERA-INTERIM data at 12:00 UTC, since this profile best matched the observations and are interpolated in the lowest 100 metres to the surface values measured by the AWS. The profiles of liquid potential temperature and specific humidity are taken as constant with height, with the value measured at the AWS, since MicroHH is highly sensitive to these initial vertical profiles and varying them did not lead to improvement of the simulation of the latent and sensible heat flux. The ERA-INTERIM profiles contain a temperature and moisture bias at the surface when compared to the AWS measurements and, in order to get realistic profiles, we interpolated the lower part of the atmosphere to the AWS value. However, this would imply a strong contrast between low air and air at several hundreds of metres. We found that after the mixing of the atmosphere, strong gradients and biases appeared in the simulations. We therefore assumed constant profiles for temperature and specific humidity rather than adjusted ERA-INTERIM profiles, and that the spin up time (1 hour) is sufficient to acquire temperature and specific humidity profiles that represent the prescribed surface properties.

\subsubsection{Experiments}

In total seven experiments were designed to investigate the effects of surface roughness, surface temperature and surface moisture on turbulent fluxes, wind and temperature fields on a debriscovered glacier. These experiments were chosen to determine the separate effects of topography, surface temperature and surface specific humidity on the surface energy balance. 
The experiments are listed in Table 2.1. The first two columns indicate the name and the description of the experiments respectively, and the last three columns define which surface boundary conditions are used. If a number is given, this means the surface is homogeneously forced with that value. Spatially variable measured values are available for the DEM and for surface temperature, and this is indicated with real in Table 2.1. A DEM of 0 indicates no topography input is used and that the surface is flat and homogeneous. In the last experiment ( $R E A L)$ all variables are prescribed spatially. A specific humidity of $8.6 \mathrm{~g} \mathrm{~kg}^{-1}$ and surface potential temperature of $313.3 \mathrm{~K}$ are the averages of the measured spatial fields.

Table 2.1: Overview of experiments done with MicroHH. The DEM indicates the boundary condition used for the topography (0 means no DEM, $1 / 2$ DEM is the original DEM halved in height, real is the spatially measured value), $T_{s}$ is the surface potential temperature $(313.3 \mathrm{~K}$ is a homogeneous value, real is the spatially measured value), $q_{s}$ is the surface specific humidity (8.6 $\mathrm{g}$ $\mathrm{kg}^{-1}$ is a homogeneous value; the choice for the relative humidity range is described in Section. 2.4)

\begin{tabular}{lllll}
\hline \hline Experiment & Description & DEM & $\mathrm{T}_{\mathrm{s}}$ & $\mathrm{q}_{\mathrm{s}}$ \\
\hline $\mathrm{HOM}_{\text {flat }}$ & Homogeneous & 0 & $313.3 \mathrm{~K}$ & $8.6 \mathrm{~g} \mathrm{~kg}^{-1}$ \\
& glacier & & & \\
$\mathrm{HOM}_{1 / 2 \mathrm{DEM}}$ & $1 / 2 \mathrm{DEM}$ & $1 / 2 \mathrm{DEM}$ & $313.3 \mathrm{~K}$ & $8.6 \mathrm{~g} \mathrm{~kg}^{-1}$ \\
$\mathrm{HOM}_{\mathrm{DEM}}$ & Roughness effects & real & $313.3 \mathrm{~K}$ & $8.6 \mathrm{~g} \mathrm{~kg}^{-1}$ \\
$\mathrm{HET}_{\mathrm{T}}$ & $\mathrm{T}_{\mathrm{s}}$ effects 'normal' & real & real & $8.6 \mathrm{~g} \mathrm{~kg}^{-1}$ \\
$\mathrm{HET}_{\text {qdry }}$ & $\mathrm{q}_{\mathrm{s}}$ dry & real & $313.3 \mathrm{~K}$ & Spatially $\mathrm{RH}=70-75 \%$ \\
$\mathrm{HET}_{\text {qmoist }}$ & $\mathrm{q}_{\mathrm{s}}$ wet & real & $313.3 \mathrm{~K}$ & Spatially $\mathrm{RH}=70-85 \%$ \\
$\mathrm{REAL}$ & "Reality" & real & real & Spatially $\mathrm{RH}=70-85 \%$ \\
\hline \hline
\end{tabular}

Our experiments are representative for the meteorological conditions on 12 October 2016, at 11:00 LT, assuming this is a static state over the time period examined. For each experiment we have output for one hour (without considering spin up) and we consider these results as the range of possible outcomes at 11:00 LT.

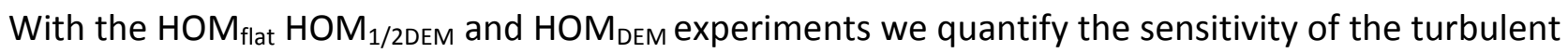
fluxes to the topography. The $\mathrm{HET}_{\mathrm{T}}$ experiment will reveal the effects of a spatially variable surface temperature compared to a homogeneous surface temperature $\left(H_{D O M}\right)$. The $H_{\text {Edry }}$ and $\mathrm{HET}_{\text {qmoist }}$ experiments are aimed to reveal the influence of heterogeneous surface specific humidity when compared to a homogeneous value $\left(H_{D E M}\right)$; this will show the differences 
between a relatively dry and a moist debris layer. In the REAL experiment all effects are combined and will be compared to $\mathrm{HOM}_{\text {flat }}$ and $\mathrm{HOM}_{\mathrm{DEM}}$ so as to also give an understanding of the combined effects.

The extent of the domain is $660 \times 331 \times 500(x, y, z)$ metres. $672 \times 384 \times 480$ grid points are used, so the spatial resolution is approximately 1 metre. The number of grid points is determined by thenumber of nodes used on the Cartesius cluster (www.surfsara.nl). One run, on 1024 processors, typically takes 10.5 hours to complete.

\subsubsection{Conductive flux}

The surface energy balance determines how much energy is left at the surface that can be used to heat up the debris or melt ice. The conductive flux $\left(Q_{c}\right)$ is the energy flux into the debris (Nicholson and Benn, 2006, 2012). This can be quantified by:

$Q_{c}=Q_{s W}+Q_{L W}+Q_{L}+Q_{H}$,

where $Q_{s w}$ and $Q_{L w}$ are net shortwave and longwave radiation, and $Q_{L}$ and $Q_{H}$ the latent and sensible heat flux respectively. $Q_{s w}$ is the sum of the direct incoming $\left(I_{s}\right)$, diffuse radiation $\left(D_{s}\right)$ and reflected shortwave radiation from surrounding terrain $\left(D_{t}\right)$ multiplied by (1-albedo). A constant value of 0.18 is used for the surface albedo of both the debris and the ice cliffs. This was measured by the AWS and is in the range of the expected albedo for ice cliffs on the Lirung Glacier (Steiner et al., 2015). $D_{s}$ is calculated as:

$\mathrm{D}_{\mathrm{s}}=\mathrm{V}_{\mathrm{s}} \mathrm{k}_{\mathrm{d}} \mathrm{l}_{0}$

where $V_{s}$ is the sky-view factor, $k_{d}$ the diffuse fraction and $I_{0}$ the shortwave radiation measured by the AWS. The shortwave radiation reflected by the surrounding terrain is calculated with the albedo $(\alpha)$ as:

$D_{t}=\alpha I_{0}\left(1-V_{s}\right)$.

$\mathrm{Q}_{\mathrm{Lw}}$ is calculated as:

$\mathrm{Q}_{\mathrm{LW}}=\mathrm{V}_{\mathrm{l}} \mathrm{L} \mathrm{W}_{\text {in }}+\mathrm{LW}_{\mathrm{d}}-\mathrm{LW}_{\text {out }}$ 
where $V_{l}$ is the sky-view factor for longwave radiation, $L W_{\text {in }}$ the incoming longwave radiation, $L W_{d}$ the longwave radiation emitted by surrounding debris, and LW $_{\text {out }}$ the outgoing longwave radiation related to the surface temperature $\mathrm{T}_{s}$ :

$\mathrm{LW}_{\text {out }}=\varepsilon_{\mathrm{d}} \sigma \mathrm{T}_{\mathrm{s}}^{4}$

with an emissivity $\left(\varepsilon_{\mathrm{d}}\right)$ of 0.95 and $\sigma$ the Stefan Boltzmann constant. LW in is taken to be homogeneous as measured by the AWS (hourly average) and the longwave radiation emitted by surrounding debris is calculated spatially as:

$\mathrm{LW}_{\mathrm{d}}=\mathrm{V}_{\mathrm{d}} \varepsilon_{\mathrm{d}} \sigma \mathrm{T}_{\mathrm{s}}^{4}$

where $V_{d}$ is the debris-view factor (see Steiner et al. 2015 for details).

The latent and sensible heat fluxes are calculated as stated in Section 2.2.3. This method assumes the debris is in steady state and no heating or cooling of the debris occurs during that period. All fluxes are defined as positive towards the surface except for the conductive heat flux. All averages and standard deviations discussed in this paper are spatial averages, unless specified otherwise.

\subsection{Results and discussion}

\subsubsection{Spatial distribution of LHF and SHF}

Seven experiments are performed (Table 2.1) where key parameters that control turbulent heat fluxes are varied in order to investigate the relative importance of topography, humidity and surface temperature. In Figures 2.3 and 2.4 the average surface turbulent fluxes and spatial variability are shown for all experiments. The effects of the experiments can be subdivided into effects of surface roughness $\left(H O M_{\text {flat }}, H O M_{1 / 2 D E M}\right.$ and $\left.H O M_{D E M}\right)$, spatial temperature $\left(H E T_{T}\right)$, and surface specific moisture ( $H E T_{\text {qdry }}$ and $H E T_{\text {qmoist }}$ ).

\subsubsection{Surface roughness}

The effect of surface roughness on the SHF and LHF is evident (Figure $2.3 \mathrm{~A}-\mathrm{F}$ ). The turbulent fluxes are intensified with increasing variability in topography, since increasing the surface roughness is directly related to the surface roughness length and the generation of turbulence. 

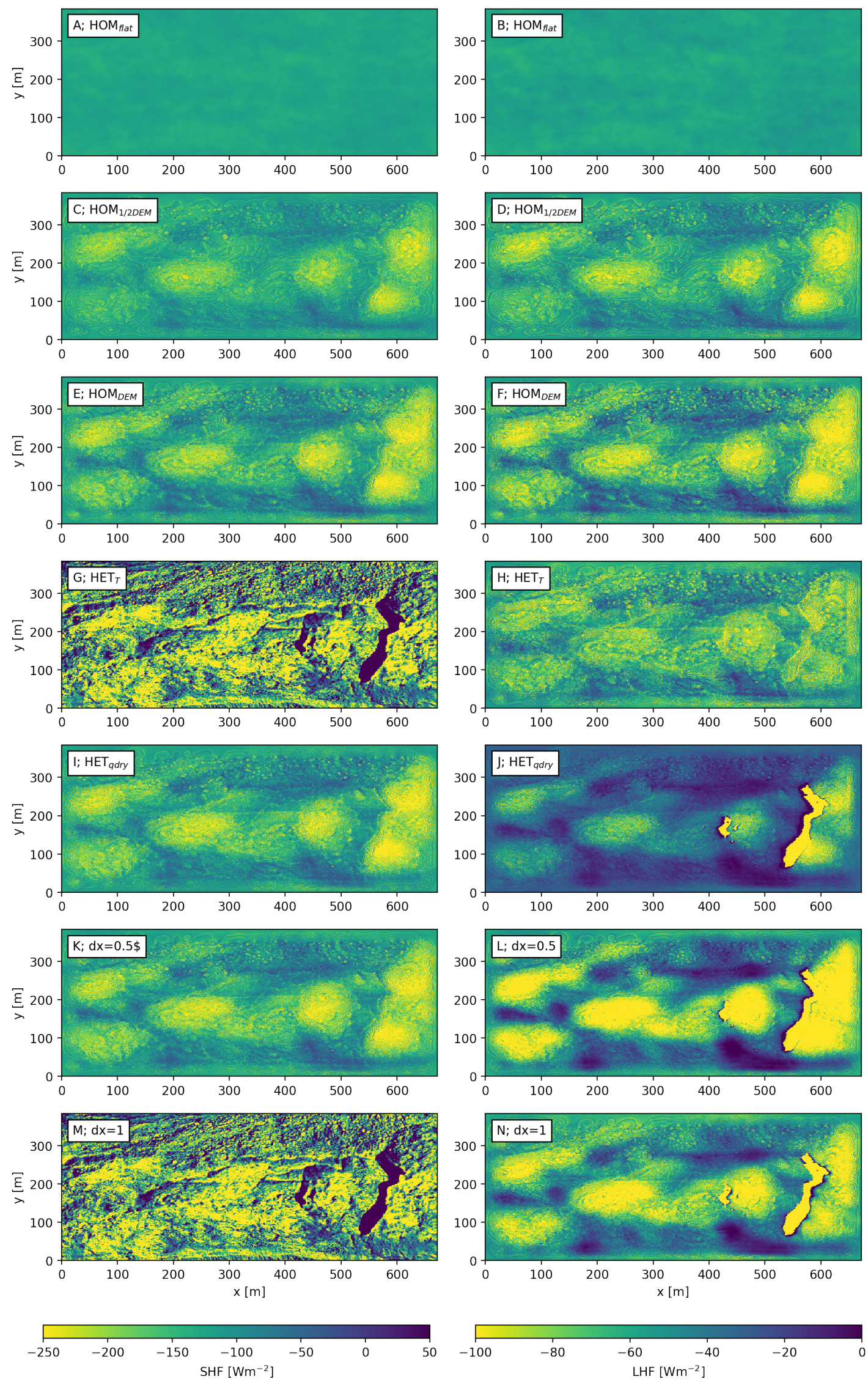

Figure 2.3: $2 D$ plots of average variables SHF (left panels) and LHF (right panels) for each experiment in the same order as presented in Table 2.1 (rows). Elevation increases from left to right and the main wind direction is from left to right. 
A homogeneous topography therefore results only in small spatial differences in turbulent fluxes ( $H_{\text {OM }}$ flat, 5 and $2 \mathrm{~W} \mathrm{~m}^{-2}$ for SHF and LHF respectively). Including a real topography (HOM $\left.{ }_{D E M}\right)$ results in more variation of the turbulent fluxes (64 and $30 \mathrm{~W} \mathrm{~m}^{-2}$ for SHF and LHF respectively) with lowest fluxes at higher locations and the highest fluxes in the depressions. This is caused by the combination of an accumulation of heat and moisture in the topographic depressions, and homogeneous surface temperature and specific humidity, resulting in high temperature and moisture gradients.

\subsubsection{Surface temperature}

The spatially variable temperature $\left(H E T_{T}\right)$ has the largest impact on the SHF (Figure 2.3G). Prescribing the surface temperature heterogeneously $\left(H E T_{T}\right)$ impacts the surface vertical temperature gradient and is therefore extremely important for the SHF. The LHF is less variable in space when including only spatial heterogeneous surface temperatures. This is because the surface temperature pattern is partly inversely related to the topography and the LHF is driven primarily by the moisture gradient. Cold surfaces are now located at the lowest parts of the domain, where it was warmer in $H_{D O M}$, and LHF is positively related to temperature. Additionally, the spatial variability of the SHF increases from 64 to $193 \mathrm{~W} \mathrm{~m}^{-2}$, while the spatial variability in the LHF does not change much ( $30 \mathrm{vs} 23 \mathrm{~W} \mathrm{~m}^{-2}$ ). Further to this, due to the heterogeneous temperatures, positive sensible heat fluxes are present at the locations where the surface is colder than the atmosphere. This is particularly important in understanding the energy balance of ice cliffs and ponds (Section 2.3.5).

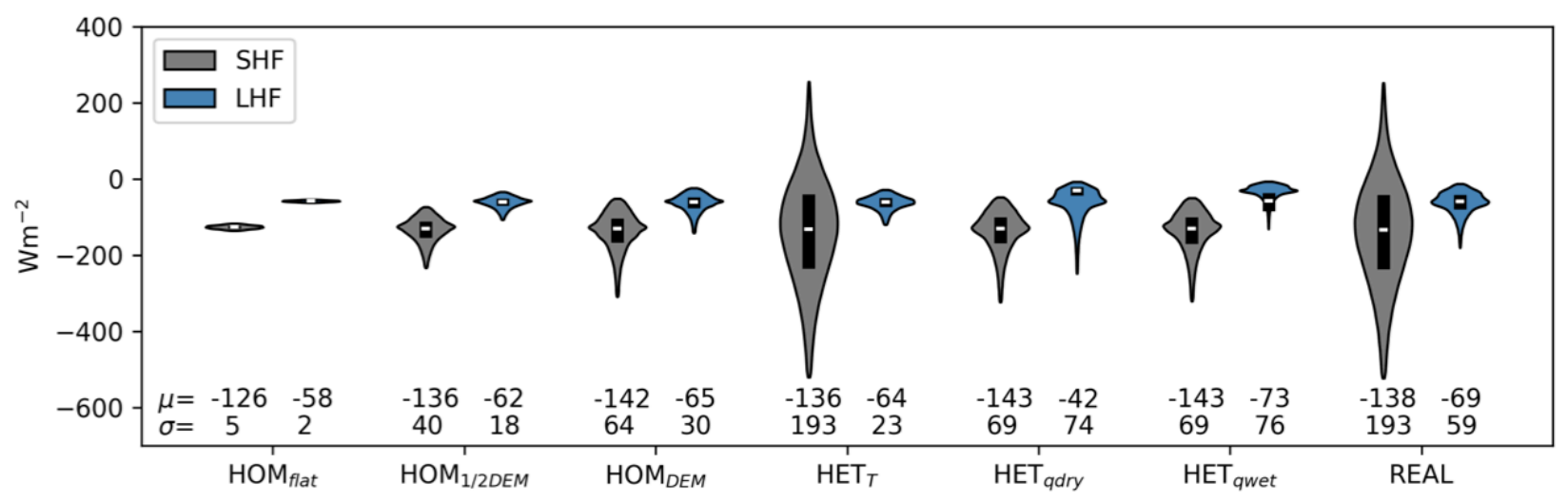

Figure 2.4: Violin plots to show spatial variability of time average fluxes (95\% confidence interval) within the domain for the SHF (grey) and LHF (blue). The numbers indicate the domain average ( $\mu$ ) and standard deviation ( $\sigma)$. Fluxes pointing towards the surface are positive. 


\subsubsection{Surface specific humidity}

The surface specific humidity has the greatest effect on the LHF. The assumption of dry debris $\left(H E T_{\text {qdry }}\right)$ results in an average LHF of $-42 \mathrm{~W} \mathrm{~m}^{-2}$. The LHF for moist debris is $-73 \mathrm{~W} \mathrm{~m}^{-2}$, indicating the important impact of surface moisture on the LHF. A higher surface specific humidity results in more evaporation under the same conditions, given the increase in the vertical moisture gradient at the surface. Moistening the surface (HET qwet) results in less extreme differences spatially in the LHF, since both experiments include saturated areas at the locations where the real surface temperature is 0 degrees Celsius. Moistening the surface will increase the atmospheric specific humidity and, since the relative humidity is fixed for the cliffs at $100 \%$ in both experiments, the variability in specific humidity decreases. Interesting is the high LHF on the leeward side of the ice cliff where the wind transports the moisture originating from the ice cliff over the domain. Note that the main wind flow is from left to right - see Figure 2.3.

\subsubsection{Spatial variation of elevation, surface temperature and specific humidity}

Including spatial variation in specific humidity and surface temperature (REAL) does not affect the average turbulent fluxes much when compared to homogeneous conditions (HOM DEM). However the spatial variability is nearly doubled for the sensible heat flux and tripled for the latent heat flux (Figure 2.4).

If we assume REAL as the truth, the sensible and latent heat fluxes will be underestimated by $9 \%$ and $8 \%$ respectively when ignoring the topography $\left(H O M_{\text {flat }}\right)$. Assuming both homogeneous surface temperature and specific humidity $\left(H O M_{D E M}\right)$ results in an overestimation of the SHF of $3 \%$ and an underestimation of $4 \%$ of the LHF (Figure 2.4).

Increasing the surface roughness has a larger effect on domain-averaged turbulent fluxes than the inclusion of spatial variations for surface temperature or specific humidity. However, prescribing the surface temperature and specific humidity has the greatest impacts on the spatial distribution of the SHF and LHF and results in a high spatial variability. So, for glacier tongue-wide averages, area-averaging of the input variables is justifiable, but if one is interested in detailed spatial patterns of melt it becomes questionable.

\subsubsection{Vertical distribution of temperature, wind and specific humidity}

In Figures 2.5, 2.6 and 2.7 cross sections and vertical profiles of all experiments are shown for the wind speed, specific humidity and potential temperature respectively for the lowest 100 metres of the domain. Increasing the surface roughness (HOM ${ }_{1 / 2 D E M}$ and $\left.H O M_{D E M}\right)$ leads to more mixing 
of heat and moisture in the atmosphere, due to the higher associated surface roughness length. The topography has a direct influence on the wind speed close to the surface; in depressions the wind speed is low and at high-elevations the wind speed increases. Due to the differences in wind speed, the mixing of heat and moisture is also spatially heterogeneous close to the surface. Moisture and heat accumulates in depressions, but wind mixes these regularly into the lower atmosphere.

The vertical profiles are an average of all model grid points above the surface. The mixing of variables extends higher into the atmosphere when the real topography is included. In the $R E A L$ experiment, mixing occurs to an altitude of 40-60 metres above the surface, while this is only 2030 metres in $H O M_{\text {flat }}$. On a larger scale it is established that debris influences the near-surface atmosphere (Collier et al., 2015). We show that the micro-scale meteorology is also strongly affected by debris, influencing, for example, the local temperature and moisture lapse rates. Heterogeneous surface temperatures allow negative surface temperatures at ice cliffs, resulting in reversed temperature gradients close to the surface (HET $\mathrm{T}_{\mathrm{T}}$ and REAL; Figure 2.7).

The surface roughness causes local differences in wind speeds, especially where there are large elevation differences over a small horizontal range. This is, for example, visible above the ice cliff $(x=510-600 \mathrm{~m})$, where the wind gradient decreases towards the bottom. This is confirmed with station observations, where higher located stations measure consistently higher wind speeds than at lower locations. The three dimensional simulation approach used quantifies the spatial differences in wind speed. In local depressions accumulation of heat and moisture frequently occurs, and this is further amplified when including heterogeneous surface specific humidity and temperature. If the accumulated heat and moisture are regularly removed by cold and dry air, these heterogeneous differences create local hot spots of SHF and LHF. Surface roughness can therefore be seen to play an important role and can alter the conductive flux into the debris. At locations where the air is stagnant, fluxes are attenuated since gradients in moisture and temperature between the surface and atmosphere gradually decrease with the accumulation of heat and moisture. Of particular interest are the locations where the specific surface humidity is high and temperature low, such as ice cliffs. We take a more detailed look at these supraglacial features in Section 2.3.5. 

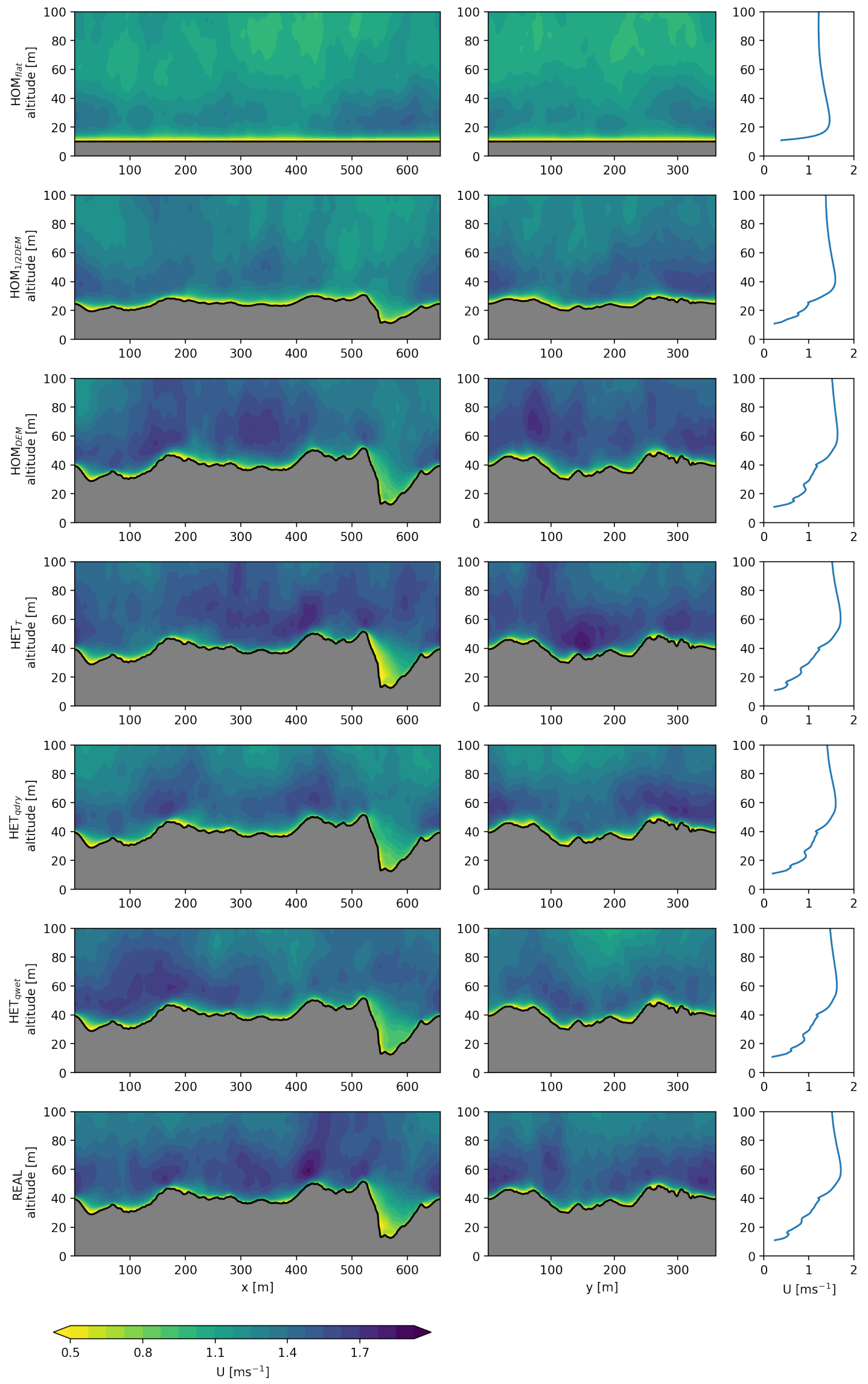

Figure 2.5: Cross sections (left and middle columns) and average vertical profile (right columns) of the wind speed for all experiments presented in the same order as in Table 2.1. The location of the cross sections is shown in Figure 2.2. 

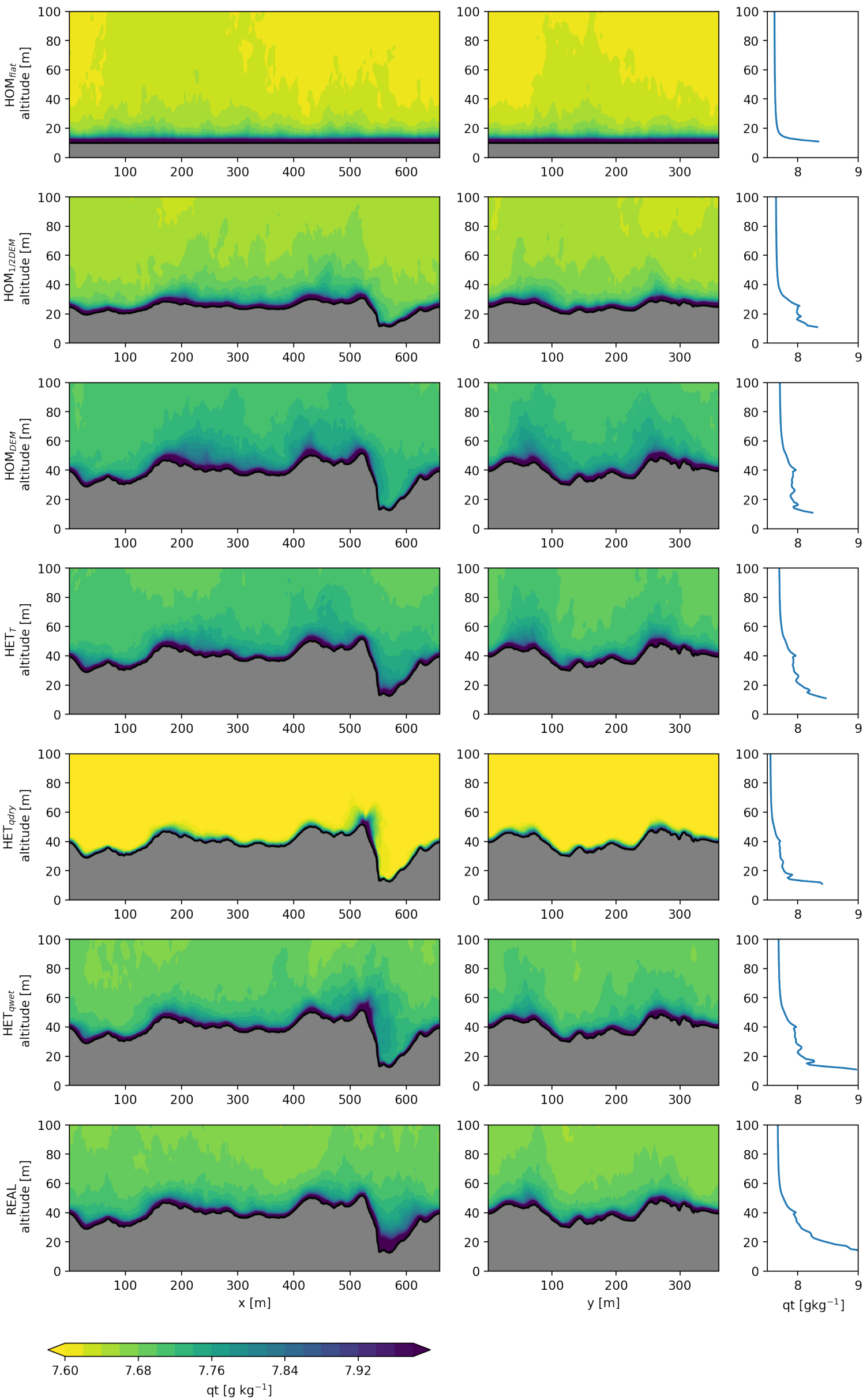

Figure 2.6: As in Figure 2.5 but here for the specific humidity. 

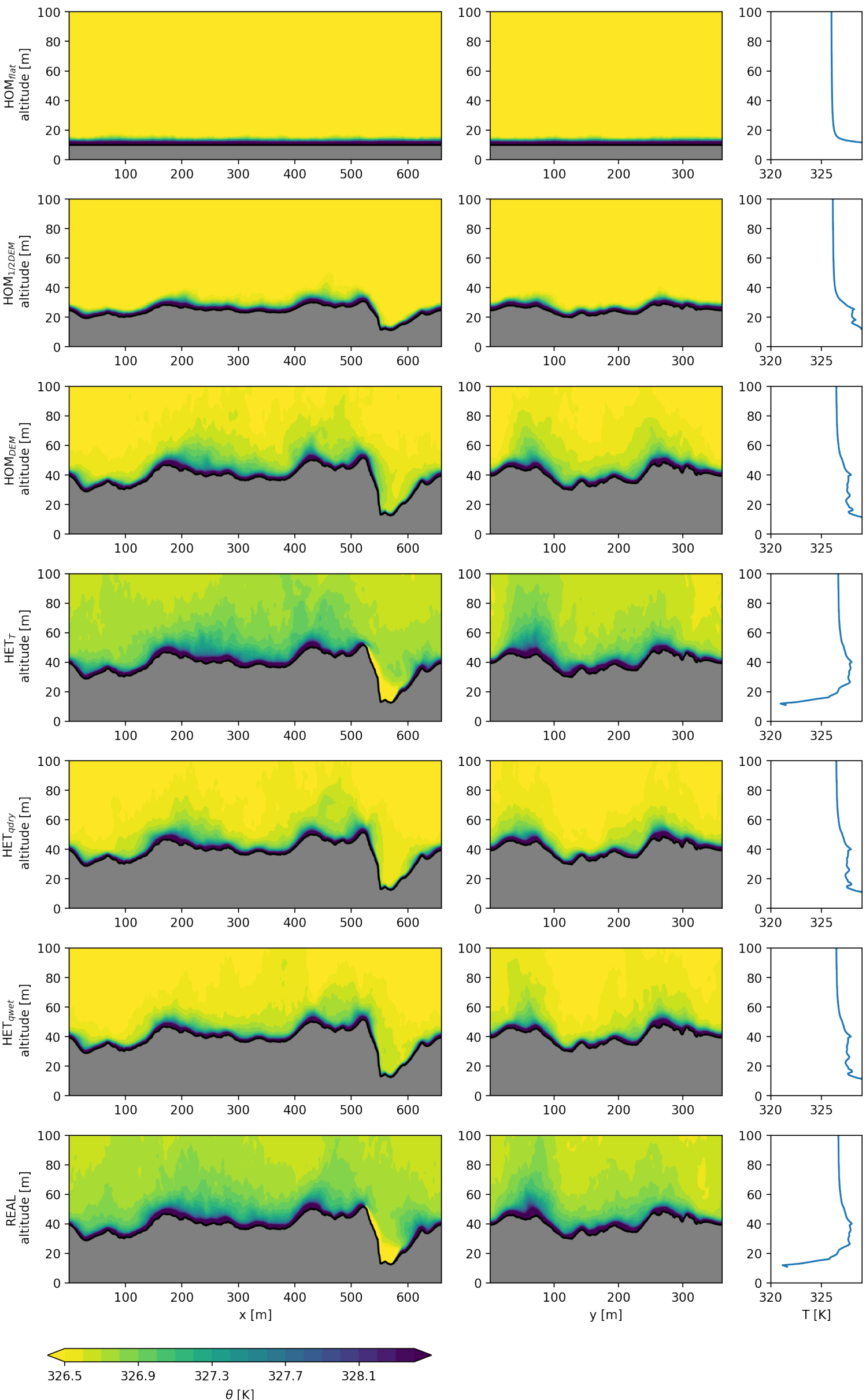

Figure 2.7: As in Figure 2.5 but for the potential temperature. 


\subsubsection{Spatial analysis}

In Figure 2.8 the possible range of the SHF and LHF are plotted for four locations: dry debris (A), wet debris (B), an ice cliff (C) and the location of the AWS (D). The exact locations are indicated in Figure 2.2. The simulations represent a static state at 11:00 LT and we interpret the results as a possible range of outcomes for that state. Turbulent fluxes can vary greatly at one location, since they depend on the instantaneous turbulent conditions. This means the variability of turbulent fluxes is large, even with constant surface boundary conditions.

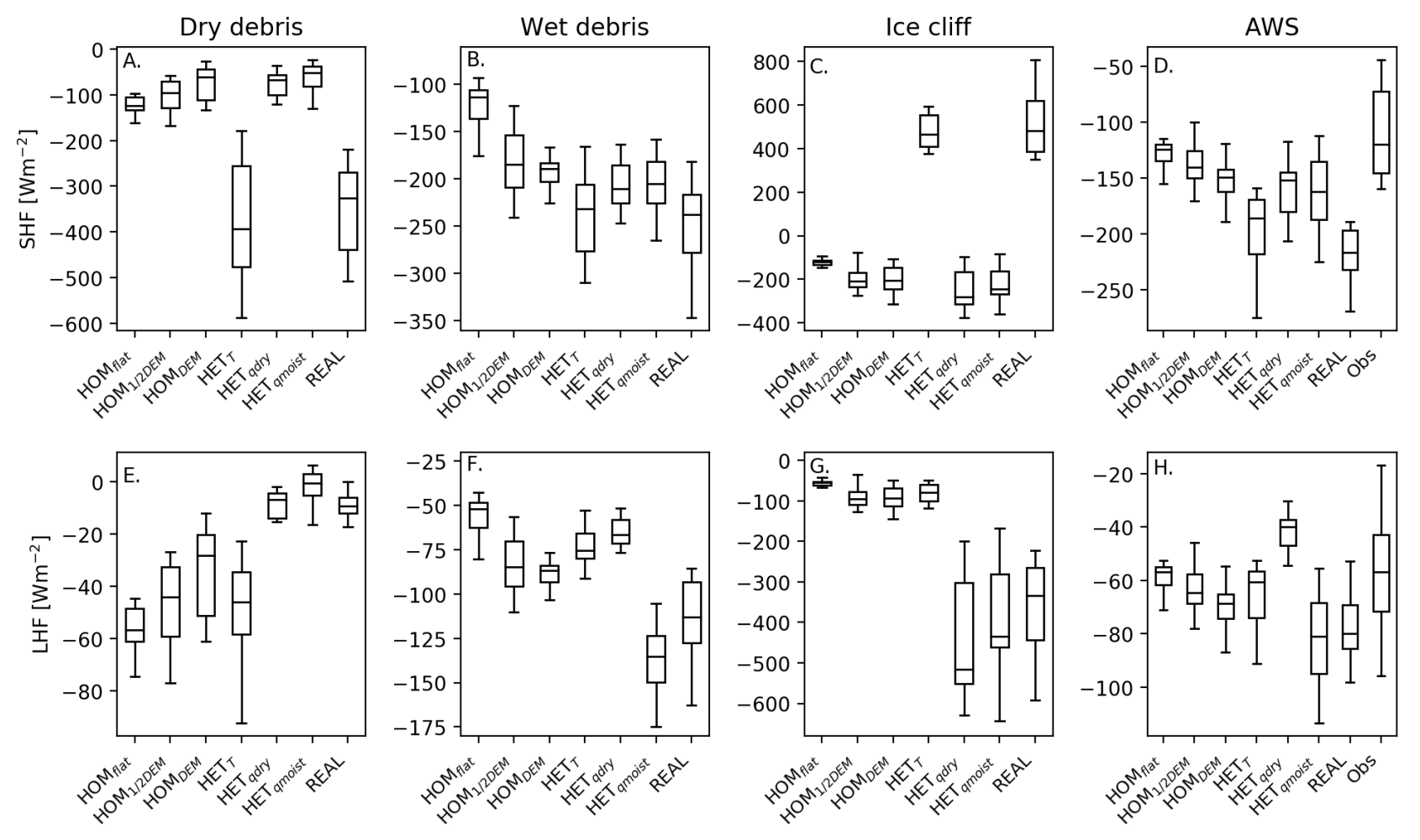

Figure 2.8: Box plots to show variability in possible outcomes at four different locations: dry debris $(A+E)$, wet debris $(B+F)$, ice cliff $(C+G$; all three points are taken as average of 9 grid points) and AWS location (weighted average over the footprint; $D+H$ ), for all experiments (Table 2.1). Observations (Obs) of the SHF and LHF are shown in Figure $D$ and $H$. For all simulations the last hour of simulation data is taken and is resampled to a 5 minute average. Measurements are averaged over 5 minutes. The time period taken from the AWS is 10:30-11:30 LT.

\subsubsection{Debris}

For comparison between dry and moist debris, two locations are chosen where both surface temperatures are $291 \mathrm{~K}$ in the REAL experiment. Surface moisture for the dry and wet debris for $\mathrm{HET}_{\text {dry }}$ are 8.0 and $8.1 \mathrm{~g} \mathrm{~kg}^{-1}$, and for $\mathrm{HET}_{\text {qmoist }} 8.5$ and $9.0 \mathrm{~g} \mathrm{~kg}^{-1}$ respectively. Attributing the differences in fluxes between wet and dry debris to surface moisture is not straightforward since 
the spatial distribution of surface moisture is dependent on the DEM (dry debris is located at higher elevated parts, while moist debris is located at depressions). In addition the surrounding grid points influence the turbulent fluxes. Dry debris is generally located in areas exposed to higher wind speeds and surface roughness, while the opposite holds for wet debris. The SHF is more sensitive to surface temperature for dry debris than for wet debris, and in the REAL experiment the LHF is approximately 10 times as high over wet debris compared to dry debris. Turbulent fluxes have different sensitivities to surface temperature and moisture, indicating that the sensitivities are different in wet and dry climates. As a result surface boundary conditions should be chosen carefully for simulations.

The LHF over dry debris, when domain averaged (with its spatial standard deviation) in the REAL case, is lower $\left(\mathrm{q}_{\mathrm{s}}<8.4 \mathrm{~g} \mathrm{~kg}^{-1}, 34 \pm 17 \mathrm{~W} \mathrm{~m}^{-2}\right)$ than over wet debris $\left(\mathrm{q}_{\mathrm{s}}>8.8 \mathrm{~g} \mathrm{~kg}^{-1}, 117+52 \mathrm{~W} \mathrm{~m}^{-2}\right)$. This is caused by less moisture availability. The SHF over wet debris $\left(-237 \pm 247 \mathrm{~W} \mathrm{~m}^{-2}\right.$, excluding ice cliffs) is considerably higher than over dry debris $\left(-135.3 \pm 161 \mathrm{~W} \mathrm{~m}^{-2}\right)$ and is caused by the location of the wet debris in the depressions, where there is an accumulation of heat that increases the vertical temperature gradient as discussed in Section 2.3.2.

\subsubsection{Ice cliff}

The surface conditions at an ice cliff are different to those of the surrounding debris surface. This is because the surface is at (or around) melting point and the near-surface air is saturated. As a result the reversed (positive) SHF is the most pronounced difference compared to the debris surface. Additionally, spatially different surface temperatures result in cold and warm eddies that can pass over the ice cliff and increase the variation in the SHF. The variation in the LHF is mainly influenced by the surface specific humidity, since with heterogeneous surface variables dry and wet eddies can flow over the saturated surface causing different vertical moisture gradients above the ice cliff. This is described in more detail in Section 2.3.5.

\subsubsection{AWS measurement comparison}

The use of the location of the AWS allows comparison of the simulations to actual measurements. However, while the measurements are an average of the footprint of the station this varies with time and exceeds the domain slightly. We have taken a weighted average over the grid points that are located in the domain. The averaged measured SHF is $49 \%$ lower than the modelled SHF; the LHF is $23 \%$ lower. The range between the first and third quartile for the LHF (SHF) is 16 (36) for the REAL case and 29 (73) W $\mathrm{m}^{-2}$ for the observations, showing that the model underestimates the variation. The ranges of simulated LHF overlap with the observed range, 
however for the SHF the observed and simulated ranges do not overlap. The comparison between the simulations and the observations give an indication of the model performance, however a one-to-one comparison is complex, since our simulations are an idealized representation of the reality in a limited domain and exclude effects of, for example, the moraines or glacier at higher altitude. The disagreement between simulated and observed fluxes may also be caused by the location of the AWS, which is situated close to the moraines. Steiner et al. (2018) estimated the average surface energy balance for Lirung Glacier at the AWS location to be $\pm 350 \mathrm{~W} \mathrm{~m}^{-2}$ for clear-sky around 11:00 LT, while in REAL this is $294.2 \mathrm{~W} \mathrm{~m}^{-2}$, using a weighted average for the footprint of the AWS. However the model domain averaged conductive flux is $348.8 \mathrm{~W} \mathrm{~m}^{-2}$, indicating that the model performs well and within a reasonable range.

\subsubsection{Surface energy balance}

Figure 2.9 shows conductive flux into the debris under the seven simulations. Spatial heterogeneous shortwave and longwave radiation fields based on the real DEM are used as inputs. The LHF and SHF vary, depending on the experiments to isolate the effects of the individual experiments. For example, the ice cliff signal in Figure 2.9A is visible, despite the homogeneous surface conditions in $H O M_{\text {flat }}$ due to the longwave and shortwave signal derived from the real DEM. The energy reaching the ice below the debris is dependent on the thermal conductivity, density and heat capacity of the debris.

Table 2.2, the average conductive flux averaged over the domain, ice cliff cells and debris cells with standard deviations. Ice cliffs cover $2 \%$ of the domain. The standard deviation is based on all pixel values in the domain.

\begin{tabular}{llll}
\hline \hline & Domain average $\left(\mathrm{W} \mathrm{m}^{-2}\right)$ & Ice cliff average $\left(\mathrm{W} \mathrm{m}^{-2}\right)$ & Debris average $\left(\mathrm{W} \mathrm{m}^{-2}\right)$ \\
\hline $\mathrm{HOM}_{\text {flat }}$ & $391 \pm 23$ & $674 \pm 76$ & $363 \pm 191$ \\
$\mathrm{HOM}_{1 / 2 \mathrm{DEM}}$ & $377 \pm 67$ & $259 \pm 111$ & $378 \pm 65$ \\
$\mathrm{HOM}_{\text {DEM }}$ & $368 \pm 102$ & $210 \pm 187$ & $370.8 \pm 98$ \\
$\mathrm{HET}_{\mathrm{T}}$ & $375 \pm 205$ & $967 \pm 193$ & $365 \pm 190$ \\
$\mathrm{HET}_{\text {qdry }}$ & $389 \pm 136$ & $-142 \pm 396$ & $399 \pm 107$ \\
$\mathrm{HET}_{\text {qmoist }}$ & $358 \pm 147$ & $-81 \pm 366$ & $366 \pm 128$ \\
$\mathrm{REAL}$ & $368 \pm 193$ & $674 \pm 76$ & $364 \pm 191$ \\
\hline \hline
\end{tabular}


With increasing surface roughness $\left(H O M_{\text {flat }}, H O M_{1 / 2 D E M}, H O M_{D E M}\right)$ the conductive heat flux becomes more variable, as is also observed for the SHF and LHF separately in Figure 2.3. Locally it is important to prescribe the surface specific humidity, e.g. for ice cliffs. A wetter environment results in a lower conductive flux ( $H E T_{\text {qdry }}$ and $\left.H E T_{\text {qmoist }}\right)$, while a colder surface results in a higher

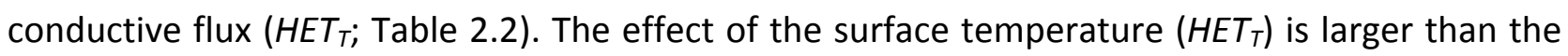
surface specific humidity ( $H E T_{\text {qmoist }}$ ) and therefore the conductive flux of $R E A L$ is closely related to the signal imposed by the surface temperature.

The aim of this study is to get insight in the spatial variable conductive heat flux and it goes beyond the scope of present study to investigate the melt dynamics of sub-debris ice. However, this would be an interesting field of future research and in order to do this spatial variable observations of the thermal conductivity, density and heat capacity of the debris layer are needed, which are currently unavailable. Our interpretation of the results is focused on the surface energy balance and stops at the debris-atmosphere interface.

A heterogeneous conductive flux contributes to heterogeneous melting, depending on the debris thickness. For example in REAL the average conductive flux on the ice cliffs is $674 \pm 76 \mathrm{~W} \mathrm{~m}^{-2}$, while this is only $364 \pm 191 \mathrm{~W} \mathrm{~m}^{-2}$ averaged over the debris. The conductive heat flux at ice cliffs can be used exclusively for ice melt, while for debris the conductive flux is partly used to penetrate and warm the debris. Turbulent fluxes decrease the energy available for melt by $39 \%$ for the REAL case averaged over the domain. Over debris, turbulent fluxes reduce the available melt energy by $40 \%$ and act as a sink of energy, while on ice cliffs turbulent fluxes enhance it by $51 \%$ and are a contributor to melt. Other studies found that ice cliffs melt between 5.7 and 13.7 times faster than ice below surrounding debris (Brun et al., 2016; Sakai et al., 2002; Buri et al., 2016; Reid and Brock, 2014). Although those studies consider total melt rather than the surface energy balance, the pronounced differences between melt on ice cliffs and debris are in line with our research.

The surface specific humidity is relatively uncertain and the range used in the experiments is based on scarce observations. It is spatially distributed using a simple relation with elevation. We performed additional sensitivity tests of two extreme cases of a homogeneous surface relative humidity of $20 \%$ and of $85 \%$, with the relative humidity at ice cliffs at $100 \%$, to quantify the effect on the conductive heat flux. The domain averaged ( \pm spatial deviation) conductive heat flux when $\mathrm{RH}=20 \%$ is $490 \pm 201 \mathrm{~W} \mathrm{~m}^{-2}$, and $89 \pm 276 \mathrm{~W} \mathrm{~m}^{-2}$ when $\mathrm{RH}=85 \%$. This indicates that the mean conductive flux is positive, regardless of the surface specific humidity. Secondly, if the surface 

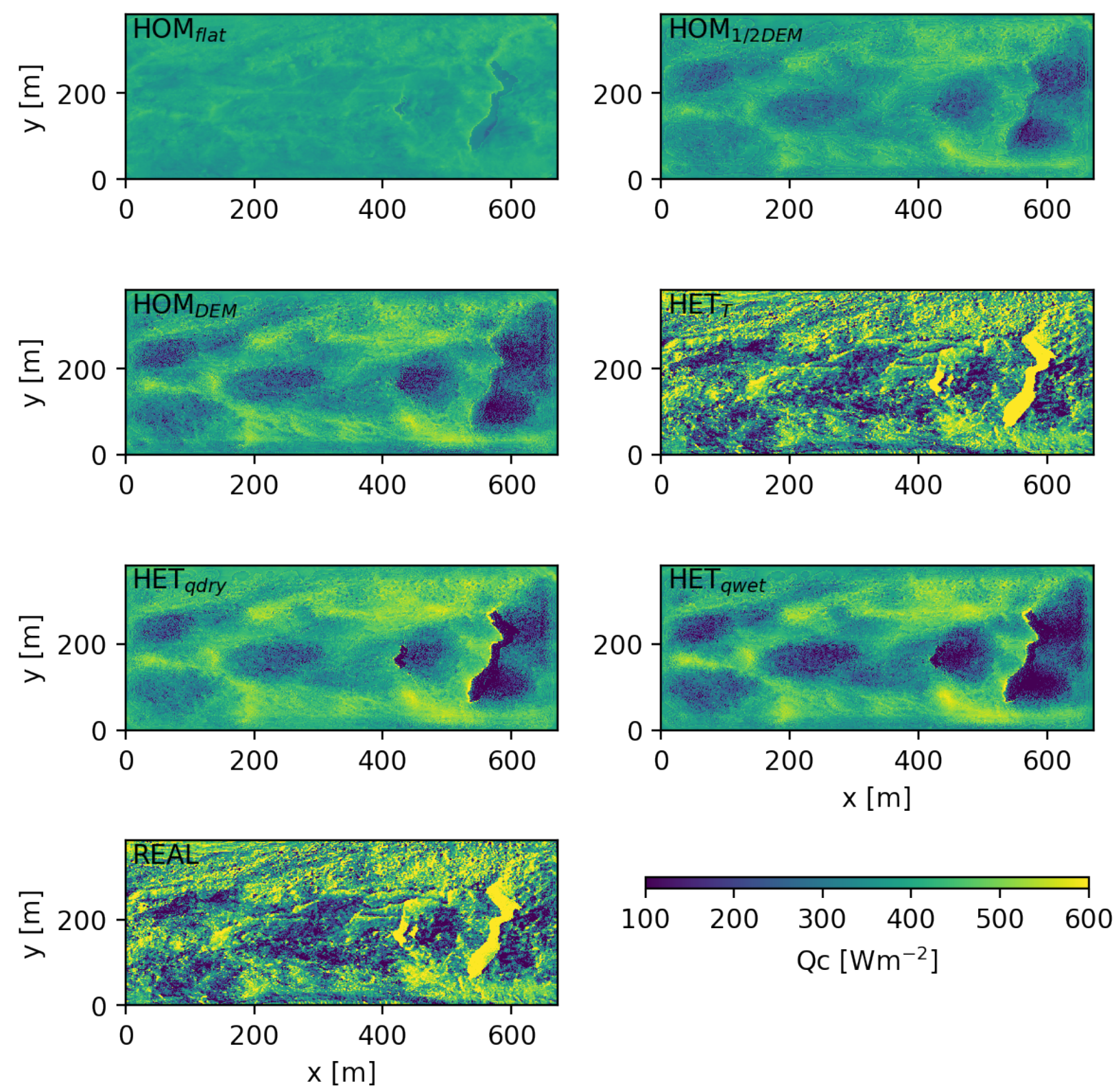

Figure 2.9: Effect of turbulent fluxes on conductive flux into the surface for all experiments. $A$ positive flux means energy is available to go into the surface. 
relative humidity is lower than the atmosphere the latent heat flux is directed towards the surface and contributes to the conductive heat flux. The opposite occurs with a higher relative humidity, which can happen at ponds and ice cliffs. Moreover, the conductive heat flux decreases with increasing relative humidity, which shows the regulating effect of moisture on the total energy budget. At ice cliffs, the latent heat flux can become highly negative if the atmosphere is dry and can even reverse the sign of the conductive heat flux. During the monsoon season (summer months) the surface moisture will be higher than over the rest of the year, and the conductive heat flux at the surface will be higher than in winter and spring.

In summary, these results show turbulent fluxes can be key in explaining of the formation of ice cliffs. Locations with already thick debris (and hence higher surface temperatures) do not melt as fast as the surrounds due to the SHF and LHF reducing the conductive flux, as well as the general insulation of the debris (Figure 2.9). A crest will develop, introducing the topographic effects as discussed above. This acts as a positive feedback and enhances the local topographic differences on debris-covered glaciers. These results show that turbulent fluxes can be an additional driver for the typically variable topography of a debris-covered tongue and for the formation of ice cliffs, along with collapsing channels, as has been hypothesised (e.g. Benn et al., 2012).

\subsubsection{Ice cliff analysis}

Ice cliffs on debris-covered glaciers are particularly interesting to study in terms of turbulence given their steep topography, anomalous surface temperature and moisture conditions compared with the surrounding debris. We showed in the previous section that on an irregular surface, local hot spots of the conductive flux into the surface exist, amplifying the melt. Such irregularities are likely to favour the formation of ever deeper depressions and eventually expose ice cliffs. Our simulations do not allow dynamic modelling of ice cliff evolution, however we can gain insight in the microclimate around such cliffs to better understand the fundamental mechanisms of ice cliff melting. Three dimensional modelling can thus provide insight into processes such as advection of heat and moisture.

In Figure 2.10 six vertical profiles of wind speed, potential temperature and specific humidity over an ice cliff are shown with a time interval of 10 seconds. On the leeward side of an ice cliff eddies are generated by both the thermal and moisture gradients and the topography. In the situation we examine the clean ice is on the left side of the local depression and the dominant wind flow is from the left to right. When relatively warm air is advected over the ice cliff this air cools, falls 
down (first column) and generates an eddy where the accumulated moisture is transported out of the depression and the cold air is replaced by warmer air (columns 2-3). At this point the SHF and LHF are intensified, since the moisture and temperature gradients are increased within the depression. Intensification of the turbulent fluxes occurs, since warm air from the right side of the depression is transported towards the clean ice by the rotating eddy (column 4). After such an advection event the ice will cool and moisten the air in the depression. The vertical moisture and temperature gradients decrease in time and the SHF and LHF decrease until the process of refreshment repeats itself.
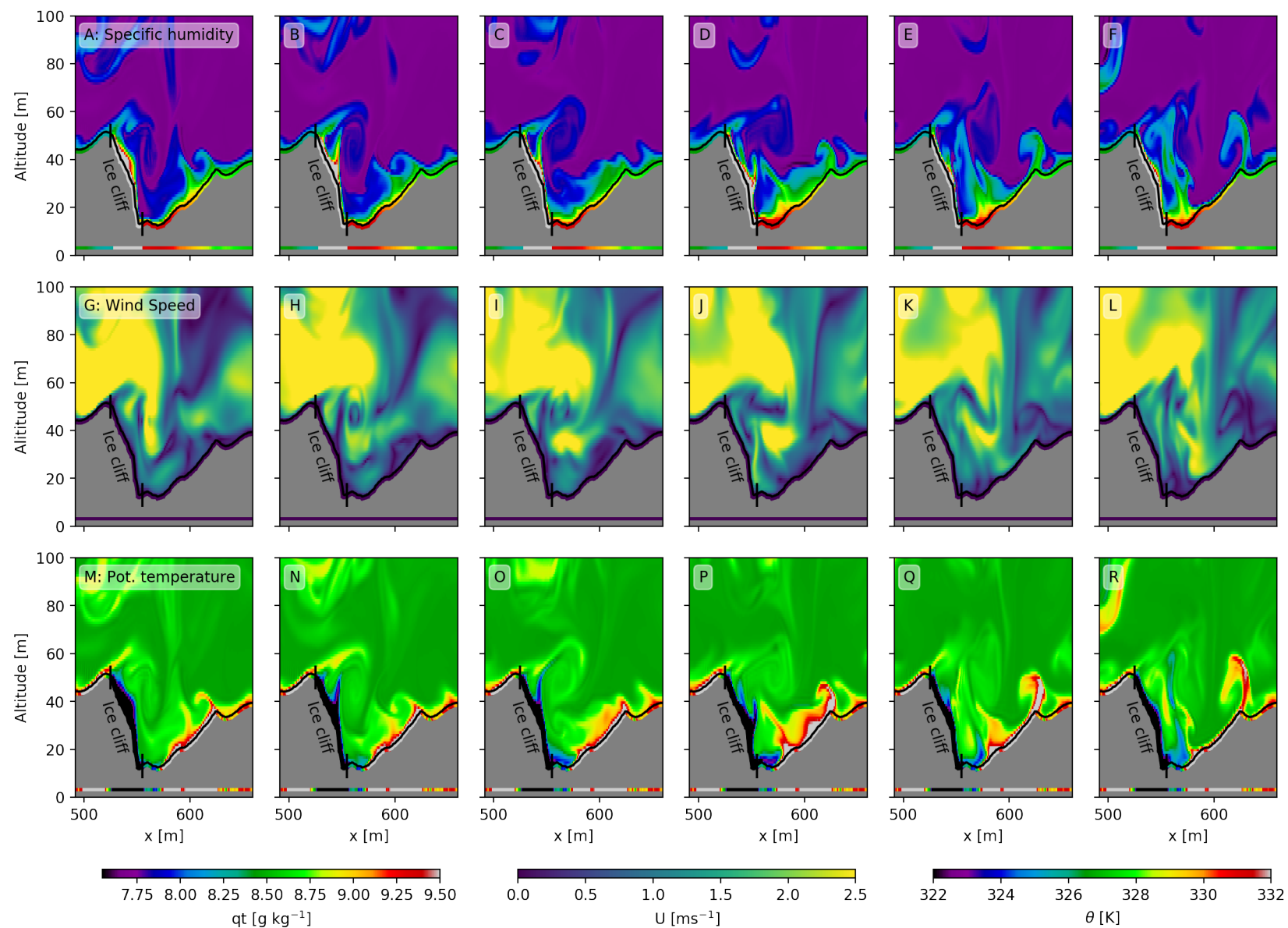

Figure 2.10: The specific humidity $(A-F)$, wind speed (G-L) and temperature $(M-R)$ for a zoom-in around an ice cliff $(660<x>500 \mathrm{~m})$ at time $=6570-6630 \mathrm{~s}$ with $10 \mathrm{~s}$ time interval. The black line indicates the topography. The surface boundary conditions are plotted directly below the surface and, for clarity, also at $y=0$.

During an advection event warm and dry air flows over the ice cliff and is transported into the depression. This causes (temporarily) a strong gradient and sensible heat contributes to melt, until the air has cooled down. This process gives an intensified melt signal at the ice cliff and causes it to deepen and, in this specific case, to retreat to the left. This is congruent with ice cliff 
backwasting found in previous studies (Reid and Brock, 2014; Steiner et al., 2015). Similarly, Mott et al. (2014) found that net surface radiation over snow patches is not the only driver of energy exchange between the surface and atmosphere in mountainous areas, with secondary flows induced by surface heterogeneities also being an important driver. We hypothesize that ice cliff backwasting can also be related to the main wind direction in the domain. Cliffs that are in the leeward direction of the main wind direction during daytime receive additional warm dry air through the advection mechanism, causing extra melt.

Ice cliffs typically have a knick-point shape, previously explained by differences in local radiation (Sakai et al., 2002). However this explanation ignores the extra amount of longwave radiation in the depressions (Steiner et al., 2015) and does not explain why crests generally do not flatten over time. Turbulent fluxes are also likely to play a role in the shape of the ice cliffs as a result of the vertical variations in wind speed induced by the topography. This can be seen in Figure 2.5, where the wind speed decreases with depth at the ice cliff $(x=550 \mathrm{~m})$, and the knick-point of the ice cliff is at the location of strongest decline in wind speed. The heat and moisture exchange are therefore strongest at the top of the ice cliff and lowest in the depression, with the main wind flow being over the depression, and not reaching the deepest parts of the ice cliff.

\subsection{Sensitivity to Reynolds number}

In order to simulate atmospheric turbulent flows there are two options: DNS and LES. Both options come with advantages and drawbacks. DNS is computationally extremely expensive when resolving all scales in the flow and its use was not possible in our case study. An advantage of DNS is that the correctness of a simulation can be checked by testing whether the results of sensitivity tests converge, as we will do in this section. With LES however this approach would not be possible, as sensitivity tests can be evenly wrong caused by the inappropriate surface model under high Reynolds numbers in complex terrain. This means that even when resolving all scales in the flow with LES this does not give direct confidence in the results and LES does not outperform DNS by definition.

The Reynolds number $(\mathrm{Re})$ is a measure for the flow characteristics and is the ratio between inertial and viscous forces in a fluid (Eq. 18). A low Reynolds number would indicate a laminar flow and a high Reynolds number a turbulent flow.

$\mathrm{Re}=\frac{\mathrm{uL}}{v}$ 
Where $u$ is the velocity $(\mathrm{m} / \mathrm{s}), L$ is the characteristic length scale $(\mathrm{m})$ and $v$ is the kinematic viscosity $\left(\mathrm{m}^{2} \mathrm{~s}^{-1}\right)$ of the fluid. By decreasing the kinematic viscosity the fluid will become more turbulent and resolve smaller scales.

To show that turbulence is fully developed in our study, we double the Reynolds number by decreasing the viscosity from 0.2 to $0.11 \mathrm{~m}^{2} \mathrm{~s}^{-1}$, and we repeated the REAL experiment. Computationally the run with low viscosity is 15 times more demanding than the high viscosity as the viscosity is halved and the number of grid points is doubled in $x, y$ and $z$. The LHF and SHF have the same patterns and are in same order of magnitude at both viscosities (Figure A1). Furthermore, the averaged vertical profiles of potential temperature and specific moisture are also similar, which gives confidence in the use of 1 metre resolution for this type of simulations (Figure A2).

The energy spectrum of specific humidity is shown in Figure A3; energy spectra of other variables (e.g. temperature and wind) show the same pattern. As this run is very complex and far from idealized, comparison of energy spectra of the viscosities is not straightforward. The energy spectra are derived from a horizontal cross section at a fixed height of 65 metres above the lowest point in the topography, implying that the cross section is not at a constant height above the surface. As a result, the spectrum contains not only a signature of the turbulence but also of the topography. The peak of the spectrum is located around a wave number of 1 , which corresponds to a wavelength of $2 \pi / 1 \approx 6$ metres and is resolved by both experiments. This shows that large structures are dominant in the flow and small structures are of minor importance. The spectra averages for both experiments differ, although located in the centre of the bandwidth of one standard deviation.

The simulation at low viscosity naturally resolves smaller scales than the simulation with a higher viscosity (see Equation 18). In Figure A3 we see that the additional variability does only add a small amount of variance to the signal and is therefore irrelevant for the flow (wave numbers $>11$ ). We therefore conclude that a viscosity of $0.2 \mathrm{~m}^{2} \mathrm{~s}^{-1}$, in combination with a spatial resolution of 1 metre, is fine enough to capture the bulk characteristics of the flow as well as its most important features.

\subsection{Limitations}

There is an initial but incomplete understanding of micro-meteorological processes for debriscovered glaciers with highly variable surface temperature and moisture conditions. In particular 
the role that turbulent fluxes have in the net conductive energy flux towards the ice below the debris is unknown. For the first time, in this study, a 3D turbulence resolving high-resolution model was used to gain understanding of these local processes and interactions between the surface and the overlying atmosphere. We show that such turbulence-resolving models provide important insights into these processes, supporting a better quantification of debris covered glacier melt. However, we identified a number of limitations associated with data availability, the model assumptions and computational constraints, which we discuss in the following paragraphs.

Information about surface moisture on debris-covered glaciers is scarce, highly variable, and measurement is difficult. Surface moisture is, however, an important variable in assessing the surface energy balance since it influences the latent and sensible heat flux and therefore the conductive heat flux that ultimately melts the ice. Studies normally deal with the limited information available for surface moisture by assuming that the debris surface is either dry or fully saturated, to indicate the range of outcomes (e.g. Rounce et al. 2015). The approach proposed in this study is a step towards a better representation of surface specific humidity, showing the effect of a partly saturated surface and, furthermore, a heterogeneous distribution linked to the DEM. In reality the surface moisture is dependent on the surface material and texture, its relative elevation in the domain, and the aspect of the location (Qiu et al., 2001). In future, the spatial distribution could also be made dependent on debris grain size rather than the absolute height of the topography in order to make spatial patterns of surface specific humidity more realistic. During our observation period no large supra-glacial ponds were observed (Figure 2.1), but surface conditions of ponds could also be included in MicroHH in upcoming studies.

In this study we have considered the conductive heat flux and how this brings about a gradual warming of the debris, eventually melting the ice when the warming front reaches the debris-ice interface. How this energy is partitioned between the warming of the debris and melting depends on the debris thickness, the type of rock, the texture and the moisture content. Future studies can couple a debris energy balance model (e.g. Giese, 2019; Reid and Brock, 2010) to MicroHH, investigating the total energy reaching the ice, its timing, and the impact of debris properties such as thickness, surface moisture and thermal conductivity.

One of our experimental outcomes is that the use of spatially variable surface boundary conditions for surface specific humidity and temperature results in similar domain averages of turbulent surface fluxes compared to a constant surface temperature or specific humidity. This all relies on the strong assumption that the homogeneous value (in reality taken from a weather 
station measurement) is representative of the whole domain. In our experiments the homogeneous value is per definition representative for the domain, as it is an average of the heterogeneous values. The bias induced by upscaling point measurements is given by comparing the results of the homogeneous surface conditions (HOM experiments) and the heterogeneous surface conditions (HET experiments). This shows that heterogeneity plays an important role for local supra-glacial features on a debris-covered glacier, while domain averaged the effects to the conductive heat flux are minor. In reality it is close to impossible to locate a station so that it is perfectly representative of the whole domain without having prior knowledge of the spatial distribution. This type of high-resolution modelling can therefore support the optimal selection of sites for meteorological observations to ensure representativity.

High-resolution modelling is a useful tool to investigate small-scale meteorological processes, due to its explicit treatment of turbulent processes. The modelling is, at this stage, still conceptual, since not all processes and feedbacks are included. In this study only a part of Lirung Glacier is modelled and the modelling excludes surrounding influences such as wind flows caused by the lateral moraines and circulations in the valley. Due to the high spatial resolution and computational constraints, we limited the simulation time to 1 hour and the simulation is stationary.

A correct representation of debris-covered glaciers would benefit climate, glacier and hydrological models to give a better estimation of melt water contribution to river discharge. Our study provided important insights, but also made clear that turbulence-resolving, long-term and transient simulations are currently not feasible. Our results nevertheless do provide a greater understanding of surface processes on debris-covered glaciers along with parameterizations that can be used in coarser resolution models. In order to understand the small-scale processes at the surface-atmosphere interface on a debris-covered glacier we need high-resolution data and models.

\subsection{Conclusions}

The exact melt processes of debris-covered glaciers are largely unknown and their total contribution to the total glacier melt remains uncertain. The surface of a debris-covered glacier is complex due to its topography, heterogeneous surface temperature and surface moisture resulting in highly heterogeneous micro-meteorological conditions. In this study, we assess the effect of surface properties of debris on the spatial distribution of micro meteorological variables, such as wind fields, moisture and temperature by sensitivity tests. Subsequently we investigated 
how those drive the turbulent fluxes and eventually the conductive heat flux for a debris-covered glacier. This is the first time an in-depth analysis is performed of micro-meteorological variables above a debris-covered glacier with a turbulent resolving model at high resolution $(\sim 1 \mathrm{~m})$. This has offered new insights into the spatial variability of turbulent fluxes and what drives these differences.

Surface roughness has the strongest impact on the magnitude of turbulent fluxes and leads to more mixing at higher altitudes due to the higher topographic variability. Surface roughness causes spatial differences in wind speed, with generally lower wind speeds at lower elevations due to isolation, whereby accumulation of heat and moisture is possible. Increasing the surface roughness leads therefore to more pronounced spatial differences in turbulent fluxes.

Heterogeneous surface temperature has its primary impact on the SHF, this because of the way it influences the temperature gradient between the surface and the atmosphere. A heterogeneous surface specific humidity affects mainly the LHF by influencing the moisture gradient between the surface and the atmosphere. Overall, including heterogeneous conditions lead to higher spatial variability and a larger range of possible outcomes. The variability of the turbulent fluxes can result in a feedback effect that eventually leads to the hummocky terrain typical for debriscovered tongues in the Himalaya. In more extreme cases this variability can bring about the formation of cliffs, and also of ponds in those depressions where melt has been accelerated.

We found that the inclusion of heterogeneous surface temperature and specific humidity is extremely important when looking at sub-glacier features such as ice cliffs as these allow both negative and positive turbulent fluxes in the domain. The microclimate around an ice cliff is influenced strongly by a combination of topographic, surface specific moisture and temperature effects, which favour high sensible and latent heat fluxes. Additionally the progression and persistence of ice cliffs is influenced by the main wind direction, since at the leeward side of the cliff turbulent fluxes contribute to melt. Longer high-resolution turbulent resolving simulations are needed to investigate fundamentals of small-scale glacier features in more detail.

We show that turbulent fluxes can decrease the energy available for melt at the debris surface by $40 \%$, acting as an energy sink. In contrast on ice cliffs turbulent fluxes were found to enhance the available energy by $51 \%$, serving as a contributor to melt. In combination with a low albedo this causes ice cliffs to be melt hot spots. 
The use of homogeneous surface temperature and specific humidity is a good alternative when spatial data is lacking but only when these values are representative of the whole domain and the interest is primarily in domain-averaged outcomes. In general a point measurement will not be representative for the whole domain and use will result in large biases in atmospheric variables when upscaling to a larger area.

Our results show that high-resolution turbulent resolving models can be used to better quantify spatially variable melt. Future studies could couple high-resolution models to a full energy balance model to determine the energy reaching the ice. This work is important for glacier mass balance modelling and for the understanding of the evolution of debris-covered glaciers. We expect that these results will be useful in improving the representation of debris-covered glaciers in hydrological and climatological models to determine their contribution to glacier melt.

\section{Data availability}

The data can be found at 10.5281/zenodo.3375325 and 10.5281/zenodo.3375490.

\section{Video supplement}

Supporting movies are available at 10.5281/zenodo.3375333

\section{Author contributions}

PB designed the study together with WI. $\mathrm{CH}$ adjusted the MicroHH model for this study. PB performed all numerical experiments and prepared the manuscript with contributions from all co-authors.

\section{Acknowledgements}

This project has received funding from the European Research Council (ERC) under the European Union Horizon 2020 Research and Innovation Program (Grant Agreement No. 676819) and Netherlands Organization for Scientific Research under the Innovational Research Incentives Scheme VIDI (Grant Agreement No. 016.181.308). Supercomputing resources were financially supported by NWO and provided by SURFsara (www.surfsara.nl) on the Cartesius cluster. We thank Joseph Shea and Maxime Litt for setting up the measurement station. We are grateful to the trekking agency Glacier Safari Treks and their staff without whom this work would not have been possible. We thank ICIMOD for their scientific support and facilitation of the fieldwork. We thank Bart van Stratum for his valuable help with the immersed boundary layer implementation and the challenges over steep orography. 


\section{The impact of spatial resolution, landuse and spin-up time on resolving spatial precipitation patterns in the Himalayas}

Frequently used gridded meteorological datasets poorly represent precipitation in the Himalaya due to their relatively low spatial resolution and the associated representation of the complex topography. Dynamical downscaling using high-resolution atmospheric models may improve the accuracy and quality of the precipitation fields. However, most physical parameterization schemes are designed for a spatial resolution coarser than $1 \mathrm{~km}$. In this study the WRF (Weather Research and Forecasting) model is used to determine which resolution is required to most accurately simulate monsoon and winter precipitation, 2-meter temperature and wind fields in the Nepalese Himalayas. Four model nests are set up with spatial resolutions of 25, 5, 1 and $0.5 \mathrm{~km}$ respectively and a typical 10-day period in summer and winter in 2014 are simulated. The model output is compared with observational data obtained from automatic weather stations, pluviometers and tipping buckets in the Langtang catchment. Results show that, despite issues with the quality of the observational data due to under-catch of snowfall, the highest resolution of 500 meter does provide the best match with the observations and gives the most plausible spatial distribution of precipitation. The quality of the wind and temperature fields is also improved, whereby the cold temperature bias is decreased. Our results further elucidate the performance of WRF at

Chapter published as:

Bonekamp, P.N.J., Collier, E., Immerzeel, W.W., The impact of spatial resolution, landuse and spin-up time on resolving spatial precipitation patterns in the Himalayas (2018), Journal of Hydrometeorology, 19 (10), 1565-1591 
high resolution and demonstrate the importance of accurate surface boundary conditions and spin-up time for simulating precipitation. Furthermore, they suggest that future modelling studies of High Mountain Asia should consider a sub-kilometer grid for accurately estimating local meteorological variability.

\subsection{Introduction}

High-Mountain Asia is sometimes referred to as the Third Pole, since the region hosts the largest reserves of fresh water stored in glacier and snow outside the Polar Regions (Qiu, 2008). The region contains approximately $5000 \mathrm{~km}^{3}$ ice and supplies water for more than 1.5 billion people living downstream, which is approximately $20 \%$ of the world population (Immerzeel et al., 2010; Kraaijenbrink et al., 2017; Yao et al., 2012). Monsoonal precipitation is the largest contributor to the hydrological budget in the Himalayas (Bookhagen and Burbank, 2010). The amount of precipitation is controlled by the monsoon circulation, westerly winds and orographic forcing, where the spatial distribution of precipitation is affected by terrain height, relief and aspect, and by moisture availability (Whiteman, 2000). However, since these processes interact with each other and play a role at different scales, it is complex to model precipitation in this region. Additionally, field observations, particularly at high altitude, are scarce and model validation is difficult (e.g. (Immerzeel et al., 2014, 2015; Maussion et al., 2014).

Frequently used gridded meteorological datasets poorly represent precipitation in the Himalaya due to their relatively low spatial resolution and the associated representation of the complex topography (Immerzeel et al., 2015). Dynamical downscaling using high-resolution atmospheric models has been found to improve the accuracy and quality of simulated meteorological fields. For example, (Dimitrova et al., 2016) found that a grid spacing of 500 meter is better in capturing flows in complex terrain than a 2-km grid spacing. In theory, simulations at higher spatial resolution better resolve the bottom boundary forcing and important valley-scale processes. However, in reality increasing the spatial resolution does not necessarily lead directly to higher accuracy of the results (Zhang et al., 2013), as specific parameterizations may not be suitable for very high resolution. (Horvath et al., 2012) showed that decreasing the grid spacing to $1 \mathrm{~km}$ has the highest accuracy for wind speed and decreasing to $333 \mathrm{~m}$ does not lead to better results. (Collier and Immerzeel, 2015) investigated the Langtang catchment in Nepal with 1-km resolution and showed the importance of near-kilometer grid spacing for capturing local meteorological variability. However, even at this resolution, significant biases in simulated precipitation remained. Therefore, there is a need to investigate the impact of sub-kilometergrid spacing on the accuracy of simulated meteorological fields in this region of complex topography. 
The meso-scale atmospheric Weather Research and Forecasting (WRF) model (Skamarock and Klemp, 2008) is becoming an established tool for modelling mountainous areas in general and for High Mountain Asia, specifically. Running WRF for mountainous areas with high resolution can help to resolve spatial variability of atmospheric key variables and land-atmosphere exchanges better than larger grid sizes, since heterogeneous surface fluxes and near-surface meteorological parameters are better resolved (Talbot et al., 2012). (Maussion et al., 2014) showed that WRF can be used to model different weather systems in the Himalaya, including mountain-induced orographic precipitation at a grid spacing of 10 kilometer. (Maussion et al., 2011) used WRF configured with a grid spacing down to $2 \mathrm{~km}$ over the Tibetan plateau to simulate one month and validated the precipitation with the Tropical Rainfall Measuring Mission (TRMM) data set and the snow extent with the Moderate Resolution Imaging Spectro radiometer (MODIS) data set. Results show WRF simulates snow and rainfall for that period in reasonable agreement with observations. However, previous studies with WRF have shown that simulations are sensitive to the spin-up time (Román-Cascón et al., 2016; Wang et al., 2012). In general, numerical atmospheric prediction models require spin-up time when there is no data assimilation applied. Spin-up time allows the model to adjust from the initial conditions to a state that is consistent with its own numerics and physics, and to develop appropriate large-scale circulations (Jankov et al., 2007; Skamarock, 2004). In order to prevent instabilities in WRF the spin-up should be at least 12 hours (Jankov et al., 2007) and depends likely on the quality of the model input and the condition of the soil fields (Kleczek et al., 2014). The spin-up time influences the initial conditions such as soil moisture content and therefore the latent heat flux, which influences in turn the precipitation. In addition, the default landuse data has been found to be sub-optimal for the central Himalayas, with the forested area in the Langtang catchment underestimated by $60 \%$ (Collier and Immerzeel, 2015). The landuse likely has a significant effect on the model results, since it controls the exchange of heat and momentum between the land and air (e.g. Cheng et al., (2013)). Therefore, the impact of the grid spacing, landuse and spin-up time need to be assessed.

In this study, we use the WRF model to investigate the role of sub-kilometer grid spacing and the representation of land surface heterogeneity on simulated precipitation in the Langtang catchment, located in the Nepalese Himalaya. The aim of this research is to determine an optimal spatial resolution for modeling key atmospheric variables in high-altitude catchments, as a compromise between the agreement with observations and computational time. We also investigate the effects of spin-up time and landuse on the atmospheric variables respectively, by testing a range of starting dates for two 10-day simulations during the monsoon and winter 
periods, and by introducing a new landuse dataset in WRF. The results of the simulations are compared to observational data obtained from automatic weather stations (AWS), pluviometers and tipping buckets (TB) located in the Langtang catchment.

\subsection{Methods}

\subsubsection{Study area}

The Langtang catchment is located in central Hindu-Kush-Himalaya region, $100 \mathrm{~km}$ north of Kathmandu (Nepal) and has an area of $584 \mathrm{~km}^{2}$ including $140 \mathrm{~km}^{2}$ of glacier area, of which $40 \%$ is debris covered (Collier and Immerzeel, 2015). The catchment has a steep topographic gradient and ranges in elevation from 1406 up to 7180 meter above sea level. Most precipitation events occur during the monsoon period (June to September), while in winter precipitation is produced by passing low-pressure systems. The relation between precipitation and topography in the catchment varies throughout the year and depends on the large-scale circulation in combination with mesoscale orographical and thermal induced circulation (Collier and Immerzeel, 2015).
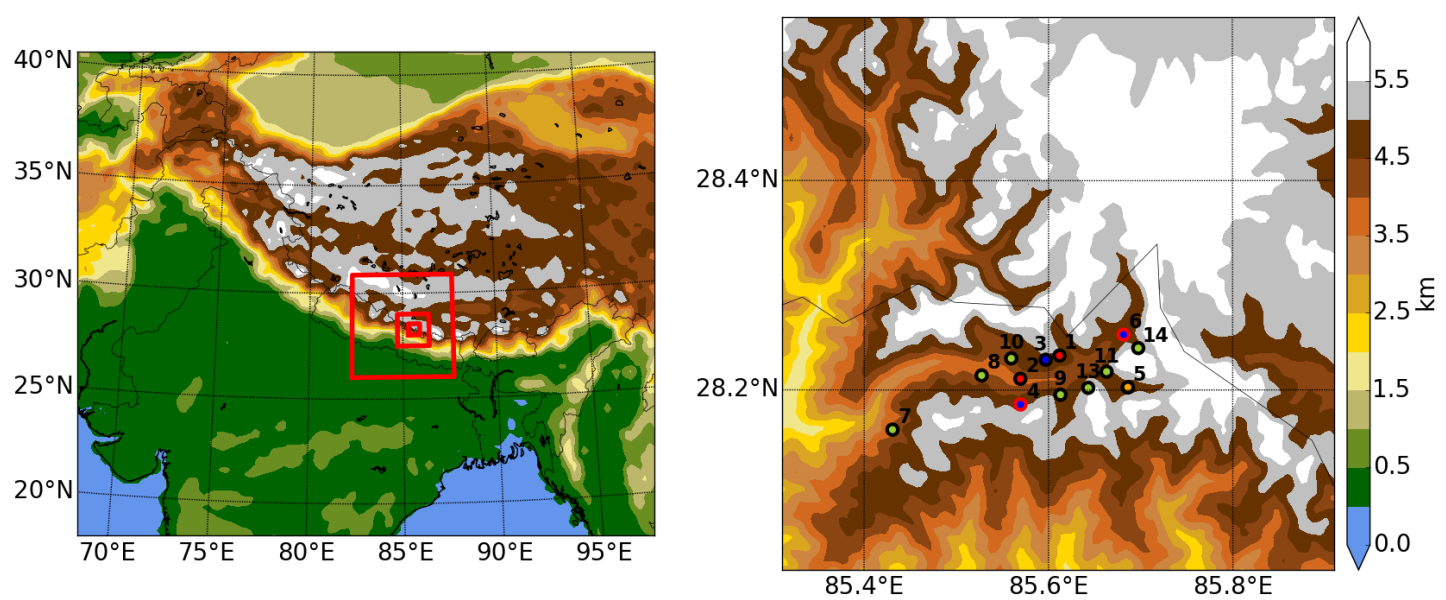

Figure 3.1: The topography and locations of each domain (left panel). In the right panel the topography in D4 and the locations of used measurement stations are shown: 8 tipping buckets (green), 2 automatic weather stations (red) and 4 pluviometers (blue). The orange point is the place wereboth a tipping bucket and a pluviometer are located. A black edge means the station is used for both the winter and summer period, a red edge the station is only used for the summer period. The numbers correspond to the numbers in Table 3.1. The black contour line is the country border of Nepal with China. 
Table 3.1: Available observation stations for both the winter and summer event. $W=$ winter and $S=$ summer event. The automatic weather stations (AWS) measure precipitation, air temperature, relative humidity, snow depth and wind speed, the pluviometer (Pluvio) precipitation, air temperature and relative humidity, and tipping buckets (TB) only precipitation.

\begin{tabular}{|c|c|c|c|c|c|c|c|}
\hline & & Station & W & $S$ & Lat & Lon & $H(m)$ \\
\hline \multirow[t]{2}{*}{ AWS } & 1. & Yala & $\checkmark$ & $\checkmark$ & 28.23230 & 85.60967 & 5090 \\
\hline & 2. & Kyanging & $\checkmark$ & $\checkmark$ & 28.21081 & 85.56948 & 3862 \\
\hline \multirow[t]{4}{*}{ Pluvio } & 3. & Yala & $\checkmark$ & $\checkmark$ & 28.22900 & 85.59700 & 4831 \\
\hline & 4. & GangjaLa & $x$ & $\checkmark$ & 28.18625 & 85.56961 & 4361 \\
\hline & 5. & Langshisha & $\checkmark$ & $\checkmark$ & 28.20265 & 85,68619 & 4452 \\
\hline & 6. & Morimoto & $x$ & $\checkmark$ & 28.25296 & 85.68152 & 4919 \\
\hline \multirow[t]{8}{*}{ TB } & 7. & TB2 & $\checkmark$ & $\checkmark$ & 28.16212 & 85.43073 & 2370 \\
\hline & 8. & TB3 & $\checkmark$ & $\checkmark$ & 28.21398 & 85.52745 & 3539 \\
\hline & 9. & TB5 & $\checkmark$ & $\checkmark$ & 28.19558 & 85.61304 & 3875 \\
\hline & 10. & TB7 & $\boldsymbol{\nu}$ & $\boldsymbol{\nu}$ & 28.23027 & 85.55958 & 4141 \\
\hline & 11. & TB8 & $\checkmark$ & $\checkmark$ & 28.21760 & 85.66306 & 4312 \\
\hline & 12. & TB9 & $\checkmark$ & $\checkmark$ & 28.20265 & 85.68619 & 4452 \\
\hline & 13. & TB14 & $\checkmark$ & $\boldsymbol{\nu}$ & 28.20216 & 85.64315 & 3974 \\
\hline & 14. & TB15 & $\checkmark$ & $\checkmark$ & 28.24014 & 85.69743 & 4617 \\
\hline
\end{tabular}

\subsubsection{Simulation period and measurements}

Since different meteorological processes play a role in winter and summer we selected two representative simulation periods for the numerical experiments: one typical winter period including a precipitation event (10-20 February 2014) and one monsoon period (18-28 July 2014). These periods are selected by checking the available observations of precipitation and are found to be representative of the winter and summer respectively (i.e., no extreme events when looking at adjacent years). For the winter period we selected the period such that a typical winter precipitation event is included, and for the summer period we selected a period with a typical monsoon daily rainfall regime. The observation stations used for validation of WRF for both the winter and summer period are listed in Table 3.1. We note that the number of stations is different for the observations of precipitation, temperature and wind speed. See for details and quality checks of the sensors (Immerzeel et al., 2014). Comparison between the measurements and the simulation is based on the closest grid point to the coordinates of the measurement station, without correcting for differences between the real and modelled elevation. 

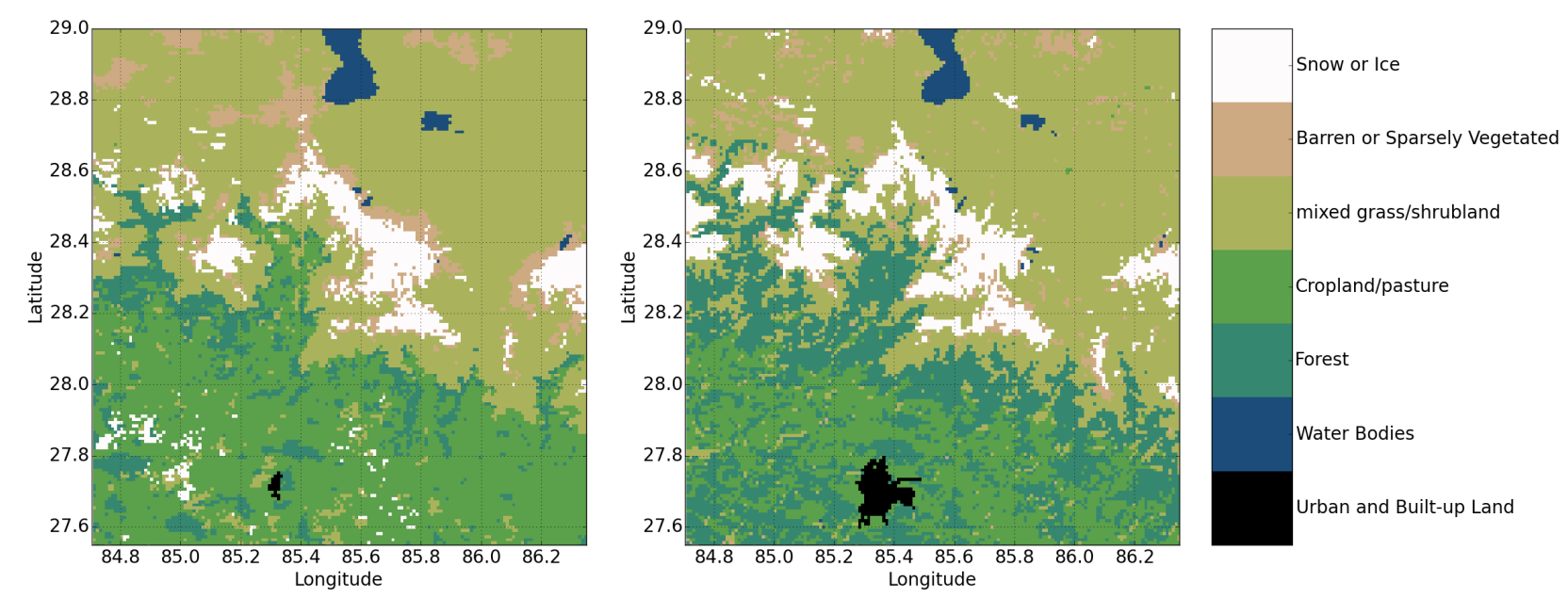

Figure 3.2: The default (left panel) and FAO (right panel) defined landuse in WRF.

\subsubsection{Model}

The advanced research WRF model V3.8.1 is used for the numerical experiments described in the following section. This model is a mesocale non-hydrostatic numerical weather prediction model and can be used for both operational weather forecasting applications as well for atmospheric research. In this research we use the configuration of (Collier and Immerzeel, 2015) and the model settings are listed in Table 3.3. Four nested domains are used in each numerical experiment, configured with horizontal grid spacings of 25, 5, 1 and 0.5 kilometer, which we refer to as D1, D2, D3 and D4, respectively (Figure 3.1). For D1 and D2, 2 arcminute $~ 3700 \mathrm{~m}$ at the equator) input topography is used, while in D3 and D4 3 arcsecond ( $90 \mathrm{~m}$ at the equator) data are used, which are resampled to the respective domain resolutions during the pre-processing. The model results were reproducible with a higher number of vertical levels (65 layers) and indicate 50 vertical layers are sufficient in the experiments. The model configuration is the same for both the winter and the summer periods, such that in future studies multi-annual model runs can be performed with a single configuration. The model settings for these domains are listed in Table 3.3 and are based on the study of (Collier and Immerzeel, 2015) and several additional tests. Differences from the configuration used in the previous study include the planetary boundary layer (PBL) scheme and the radiation scheme. The YSU (Yonsei University) PBL scheme was used in all four domains, since it includes an option to correct the high wind speed bias in WRF. PBL parameterisations can be used when the scale of large turbulent eddies is much smaller than the scale of the spatial grid. Between the PBL and Large Eddy Simulation (LES) range the 'terra incognita' (Wyngaard, 2004) is located, in which the dominant length scale of the flow is comparable to the grid spacing (roughly between $1 \mathrm{~km}$ and $100 \mathrm{~m}$ ). (Hong and Dudhia, 2012) show that PBL schemes may work down to 500 meter grid spacing. In addition, LES requires a grid spacing smaller than 100 meters to resolve convective boundary layer eddies (Arnold et al., 
2012). Therefore, we chose to include a PBL parameterization in D4. As forcing for the lateral boundaries, 6-hourly ERA-INTERIM data $\left(0.75^{\circ} \times 0.75^{\circ}\right)$ are used (Dee et al., 2011)and we employ one-way nesting.

Table 3.2: Overview of WRF configuration.

\begin{tabular}{|c|c|c|}
\hline \multicolumn{3}{|l|}{ Domain configuration } \\
\hline Horizontal grid spacing & $25,5,1,0.5 \mathrm{~km}$ & \\
\hline \multirow[t]{2}{*}{ Grid dimensions } & $125 \times 105,111 \times 111$ & \\
\hline & $171 \times 171,121 \times 121$ & \\
\hline Vertical levels & 50 & \\
\hline Time step & $50,10,1,0.2$ seconds & \\
\hline Model top pressure & $50 \mathrm{hPa}$ & \\
\hline Nesting approach & One way & \\
\hline \multicolumn{3}{|l|}{ Model physics } \\
\hline Microphysics & Morrison & (Morrison et al., 2009) \\
\hline Planetary boundary layer & YSU (topo wind=1) & (Hong and Dudhia, 2012) \\
\hline Land surface & NoahMP & (Niu et al., 2011) \\
\hline Cumulus & Kain Fritsch Scheme (Only in D1) & (Kain, 2004) \\
\hline Radiation & RRTMG & (lacono et al., 2008) \\
\hline Surface layer & MM5 Similarity Scheme & (Paulson, 1970) \\
\hline Slope/shadowing effects & Zängl & (Zängl, 2002) \\
\hline \multicolumn{3}{|l|}{ Dynamics } \\
\hline Top boundary condition & Rayleigh damping & \\
\hline Diffusion & Calculated in physical space & \\
\hline Lateral boundary forcing & 6-h ERA-INTERIM data $\left(0.75^{\circ} \times 0.75^{\circ}\right)$ & (Dee et al., 2011) \\
\hline
\end{tabular}

\subsubsection{Numerical experiments}

The landuse controls the latent heat flux and therefore the moisture content in the air and local precipitation as a consequence. The default landuse data set in WRF is not representative for the Langtang region, since the amount of forest area is underestimated and the glacier outlines are not correct (Collier and Immerzeel, 2015). Therefore, the landuse map of the Food and Agriculture Organisation of the United Nations (FAO, 2017) is used in this research. Important differences between the default and new landuse include the increase in forest (16\%) and glacierized area (2\%). The default and FAO landuse data sets used for D3 and D4 are shown in Figure 3.2. In our simulations we investigate the influence of spin-up times ranging from 12 hours 
to 5 days in length on the 2-meter air temperature, 10-meter wind speed and amount of precipitation in D3.

Table 3.3: Overview of performed numerical experiments. All experiments include D1, D2, D3 and D4 and are run for both the summer and winter period.

\begin{tabular}{llll}
\hline \hline Name & Landuse & Spin-up & time \\
\hline DEF & Default & 1 & day \\
EXP1 & FAO & 12 & hours \\
EXP2 & FAO & 1 & day \\
EXP3 & FAO & 3 & days \\
EXP4 & FAO & 5 & days \\
\hline \hline
\end{tabular}

An overview of the numerical experiments performed in this paper is given in Table 3.4. These experiments are performed for both the winter and summer period on the Dutch supercomputer Cartesius. Simulating a 10-day period typically takes 2 days to complete while running on 192 processors.

\subsubsection{Statistical evaluation}

To evaluate the simulated 2-meter air temperature, 10-meter wind speed and amount of precipitation with the observations, several statistical techniques are used: the Pearson correlation coefficient, mean, bias and root mean squared error (RMSE). We compute these quantities at each station and report the average value over all stations for model evaluation. To assess the correctness of the timing of the simulated events we make use of the Rousseau index (RI, Rousseau (1980)), which is expressed as:

$$
\frac{S O \cdot N S N O-\left(\frac{N S O+S N O}{2}\right)^{2}}{\left(S O+\frac{N S O+S N O}{2}\right) \cdot\left(N S N O+\frac{N S O+S N O}{2}\right)}
$$

Each precipitation event for each time step is categorized into one of the 4 categories: SO, NSO, SNO and NSNO, where SO is the amount of events when precipitation is simulated and also observed; NSO when the event is not simulated but observed; SNO when the event is simulated but not observed and NSNO when no precipitation is simulated and also not observed. In case of SO and NSNO the simulation is consistent with the observation and when NSO or SNO occurs there is a mismatch between the model and the observations. RI has a value between -1 and 1 where the model fully agrees with the measurements if $\mathrm{Rl}=1$. 


\subsubsection{Snow correction factor}

Solid precipitation is hard to monitor since the gauge geometry can induce systematic errors due to wind flow. The airflow around a gauge is disturbed, whereby under-catch of snow increases with increasing wind speed. Several studies try to quantify the amount of under-catch of snow (e.g. Goodison et al., 1998; Thériault et al., 2011). In this study, we use the dry and mean theoretical relationship derived from (Thériault et al., 2012) to show the effect and range of the amount of under-catch, which is highly dependent on the snow type. We assume the precipitation type is snow if $\mathrm{T}_{\text {air }}<0{ }^{\circ} \mathrm{C}$ (Liu and Chen, 2016) and test two different assumptions about the liquid water content of snow to see the effect on the under-catch of snow. The relationships (Thériault et al., 2012) between the collection efficiency (C) and wind speed (U) for a mixture of wet and dry snow and dry snow are:

Mixture :
$\mathrm{U}<2.0 \mathrm{~ms}^{-1}$
$\mathrm{C}=1.0-0.01 \mathrm{U}$
$2.0 \leq \mathrm{U}<7.0 \mathrm{~ms}^{-1}$
$C=1.3-0.16 \mathrm{U}$
$\mathrm{U} \geq 7.0 \mathrm{~ms}^{-1}$
$\mathrm{C}=0.18$

Dry:
$\mathrm{U}<2.0 \mathrm{~ms}^{-1}$
$C=1.0-0.01 \mathrm{U}$
$2.0 \leq \mathrm{U}<5.0 \mathrm{~ms}^{-1}$
$\mathrm{C}=1.6-0.32 \mathrm{U}$
$\mathrm{U} \geq 5.0 \mathrm{~ms}^{-1}$
$\mathrm{C}=0.18$

\subsection{Results and discussion}

\subsubsection{Landuse}

In Figure 3.3 the effect of the new landuse on the total and solid precipitation is shown for both the winter and summer period. Landuse influences the total accumulated precipitation by describing the surface characteristics that affect the surface energy balance and the moisture budget. The amount of vegetation affects the latent heat flux and therefore clouds and precipitation, and also the surface temperature and therefore sensible heat flux, lower atmopsheric stability and turbulence. For example, the effect of the FAO landuse is stronger in summer than in winter, since there is a more humid environment (monsoon) compared to the winter period. The latent heat flux in summer is 4.5 times larger than in winter averaged over D3. Secondly, important weather processes are valley-scale driven in summer while in winter they are acting on the synoptic-scale. 
In summer the surface moisture flux and precipitation averaged over the whole domain (catchment) are $2 \%(6 \%)$ and $10 \%(16.9 \%)$ lower with the FAO landuse compared to the default landuse data set in WRF. The reductions in the moisture flux and precipitation are comparable in value, which indicates they are highly related. In summer the dominant precipitation type is rain but at higher altitudes snow is also present. The decreased snowfall in summer is clearly visible above the glacierized areas and is caused by the general drying trend by the FAO landuse, which affect both the solid and liquid precipitation. The surface moisture flux is less pronounced south of the catchment with the FAO landuse and contributes to the decrease in precipitation in that region. The decrease in precipitation north of the catchment is consistent with lower wind speeds in the surrounding high elevation regions. As a result, less moisture is advected into this region and therefore less moisture is available (see Figure B1). In winter almost all precipitation falls as snow and is not as clearly distributed as in the summer period. Winter precipitation patterns are comparable when using the FAO landuse data set and the total amount of precipitation stayed the same in the domain (both $4.9 \mathrm{~mm} \mathrm{day}^{-1}$ ), which indicates that the latent heat flux is the main driver of the change in locally driven precipitation in summer. The temperature differences are negligible $\left(<0.05{ }^{\circ} \mathrm{C}\right.$ averaged over D3) in both seasons which means that the drying effect of the FAO landuse does not result in higher temperatures. However locally temperature differences range from $-4.2{ }^{\circ} \mathrm{C}$ to $2.7^{\circ} \mathrm{C}$.

In Table 3.5 an overview of statistics for the default (DEF) and FAO (EXP2) landuse is given. All values in that table are an average for the observation stations mentioned in Table 3.1 and all statistics are calculated compared to the observations. Indeed, the largest differences can be found in the statistics of summer precipitation, and the total accumulated precipitation is reduced to $135 \mathrm{~mm}$ (165 $\mathrm{mm}$ by the default landuse), whereby it is in closer agreement with the observations $(133 \mathrm{~mm})$. In winter the differences in statistics for precipitation, temperature and wind speed between the two landuses are small, and is likely due to the low moisture flux, as discussed above. The FAO landuse represents the total accumulated summer precipitation better than the default landuse data set and will be used in upcoming experiments.

\subsubsection{Spin-up time}

The temporal evolution of the precipitation averaged over the catchment for the spin-up experiments is shown in Figure 3.4. During the winter period the precipitation amount and timing do not differ significantly between the different spin-up times, unlike in summer. During the monsoon precipitation is driven locally, hence the correct representation of e.g. soil moisture and therefore spin-up time is important. In winter synoptic disturbances drive precipitation, therefore 

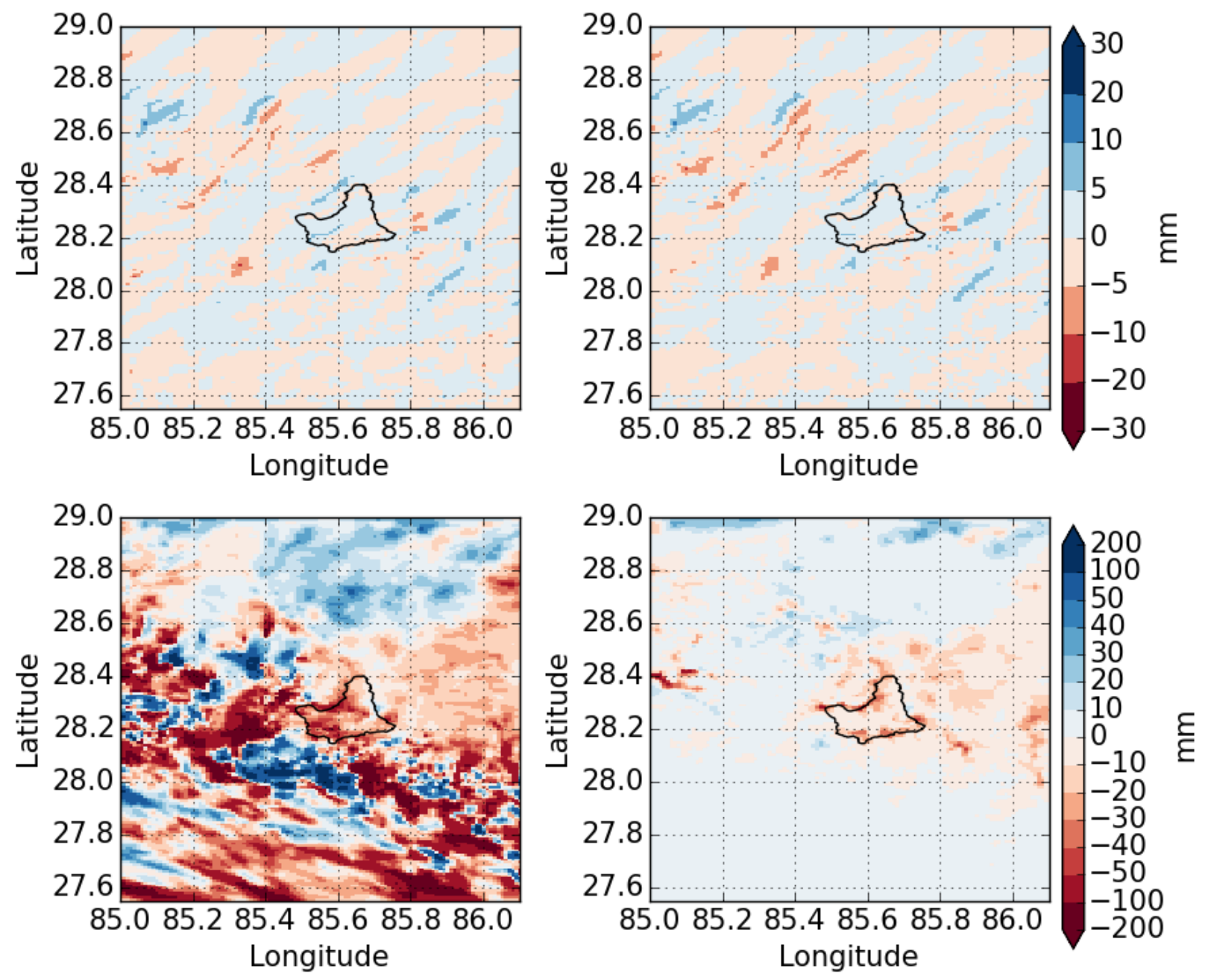

Figure 3.3: Effect of the FAO landuse (the difference between the model, results using FAO and default landuse) on the amount of total (left panels) and solid (right panels) accumulated precipitation over 10 days for both the winter (upper panels) and summer (lower panels) for D3. The black contour indicates the catchment outline, and the grey lines indicate the glacier outlines. The glacierized areas are visible in Figure 3.2 and the topography of the domain in Figure 3.1. 

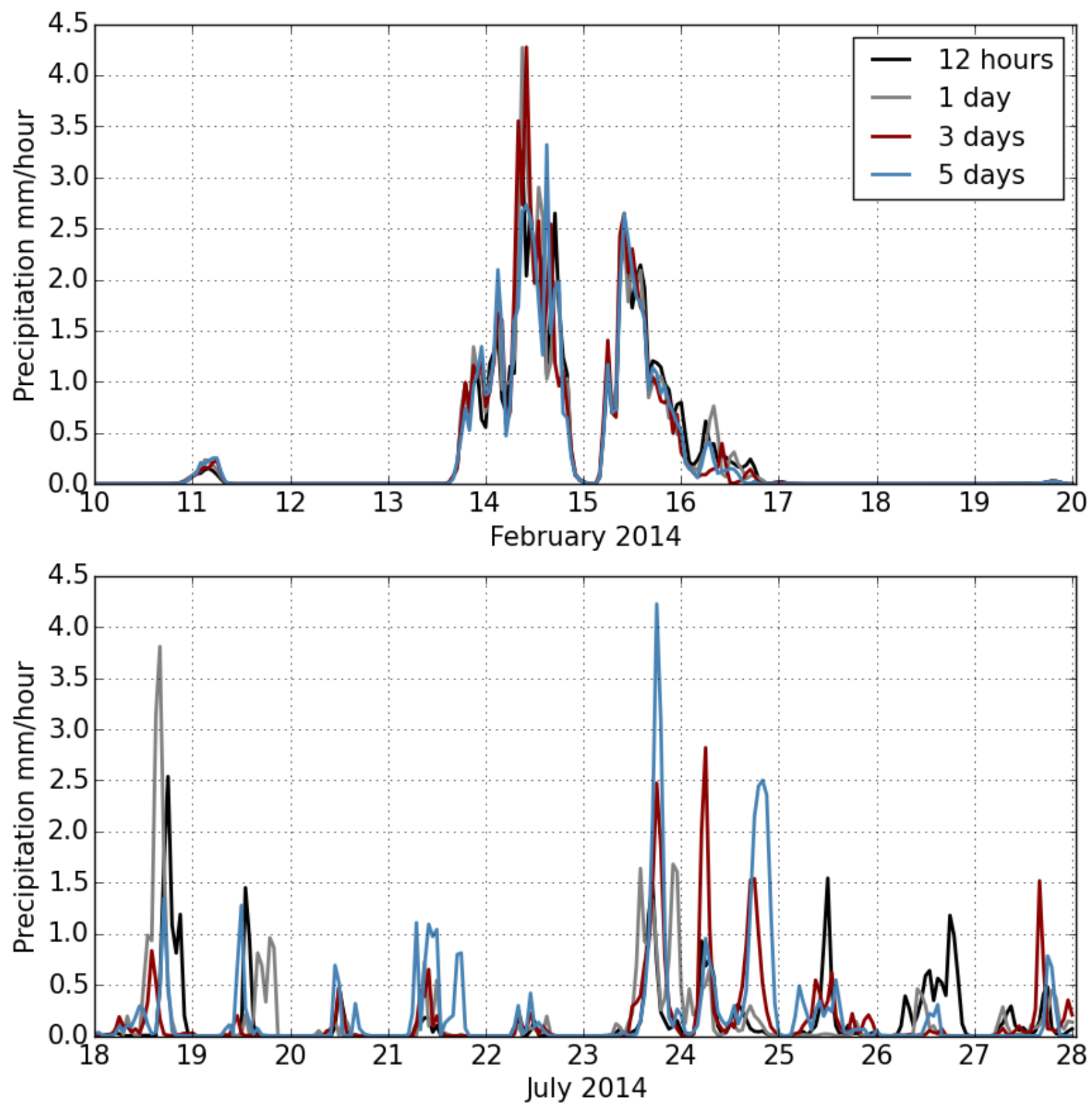

Figure 3.4: The hourly precipitation averaged over all grid cells in the catchment for the different spin-up times (12 hour, 1, 3 and 5 days) for the winter (upper panel) and summer (lower panel) respectively. 
the winter is less sensitive to the spin-up time. In Table 3.5 an overview of statistics for the spinup time experiments is given. Small differences can be found between the different spin-up times in winter for the accumulated precipitation (between 70 and $76 \mathrm{~mm}$ ), averaged temperature (between -15.2 and $-14.8^{\circ} \mathrm{C}$ ) and averaged wind speed (between 5.9 and $6.2 \mathrm{~ms}^{-1}$ ).

In the summer period the average temperature and wind speed are also comparable between the experiments: between 3.5 and $3.6^{\circ} \mathrm{C}$ and 2.7 and $3.0 \mathrm{~ms}^{-1}$ respectively. (Kleczek et al., 2014) found that above flat terrain a spin-up time longer than 24 hours decreases the wind speed bias but increases the negative temperature bias, but our results do not confirm this trend. The amount of precipitation is extremely sensitive to the spin-up time in summer and does not show a clear trend with increasing spin-up time. Correlations with observations based on 3-hourly data vary between 0.1 and 0.3 , while accumulated precipitation varied from 118 and $146 \mathrm{~mm}$. The spin-up time influences the timing and amount of precipitation and in lesser amount the temperature and wind speed (Table 3.5). An increase in the quality of the statistics can be seen when increasing the spin-up time from 12 to 24 hours, especially in the amount of accumulated precipitation in summer, but not for longer spin-up times (Table 3.5). Therefore a spin-up time of 24 hours is chosen for subsequent simulations.

\subsubsection{Spatial resolution}

Increasing the spatial resolution has a positive effect on the model results. Figure 3.4 shows the accumulated precipitation over the winter (upper) and summer period (lower) for the four domains. Statistics of the accumulated precipitation, 2-meter air temperature and wind speed at the measurement stations (Table 3.6) show improvement when increasing the spatial resolution. For the temperature and wind speed the RMSE, bias and mean are improved, and the correlation coefficient improved or stayed the same as in D3. For precipitation, correlations stayed the same, and the RMSE, bias and total precipitation did not show a clear improvement (only RMSE and bias increased for the summer period). Precipitation however is more spatially variable than wind speed and temperature. The spatial differences in accumulated precipitation between D3 and D4 for the summer and winter period are shown in Figure 3.10. In winter the locations with the precipitation maxima in D3 are intensified in D4. In D4 more precipitation is present along steep slopes, since precipitation is orographically forced and the topography is better resolved in this domain. The higher resolution leads to stronger simulated updrafts and accounts for more precipitation at higher elevation. When katabatic winds and valley winds collide, they can lead to strong mixing and therefore to short-lived and intense sporadically turbulent events (Dimitrova et al., 2016). The $95^{\text {th }}$ percentile of the vertically averaged vertical velocity increases by $15 \%$ in D4 
Table 3.4: Statistics of different spin-up times for the 10-meter wind speed (U), 2-meter air temperature $(T)$ and precipitation $(P)$ in $D 3$ and are based on three-hourly averaged data (WRF output was available for every hour). All values compare the simulation to the measurements. The accumulated precipitation, mean temperature and mean wind speed were 14 (133) $\mathrm{mm}-7.1$ (6.0) ${ }^{\circ} \mathrm{C}$ and 3.8 (2.1) $\mathrm{ms}^{-1}$ respectively for winter (summer) period. $A^{*}$ indicates $p<0.01$ and ${ }^{* *} p<0.05$.

\begin{tabular}{|c|c|c|c|c|c|c|c|c|c|c|c|}
\hline & & \multicolumn{5}{|c|}{ Winter } & \multicolumn{5}{|c|}{ Summer } \\
\hline & & DEF & EXP1 & EXP2 & EXP3 & EXP4 & DEF & EXP1 & EXP2 & EXP3 & EXP4 \\
\hline \multirow[t]{4}{*}{$P$} & $r$ & $0.37^{*}$ & $0.35^{*}$ & $0.38^{*}$ & $0.33^{*}$ & $0.33^{*}$ & 0.21 & $0.23 * *$ & $0.30 *$ & 0.09 & 0.20 \\
\hline & RMSE $[\mathrm{mm}]$ & 2.0 & 2.0 & 2.1 & 2.0 & 2.1 & 3.5 & 3.3 & 2.9 & 2.8 & 2.7 \\
\hline & Bias [\%] & 281 & 297 & 287 & 284 & 290 & 456 & 333 & 339 & 358 & 350 \\
\hline & Total [mm] & 74 & 74 & 76 & 70 & 72 & 165 & 119 & 135 & 118 & 146 \\
\hline \multirow[t]{4}{*}{$\mathrm{T}$} & $r$ & $0.82^{*}$ & $0.81 *$ & $0.81^{*}$ & $0.81 *$ & $0.81^{*}$ & 0.85 & $0.85 * *$ & $0.85^{*}$ & 0.87 & 0.85 \\
\hline & $\operatorname{RMSE}\left[{ }^{\circ} \mathrm{C}\right]$ & 8.0 & 8.0 & 8.2 & 8.3 & 8.5 & 2.5 & 2.6 & 2.6 & 2.6 & 2.6 \\
\hline & $\operatorname{Bias}\left[{ }^{\circ} \mathrm{C}\right]$ & 7.6 & 7.7 & 7.9 & 8.0 & 8.2 & 2.4 & 2.5 & 2.5 & 2.3 & 2.5 \\
\hline & Mean $\left[{ }^{\circ} \mathrm{C}\right]$ & -14.7 & -14.8 & -15.0 & -15.1 & -15.2 & 3.6 & 3.5 & 3.6 & 3.5 & 3.6 \\
\hline \multirow[t]{4}{*}{ U } & $r$ & $0.47^{*}$ & $0.43^{*}$ & $0.46^{*}$ & $0.45^{*}$ & $0.43^{*}$ & 0.56 & $0.41^{* *}$ & $0.51^{*}$ & 0.46 & 0.40 \\
\hline & $\mathrm{RMSE}\left[\mathrm{ms}^{-1}\right]$ & 3.5 & 3.5 & 3.3 & 3.3 & 3.4 & 1.3 & 1.3 & 1.2 & 1.4 & 1.5 \\
\hline & Bias [ms-1] & 2.9 & 2.7 & 2.6 & 2.6 & 2.6 & 1.0 & 1.0 & 0.9 & 1.03 & 1.2 \\
\hline & Mean [ms-1] & 6.4 & 6.2 & 6.1 & 5.9 & 6.0 & 3.0 & 2.8 & 2.7 & 2.9 & 3.0 \\
\hline
\end{tabular}


compared to D3 and could be due to a better representation of the topography but could also be an artifact of instabilities in WRF. On average the vertical velocities are in agreement with other studies (e.g. Giovannini et al., 2014; Reinert and Wirth, 2009). The orographic influence on the temperature and wind speed patterns becomes more apparent and glaciers and mountain ridges are better resolved with increasing grid size (see Figure 3.5 and 3.11).

We hypothesize that the improved total accumulated precipitation at higher elevations is caused by these better resolved vertical winds, and agrees with (Rasmussen et al., 2011), which found that increasing the spatial resolution results in more snowfall at mountain peaks instead of evenly distributed patterns due to better and narrower simulated updrafts in WRF. Another significant improvement is the strong reduction in temperature bias by $3.0^{\circ} \mathrm{C}$ with increasing resolution from D3 to D4 during the winter period (Table 3.6), likely caused by the better resolved topography and corresponding wind fields. The mean wind velocity at the stations in winter decreases from $6.1 \mathrm{~ms}^{-1}$ in D3 to $3.5 \mathrm{~ms}^{-1}$ in D4 and leads to less cooling of the air. In the summer period increasing the grid spacing from 1 kilometer to 500 meters leads to higher correlations between observed and simulated precipitation, while in winter the improvement is not observed and is likely caused by the uneven distribution of the observations by elevation.

Correlations between the simulations and the observations of precipitation are relatively low, which is common for WRF simulations in the Himalayas (e.g. Ochoa et al., 2014 and Norris et al., 2017). Ochoa et al. (2014) found, for example, a Pearson correlation coefficient between 0.2-0.6 for daily precipitation at a resolution of 30 kilometer in the Pacific-Andean region. Norris et al. (2017) looked in detail at precipitation patterns with WRF (grid spacing of $6.67 \mathrm{~km}$ ) in the Himalayas. They found WRF is accurate in the timing of winter storms on the windward slopes of the Himalaya, but that the more complex flow patterns forming further into the mountains are not represented correctly by the model. In accordance, the correlations of the time series of daily precipitation through winter vary between 0.13 and 0.82 , and the difference between low (below $3 \mathrm{~km}$, correlation of 0.78 ) and high elevation (correlation of 0.41 ) stations is large. In this research 3-hourly averaged data is used rather than commonly used daily-averaged (e.g Ochoa et al., 2014 and Norris et al., 2017). However, since our simulation period is relatively short the averagingwindow can not be increased.

The stations used for the statistics are concentrated in the lower parts of the valley, therefore any improvement in the higher elevated parts $(>5500 \mathrm{~m})$ can not be evaluated. Especially in the winter period, the 500 meter grid spacing reveals more detailed precipitation patterns at higher 
Table 3.5: Statistics of different spatial resolutions for the 10-meter wind speed (U), 2-meter air temperature $(T)$ and precipitation $(P)$ in $D 3$. All values compare the simulation to the measurements and are three-hourly averaged. The accumulated precipitation, mean temperature and mean wind speed were 14 (133) $\mathrm{mm}-7.1(6.0)^{\circ} \mathrm{C}$ and $3.8(2.1) \mathrm{ms}^{-1}$ respectively for winter (summer) period. The mean observed station height is $4200 \mathrm{~m}$, while the mean modeled station height is 4893, 5049, 4883, 4739 meter for D1-4 respectively. $A *$ indicates $p<0.01$ and ${ }^{* *} p<0.05$.

\begin{tabular}{|c|c|c|c|c|c|c|c|c|c|}
\hline & & \multicolumn{4}{|c|}{ Winter } & \multicolumn{4}{|c|}{ Summer } \\
\hline & & D1 & D2 & D3 & D4 & D1 & D2 & D3 & D4 \\
\hline \multirow[t]{4}{*}{$P$} & $r$ & 0.21 & $0.36^{*}$ & $0.38^{*}$ & $0.38 *$ & -0.06 & 0.19 & $0.30 *$ & $0.34^{*}$ \\
\hline & RMSE [mm] & 0.3 & 2.0 & 2.1 & 2.20 & 2.9 & 4.2 & 2.9 & 2.7 \\
\hline & Bias [\%] & 36 & 279 & 287 & 295 & 416 & 547 & 339 & 290 \\
\hline & Total [mm] & 2 & 73 & 76 & 79 & 76 & 192 & 135 & 120 \\
\hline \multirow[t]{4}{*}{$T$} & $r$ & 0.6 & $0.79 *$ & $0.81^{*}$ & $0.84^{*}$ & 0.78 & 0.83 & $0.85^{*}$ & $0.86^{*}$ \\
\hline & RMSE $\left[{ }^{\circ} \mathrm{C}\right]$ & 9.7 & 9.4 & 8.2 & 5.3 & 2.2 & 3.5 & 2.6 & 1.6 \\
\hline & $\operatorname{Bias}\left[{ }^{\circ} \mathrm{C}\right]$ & 7.9 & 8.9 & 7.9 & 4.8 & 1.9 & 3.3 & 2.5 & 1.5 \\
\hline & Mean $\left[{ }^{\circ} \mathrm{C}\right]$ & -14.9 & -16.0 & -15.0 & -12.0 & 6.4 & 2.7 & 3.6 & 4.6 \\
\hline \multirow[t]{4}{*}{$U$} & $r$ & 0.44 & $0.19 *$ & $0.46^{*}$ & 0.49* & 0.64 & 0.26 & $0.51^{*}$ & $0.72^{*}$ \\
\hline & $\mathrm{RMSE}\left[\mathrm{ms}^{-1}\right]$ & 1.6 & 6.2 & 3.3 & 1.5 & 1.0 & 1.3 & 1.2 & 0.8 \\
\hline & Bias [ms-1] & 1.3 & 5.2 & 2.6 & 1.1 & 0.8 & 1.0 & 0.9 & 0.6 \\
\hline & Mean [ms-1] & 3.3 & 8.9 & 6.1 & 3.5 & 1.4 & 2.5 & 2.7 & 1.7 \\
\hline
\end{tabular}



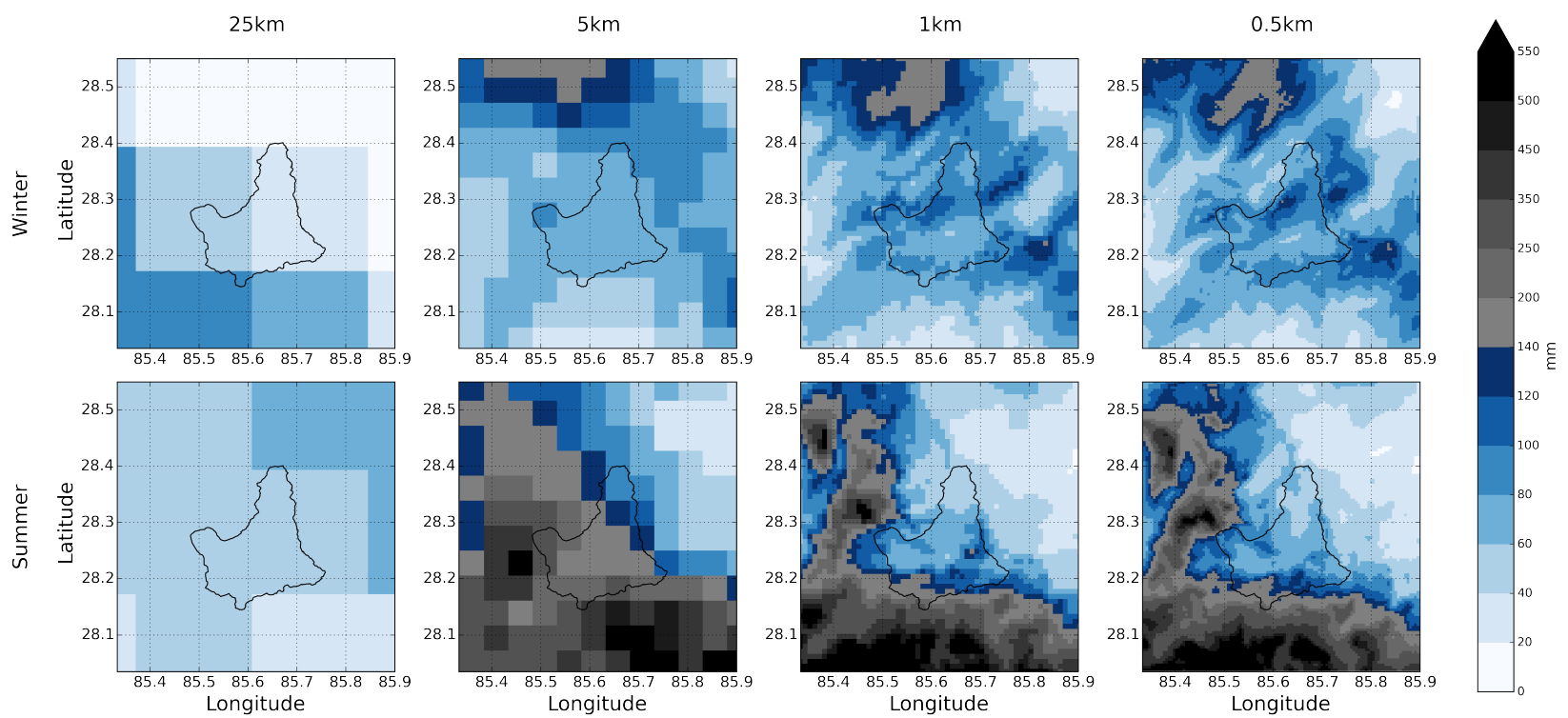

Figure 3.5: The difference in total accumulated precipitation over 10 days between D3 and D4 for the winter (left) and summer period (right). The 500 meter grid spacing cells were resampled into a $1 \mathrm{~km}$ grid to compare the diferent grid spacings. The black contour indicates the catchment outline. The topography of the domain is visible in Figure 3.1.
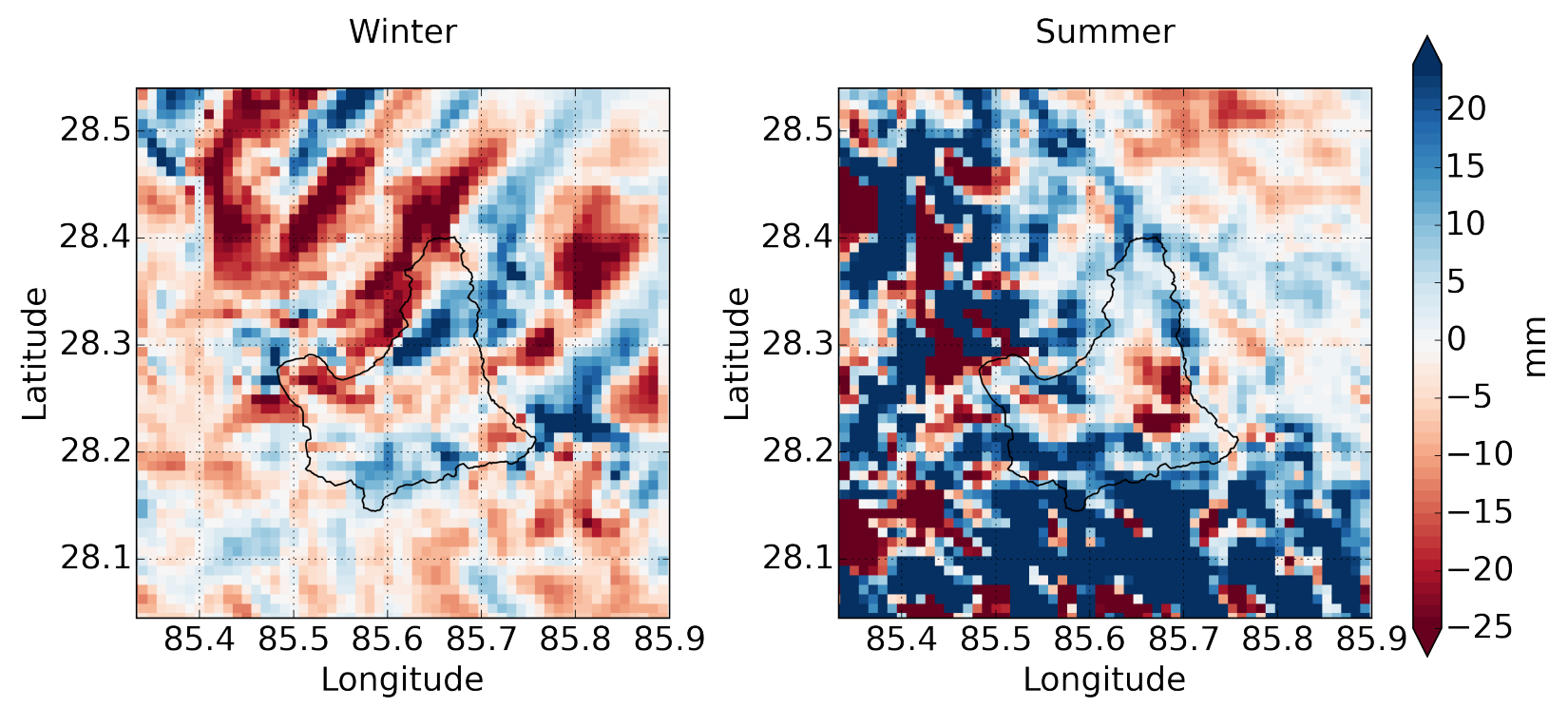

Figure 3.6: Accumulated precipitation for $D 1 * D 2 * D 3^{*}$ and $D 4$ (from left to right). These results are from EXP2 for the winter (upper panels) and summer (lower panels) period. Note the precipitation band in D1 is outside the showed area. The black contour indicates the catchment outline. *Cut to extent of D4. The topography of the domain is visible in Figure 3.1. 
altitudes and shows that the precipitation distribution in winter is driven by the interaction with topography. The statistics in Table 3.6 are performed with uncorrected observations, however during winter the under-catch of snow plays a major role and complicates model evaluation. The role of under-catch of snow will be discussed in Section 3.5.

\subsubsection{Optimal model configuration}

The 500-meter grid spacing in combination with the FAO landuse data set and a spin-up time of one day had the closest agreement with observations (EXP2, D4). The statistics of these experiments are shown in Table 3.6 and discussed in the previous section. In Figure 3.7 and 3.8, the temporal evolution of the 2-meter air temperature and precipitation (Panel A), 10-meter wind speed (Panel B), the total accumulated precipitation compared to observations (Panel C) and the temporal evolution of the snow depth (Panel D) are given for respectively the winter and summer period averaged over all available stations. In the supplementary material also a comparison between the simulations and measurements is shown for three individual station for precipitation, temperature and wind speed. The general behaviour of the temperature evolution is captured by WRF, however an average cold temperature bias during winter and summer of 4.8 ${ }^{\circ} \mathrm{C}$ and $1.5{ }^{\circ} \mathrm{C}$ respectively is present at the station locations in D4. Increasing the spatial resolution from $1 \mathrm{~km}$ to 500 meters does decrease the cold bias by 3 and $1{ }^{\circ} \mathrm{C}$ for the winter and summer period respectively. The cold bias could be exacerbated by a similar bias in the ERAINTERIM boundary conditions (Dee et al., 2011), inaccuracies in the modelled terrain height or the radiation scheme. The radiation scheme is tuned for lower elevations, since there are generally more stations at lower altitudes available for verification (Liu et al., 2008). A cold bias is a common issue in WRF (García-Díez et al., 2013; Hu et al., 2010; Kleczek et al., 2014; Steeneveld et al., 2008). (Kleczek et al., 2014) tested the performance of seven PBL schemes for flat terrain in the Netherlands and found WRF underestimates the 2-meter air temperature by $2{ }^{\circ} \mathrm{C}$ during daytime and $4{ }^{\circ} \mathrm{C}$ during nighttime. Since errors differ seasonally and increase with complex terrain, errors in our simulations are expected to be larger than in simulations over flat terrain (Liu et al., 2008). The 2-meter air temperature is also sensitive to the selected land-surface scheme (Jin et al., 2010).

The timing of the precipitation events is captured better during winter ( $R I=0.46)$ than in summer $(\mathrm{RI}=0.09)$. In winter, generally a stratiform type of precipitation is present, while in summer relatively short duration and high intensity monsoon showers occur, which are more difficult to reproduce. The measured precipitation signal at 17 February 2014 appears to be caused by snowmelt in the tipping buckets and is therefore not a mismatch between the model and the 

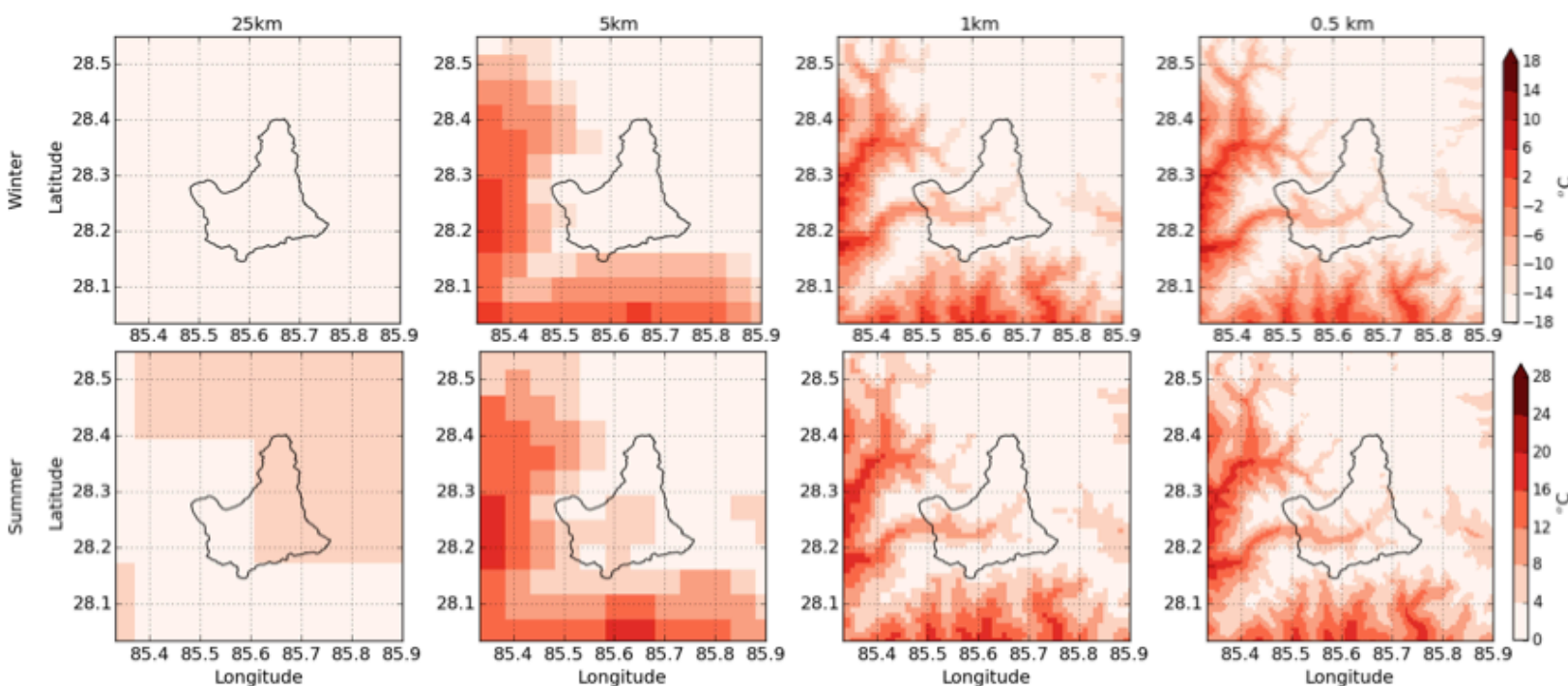

Figure 3.7: As in Figure 3.5, but now for the 2-meter air temperature.
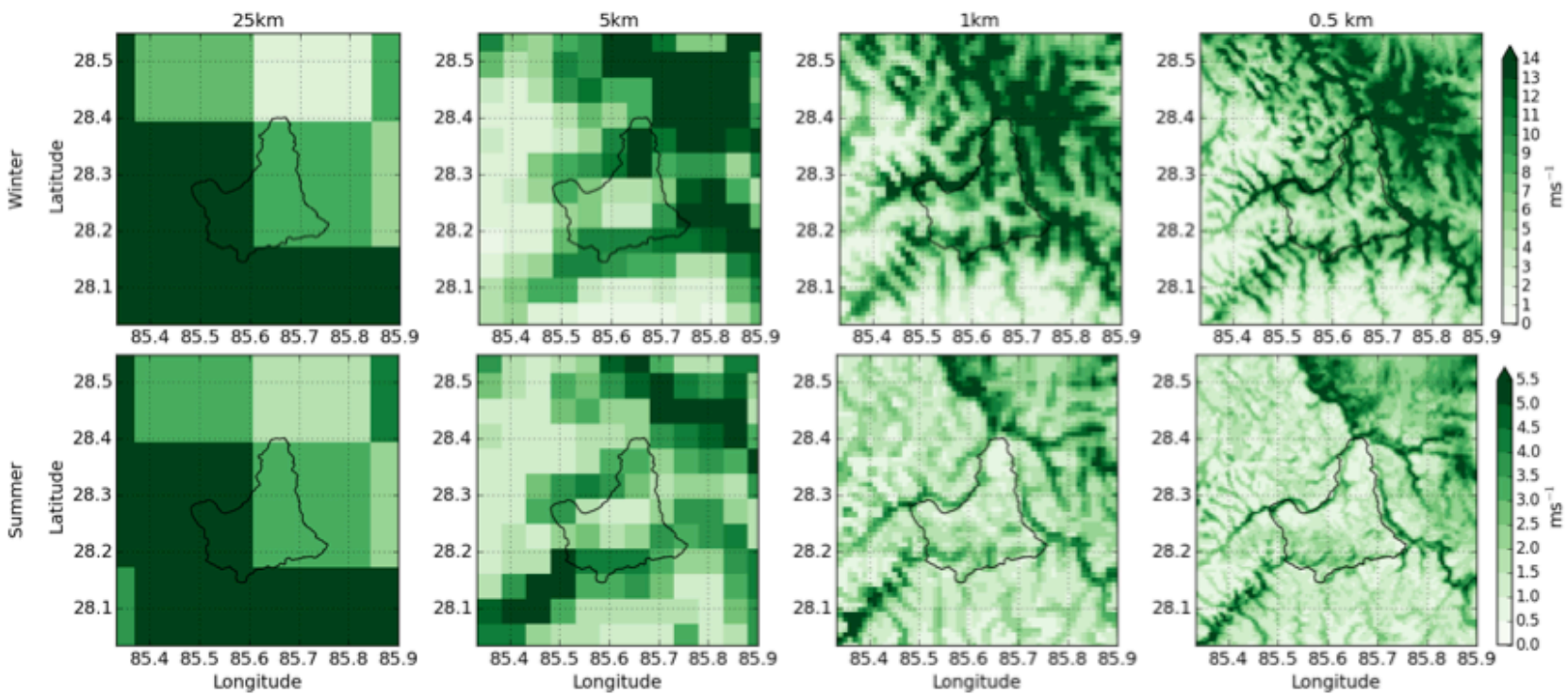

Figure 3.8: As in Figure 3.5, but now for the 10-meter wind speed. 
observations (Figure 3.7A). When excluding the period after 17 February, the RI and $r$ are higher during winter in $\mathrm{D} 4(\mathrm{Rl}=0.90$ and $\mathrm{r}=0.6)$. During the summer (winter) period the total accumulated precipitation of stations above $4600 \mathrm{~m}$ is underestimated (overestimated) by WRF by $57 \%$ (330\%) and does (not) show a height dependence as at the lower altitude stations (Figure 3.7C and 3.8C). The lower altitude stations overestimate precipitation during summer (Figure 3.8C).

WRF also shows snowfall in summer, which was not observed and could be caused by the cold bias in WRF (Figure 3.8D). During the winter simulation WRF greatly overestimates the total accumulated precipitation at all measurement stations (between 37 and $92 \mathrm{~mm}$ ), which is not height dependent as can be seen in Figure 3.7C. However, the underestimation of measured precipitation due to under-catch of snow likely plays an important role in the winter season, as will be discussed in the following section.

\subsubsection{Correction for under-catch of snow}

To estimate the amount of under-catch of snow by the measurement stations, the observed precipitation of the two pluviometers is compared to the observed snow depth measured at the same two pluviometers. A fresh snow density of $200 \mathrm{kgm}^{-3}$ to snow water equivalent (SWE) is used to convert changes in snow depth (Cuffey and Paterson, 2010). Averaged over the two available pluviometers in winter, the observed precipitation and total increase in snow depth were $1.6 \mathrm{~cm}$ and $40 \mathrm{~cm}(8 \mathrm{~cm} \mathrm{SWE})$ respectively. The discrepancy suggests that the precipitated snow measured by the pluviometers is underestimated by a factor 5 compared to the snow depth, neglecting the uncertainties in the latter field (e.g. snow density and melt, compaction, transport by wind). WRF models $7.3 \mathrm{~cm}$ of SWE averaged over the two gridpoints of the locations of the pluviometers. This value is consistent with the amount of snow derived from snow depth measurements and supports that under-catch of the pluviometer may contribute significantly to an underestimation. For a similar region in the Himalayas (Norris et al., 2017) found also an overestimation of a factor of two to five by WRF compared to observed precipitation, which is also likely caused by the under-catch of snow. Figure 3.9 shows the impact of applying the snow correction factors to the Kyanging AWS (Table 3.1) for both assuming dry snow (upper limit) and mixed snow (lower limit). As a result, the uncertainty of the corrected snow amounts due to the type of snow is delineated by the grey shaded area between the two curves. These correction factors are applied on the observed precipitation, wind and temperature from the AWS in Kyanging. The correction has a large influence on the total measured accumulated precipitation. The amount of uncorrected precipitation is $25 \mathrm{~mm}$, while the corrected values are 76 and $48 \mathrm{~mm}$ 
A.)

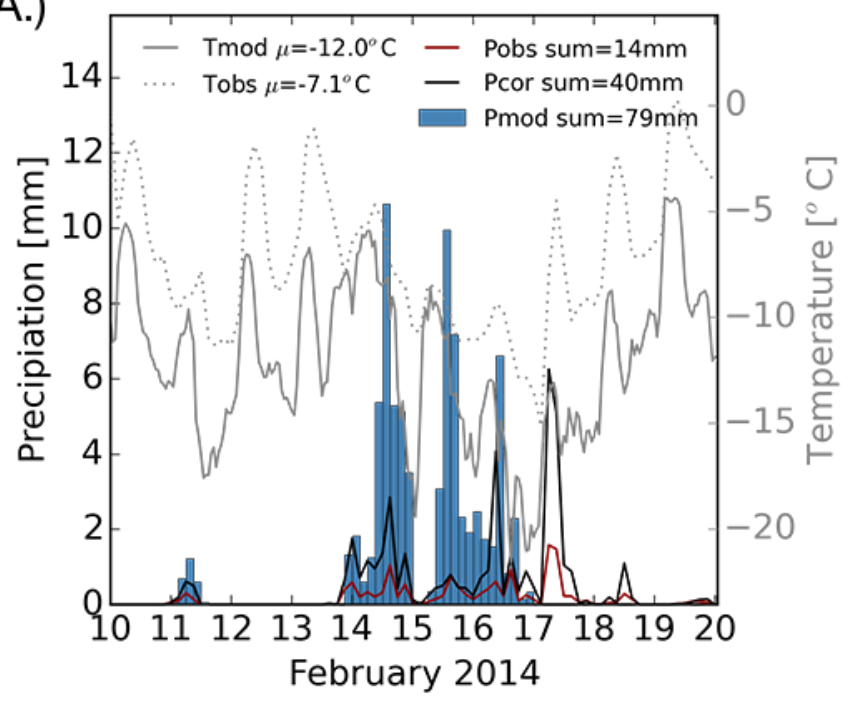

C.)

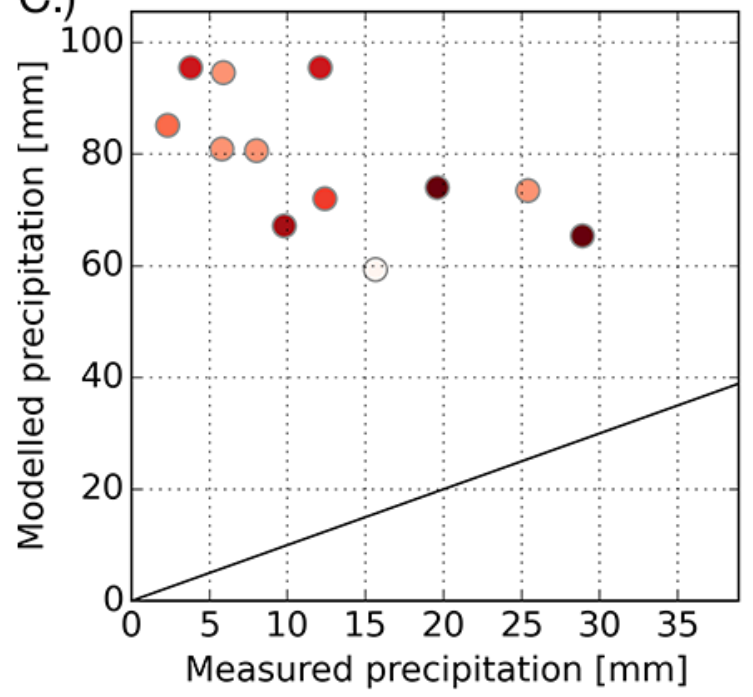

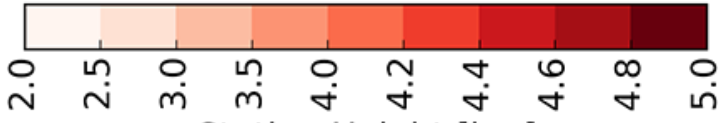

B.)

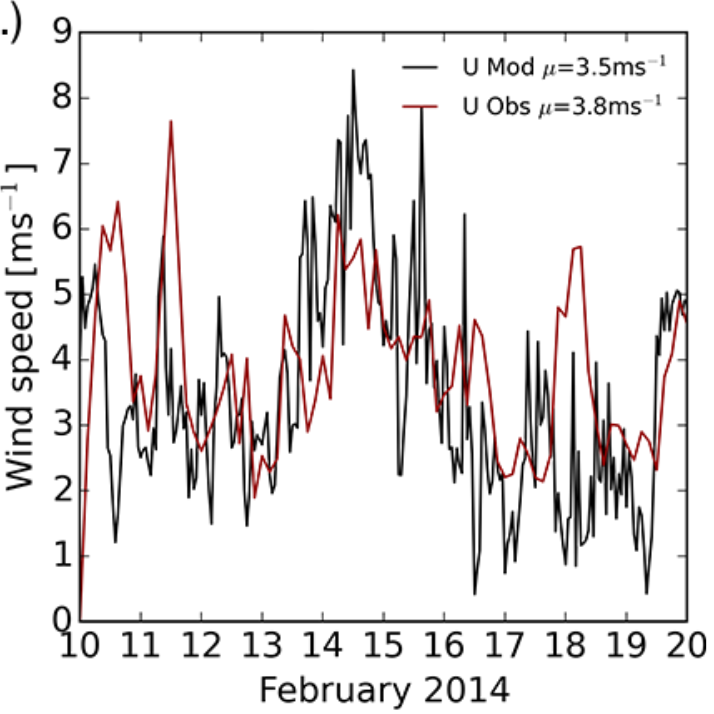

D.)

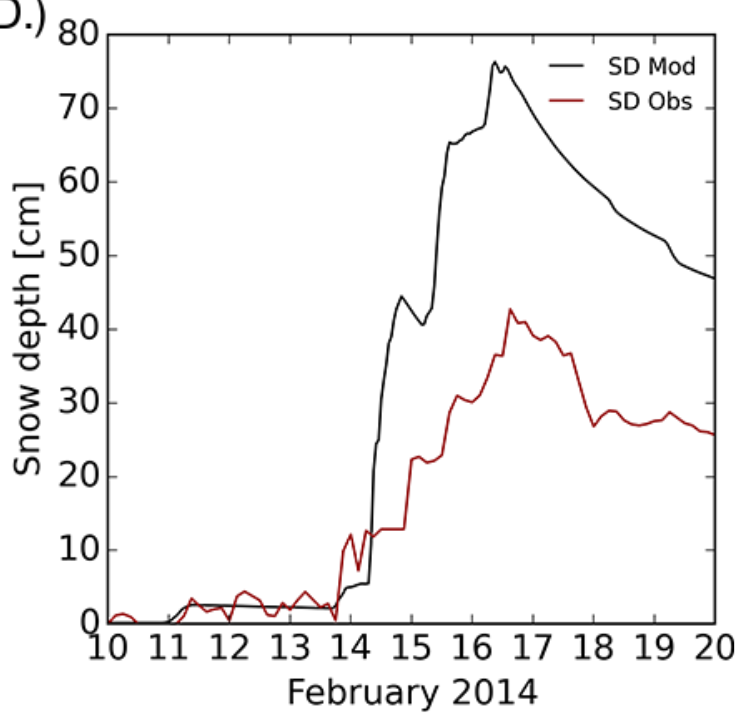

Figure 3.9: Results of EXP2 for the winter period of D4. Panel A shows modelled (solid gray line) and simulated (dashed gray line) 2-meter air temperature, modelled precipitation (blue bars), uncorrected observed precipitation (red line) and corrected observed precipitation (black line), Panel B the 10 meter observed (black line) and modeled (red line) windspeed, Panel $C$ the total accumulated precipitation colored by elevation and Panel $D$ the modelled (black line) and observed (red line) snow depth. The data in Panels A, B and D are 3-hourly averaged and is averaged over all available stations. 

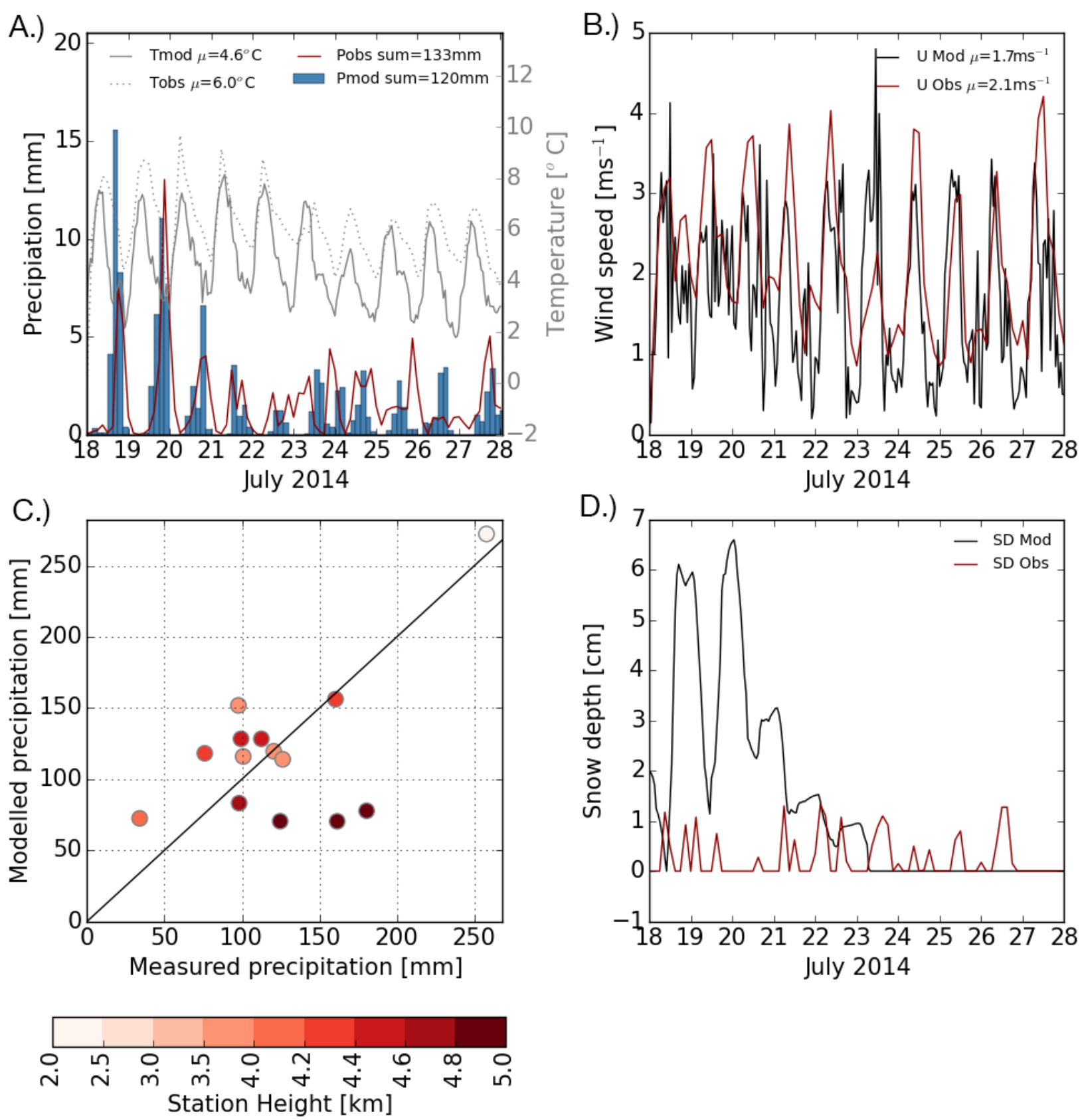

Figure 3.10: As in Figure 3.9 but now for the summer period. Panel A shows modelled (solid gray line) and simulated (dashed gray line) 2- meter air temperature, modelled precipitation (blue bars), uncorrected observed precipitation (red line), Panel B the 10 meter observed (black line) and modelled (red line) windspeed, Panel $C$ the total accumulated precipitation colored by elevation and Panel $D$ the modelled (black line) and observed (red line) snow depth. The data in Panels $A, B$ and $D$ are 3-hourly averaged and is averaged over all available stations. 


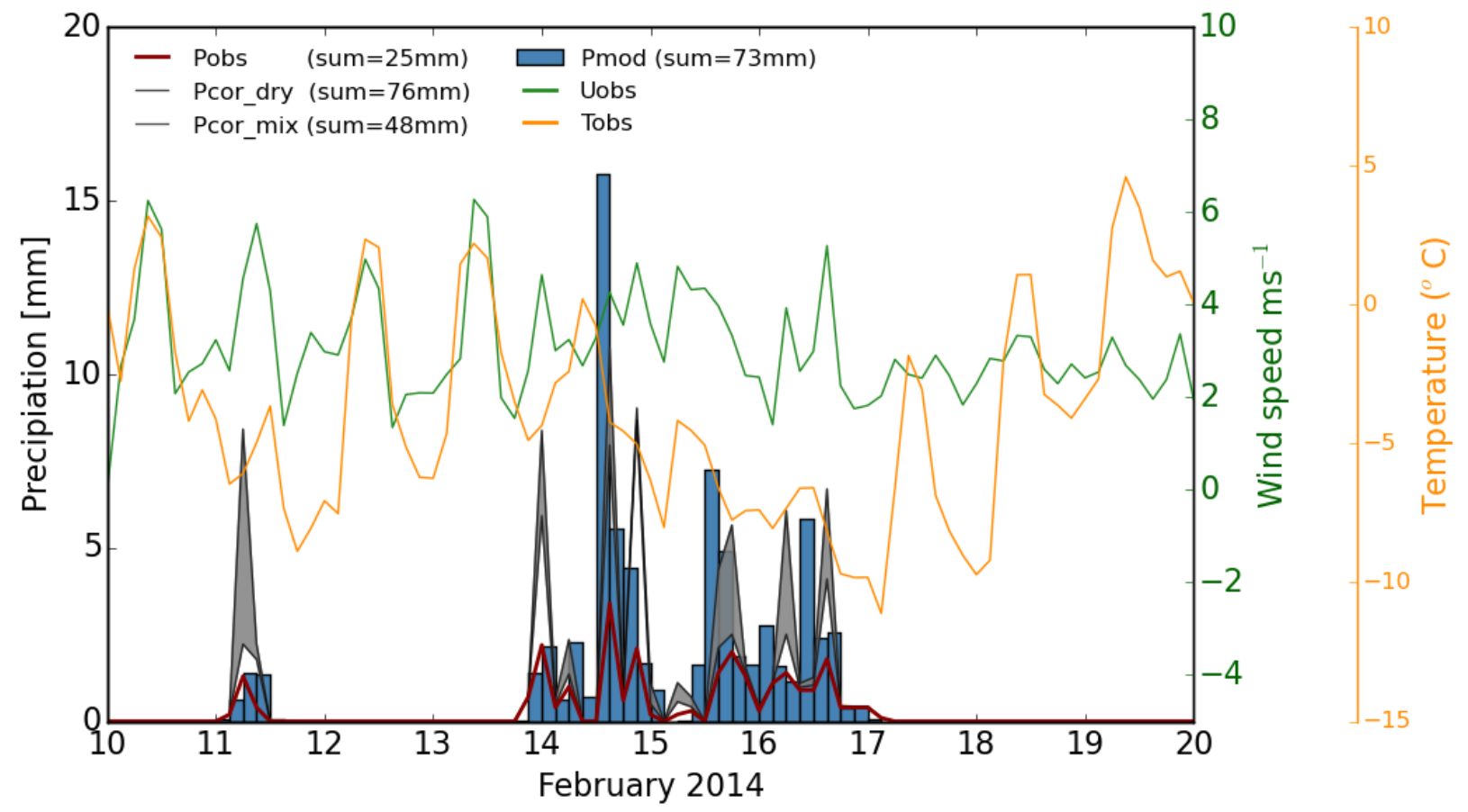

Figure 3.11: The figure shows the modelled precipitation (blue bars), observed 2-meter air temperatures (yellow), 10 meter observed wind speed (green), uncorrected observed precipitation (red line) and the corrected observed precipitation when assuming dry snow (upper black line) and a mixture of snow (lower black line) for the measurement station of Kyanging. The grey color indicates the uncertainty of the corrected snow amounts due to the type of snow. 
for dry snow and a mixture of wet and dry snow, respectively. The correction results in a much closer match with the WRF simulations (73 mm).

The wind speed is only measured by the AWS and in order to apply the correction factor to all measurement stations for a spatial indication of the under-catch of snow, the modelled wind speed and temperature are used. Since temperatures are consistently below zero, the dry correction factor is used for all stations (black line in Figure 3.7). Averaged over all stations, the observed, corrected and modelled precipitation are 14, 40, $79 \mathrm{~mm}$ respectively. The correction does not entirely close the gap with model results and there could be several explanations. The modelled wind speed could be underestimated at the steep slopes in D4 caused by the representation of topography. Secondly, the snow measurements are only corrected for the wind speed, however also other uncertainties are present. For example, evaporation takes place in tipping buckets when the rainfall intensity is low and the conditions are favourable for evaporation. Due to this loss of water it is not certain if all precipitation is measured by the tipping buckets. Thirdly, the melting peak at 17 February indicates that the buckets of the tipping buckets were likely filled, whereby no new snow is registered and the accumulated precipitation is underestimated. For solid precipitation the uncertainties are larger than for liquid precipitation, since snow accumulates in the bucket and is only recorded when it melts, which causes a delay in the measurements. Additionally snow can be blown out of the bucket and the amount cannot exceed the volume of the bucket. For the pluviometers these problems do not occur, since these are larger and measure every minute. Another source of uncertainty of $\sim 4 \%$ is present in tipping buckets during high intensity rain fall, whereby precipitation is splashed out the bucket (Orr et al., 2017). For quantification of errors in future we installed time lapse cameras in the field campaign of spring 2017 to identify if precipitation events match with the records. On top of all the measurement uncertainties the cold bias in WRF can also lead to more snow and increase the bias with this positive feedback.

\subsection{Conclusion}

In this study we modelled a summer and winter period for a high-altitude catchment in Nepal (Langtang) with a grid spacing down to 500 meter in WRF and compared the results to observations of precipitation, 2-meter air temperature and 10-meter wind speed. The sensitivity of the results to the landuse and the spin-up time in WRF were also investigated.

The largest improvements were observed when increasing the grid spacing to 500 meter in the 2meter temperature and wind speed. The 2-meter temperature shows a large negative bias in 
both periods, which decreases with increasing resolutions $\left(8.9\left[3.3{ }^{\circ} \mathrm{C}\right.\right.$ in $\mathrm{D} 2$ to $4.8[1.5]{ }^{\circ} \mathrm{C}$ in winter [summer] in the 500-meter grid spacing domain). Simulated precipitation improves mostly in the higher elevated parts of the valley, with values at the higher measurement stations (>4600 meter) underestimated (overestimated) significantly in summer (winter) by $57 \%(330 \%)$. In the 500-meter grid spacing domain more orographically forced precipitation is modelled at higher elevations than in the coarser domains. Currently available gridded precipitation products underestimate precipitation in this region (Immerzeel et al., 2015) and we show that increasing the spatial resolution contributes to more realistic amounts and patterns in complex terrain.

The influence of the landuse on the amount of precipitation is large in summer, since it affects the latent heat flux. In this simulated summer (winter) period the FAO landuse dataset results in a decrease in precipitation averaged over the 1-km grid spacing domain of $10 \%(0 \%)$, which shows the importance of correctly specifying this field during the monsoon. Simulations are also sensitive to the spin-up time (especially in the summer period), without a clear trend with increasing length. We found a spin-up time of 24 hours gave the highest correlations of precipitation, 2-meter air temperature and 10-meter wind speed compared to the periods of 12 hours, 3 and 5 days.

The evaluation of the simulations was done with relatively low elevation stations and the sparsity of stations above $5500 \mathrm{~m}$ prevents a full evaluation of the distributed fields. More high-elevated stations are needed for a thorough validation, however the results from low elevation stations are promising. We showed that the under-catch of snow complicates model evaluation for the winter period. Relationships of under-catch of snow with wind speed and temperature (Thériault et al., 2012) were used to determine the corrected amount of snow. For a 10-day period in winter, the under-catch of dry snow $(48 \mathrm{~mm})$ contributed strongly to the discrepancy between the model $(73 \mathrm{~mm})$ and uncorrected $(25 \mathrm{~mm})$ measurements. Applying the correction factor to all measurement stations with the modelled wind speed and temperature is difficult, since the wind speed at steep slopes is likely too low.

To our knowledge this study is the first sub-kilometer investigation of a High Mountain Asian catchment with WRF and shows that there is an improved agreement with observations compared to the kilometer scale (except for winter precipitation). Modest improvements were observed when the resolution was decreased to 500 meter, suggesting that, in combination with future improvements to atmospheric models for applications in complex terrain, sub-kilometer grid spacing may more accurately resolves catchment-scale meteorological variability and 
therefore the resulting glacio-hydrological changes. An important avenue of future research would be to evaluate possible improvements when the resolution is further refined and LES modelling is used, however this is computationally unfeasible for interannual investigations.

Our results increase confidence in the performance of WRF at high resolution and demonstrates the importance of reasonably accurate surface boundary conditions for simulating precipitation. It resolves weather parameters more explicitly with altitude, provides a better match with observations and is still computationally feasible. Furthermore, they suggest that future modelling studies in complex terrain should consider sub-kilometer grid for accurately resolving local meteorological variability.

\section{Acknowledgments}

This project has received funding from the European Research Council (ERC) under the European Union's Horizon 2020 research and innovation programme (grant agreement number 676819) and the Netherlands Organization for Scientific Research under the Innovational Research Incentives Scheme VIDI (grant agreement 016.181.308). E. Collier was supported by the German Research Foundation (DFG) Grant No. MO 2869/1-1. ICIMOD is acknowledged for the observational data of Yala and Kyanging stations. Supercomputing resources were financially supported by NWO and provided by SURFsara (www.surfsara.nl) on the Cartesius cluster. 


\section{4}

\section{Contrasting meteorological drivers of the glacier mass balance between the Karakoram and central Himalaya}

There is strong variation in glacier mass balances in High Mountain Asia. Particularly interesting is the fact that glaciers are neutral or even gaining mass in the Karakoram and Kunlun Shan ranges, which is in sharp contrast with the negative mass balances in the rest of High Mountain Asia. To understand this difference, an in-depth understanding of the meteorological drivers of the glacier mass balance is required. In this study, two catchments in contrasting climatic regions, one in the central Himalaya (Langtang) and one in the Karakoram (Shimshal), are modelled at 1 kilometer grid spacing with the numerical atmospheric model WRF for the period of 2011 to 2013. Our results show that the accumulation and melt dynamics of both regions differ due to contrasting meteorological conditions. In Shimshal, 92\% of the annual precipitation falls in the form of snow, in contrast with $42 \%$ in Langtang. In addition, $80 \%$ of the total snow falls above an altitude of $5000 \mathrm{~m}$ a.s.l., compared with 35\% in Langtang. Another prominent contrast is that most of the annual snowfall falls between December and May (71\%), compared with 52\% in Langtang. The melt regimes are also different, with 41\% less energy available for melt in Shimshal. The melt in the Karakoram is controlled by net shortwave radiation ( $r=0.79 \pm 0.01)$ through the relatively low glacier albedo in summer, while net longwave radiation (clouds) dominates the energy balance in

Chapter published as:

Bonekamp, P.N.J., R.J. de Kok, Collier, E., Immerzeel, W.W., Contrasting meteorological drivers of the glacier mass balance between the Karakoram and central Himalaya (2019), Frontiers Earth Science, 7:107. doi: 10.3389/feart.2019.00107 
the Langtang region $(r=0.76 \pm 0.02)$. High amounts of snowfall and low melt rates result in a simulated positive glacier surface mass balance in Shimshal $\left(+0.31 \pm 0.06 \mathrm{~m}\right.$ w.e. $\left.y \mathrm{r}^{-1}\right)$ for the study period, while little snowfall and high melt rates lead to a negative mass balance in Langtang ($0.40 \pm 0.09 \mathrm{~m}$ w.e. $\mathrm{yr}^{-1}$ ). The melt in Shimshal is highly variable between years, and is especially sensitive to summer snow events that reset the surface albedo. We conclude that understanding glacier mass balance anomalies requires quantification and insight into subtle shifts in the energy balance and accumulation regimes at high altitude and that the sensitivity of glaciers to climate change is regionally variable.

\subsection{Introduction}

Generally, glaciers are retreating due to global warming, yet glaciers in the Karakoram - Kunlun Shan region remain stable or have even gained mass. This irregularity is often called the Karakoram anomaly and was first noticed by Hewitt (2005) before being confirmed by subsequent geodetic studies. Glacier behavior in the Karakoram is highly heterogeneous, both spatially and temporally, and its drivers are not yet fully understood (Brun et al. 2017; Kääb et al. 2015; Gardelle et al. 2012; Bolch et al. 2012; Jacob et al. 2012).

Several explanations have been proposed for this anomaly. Firstly, the westerly winds, which act as a moisture source in winter, could have strengthened and lowered in altitude, leading to increased winter precipitation (Archer \& Caldeira 2008). Secondly, a decrease in summer temperatures in the Karakoram has been proposed to contribute to more (solid) precipitation and clouds and therefore less glacier melt (Fowler \& Archer 2005; Forsythe et al. 2017). Thirdly, de Kok et al. (2018) showed that large-scale irrigation in the surrounding areas affect the hydrological cycle and leads to more snow in the Karakoram and Kunlun Shan mountains.

The climate in High Mountain Asia is highly variable: it ranges from monsoon-dominated in the central Himalaya to being dominated by westerly disturbances in the Karakoram and western Himalaya (Bookhagen \& Burbank 2010). Monsoon precipitation generally falls every day in the summer months, while westerlies provide event-based precipitation during the winter months (Bookhagen \& Burbank 2010).

The region is highly inhomogeneous, with complex topography and meteo-climatic regimes that current gridded observational data sets are too coarse to resolve (Immerzeel et al. 2015; Andermann et al. 2011; Palazzi et al. 2013). Observations of precipitation and temperature are scarce at high elevations in High Mountain Asia, leading to a bias in gridded observational datasets (Immerzeel et al. 2015). In order to overcome spatial and temporal gaps, high-resolution 
modelling is useful and can provide key inputs for glacio-hydrological studies (Immerzeel et al. 2015).

The surface mass balance of a glacier is largely driven by accumulated snow and melt. Understanding the mass balance therefore requires insight into the distribution and seasonality of snowfall and into the variability in the components of the surface energy balance. Here, we investigate the contrasts in the seasonal and altitudinal distribution of the surface energy balance and snow accumulation between the central Himalaya and the Karakoram region that underlie this glaciological anomaly. We model two contrasting catchments with the Weather Research and forecasting (WRF) model and use nested domains from 25 to 5 to $1 \mathrm{~km}$ to obtain a highresolution data set of the Shimshal (Karakoram) and Langtang (central Himalaya) catchments for 3 years (2011-2013). We analyse systematic differences between years, seasons and altitude. We show detailed differences in seasonality of precipitation and identify primary drivers of glacier melt by examining different components of the energy balance. Using this information we reveal the differences in glacier sensitivity, which offers important clues for understanding potential drivers of the Karakoram anomaly.

\subsection{Methods}

\subsubsection{Study area}

To represent the two different climates in High Mountain Asia, two contrasting catchments are chosen: the Shimshal valley (Karakoram) and Langtang valley (central-Himalaya).

Shimshal is an east-west positioned, $60 \mathrm{~km}$ long, V-shaped valley in Pakistan $\left(\sim 2900 \mathrm{~km}^{2}\right)$ and ranges in altitude from 2500 to $8000 \mathrm{~m}$ a.s.I. with a steep relief (Figure 4.1). The yearly averaged snowline is located between 4800 and $5300 \mathrm{~m}$ a.s.l. (Iturrizaga 1997). The catchment is $32.5 \%$ glacierized and $20.7 \%$ of the glacier surfaces are debris-covered, with a mean glacier size of 11.1 $\mathrm{km}^{2}$. Important glaciers are the Lupghar (13 km long), Momhil (35 km), Malangutti $(23 \mathrm{~km})$ and Yazghil $(31 \mathrm{~km})$ glaciers and the Khurdopin glacier $(47 \mathrm{~km})$, which blends with the Yushkin-Gardan and Virjerab glacier (40 km) (RGI Consortium 2017). The Karakoram precipitation regime is dominated by westerlies and most of the precipitation falls during winter as snow. The glaciers predominantly accumulate mass during winter and ablation occurs during summer (Bookhagen \& Burbank 2010; Hewitt 2005).

The second catchment is the Langtang valley $\left(\sim 600 \mathrm{~km}^{2}\right)$, located in the central Himalaya, $70 \mathrm{~km}$ north of Kathmandu (Nepal) and ranges in altitude from 1406 to $7180 \mathrm{~m}$ a.s.l.. This valley is Ushaped upstream, while V-shaped downstream. $24 \%$ of the catchment is glacierized and the average glacier size is $2 \mathrm{~km}^{2}$ (Collier \& Immerzeel, 2015). Glacier tongues are generally debris- 
covered $\left(32 \mathrm{~km}^{2}\right.$ ). Most precipitation (>70\%) falls during the monsoon period and glaciers have simultaneous accumulation and ablation during this period (Immerzeel et al. 2014).

\subsubsection{Model}

We used the advanced research WRF model version 3.8.1 (Skamarock et al. 2008) to simulate the period from January 2011 till January 2014, excluding 1 month of spin up (December 2010). In total we simulate 3 years, to get insight into inter-annual variability. This period is chosen such that no El Niño events are included in the simulation, as they are associated with positive precipitation and temperature anomalies (Syed et al. 2006). The outer domain is showed in Figure 4.1 and has two nests for each catchment, with resolutions of 5 and $1 \mathrm{~km}$ respectively. All domains have 50 terrain-following vertical levels, stretching from the surface to $50 \mathrm{hPa}$, with 11 levels in the lowest $\mathrm{km}$ above the surface. The outer domain is forced with 6-hourly ERA-Interim data $\left(0.75^{\circ} \times 0.75^{\circ}\right.$, Dee et al. 2011), and grid analysis nudging is applied to the horizontal wind, water vapour mixing ratio and potential temperature fields in the highest 15 vertical levels. Since we are running a 3-year simulation, grid analysis nudging is employed to constrain large-scale circulation (Bowden et al. 2013). We used the same nudging coefficients as Collier \& Immerzeel (2015), since that improved the simulated monsoon precipitation for a similar domain as tested in previous work (Collier \& Immerzeel 2015). The model configuration and parameterizations are similar to the ones described in (Bonekamp et al. 2018) and are shown in Table 4.1.

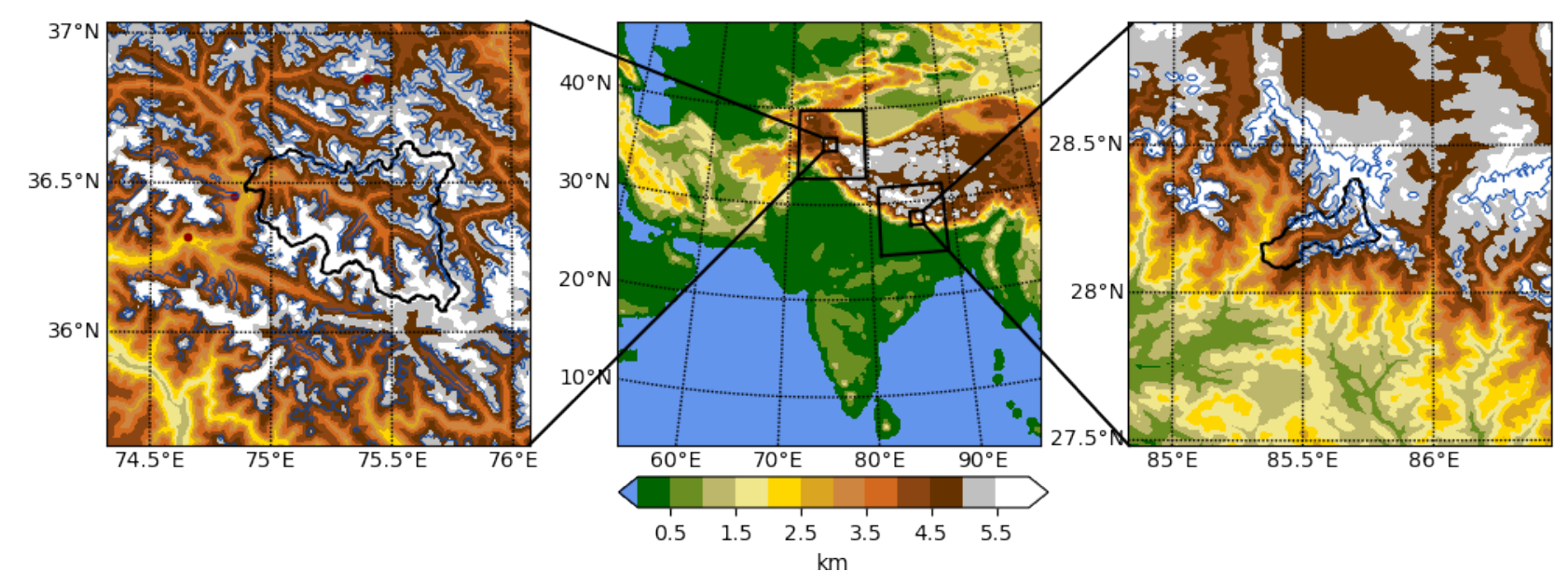

Figure 4.1: The outer domain (D1, $25 \mathrm{~km}$, middle panel), with its nests. Left panel shows the $1 \mathrm{~km}$ domain of Shimshal catchment (D3), right panel $1 \mathrm{~km}$ domain of Langtang catchment (D5). The catchment outlines are indicated by black contours and glacier outlines of GLDAS dataset (Rodell et al. 2004) by blue contours. 
The default land cover map in WRF is not representative for the region and underestimates both the glacier and forest area (Bonekamp et al. 2018). As the correct representation of land-use is very important for the surface energy balance and thus the valley climate, the land cover dataset is updated using the climate change initiative dataset (CCl; Defourny et al. (2017)) of the European Space Agency (ESA), which has a spatial resolution of $300 \mathrm{~m}$.

We initialized the soil moisture, soil temperatures and skin temperatures with the GLDAS (Global Land Data Assimilation system) dataset $\left(0.25^{\circ} \times 0.25^{\circ}\right.$; Rodell et al. 2004) as the ERA-Interim initial conditions are unrealistic, in particular the snow depths. The snow height is limited by the amount of snow water equivalent available at each grid point in the GLDAS dataset. The topography is smoothed in D3 only, at a total of 8 grid points to reduce numerical instability. The affected grid points are located outside of the studied catchments. WRF simulations are compared to observations for the Langtang catchment in Bonekamp et al. (2018), however not explicitly for the Shimshal catchment, since those measurements are very limited and the quality is low.

The simulation was performed on the Cartesius cluster of the SURFsara Supercomputing Center (www.surfsara.nl) on 192 processors and took approximately 55 days to complete.

\subsubsection{Glacier mass balance}

The surface mass balance (SMB) of a glacier is the sum of all processes adding mass (accumulation) and removing (ablation) mass from the glacier surface over a 1-year period. In our approach, we approximate the glacier mass balance by the difference between snowfall and melt (including refreezing). Melt and refreezing are computed at hourly intervals from the residual in the surface energy balance (SEB) for all glacier cells, which are designated as clean ice, using the terms calculated by the Noah-MP land surface model (Niu et al. 2011):

$S E B=S W_{\text {in }}-S W_{\text {ref }}+L W_{\text {in }}-L W_{\text {out }}-S H F-L H F+G H F$

Incoming shortwave $\left(\mathrm{SW}_{\text {in }}\right)$ and longwave radiation $\left(\mathrm{LW}_{\text {in }}\right)$, outgoing longwave radiation ( $\left(L W_{\text {out }}\right)$, as well as the sensible (SHF), latent (LHF) and ground heat fluxes (GHF), are direct WRF output. The refrlected shortwave radiation $\left(S W_{\text {ref }}\right)$ is calculated using the simulated surface albedo. Fluxes directed away from the surface are defined as negative. The GHF is driven by the temperature gradient between the surface and the upper soil layer, the upper layer thickness and the thermal conductivity (Niu et al. 2011). If the surface temperature exceeds the melting point, the surface temperature is reset to $273.15 \mathrm{~K}$ and the excess energy is used to melt snow or glacier ice. In Noah-MP, the snow layer can consist of 3 layers and a glacier is treated as frozen soil with appropriate values for albedo, surface roughness and heat conductivity. In the snowpack 
Table 4.1: Overview WRF configuration

\begin{tabular}{|c|c|c|}
\hline \multicolumn{3}{|l|}{ Domain Configuration } \\
\hline Horizontal grid spacing & \multicolumn{2}{|c|}{25 - 5 - $1 \mathrm{~km}$ (D1, D2 and D4, D3 and D5) } \\
\hline Grid dimensions & \multicolumn{2}{|l|}{ 200x200 (D1) 161×161 (D2-5) } \\
\hline Vertical levels & \multicolumn{2}{|l|}{50} \\
\hline Time step & \multicolumn{2}{|l|}{$120-24-4.8-24-4.8 \mathrm{~s}$} \\
\hline Model top pressure & \multicolumn{2}{|l|}{$50 \mathrm{hPa}$} \\
\hline Nesting approach & \multicolumn{2}{|l|}{ One way } \\
\hline \multicolumn{3}{|l|}{ Model physics } \\
\hline Microphysics & Morrison & (Morrison et al. 2009) \\
\hline \multicolumn{3}{|l|}{ layer } \\
\hline Land surface & Noah-MP & (Niu et al. 2011) \\
\hline Cumulus & Kain Fritsch Scheme (D1 only) & (Kain 2004) \\
\hline Radiation & RRTMG & (lacono et al. 2008) \\
\hline Surface layer & MM5 Similarity Scheme & (Paulson 1970) \\
\hline Slope/shadowing effects & Zängl & (Zängl 2002) \\
\hline \multicolumn{3}{|l|}{ Dynamics } \\
\hline Top boundary condition & \multicolumn{2}{|l|}{ Rayleigh damping } \\
\hline Diffusion & \multicolumn{2}{|l|}{ Calculated in physical space } \\
\hline Lateral boundary forcing & \multicolumn{2}{|l|}{ 6-hourly ERA-INTERIM data } \\
\hline
\end{tabular}


and glacier, processes such as refreezing, retention and percolation of melt water and densification are modelled (Niu et al. 2011). This method allows us to investigate the contribution of individual energy balance components to the residual flux. The Pearson correlation coefficients are calculated with 5-day averaged data and the interannual variability is calculated as the standard deviation of each variable.

Our approach involves one-way and offline mass balance modeling (Eq. 1), however we do implicitly include the feedbacks between the glacier surface and the atmosphere, since those processes are treated by Noah-MP. Since the ground flux accounts for temperature change in the snowpack/ground, there is no need to take the cold content of the snow pack into account for the amount of potential melt in the offline calculations. We assume melt (refreeze) occurs if the residual energy is positive (negative). A snow layer can hold $5 \%$ of its volume of water (Pu et al. 2007). We assume that enough liquid water is available in the snow pack or glacier for all negative residual energy to produce a mass gain through refreezing.

\subsection{Results}

\subsubsection{Precipitation, temperature and wind}

The climates of the central Himalaya and the Karakoram differ considerably. A major contrast between the regions is the precipitation regime: Langtang has a clear monsoon climate, with the highest precipitation amounts during the summer months and a rather dry winter (Figure 4.2A). Rain dominates the precipitation budget (58\%) and falls throughout the year. In January, February and March a few winter events occur, and precipitation events are more intense than during monsoon. Shimshal, on the other hand, is snow-dominated $(92 \%$ of the annual precipitation), with most precipitation during the winter months. During the summer months, the monsoon penetrates only episodically into the Karakoram region and provides some rainfall (see section 4.3.2). This implies that the summers in Shimshal are relatively dry with limited snow accumulation. $71 \%$ of the snowfall in Shimshal occurs between December and May, compared to $52 \%$ in Langtang. The glaciers in the central Himalaya are therefore simultaneously accumulating and ablating, while glaciers in the Karakoram are gaining mass in winter and melt during summer. Precipitation is variable between years, with potentially large implications for the glacier mass balance (see section 4.3.4).

Shimshal is generally colder than Langtang, with average yearly temperatures of $-8.8{ }^{\circ} \mathrm{C}$ and -4.0 ${ }^{\circ} \mathrm{C}$ respectively, and has slightly higher wind speeds on average $(4.8 \mathrm{~m} / \mathrm{s}$ compared to $4.1 \mathrm{~m} / \mathrm{s}$ in Langtang). Clear similarities in the annual cycle is visible in the two catchments, with the highest temperatures and lowest wind speeds during the summer months. (Figure 4.2B and C) 
The precipitation varies with altitude, season and region. In Figure 4.3, the seasonal precipitation distribution with altitude is shown for the Shimshal and Langtang catchments. In Langtang, the total annual precipitation is $43 \%$ less between $6-8 \mathrm{~km}$ a.s.l. elevation compared to the $2-4 \mathrm{~km}$ a.s.l. range. The monsoon rain dominates the annual signal, and rain between 2-4 km a.s.l. altitude is five times higher than between 6-8 $\mathrm{km}$ a.s.l.. Snow between $2-4 \mathrm{~km}$ a.s.l. altitude is seventeen times less than between 6-8 $\mathrm{km}$ a.s.l.. The snowfall above $5000 \mathrm{~m}$ a.s.l. is rather constant with altitude throughout the year. The precipitation peak occurs at the entrance of the Langtang catchment, where the topography blocks the large-scale monsoon winds (Collier \& Immerzeel 2015).

In Shimshal an increase of total precipitation with altitude is observed. The total precipitation is 6 times larger, and snow even 13 times larger, between 6-8 km a.s.l. than between 2-4 km a.s.l.. Rain decreases with altitude, as in Langtang, and is $40 \%$ lower between 6-8 km a.s.l. than between 2-4 km a.s.I.. In Shimshal, $80 \%$ of the total snow falls above an altitude of $5000 \mathrm{~m}$ a.s.l., while this is only $35 \%$ in Langtang.

In summary, in Shimshal, snow dominates the precipitation budget and the total annual signal shows a positive gradient with altitude, while in Langtang the budget is rain-dominated and the precipitation signal is negative with altitude, consistent with monsoon precipitation peaking at lower altitude than westerly driven precipitation (Collier \& Immerzeel 2015; Immerzeel et al. 2014). Whether the dominant type of precipitation is snow or rain, caused by different circulation systems, is therefore associated with the reverse precipitation gradient with altitude found in Collier \& Immerzeel (2015). These results agree with (Hewitt 2005), who found a 5-10 fold increase in precipitation the Karakoram between 2500 and $4800 \mathrm{~m}$ a.s.l. Winiger et al. (2005) estimated that snowfall above $4000 \mathrm{~m}$ a.s.l. ranges from $1000 \mathrm{~mm}$ to more than $3000 \mathrm{~mm}$, and that above $5000 \mathrm{~m}$ a.s.l. altitude, $>90 \%$ of the precipitation is snowfall, while at lower altitudes $>90 \%$ of the total precipitation is rain.

\subsubsection{Origin of precipitation events}

The origin of precipitation events is an important unknown in the Karakoram, as both westerlies and monsoon winds influence this region. In this research we propose a simple method to classify the origin of precipitation events in the Karakoram (Figure 4.5). It would be interesting to combine WRF with a moisture tracking model to fully understand the precipitation sources during the monsoon in the Karakoram (de Kok et al. 2018; Tuinenburg et al. 2012). However, this goes beyond the scope of the present study. During the winter months (January to March), moisture is transported from west to east, with highest precipitation intensities in the west (Figure 4.4). Two 

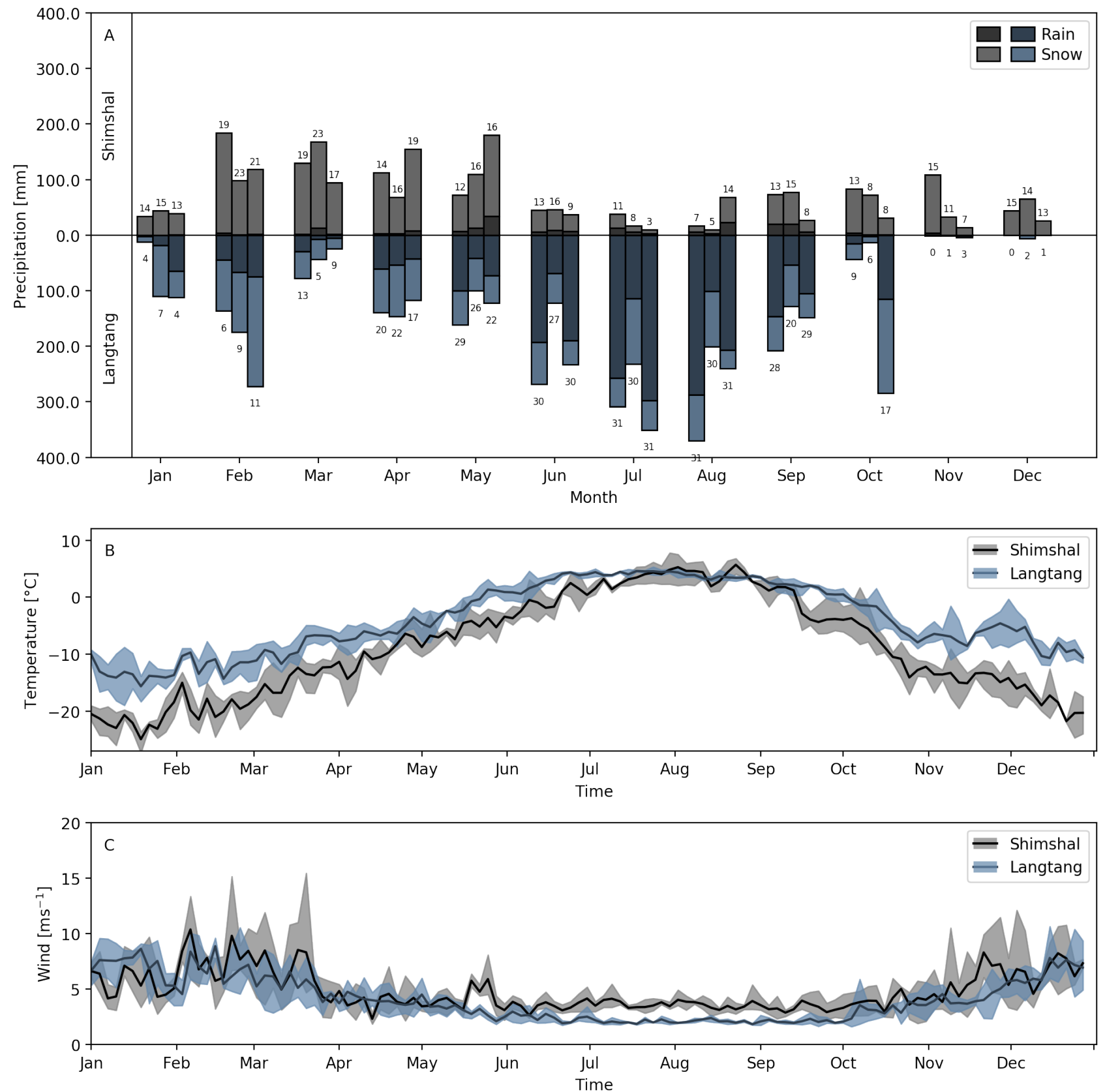

Figure 4.2: A. Monthly accumulated catchment-precipitation, with the number of wet days ( $P>$ $0.5 \mathrm{~mm} /$ day) for 2011 to 2013 (one bar per year). B. 5-day catchment average temperature for the Shimshal (black) and Langtang (blue) catchment. C. As B but for the 10-m wind speed. The shading indicates the minimum and maximum value of the individual year. 

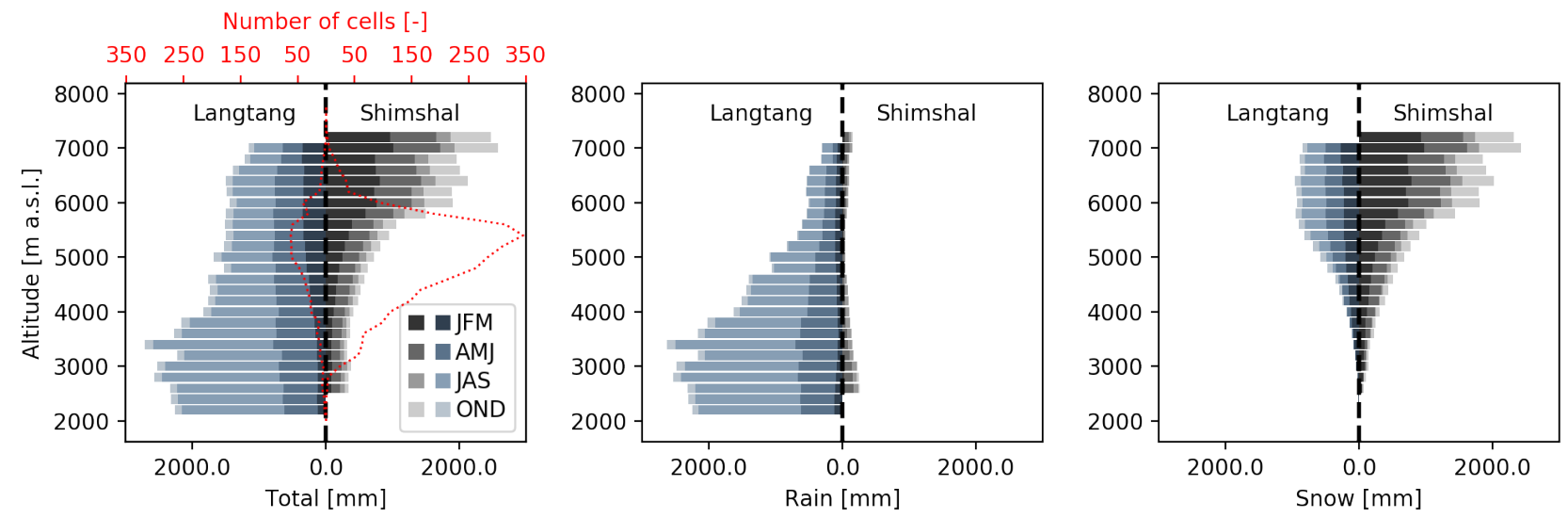

Figure 4.3. Three-year seasonal average of precipitation (left), rain (middle) and snow (right) by 200-m elevation bin. Each bin represents an average of all catchment cells in that altitude range. JFM is the period January, February, March, AMJ is the period April, May June, JAS is the period July, August, September, OND is the period October, November, December. The red dotted lines indicate the number of grid cells in each bin for the two catchments (left).

precipitation bands are clearly visible, which follow the topography clearly. In those months, snow is the dominant precipitation type.

During the summer months (July to September), the monsoon influence is increasing with longitude and it also has a strong south-north decreasing gradient (Figure 4.4). During those months, snow falls predominantly at high altitudes (>5000 m a.s.l.; see Figure 4.3 ). In general, moisture is transported from lower to higher latitudes by monsoon winds and provides almost daily precipitation in the central Himalaya.

To investigate the influence and occurrence of the Indian summer monsoon precipitation events in the Karakoram region, the precipitation events with the associated moisture flux and moisture flux direction during the summer period for three different areas are plotted in Figure 4.5. The precipitation events in box 1 , representing the Shimshal catchment, are categorized by the moisture flux direction in box 2, south of Shimshal (75E; 31N). Box 2 is chosen due to its location at the foot of the Himalaya, where winds are generally flowing parallel to the topography and giving a clear separation between monsoon winds (between 40 and 170 degrees) and westerly winds (larger than 170 degrees and smaller than 40 degrees). Box 3 is chosen due to its location in the Karakoram that acts as a funnel for westerly winds.

During the monsoon, the dominant moisture flux direction during a precipitation event is southwest in Karakoram, while the origin of precipitation differs. In other words, it is possible that the direction of the moisture flux as a result of the interaction with the topography during a precipitation event in monsoon is southwest, but that it has a westerly source. The moisture flux 

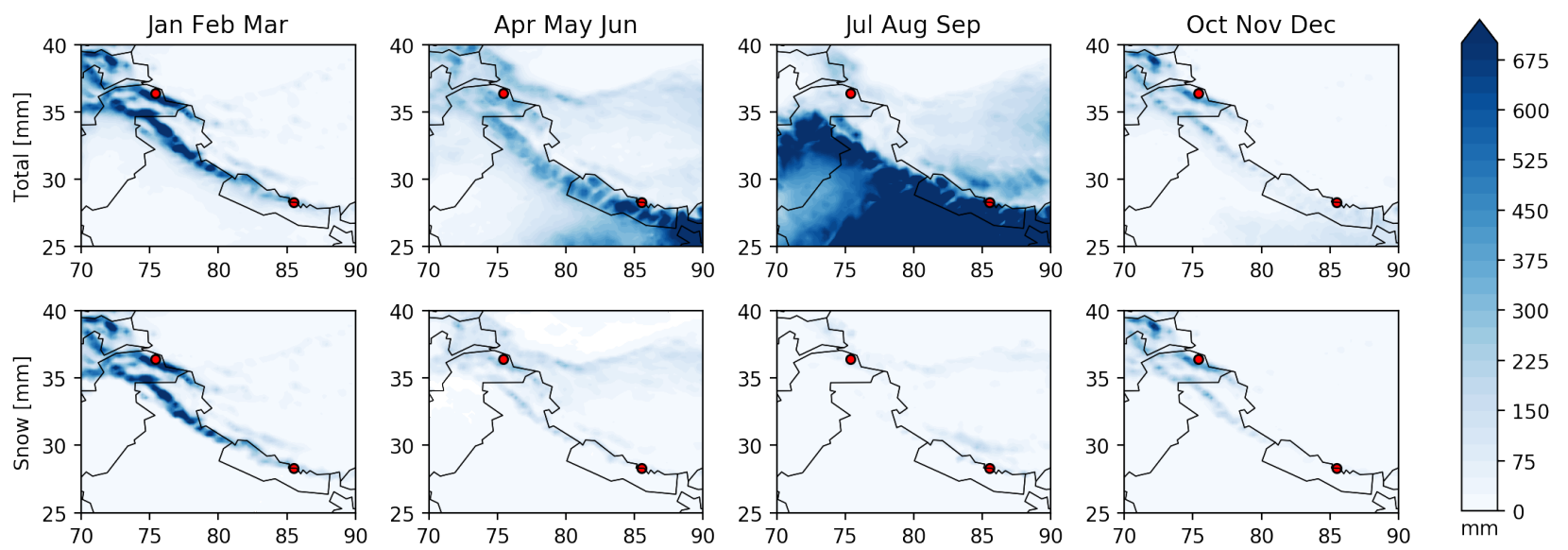

Figure 4.4: Three-year-averaged seasonal total precipitation (upper panels) and solid precipitation (lower panels) for a subset of the $25-\mathrm{km}$ resolution domain. Black contours indicate country outlines and the red markers the Shimshal (left) and Langtang (right) catchment.

direction in the Shimshal catchment (Figure 4.5A) does not give information directly about the origin of the precipitation events due to the complex topography that creates regional meteoclimatic regimes. The three different boxes are used to track the large scale forcing and therefore origin of the precipitation events. A precipitation event in Shimshal (Box1, Figure 4.5A) is classified as monsoon event if the integrated moisture flux in box 2 is between 40 and 170 degrees, and classified as westerly event if the moisture flux direction is smaller than 40 or larger than 170 degrees (Figure 4.5A, B). Based on this characterization, the monsoon period in the Shimshal catchment starts in July and ends halfway September and agrees well with other studies (Lau \& Yang 1997). In the 3-year simulation, on average 22 days with precipitation above $0.5 \mathrm{~mm} /$ day occurred between 1 June and 31 August. Two third of these events are classified as direct monsoon incursions, an example of which is shown in Figure 4.5E, and one third from other origins.

Precipitation and moisture fluxes clearly follow the topography. During the winter the westerly disturbances split due to the Hindu-Kush and Pamir mountain ranges, and during summer months the monsoon penetrates deepest in the Karakoram where the topography is lowest. However, this categorization based on the moisture direction in one specific box is rather simple and depends on our selected range of moisture flux direction. Although it works well and provides a clear indication of the large-scale origin of precipitation in the Karakoram, some specific circulation patterns may be missed. An example in shown in Figure 4.5F, where a monsoon event is wrongly categorized as westerly event and gives noise in the signal. 

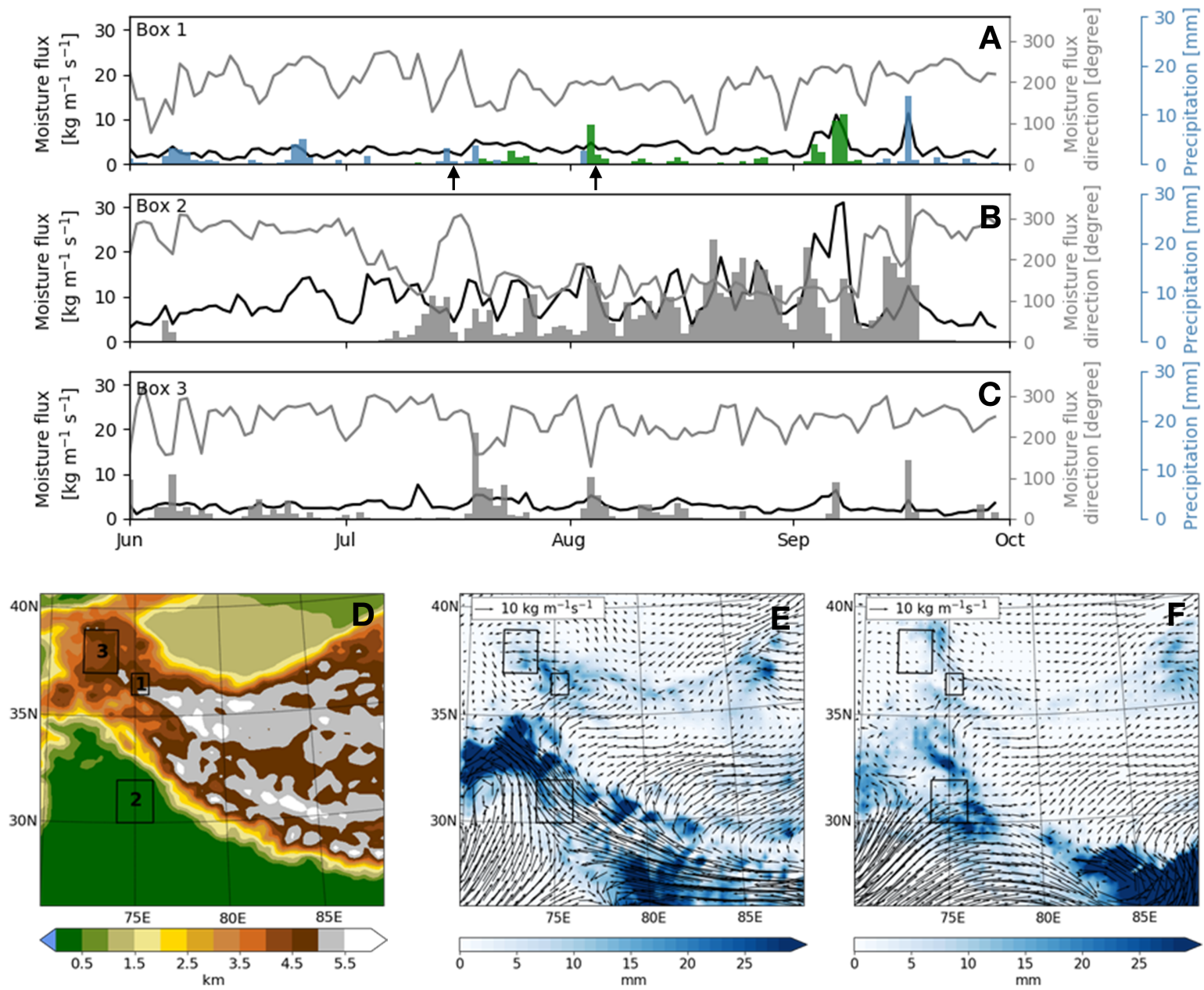

Figure 4.5: Panels A-C show for three different boxes for the months June to October 2012 the daily averaged vertically integrated moisture flux (black), daily averaged moisture flux direction (gray) and daily sum of precipitation (bars). Box 1 (A) represents an average around the Shimshal catchment $(75.3 E ; 36.5 N)$, box $2(B)$ is positioned in a monsoon source area $(75 E ; 31 N)$ and box 3 (C) in a westerly source area $(73 \mathrm{E} ; 38 \mathrm{~N})$. In panel $D$ the topography and the position and extent of the boxes is shown. The source of the precipitation events in box 1 are categorised and a green colour indicates the precipitation event is monsoon-driven, while a blue colour westerly-driven. In panel $E$ the daily-averaged vertically integrated moisture flux (arrows) and daily-averaged accumulated precipitation (blue) for a monsoon categorized event (4 August 2012) for the area same as in D. Panel $F$ is similar to panel $E$, but for a westerly categorized event during the monsoon (15 July 2012). The arrows in A indicate the timing of the events used in $E$ and $F$. 


\subsubsection{Glacier energy balance}

There are clear differences in the simulated surface energy dynamics between the two catchments. The relative contribution of the different terms in the surface energy balance of a glacier controls how sensitive a glacier is to changes in climate, such as increasing temperatures and changing cloud coverage. In Figure 4.6 the individual energy balance components, as well the residual flux of all glacier grid cells in the Shimshal and Langtang catchments are shown. In Figure 4.7 the average contribution of each of the individual energy balance components to the residual flux for the months May to September are given to indicate the main drivers of the melt signal.

The net shortwave radiation provides the largest energy input at the surface (Figure 4.6 and 4.7) and, due to a lower and more variable surface albedo, its variations correlate (Pearson correlation) most strongly with those of melt in Shimshal $(r=0.79 \pm 0.01)$. Conversely, the net longwave radiation dominates the melt signal in the Langtang ( $r=0.76 \pm 0.02)$, due to greater cloud cover and higher atmospheric humidity during the monsoon. The net longwave radiation itself is negative, but variations in this flux have the strongest influence on the residual flux in Langtang. The absolute values of the sensible, latent and ground heat flux are low compared to the shortwave and longwave radiation components (Figure 4.6). However, the latent heat flux could also be an important contributor to the regional differences in the residual flux and thus glacier melt, as it shows the opposite temporal pattern in the two regions (Figure 4.6H). During the melt season, the LHF is almost zero in Langtang $(r=-0.83)$ due to high relative humidity, while in Shimshal this flux is larger and negative $(r=0.43)$ due to relatively dry conditions during summer, indicating that significant amounts of energy are extracted from the surface by sublimation and evaporation. Previous estimates have shown that snow sublimation in Langtang could account for $21 \%$ of the loss of the total snowfall (Stigter et al. 2018). For the Karakoram, however, no studies have been done to quantify the effects of sublimation. Understanding regional and seasonal differences in the LHF could therefore be important to understand the glacier mass balance anomaly in more detail.

The variation in the residual flux is more pronounced at Shimshal, mainly due to variability in the surface albedo, which is infrequently increased by a small number of snow events during the melt season. The surface albedo influences the shortwave reflected radiation and is mainly influenced by the age of the snow pack on the glacier. In Langtang, however, snow events happen on a daily basis at high altitude, resulting in a consistently higher surface albedo (Figure 4.6B). The surface albedo resets to the albedo of fresh snow in the Noah-MP land surface model (0.84) when fresh snow covers the old layer by a depth of at least $10 \mathrm{~mm}$. Due to the land surface model treatment of glacier surfaces as being permanently snow covered, glacier surface albedo ranges between 

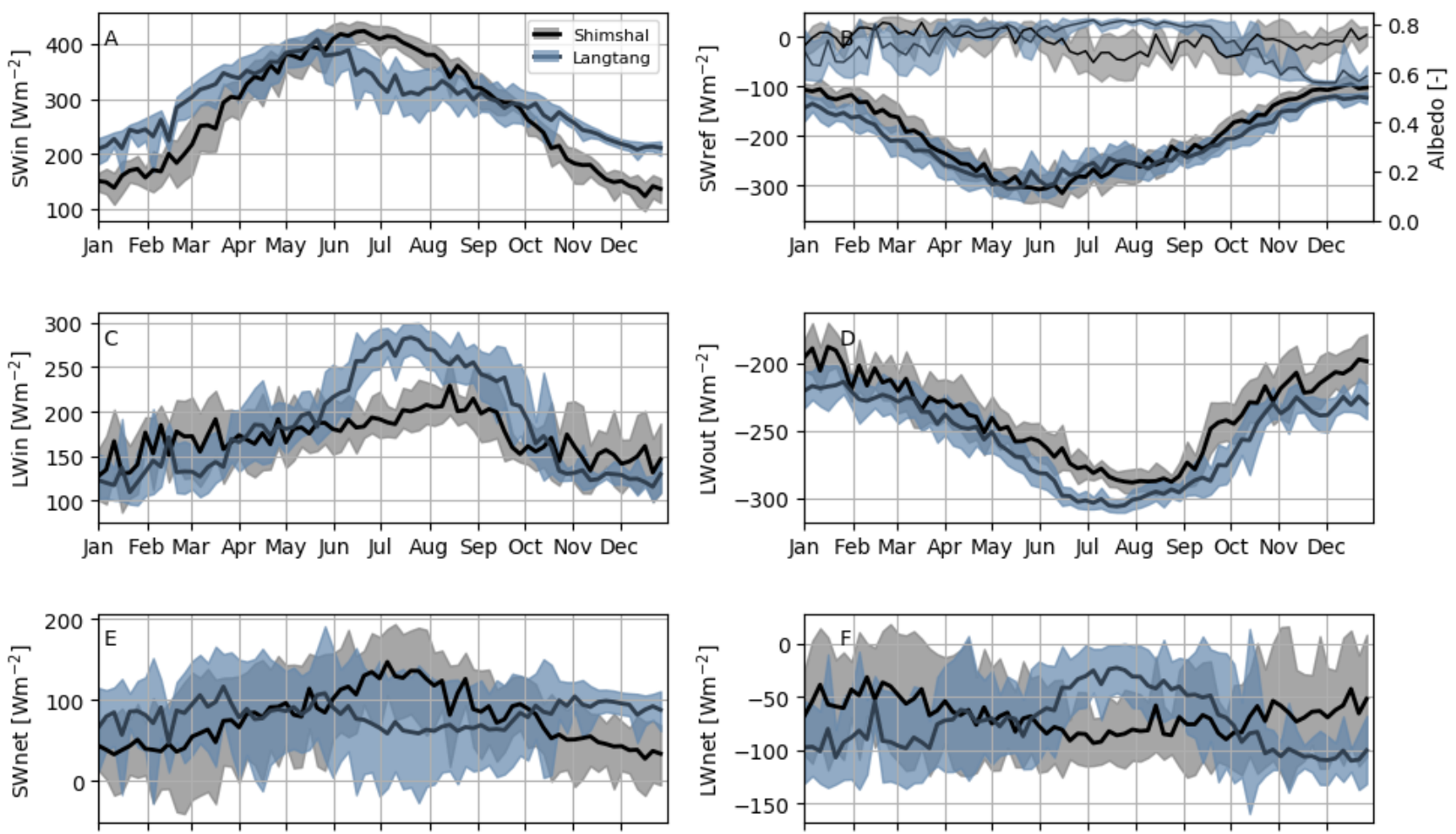

Jan Feb Mar Apr May Jun Jul Aug Sep Oct Nov Dec Day of year

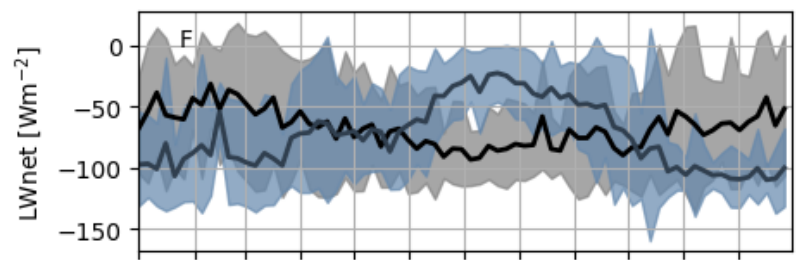

Jan Feb Mar Apr May Jun Jul Aug Sep Oct Nov Dec Day of year

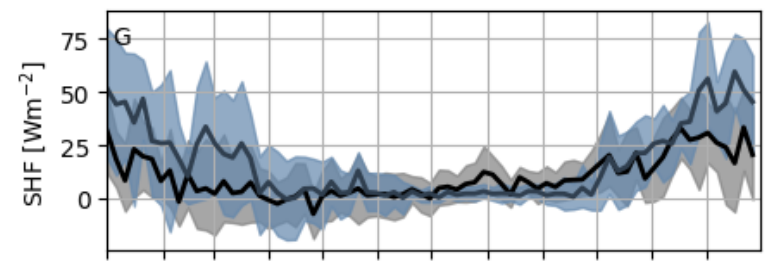

Jan Feb Mar Apr May Jun Jul Aug Sep Oct Nov Dec

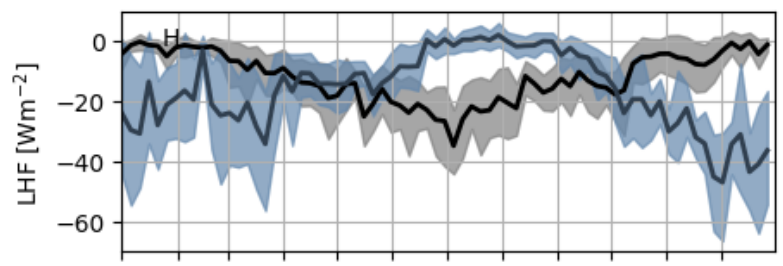

Jan Feb Mar Apr May Jun Jul Aug Sep Oct Nov Dec
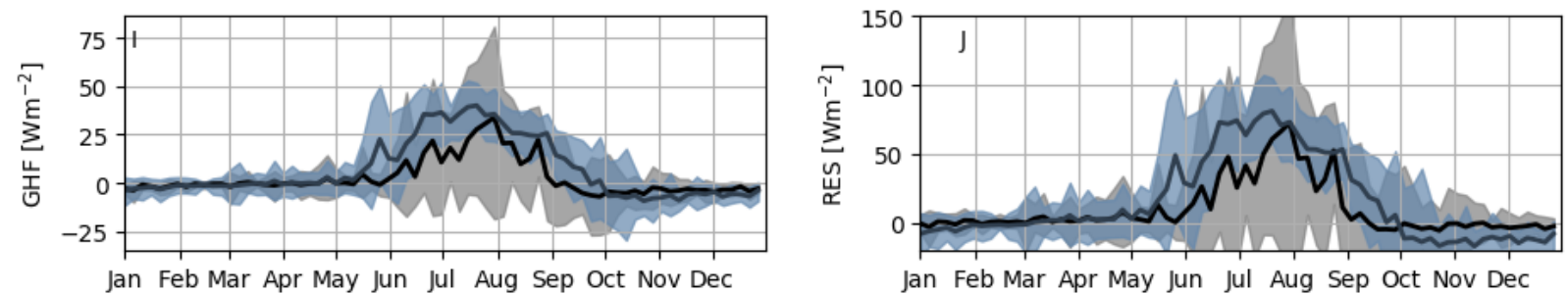

Figure 4.6: The surface energy balance components, 5-day averaged, 3-years average for the glacierized cells in Shimshal (black) and Langtang (blue). The shading indicates the lowest and maximum value of the individual year. SWin (Panel A) and LWin (Panel C) are the short and longwave incoming radiation components, SWref (Panel B) and LWout (Panel D) the shortwave reflected and longwave outgoing radiation components and SWnet (Panel E) and LWnet (Panel F) the net radiation components. SHF (Panel G), LHF (Panel H) and GHF (Panel I) are the sensible, latent and ground heat flux respectively. The albedo is plotted in panel B (thin lines) The residual term (RES, Panel J) is calculated as SWnet+LWnet+SHF+LHF+GHF. 


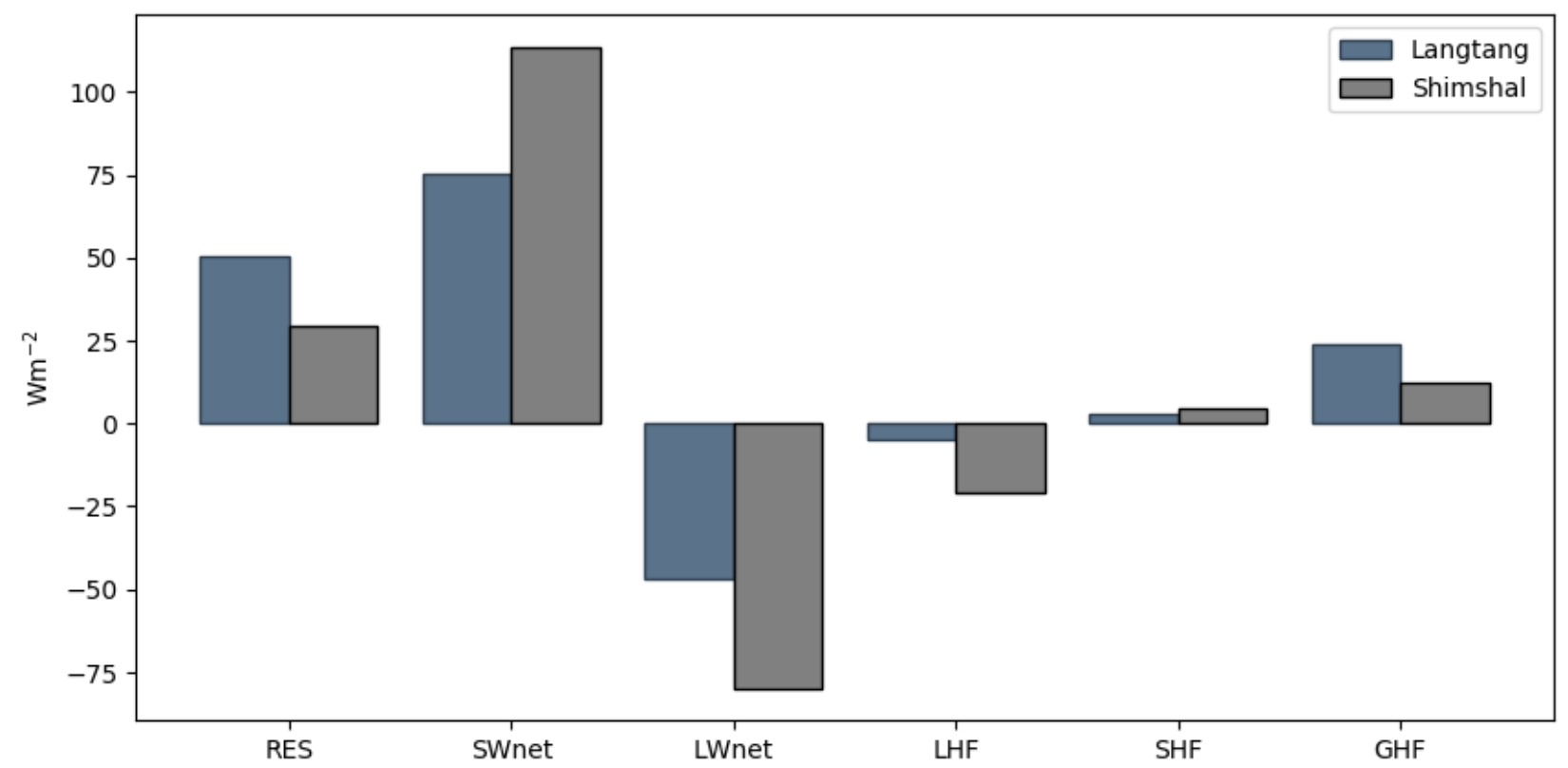

Figure 4.7: The average residual flux (RES), shortwave net (SWnet), longwave net radiation (LWnet), latent heat flux (LHF), sensible heat flux (SHF) and ground heat flux (GHF) for all glacierized cells in Langtang (blue) and Shimshal (gray) for the three melt seasons (May to September).

0.6 and 0.84 for both catchments throughout the year (Figure 4.6B). The importance of the albedo effect is expressed in the fact that the shortwave incoming radiation is much higher in Shimshal during summer, while the reflected shortwave radiation of Shimshal and Langtang is comparable. The summer months in Langtang are generally cloudy with large variability in shortwave incoming and therefore net radiation as a result.

Clouds influence the surface energy balance mainly by emitting longwave radiation (thin high clouds warm the surface) and blocking the incoming shortwave radiation (low thick clouds cool the surface) (Twomey 1991). However, since clouds in a cold climate are colder and less optically thick, the warming effect of high-level clouds is small in cold regions. In Langtang, low- and highlevel clouds are present during the monsoon and lead to a decrease in incoming shortwave radiation and an increase in incoming longwave radiation (see Figures 4.6 and 4.8). In Shimshal, low-level clouds occur during the winter months and decrease the shortwave incoming radiation. Therefore, clouds impact the energy balance components and represent an important driver for the differences in the glacier energy balance between Shimshal and Langtang.

The residual flux at sub-daily time steps provides information about the melt and refreezing cycle of glacier cells in the two different regions. The differences in timing of the melt peaks are caused by the latitudinal differences of the two catchments. In the yearly averaged diurnal cycle of the 

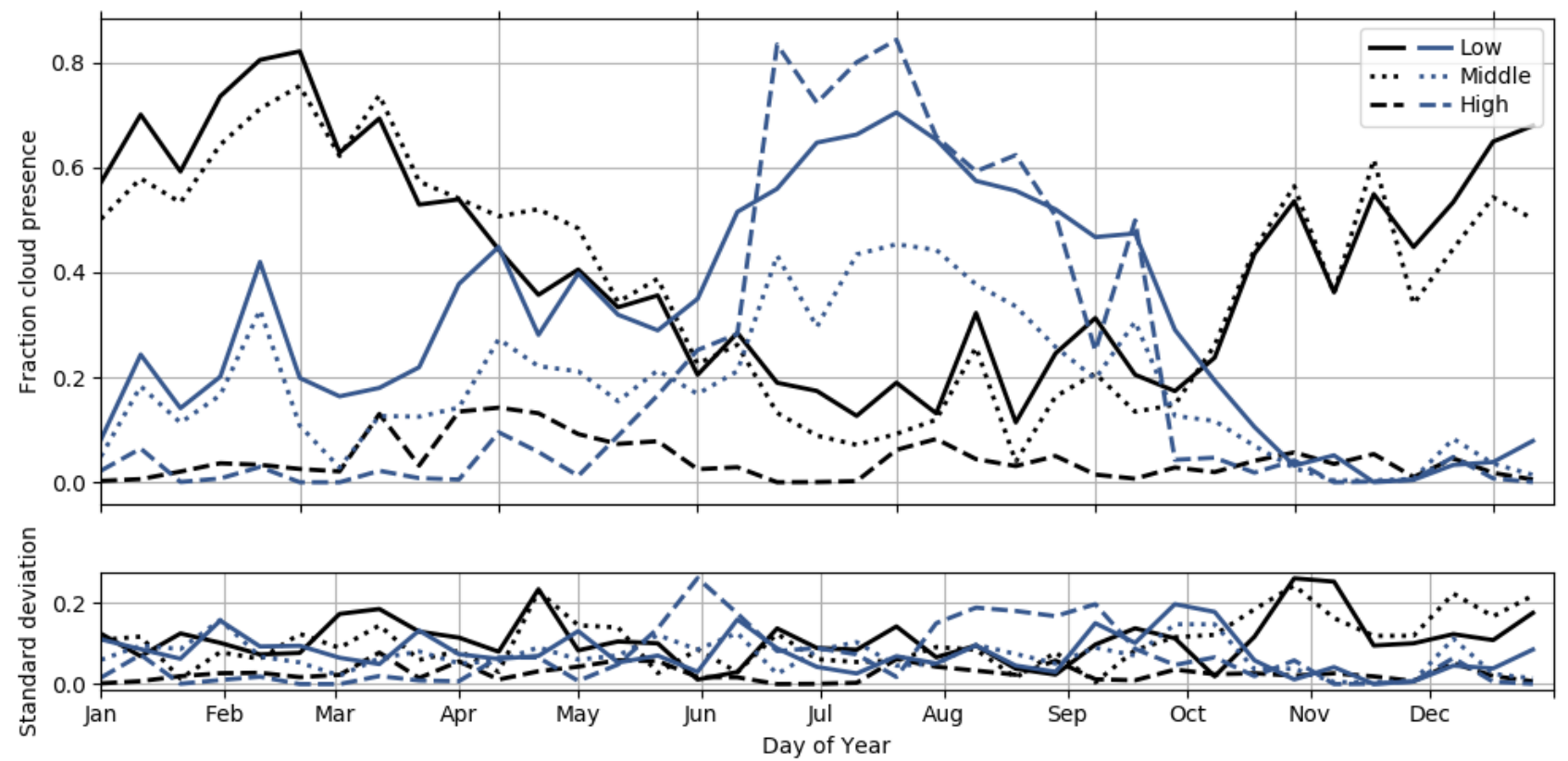

Figure 4.8: Fraction of glacierized cells which are covered by high- (>6km a.s.l.) middle- (2-6km a.s.l.) and low (<2km a.s.l.) clouds (upper panel). The lower panel indicates the standard deviation of the average values. Altitudes are indicated as altitude above the surface. 3-years averaged for Langtang (blue) and Shimshal (black).

residual flux, Langang has a higher residual-energy peak than Shimshal (Figure 4.9). In Langtang and Shimshal, average melt fluxes of 17.7 and $11.3 \mathrm{Wm}^{-2}$, respectively, are observed. Our calculations assumed that the negative residual flux is used for refreezing of melt water and liquid precipitation. Based on this assumption, the amount of refreezing on a yearly basis could amount to $60 \%$ and $52 \%$ of the total melt in Langtang and Shimshal, respectively. Calculations with station data in the Langtang catchment show refreezing in a snowpack can be up to $43 \%$ of the total snow melt (Stigter, 2019 personal communication). However, those calculations neglect rain as liquid water input and assume refreezing is water-limited, since the snow pack is shallow and can hold maximum of $10 \%$ of its mass as liquid water. Therefore, the amount of refreezing calculated in this paper is likely overestimated, which is discussed in more detail in Section 4.4.2.

\subsubsection{Glacier surface mass balance}

In Figure 4.10, the surface mass balance, snow melt and snow accumulation are shown for all glacier cells in the inner domains for each year separately.

The melt is lower in the Shimshal catchment, but more variable $\left(\sigma=0.13 \mathrm{~m}\right.$ w.e. $\left.\mathrm{yr}^{-1}\right)$ than in Langtang $\left(\sigma=0.07 \mathrm{~m}\right.$ w.e. $\left.\mathrm{y}^{-1}\right)$. This variability originates from the shortwave variation in particular (cf. Section 4.3.3). However, another important driver for the difference in mass balance between the catchments is the amount of snowfall, which leads to a positive mass balance in Shimshal (1.26 m w.e. $\mathrm{yr}^{-1}$ snowfall). In Langtang the snow amount (0.93 m w.e. $\mathrm{yr}^{-1}$ ) does not compensate 


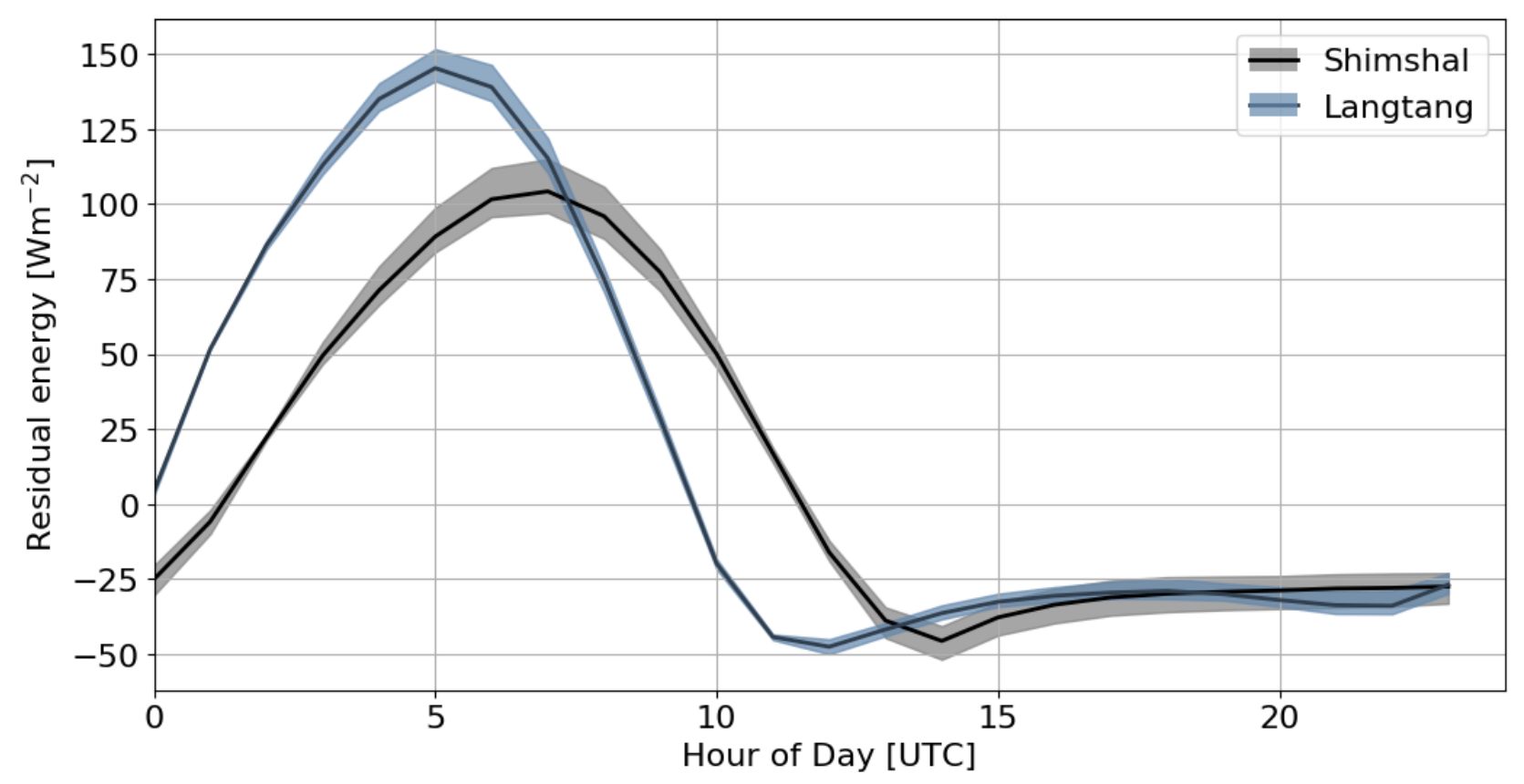

Figure 4.9: Diurnal cycle of the residual flux for Shimshal (black) and Langtang (blue). The shading indicates the interannual variability.

for melt $\left(-1.31 \mathrm{~m}\right.$ w.e. $\left.\mathrm{yr}^{-1}\right)$ and the mass balance is negative for the majority (63\%) of the glacier cells. The variability in snow accumulation is much higher in Shimshal than in Langtang, likely due to the erratic nature of snow storms produced by westerly disturbances in Shimshal, while snowfall at high-altitude in Langtang is more constantly driven by monsoon precipitation. This result suggests that the variability in the mass balance in Langtang is mainly controlled by spatially variable melt, rather than snow fall.

In Figure 4.11, the average surface mass balance per altitude bin is shown. The different sign in the mass balances of Langtang $\left(-0.40 \mathrm{~m}\right.$ w.e. $\left.\mathrm{yr}^{-1}\right)$ and Shimshal $\left(0.31 \mathrm{~m}\right.$ w.e. $\left.\mathrm{yr}^{-1}\right)$ shows the vertical glacier mass balance profile is different in the central Himalaya and the Karakoram region. The residual energy at lower altitudes shows a strong interannual variability in Shimshal, which indicates that the melt on the glacier tongues varies strongly. However, the number of glacier cells is low $(<5)$ at low elevations $(<4400 \mathrm{~m}$ a.s.l.) and could explain the sensitive signal as well.

In the Langtang catchment, glaciers are relatively small and located in a small altitude range (5200-7000 $\mathrm{m}$ a.s.l.). $17.9 \%$ of the catchment is a clean-ice glacier and 59\% (accumulation area ratio $(A A R)$ is 0.41 ) of the glacier points is located below the equilibrium line altitude $(5900 \mathrm{~m}$ a.s.l.), indicating relatively high melt rates. The Shimshal catchment is glacierized by clean-ice glaciers over $37.4 \%$ of its area, contains larger glaciers, and has a large accumulation ( $>5500 \mathrm{~m}$ a.s.l.) and ablation zone (<5500 $\mathrm{m}$ a.s.I.). Shimshal contains big glaciers, which originate at higher 


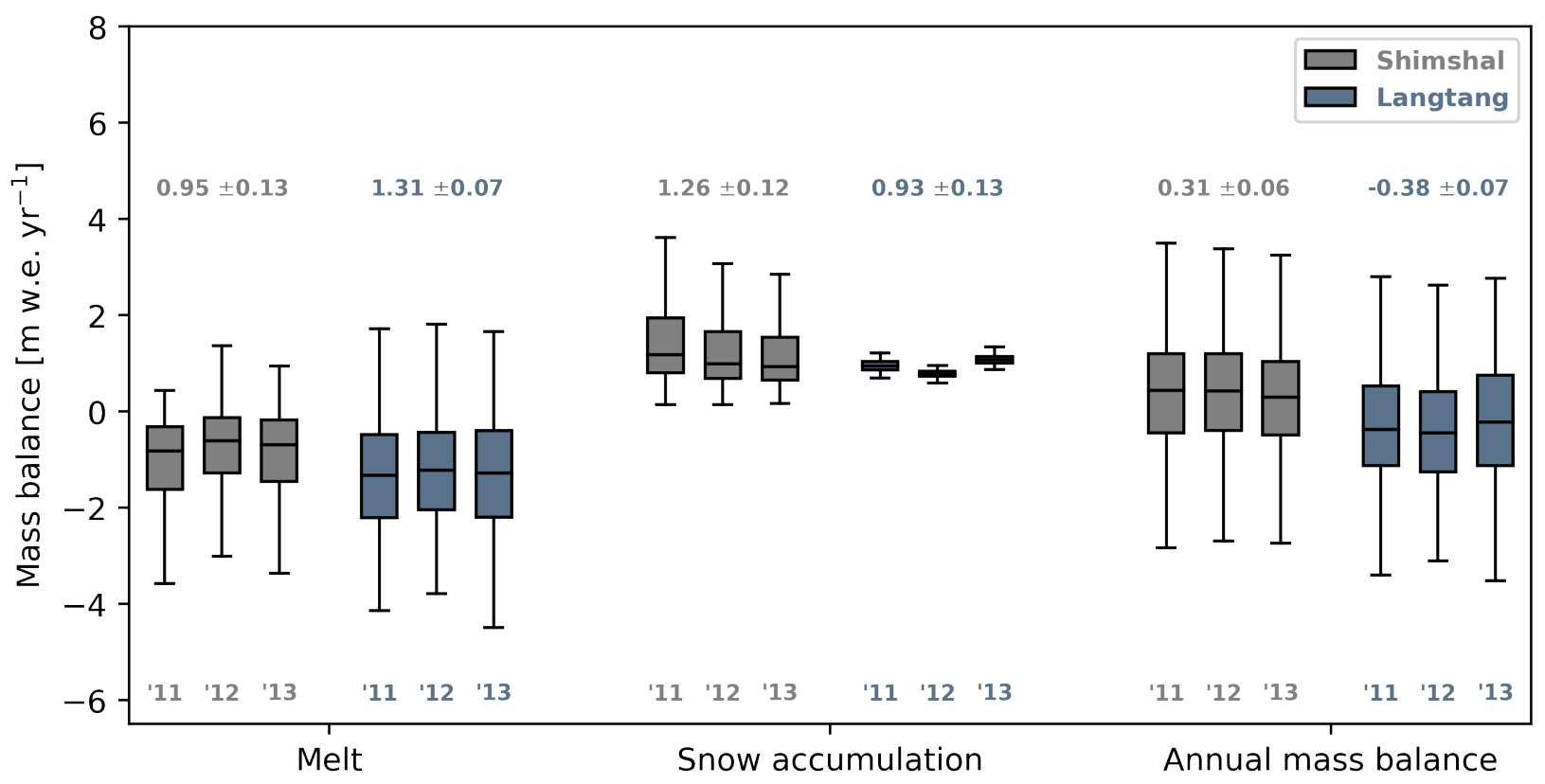

Figure 4.10: Box plots of the effect of the melt and snow accumulation on the glacier surface mass balance, and the annual mass balance for each simulated year shown for Shimshal (grey) and Langtang (blue). The 3-yearly mean and standard deviation is shown above the boxplots for each category and catchment.

altitude, and accumulation is possible due to large amounts of snow and low melt rates. The AAR is 0.61 , which leads to a positive mass balance when all glacier cells are averaged.

\subsection{Discussion}

\subsubsection{Model performance}

The simulated mass balance for years 2011-2013 in Langtang of $-0.40 \pm 0.09 \mathrm{~m}$ w.e $\mathrm{yr}^{-1}$ is in agreement with previously reported values. Baral et al. (2014) estimated the mass balance of Yala glacier in the Langtang catchment (10 November 2011-3 November 2012) to be $-0.89 \mathrm{~m}$ w.e. $\mathrm{yr}^{-1}$. Pellicciotti (2015) estimated the average mass balance of 4 glaciers in the Langtang catchment (with only non-debris parts of the glacier taken into account) at $-0.32 \pm 0.18 \mathrm{~m} \mathrm{w}$.e. $\mathrm{yr}^{-1}$ between the years 1974-1999. Ragettli et al. (2016) found a similar number for debris-free glaciers $0.38 \pm 0.17 \mathrm{~m}$ w.e. $\mathrm{yr}^{-1}$, which is an ensemble mean between the years 2006 and 2015 .

For the Karakoram region, previous studies report both positive and negative mass balances (a selection is provided in Table 4.2). Our calculated mass balance for Shimshal is comparatively high $\left(+0.31 \pm 0.06 \mathrm{~m}\right.$ w.e. $\left.\mathrm{yr}^{-1}\right)$. Previous studies have found stable and positive mass balances in the central and northeastern part of the Karakoram and negative mass balances in the west 

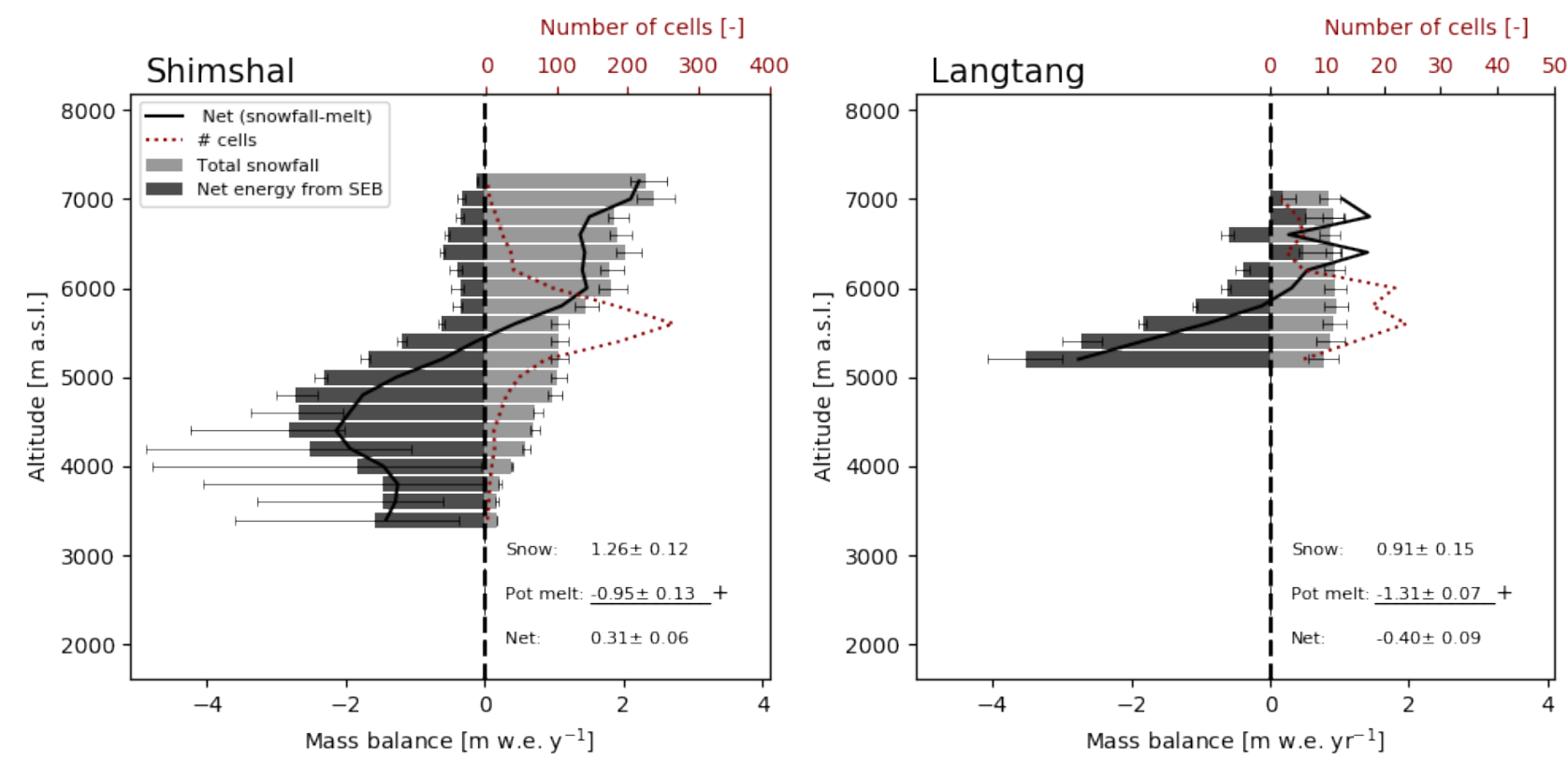

Figure 4.11: Normalized mass balance (black line) with altitude for Shimshal (left) and Langtang (right). Snow (light gray) and melt caused by residual energy (dark gray). Each bin represents an average of that altitude range. The red dashed line indicates the amount of cells. Error bars indicate the variability between simulated years. Numbers indicate the average snow (snow), residual energy flux (pot melt) and total mass balance (net) over 2011-2013.

(Groos et al. 2017). However, they have also reported high-spatial variability, indicating that regional averages could give a distorted view.

Examining individual glaciers, for example, the Yazghil glacier gained $\pm 5 \mathrm{~m}$, Malungutti $5-10 \mathrm{~m}$ and Khurdopin 15-20m in thickness between the years 1997 and 2001 (Hewitt 2005). These observations suggest accumulation rates of more than $1 \mathrm{~m}$ w.e. $\mathrm{yr}^{-1}$ may be reasonable for this region. However, we note that due to the cold bias in WRF for High Mountain Asia (Bonekamp et al. 2018), the estimation of snowfall could be overestimated.

In our study WRF appears to reproduce regional differences in glacier mass balance compared to previous studies. Critical is the high spatial resolution as shown in Bonekamp et al. (2018), Collier \& Immerzeel (2015), Groos et al. (2017). The spatial resolution of the model is also important to explicitly resolve local conditions at the glaciers, especially outside the Karakoram region, where relatively small glaciers are present. However, results in this paper exclude the smallest glaciers, due to the grid spacing of $1 \mathrm{~km}$. In general catchments and glaciers are larger in the Karakoram than in central Himalaya, and we note that the differing catchment sizes of Shimshal and 
Table 4.2: Overview of selected mass balance studies in the Karakoram.

\begin{tabular}{lll}
\hline \hline Study & Glacier mass balance $\left(\mathrm{m}\right.$ w.e. $\left.\mathrm{yr}^{-1}\right)$ & Years \\
\hline Gardelle et al. (2012) & $0.11 \pm 0.22$ & $2008-2010$ \\
Brun et al. (2018) & $-0.03 \pm 0.07$ & $2000-2016$ \\
Kääb et al. (2015) & $-0.10 \pm 0.06$ & $2003-2008$ \\
Gardner et al. (2013) & -0.12 to 0.3 & 2003 to 2009 \\
Bolch et al. (2017) & $0.03 \pm 0.22$ & 1999 to 2009 \\
Groos et al. (2017) & -0.92 & $2010-2011$ \\
\hline \hline
\end{tabular}

Langtang may impact the altitudinal gradients presented. Nonetheless, our results are consistent with previous studies that investigate the Karakoram anomaly and show the importance of winter snow accumulation (Archer \& Caldeira, 2008), lower summer temperatures and more (solid) summer precipitation (Fowler \& Archer 2005) and less net radiation (de Kok, 2018) that favour the Karakoram anomaly. Unfortunately, our study does not provide data with which any of these hypotheses could be tested due to the time frame.

A limitation of our work is that we only take clean ice glaciers into account and therefore the melt could be overestimated assuming the debris has a net insulating effect. However, the role of this insulation in debris-covered glaciers is still unclear, since the two types of glaciers seem to experience very similar melting rates (Pellicciotti et al. 2015; Brun et al. 2018). Currently, there are two hypotheses that try to explain the relatively high melting rates in debris-covered glaciers: the first is that high-melt rates at ice cliffs compensate for the low-melt rates averaged over the debris covered tongues (Pellicciotti et al. 2015). The second hypothesis is that debris-covered glacier tongues have a lower emergence velocity than clean-ice glacier tongues, whereby the similar thinning rates between the two types of glaciers are observed, while melt rates are lower at debris-covered glaciers (Anderson \& Anderson 2016).

\subsubsection{WRF caveats}

A major mass input of glaciers is caused by snow-avalanching, especially in the Karakoram region (Hewitt 1994). Although avalanching is not incorporated in WRF, we still see a positive mass balance in this region, and we conclude glaciers behave differently, even without the avalanching effect. Avalanching would also redistribute snow to lower altitudes, and could bias the simulated glacier mass balance from WRF to high altitudes. To make a better glacier mass balance 
estimation, glacier accumulation area outlines should be included to estimate the snow accumulation available from avalanching.

Snow drift and wind-blown redistribution of snow are also a major contributor to the glacier mass balance (Dadic et al. 2010), and are not taken into account in WRF. Similarly. WRF does not include glacier flow, but since glacier extents are not likely to change significantly within a threeyear period, we do not expect large uncertainties, as we consider all glacier cells in the domain.

There are also uncertainties in the treatment of glacier surfaces in the Noah-MP land-surface model. The main issue is the imposition of a minimum snow depth on glaciers often leads to an overestimate of albedo during the ablation season, which impacts local meteorological conditions on the glaciers (e.g., Collier et al. 2013). The treatment of glaciers as fully saturated and fully frozen soil surfaces in the Noah family of land-surface models is a simplification but has been found to produce reasonable simulations of glacier surface energy and mass fluxes (Mölg and Kaser 2011).

In our approach, we also assume an unlimited amount of water is available for (re)freezing of water, while in reality the refreezing process will be water-limited, especially during dry and cold periods, when there is no melt and no precipitation. In WRF, a cold bias is common at high altitudes (e.g., Bonekamp et al. 2018) and will likely influence the amount of snowfall and of melt of glacier surfaces and snow. Both issues likely bias the mass balance positively. The total simulation period of three years also gives a limited view of the interannual variability and averages presented, since those three years do not represent a climatological period. Furthermore the study period is too short to assess climatic trends that might have caused Karakoram anomaly, and/or glacier mass loss in Nepal.

Several studies have validated the performance of WRF for the Langtang region (e.g. Bonekamp et al. 2018, Collier and Immerzeel 2015), however direct observations of high-altitude precipitation are sparse and satellite derived products are of insufficient resolution and quality to capture spatial variation and the magnitude of mountain precipitation (Immerzeel et al. 2015). It is therefore difficult to draw quantifiable conclusions about potential biases at high altitude.

\subsubsection{Climate sensitivity}

The annual average temperature in Shimshal is low and the catchment is therefore likely more sensitive to future precipitation rather than temperature shifts. However, with increasing air temperatures, the air can hold more moisture and therefore potentially more precipitation can occur, which favour a positive mass balance (Kapnick et al. 2014). Furthermore, our results show 
that the longwave radiation is the dominant driver of the variations in the melt signal in Langtang. Hence, besides a decrease in mass balance due to a rise of the equilibrium line altitude, glaciers in Langtang will likely show an enhanced sensitivity to temperature due to the increase in incoming longwave radiation.

Currently, snow events are only sporadic during the melt season in Shimshal (Mayer et al. 2014), leading to lower surface albedo and more energy available for melt compared with Langtang. However, these summer snow events also input mass, reduce the amount of sunshine hours, and increase the albedo (de Kok et al. 2018; Hewitt 2005). This implies that a change in the number of summer snow events in Shimshal could influence the melt through several processes, with an increase supporting positive mass balance conditions. In contrast, slight changes in summer precipitation amounts affect the melt only marginally in Langtang, since the frequent summer snowfall already results in a high albedo. Hence, the sensitivity of the glacier melt to summer precipitation is higher in Shimshal than in Langtang.

Eventually, changes in large-scale forcings, such as westerly winds, will explain the glacier response only partly, since different glaciers will respond differently to identical changes in external conditions. We have shown that the glacier response is very different in Shimshal and Langtang, owing to a very different distribution of the energy balance. The climate system is complex and each component in it will adapt, aiming for a new equilibrium.

\subsection{Conclusions}

Understanding regional differences of meteorological variables at the catchment scale is key to understand the heterogeneous behavior of glaciers in High Mountain Asia. In this study, we modelled at 25, 5 and 1-km grid spacing two catchments in contrasting climate regions: the central Himalaya and the Karakoram. We show at high-resolution that climate and glacier behavior is spatially highly variable between the Karakoram and the central Himalaya, and that the accumulation and melt dynamics of both regions are different as a result of contrasting meteorological conditions. The interpretation of their impact on the glacier energy and mass fluxes and the elucidation of differences between catchments is novel. To our knowledge, this is the first multi-year simulation at 1-km resolution for regional comparison of catchments in High Mountain Asia and gives a unique data set to investigate catchment-scale atmospheric processes. Glacier melt is highly variable between years in the Karakoram and its variability is primarily driven by the net shortwave radiation $(r=0.79 \pm 0.01)$, with only limited cloud cover during the melt season. The surface albedo variability drives melt variation, and is strongly influenced by summer snow events in the Karakoram region. The number of snow events during the melt 
season is more important than the total amount of snow to increase the albedo and thus reduces energy available for melt. This indicates that if the frequency of summer precipitation events will increase in the Karakoram in future due to, for example, a stronger summer Indian monsoon, this will favour the mass balance of Karakoram glaciers. In Shimshal, the latent heat flux also plays an important role in extracting energy from the surface during the comparatively dry conditions during summer. Conversely, in the central Himalaya, variability in glacier melt is driven primarily by net longwave radiation $(r=0.76 \pm 0.02)$, as both high- and low-level clouds dominate the weather during the melt season. This indicates that glaciers in the central Himalaya have an additional sensitivity to air temperature, since the melt signal is dominated by the net longwave radiation (specific humidity, clouds).

In the Karakoram, there is an additional sensitivity to summer precipitation by means of the albedo increase and summer cloudiness. The precipitation sensitivity differs between the Karakoram and the central Himalaya, due to the different precipitation gradients and dominant precipitation type. Although the precipitation sensitivity of glaciers is usually less than the temperature sensitivity (Anderson \& MacKintosh 2012), this might not be the case for Karakoram and summer precipitation.

To understand glacier response to atmospheric conditions a detailed insight into the accumulation and ablation regimes is required and is for the first time done in this study for two contrasting sites in HMA. We show glaciers behave differently in central Himalaya and the Karakoram region, and that the glacier mass balance is sensitive to both the residual flux of the energy balance and snowfall. Annually, $1.26 \pm 0.12 \mathrm{~m}$ w.e. snowfall in Shimshal occurs compared with $0.91 \pm 0.15 \mathrm{~m}$ w.e. in Langtang. The residual energy available for melt is lower in Shimshal ($0.95 \pm 0.13 \mathrm{~m}$ w.e. $\left.\mathrm{y}^{-1}\right)$ compared with Langtang $\left(-1.31 \pm 0.07 \mathrm{~m}\right.$ w.e. $\left.\mathrm{y}^{-1}\right)$, resulting in positive and negative simulated surface mass balance in Shimshal $\left(+0.31 \pm 0.06 \mathrm{~m}\right.$ w.e. $\left.\mathrm{y}^{-1}\right)$ and in Langtang ($0.40 \pm 0.09 \mathrm{~m}$ w.e. $\mathrm{y}^{-1}$ ), respectively.

Our research implies that the sensitivity of glaciers to climate change is regionally driven and future work could map regions of sensitivity to different components of the energy balance and meteorological forcing fields. This will give a more detailed insight into glacier behavior under climate change, as not all glaciers behave similarly to rising temperatures. Understanding glacier mass balance anomalies requires quantification and insight in subtle shifts in the energy balance and accumulation regimes at high altitude.

\section{Acknowledgements}

This project has received funding from the European Research Council (ERC) under the European 
Union Horizon 2020 research and innovation program (Grant Agreement 676819) and the Netherlands Organization for Scientific Research under the Innovational Research Incentives Scheme VIDI (Grant Agreement 016.181.308). E. Collier was supported by the German Research Foundation (DFG) Grant MO 2869/1-1. Supercomputing resources were financially supported by NWO and provided by SURFsara (www.surfsara.nl) on the Cartesius cluster. The data are available at https://doi.org/10.5281/zenodo.2611581 (Langtang) and https://doi.org/10.5281/zenodo.2611323 (Shimshal).

\section{Author contribution}

PB and WI designed the study. PB performed the simulations and performed the analysis with input of WI, RK and EC. PB wrote the initial version of the manuscript. RK, EC and WI commented on the initial manuscript and helped improving this version. 


\section{Using large ensemble modelling to derive future changes in mountain specific climate indicators in a $2{ }^{\circ} \mathrm{C}$ and $3{ }^{\circ} \mathrm{C}$ warmer world in High Mountain Asia}

Natural disasters in High Mountain Asia (HMA) are largely induced by precipitation and temperatures extremes. Precipitation extremes will change due to global warming, but these low frequency events are difficult to analyse using (short) observed time series. In this study we analysed large 2000 year ensembles of present day climate and of a $2{ }^{\circ} \mathrm{C}$ and $3{ }^{\circ} \mathrm{C}$ warmer world produced with the EC-EARTH model. We performed a regional assessment of climate indicators related to temperature and precipitation (positive degree days, accumulated precipitation, (preand post-) monsoon precipitation), their sensitivity to temperature change and the change in return periods of extreme temperature and precipitation in a 2 and $3{ }^{\circ} \mathrm{C}$ warmer climate. In general, the $2{ }^{\circ} \mathrm{C}$ warmer world shows a homogeneous response of changes in climate indicators and return periods, while distinct differences between regions are present in a $3{ }^{\circ} \mathrm{C}$ warmer world and changes no longer follow a general trend. This non-linear effect can indicate the presence of a tipping point in the climate system. The most affected regions are located in monsoondominated regions, where precipitation amounts, positive degree days, extreme temperature, extreme precipitation and compound events are projected to increase the most. Largest changes in climate indicators are found in East Himalaya, followed by the Hindu Kush and West and

Chapter published as:

P.N.J. Bonekamp, N. Wanders, K. van der Wiel, A.F. Lutz, W.W. Immerzeel, Using large ensemble modelling to derive future changes in mountain specific climate indicators in a $2{ }^{\circ} \mathrm{C}$ and $3{ }^{\circ} \mathrm{C}$ warmer world in High Mountain Asia, Intern. Journal of Climatology, 1-16, doi:10.1002/joc.6742 
Central Himalaya regions. In general the western regions will experience drier summers and wetter winters, while the monsoon dominated regions drier winters and wetter summers and Northern regions a wetter climate year round. We also found that precipitation increases in HMA in a $3{ }^{\circ} \mathrm{C}$ warmer world are substantially larger (13\%) compared to the global average (5.9\%). Additionally, the increase in weather extremes will exacerbate natural hazards with large possible impacts for mountain communities. The results of this study could provide important guidance for formulating climate change adaptation strategies in HMA.

\subsection{Introduction}

High Mountain Asia (HMA) is home to the largest reservoir of fresh water outside the poles and 10 major river basins originate in this region. The largest water towers of the world can be found here, of which many are extremely vulnerable to climate change (Immerzeel et al., 2019). In total 1.9 billion people are dependent on the rivers' water resources for irrigation, domestic use and hydropower (Wester et al., 2019), and water demand will further increase in the future (Biemans et al., 2019; Wijngaard et al., 2018).

A global average temperature rise of $1.5{ }^{\circ} \mathrm{C}$ compared to preindustrial levels implies $2.1{ }^{\circ} \mathrm{C}$ warming in HMA (Kraaijenbrink et al., 2017) and extreme scenarios would even result in a regional temperature rise up to $5.8^{\circ} \mathrm{C}$ (RCP 8.5; Lutz et al., 2018). Even if the ambitious target of $1.5{ }^{\circ} \mathrm{C}$ is met, one third of the glacier ice volume would melt by the end of the century (Kraaijenbrink et al., 2017). Because of the buffering role of the cryosphere, glacier and snow melt currently contribute $60 \%$ of the water used for irrigation in the Indus during the premonsoon season (Biemans et al., 2019). A decrease in melt water availability could therefore have significant implications for agricultural production, hydropower production, and human health. Asia has the largest occurrence of natural disasters globally largely caused by hydrometeorological events. In Asia in the period 2000-2008 $52.3 \%$ of economic damages is caused by meteorological disasters (Vos et al., 2010)

Understanding the effect of climate change on the magnitude and return periods of extreme precipitation and temperature events is important for assessing impacts on hydropower production and occurrence of natural hazards such as floods, land slides, glacier lake outburst floods and debris flows in HMA (Lutz et al., 2013; Tariq et al., 2014). Natural risk is the interplay between weather hazards, vulnerability and exposure of people, infrastructure and the environment. Extreme weather causes a weather hazard (e.g. landslide or flood) when something or someone is exposed to this hazard and is vulnerable (Aznar-Siguan and Bresch, 2019). Extreme 
events are normally studied by analysing long time series or by modelling the tail of the distribution with a statistical approach or extrapolation. Both approaches have limitations as current observational records are short (van der Wiel et al., 2019). Consequently the statistical significance of results decreases with increasing return periods and often relies on an assumption of stationarity. Furthermore, when extrapolating the tail of the observational record, assumptions are made regarding the distribution of extremes, which is uncertain for events with a high return period and might change in a future climate.

In order to attribute specific events to climate change, natural climate variability should be disentangled from human-induced climate change. This is challenging as both processes together dynamically drive specific weather events (Trenberth et al., 2015; Hauser et al., 2017). Another method to investigate future weather is to analyse how specific current day (extreme) events will change in the future (Hazeleger et al., 2015). This approach provides important insights in how climate may amplify specific extreme events, however such an approach cannot be used as a probabilistic projection.

An approach to overcome problems with non-stationarity and limited sample size in CMIP model simulations, is to use GCMs (general circulation model) to generate long time-series of weather variables given a fixed anthropogenic forcing, by perturbing the boundary conditions. This method called large-ensemble climate simulations can provide long time series of extreme events in a changing climate and thus provide a unique opportunity to statistically quantify extreme events with a low recurrence interval. In this study we use the large ensemble modelling method in HMA to analyse extreme events using a 2000 year simulation for present and for a $2{ }^{\circ} \mathrm{C}$ and 3 ${ }^{\circ} \mathrm{C}$ warmer world respectively (van der Wiel et al., 2019).

In this study we focus on analysing differences between the present-day climate and the $2{ }^{\circ} \mathrm{C}$ and $3{ }^{\circ} \mathrm{C}$ warmer world for several climate indicators that control the cryosphere (glacier and snow melt and snow fall). In addition, we analyse differences in extreme precipitation and temperature, which are the key drivers for natural hazards such as landslides, avalanches and floods. This work can provide important guidance for formulating climate change adaptation policies.

\subsection{Methods}

In order to quantify meteorological extremes, data from three large ensembles were analysed: for present day climate (PD) and for a two degrees $(+2 C)$ and three degrees $(+3 C)$ warmer world. 
The large ensembles are performed with the fully coupled EC-EARTH global climate model v2.3 (Hazeleger et al., 2012). The EC-Earth model configuration is the same as in CMIP5 (Coupled Model Intercomparison Project phase 5, (Taylor et al., 2012). The ensembles represent three climatic periods with different global mean surface temperature. The present day ensemble has a global mean surface temperature equal to the observed temperatures in the period 2011-2015 (James et al., 2017; van der Wiel et al., 2019). The $+2 C$ and $+3 C$ ensembles have a global mean surface temperature with 2 and $3{ }^{\circ} \mathrm{C}$ increase relative to the pre-industrial period (1851-1899).

To generate the large ensembles, a combination of differing initial conditions and atmospheric perturbations was used. Initial conditions were provided by sixteen long transient RCP8.5 simulations (1860-2100). From each of these simulations 25 members were branched off, in which atmospheric perturbations were introduced by means of stochastic parameterisations (Buizza et al., 1999). Each member was integrated for five years, we assume no climate change effects occur in this five year period. The large ensembles thus consist of $16 \times 25 \times 5=2000$ years of simulated data. As noted, the five year simulation period for each large ensemble was chosen based on a target mean value of global mean surface temperature in the original transient RCP8.5 simulations (extensive details are provided in the supporting information of van der Wiel et al., 2019). The dataset has a global coverage with a spatial resolution of $1.1^{\circ}$ and has been used before to assess extreme river discharge under $+2 \mathrm{C}$ global warming (van der Wiel et al., 2019) and extreme heat occurrence in India (Nanditha et al., 2020).

Precipitation was bias-corrected and downscaled to a 0.5 degree spatial resolution using statistical bias-correction and bicubic spatial downscaling. Precipitation is adjusted for drizzle, which is a common problem in global circulation models (Dai, 2006) and can have significant implications when analysing droughts and dry spells when not corrected. The monthly accumulated precipitation of EC-Earth for each grid cell is matched with monthly sums and the number of wet days in ERA-INTERIM for the present day simulations. These correction factors of wet bias cut off and volume are then linearly interpolated between months to avoid sudden shifts in bias-corrected precipitation. Afterwards, the average daily interpolated correction factors are applied to the two and three degrees warmer large ensembles assuming the model bias in ECEARTH is stationary in time and space under global warming. This bias correction is applied stationary in time, however its real behaviour for the future is unknown and could be more complex

Temperature was also bias corrected and downscaled with ERA-INTERIM data on a pixel level to 
produce a 0.5 degree dataset. A statistical bias-correction allows for elevation corrected downscaling that ensures that monthly statistics of the present day period match the ERAINTERIM monthly averages. By taking the high-resolution temperature distribution from ERAINTERIM we can estimate the sub-pixel distribution for each EC-EARTH cell and correct for regional temperature gradients. Following the same procedure as for precipitation, we linearly interpolate the monthly correction factors to a daily temporal resolution. All analyses in this paper are performed with the bias-corrected, downscaled meteorological datasets using the daily temporal resolution of the simulations.

\subsubsection{Climate indicators}

Various climate indicators are analysed to identify sensitive regions in HMA, which either are important for cryospheric processes, monsoon water supply and/or extremes:

1. Positive degree days (PDD): the annual sum of positive degrees $\left(T>{ }^{\circ} \mathrm{C}\right)$ derived from daily mean temperature. The PDD sum is a measure of the glacier and snow melt potential.

2. Snow: accumulated precipitation for average daily temperature below $0{ }^{\circ} \mathrm{C}$. This indicator is important for glacier accumulation, as the total amount of snow controls the glacier accumulation.

3. Pre-monsoon precipitation: precipitation sum between 1 April and 1 June. During premonsoon irrigation is largely dependent on glacier and snow melt (up to 60\% in the Indus basin). Changes in precipitation during this season may compensate for a decrease in melt in the future.

4. Monsoon precipitation: precipitation sum between 1 June and 1 October. Glaciers in the Himalaya are characterized by synchronous ablation and accumulation regimes and a change in monsoon precipitation could have implications for the glacier mass balance. Secondly, shifts in monsoon strength exert a strong control on regional water availability.

5. Post-monsoon precipitation: precipitation sum between 1 October and 1 December. The post-monsoon is typically a dry season and precipitation changes in this shoulder season is important for agriculture and hydropower production.

6. $95^{\text {th }}$ percentile of temperature and precipitation: Extreme temperature and precipitation events, defined as the $95^{\text {th }}$ percentile values in the distributions of daily averaged temperature and precipitation values.

Extreme precipitation and temperature control landslides, avalanches, floods and heat waves.

7. Compound events: when both precipitation and temperature are higher than their $95^{\text {th }}$ percentile values in present day climate. Extreme events with both high precipitation 
amounts and temperature have implications for natural hazards such (melt) water floods and avalanches.

Return periods are calculated using the 2000 year empirical distribution for precipitation and temperature for the $\mathrm{PD}, 2 \mathrm{C}$ and $3 \mathrm{C}$ scenarios. For the analysis we use the same regional subdivision as used for the Randolph Glacier Inventory (rgi; RGI Consortium, 2017) (Figure 5.1). Positive degree days and accumulated solid precipitation are only calculated for glacier grid cells (RGI Consortium, 2017) or for grid cells that are snow covered for at least a month a year (Hall and Riggs, 2015).

\subsection{Results and discussion}

\subsubsection{Performance of EC Earth in HMA}

The complex topography in combination with a complex interplay of monsoon and westerly circulation systems affect the seasonality, amount and spatial distribution of precipitation in HMA. As a result, there is a very large spread between different commonly used gridded datasets (reanalysis, model simulations, satellite or gridded data sets; Palazzi et al., 2013). In the absence of station data it is therefore impossible to identify an optimal precipitation dataset to be used as a reference.

In order to validate the corrected EC-EARTH dataset in HMA the average annual cycle of temperature and precipitation of 5 year of TRMM (Huffman et al., 2007), GPM (Huffman et al., 2014), ERA5 data (Copernicus Climate Change Service, 2017; 2011-2015) and the bias corrected EC-EARTH are shown in Figure 5.2. Five years were selected because the present day EC-EARTH simulations are aimed to reflect the current climatology and thus comparing to a longer period would lead to inclusion of trends. By making a spatially aggregated evaluation of the HMA region, we reduce the effect of local extremes occurring in ERA5 in those years. For a region-specific comparison reference is made to Figure $\mathrm{C} 1$ in the supplementary material. Temperature in both datasets shows good agreement, and the simulated precipitation shows reasonable agreement. The observed precipitation bias in the bias corrected EC-EARTH dataset is $-54 \%$ and the temperature bias is $-0.3{ }^{\circ} \mathrm{C}$ compared to ERA5. GPM has a yearly precipitation sum bias of $-11 \%$ and TRMM 0\%. These biases are well within the range of uncertainty in temperature and precipitation over HMA. We therefore conclude that the seasonality of temperature and precipitation are captured satisfactory by EC-EARTH as was also found in a comparison study between ERA-INTERIM and (non bias-corrected) EC-EARTH in a similar region (Palazzi, et al., 2013). 


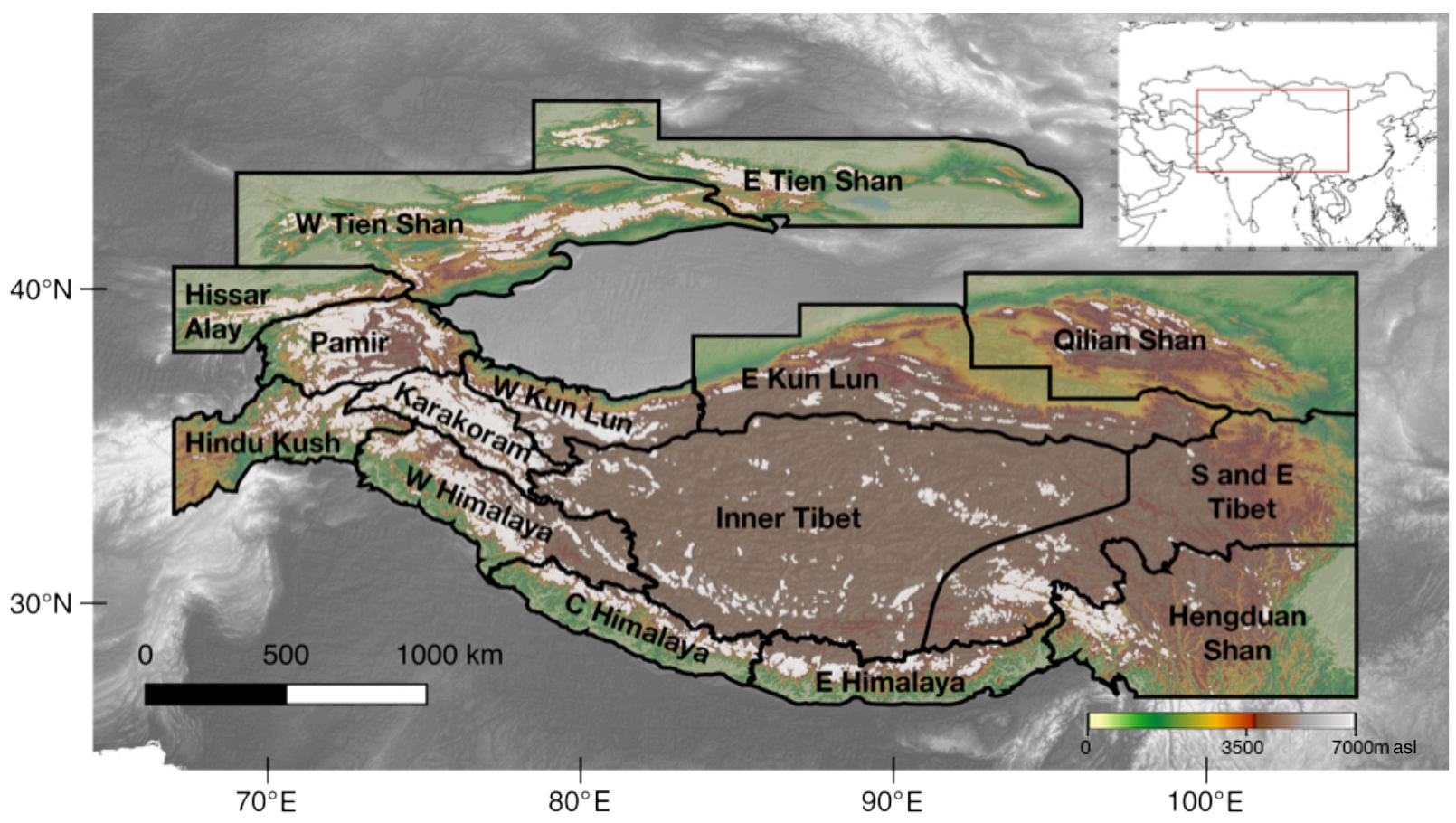

Figure 5.1: Regions for analysis with its topography and glaciers (white, rgi) with S=South, E=East, $W=$ west. 
The original EC-Earth is wetter compared to different satellite derived products (Palazzi et al., 2013), while the bias corrected EC-Earth data is well in line with the satellite products GPM and TRMM (Figure 5.2). Comparison between products is complicated as satellite products generally underestimate precipitation due to their spatial resolution and quality (Immerzeel et al., 2015). Since the bias-corrected EC-EARTH falls well within range of other gridded climate products and correctly captures the seasonality of precipitation we conclude that this product is suitable to use for climate impact studies in HMA.

\subsubsection{Changes in mean monthly temperature and precipitation}

Temperature rise is not uniform over the year and regional differences are present (Figure 5.3). The global mean surface temperature in a $2 \mathrm{C}$ warmer world is two degrees warmer compared with pre-industrial levels; hence the changes with regard to present day are logically less than 2 degrees.

Compared to the global average (1.5K, 3\% increase P), High Mountain Asia (1.5K, 5.2\% increase P) is projected to warm at a similar rate and is projected to become wetter in a $2 \mathrm{C}$ warmer world compared to present day climate. In a $3 \mathrm{C}$ warmer world regional differences become slightly more pronounced, with an average temperature rise of $2.9 \mathrm{~K}$ in HMA, while $2.7 \mathrm{~K}$ globally. Precipitation increases in HMA are substantially larger (13\%) compared to the global average (5.9\%). Regions with strongest precipitation increases are the Himalayas (23\%) and Hengduan Shan (21\%) regions.
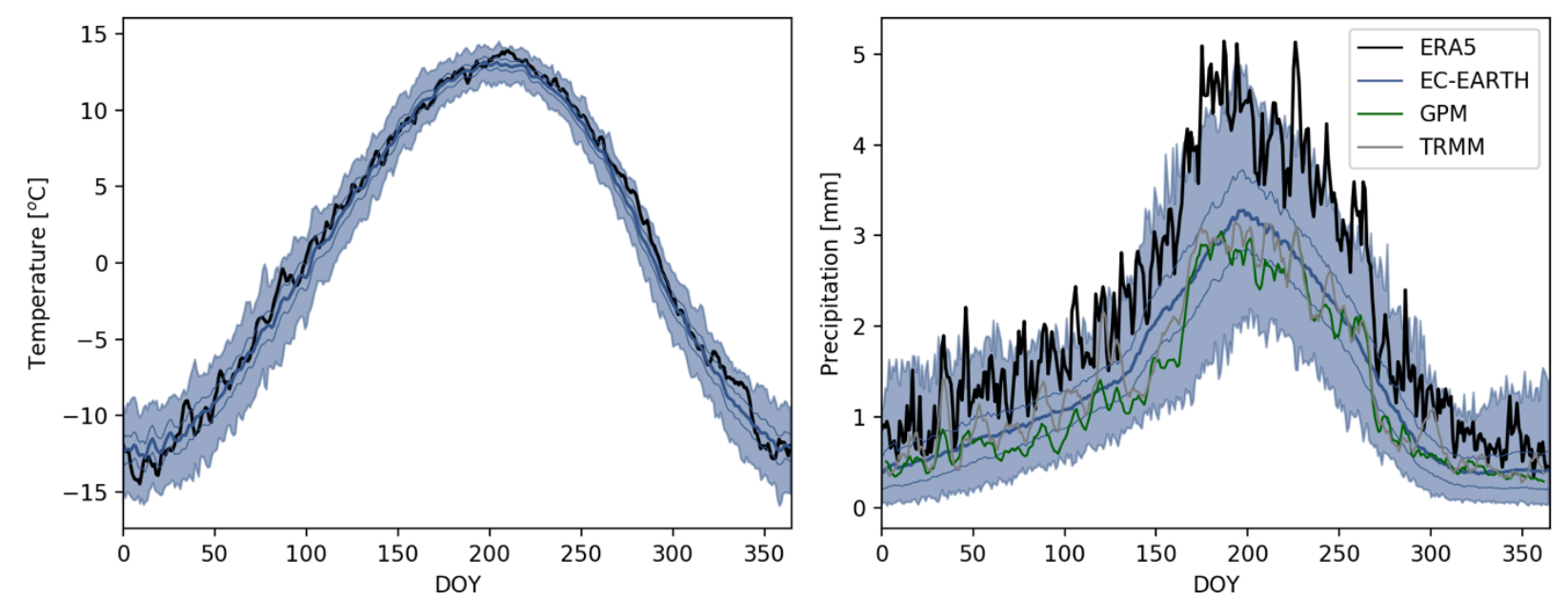

Figure 5.2: Average simulated daily temperature (left) and precipitation (right) for 2011-2015 for bias-corrected EC-EARTH (blue; 5-year average of 1000 times random selection of 5 years in the large ensemble) and ERA5 (black). The 5-year average ensemble represents the spread in outcomes of present day large ensemble. Blue shading indicates minimum and maximum values; the thin line is the standard deviation. 
The $2 \mathrm{C}$ warmer world shows a rather uniform warming in all regions (1.3K in Hengduan Shan to 1.7K in Hindu Kush), while the $3 \mathrm{C}$ warmer world shows distinct differences (1.4K in West Kun Lun and $5 \mathrm{~K}$ in East Himalaya). However, regional averages are shown and the temperature signal in West Kun Lun region for example is both negative and positive, resulting in a low regionally averaged temperature increase. A different sensitivity to processes causing elevation dependent warming can cause the differences per region (Pepin et al., 2015). The strongest warming rates can be found in the south-eastern regions (Himalayas, Hindu Kush and Hengduan Shan).

Elevation dependent warming is the phenomenon that the rate of warming generally increases with elevation and is caused by local mechanisms that amplify global warming. Important mechanisms are for example the snow albedo feedbacks and water vapour changes. The differences in the local importance of each of these individual mechanisms result in contrasting regional patterns to global warming. In our simulations we can study the differences in temperature for the different climates and therefore identity the regions with largest changes in climate.

Elevation dependent warming is not observed in all regions of HMA in a $2 \mathrm{C}$ or $3 \mathrm{C}$ warmer world, however in specific regions and seasons it is (Figure 5.3). This could be an indication that the mechanisms behind elevation dependent warming are indeed region and time specific. Coarse resolution would not explain this, since previous studies showed that elevation dependent warming is also resolved at coarse resolution, however the relative contribution of the driving mechanisms may differ in simulations with different spatial resolution (Rangwala et al. 2016; Palazzi et al., 2019). Physical processes contributing to elevation dependent warming include snow-albedo feedback, changes in clouds, sensitivity of downward longwave radiation to specific humidity and sensitivity of outgoing longwave radiation to surface temperature, aerosols and black carbon (Pepin et al., 2015). Those processes also interact and can compensate each other (Gao et al., 2018; Pepin et al., 2015). In a 3C warmer world elevation dependent warming is observed in the Hindu Kush, West Himalaya, Central Himalaya, East Himalaya, Hengduan Shan and Inner, South and East Tibet. In West and East Kun Lun some sub-regions experience a temperature decrease, indicating elevation dependent warming is non-linear and complex. Additionally to the physical processes, also changes in circulation (e.g. monsoon strengthening in Himalayas) and snow cover changes (e.g. Tibet) play an important role in elevation dependent warming. 
For precipitation we observe an overall wetting of High Mountain Asia between present day and a $2 \mathrm{C}$ and $3 \mathrm{C}$ warmer world. We also observe contrasting seasonal and regional signals. For example, the monsoon is strengthening in the Himalayas, while precipitation during the winter is decreasing. As a result differences between the wet and dry seasons are increasing (Biemans et al., 2019; Lutz et al., 2014). Overall, the differences in precipitation between present day and the 2C and $3 \mathrm{C}$ warmer worlds are spatially more heterogeneous and more profound than the temperature signals.

The Hindu Kush monsoon precipitation is projected to increase most in a $3 \mathrm{C}$ warmer world, which could be linked to strengthening and further protruding of the monsoon (Li et al., 2010). In the north-western regions (Hissar Alay, Pamir, West Tien Shan and East Tien Shan) winter precipitation is projected to increase, while summer precipitation is projected to decrease. This is likely caused by an intensification or increased occurrence of intense cyclones in winter (Lambert, 1995) and the orographic effect that results in more precipitation at the leeward side of the mountains (e.g. the Hindu Kush mountain range). The decrease in precipitation in a $2 \mathrm{C}$ warmer world is likely caused by the reduced moisture transport from the Mediterranean or projected reduced monsoon circulation, while in the $3 \mathrm{C}$ warmer world the intensification of the monsoon circulation dominates (Christensen et al., 2013). This reversed signal is also found in model ensemble averages in the Upper Indus region, with a dominantly drying signal in 2071-2100 compared to 1971-2000 in rcp4.5, while a wettening signal in rcp8.5 (Lutz et al., 2016). Precipitation changes are not linear with global temperature rise; for example a drying trend during the monsoon months is simulated in a $2 \mathrm{C}$ warmer world in Hindu Kush, Karakoram and West Himalaya, while the same regions are projected to become wetter in a $3 \mathrm{C}$ warmer world.

The Clausius-Claperyon relation predicts an increase in precipitation of $6.5 \% \mathrm{~K}^{-1}$ if precipitation is not constrained by the amount of moisture or energy (Allen and Ingram, 2002; Held and Soden, 2006; Trenberth et al., 2003). Most climate models predict a global mean increase in precipitation of 1-3 \% K $\mathrm{K}^{-1}$ (Allen and Ingram, 2002; Boer, 1993). In this study we found a global mean precipitation increase of $2 \% \mathrm{~K}^{-1}$, which is in line with the global CMIP projections. The precipitation increase in $\mathrm{HMA}$ is however between 3.5-4.6 \% $\mathrm{K}^{-1}$, which is much closer to the theoretical Clausius-Clapeyron value. The high moisture availability and high temperatures during the monsoon season likely cause the strong precipitation increase with temperature in HMA. 

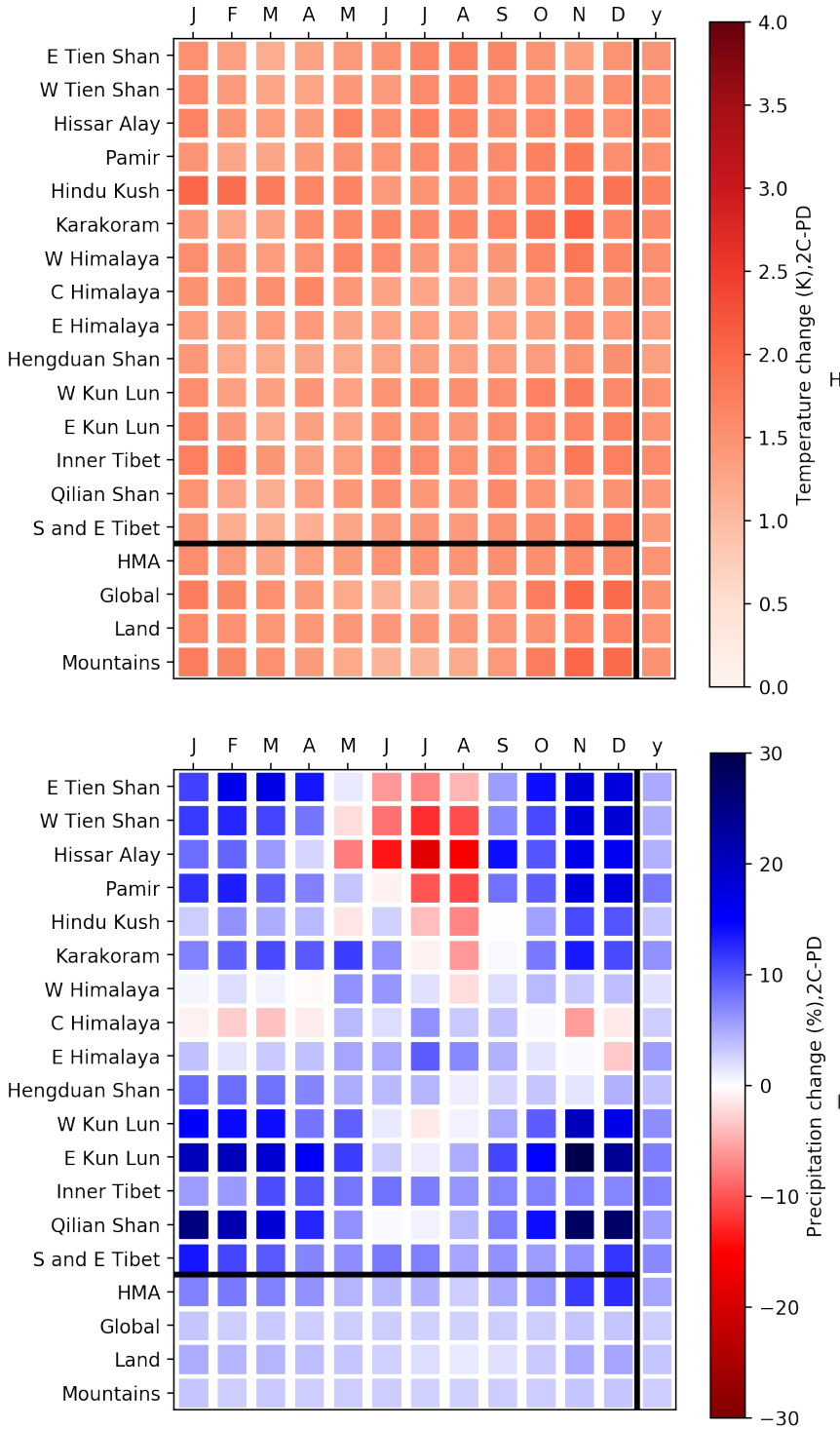
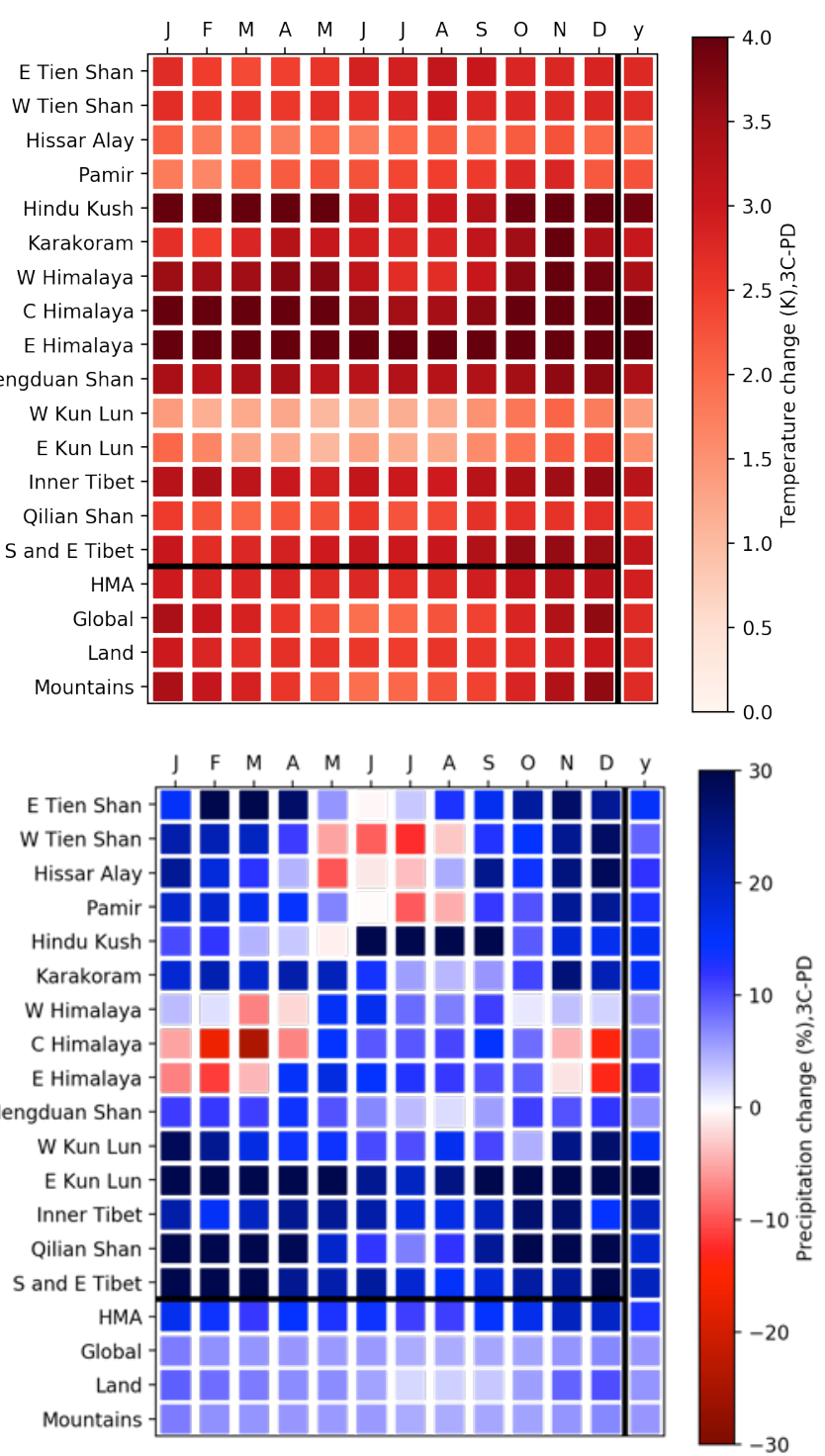

Figure 5.3: Temperature (upper panels) and precipitation (lower panels) anomalies for the $2 \mathrm{C}$ (left panels) and 3C (right panels) warmer world compared to present day climate. Columns indicate the individual months, and y=year average, rows indicate the region. Mountains are defined as all grid cells above $1500 m$ (global). 


\subsubsection{Return periods of temperature and precipitation}

Mean temperature and precipitation are increasing due to global warming and likely return levels of extreme temperatures and precipitation too (Papalexiou and Montanari, 2019; Figure 5.4). Overall, the patterns in extremes are indeed in line with the annual trends in temperature and precipitation, where extreme temperatures and more intense precipitation events occur more frequently in a $2 \mathrm{C}$ and $3 \mathrm{C}$ warmer world compared to present day climate. The largest changes in return periods of daily averaged temperature extremes are observed in the southern regions and southern part of the Tien Shan region. Extreme precipitation is mostly changing in monsoondominated areas and higher elevated regions such as the Pamir and Karakoram. Interesting is that return periods of the most extreme events ( 1 in 100 years) change more rapidly than less extreme return periods. Strengthening of the monsoon is causing the increase in precipitation extremes in the monsoon areas (see Section 5.3.4), while in higher elevated areas the increased moisture capacity effect in combination with the orography plays a role. Additionally a more erratic precipitation distribution can cause the increase in precipitation extremes (Krishna Kumar et al., 2011; Sharmila et al., 2015).

Return periods of daily averaged temperature show large spatial differences in South-Eastern HMA, where present day 1:100 year events will change to multi-year events in a $3{ }^{\circ} \mathrm{C}$ warmer world (Figure 5.4). This increase in daily averaged temperature events is severe. We would like to stress that the return periods are calculated with the averaged daily temperature and return periods of daily maximum temperature would not follow the same trend by definition. In the Hindu Kush present day 1:100 year temperature events $\left(25^{\circ} \mathrm{C}\right)$ will occur in a $3 \mathrm{C}$ warmer world 1:2 years, whereas in the Karakoram $\left(14^{\circ} \mathrm{C}\right) 1: 1$ years and in East Himalaya $\left(15^{\circ} \mathrm{C}\right)$ 1:0.02 years.

Return periods of daily precipitation sums show a similar spatial pattern as daily averaged temperature events but its absolute change in return periods is significantly less. This difference in response is caused by the variability of daily averaged temperature and daily precipitation sums. The empirical distribution estimate (Figure C2) of daily averaged temperature is relatively flat between return periods of 1 year and 100 years, resulting in large changes in return periods in a $2 \mathrm{C}$ and $3 \mathrm{C}$ warmer world. For example an event with a return period of 100 years in present day climate $\left( \pm 16{ }^{\circ} \mathrm{C}\right)$ will occur yearly in a $3{ }^{\circ} \mathrm{C}$ warmer world for that specific location. The extreme temperature events in a $3{ }^{\circ} \mathrm{C}$ warmer world are almost all higher than the most extreme values of present day temperatures, resulting in strong decreases in return periods with warmer climate. In the Hindu Kush present day 1:100 year precipitation events $\left(10 \mathrm{~mm}\right.$ day $\left.^{-1}\right)$ will occur in 

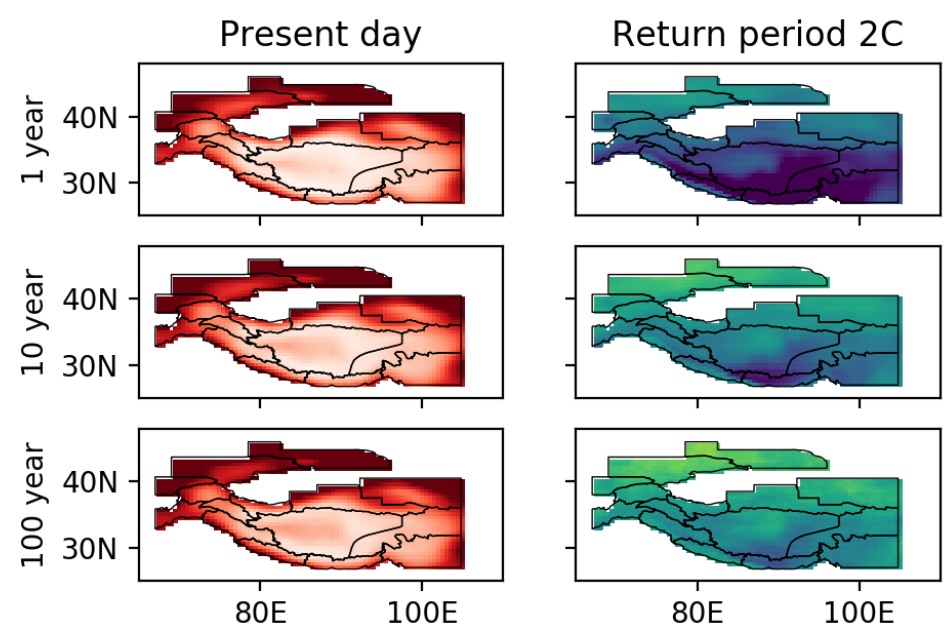

Return period 3C
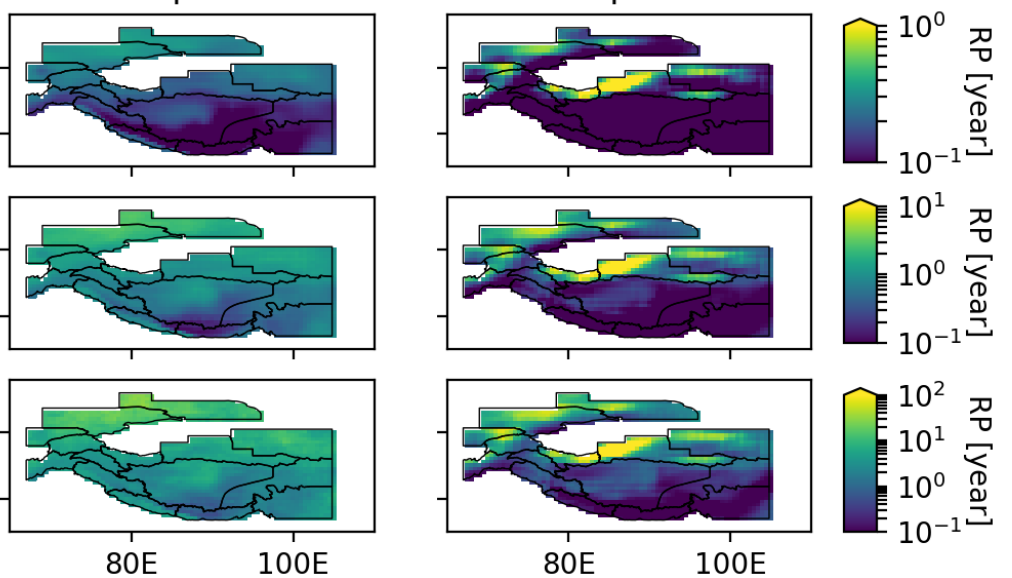

5.010 .015 .020 .025 .030 .0

$\mathrm{T}\left[{ }^{\circ} \mathrm{C}\right]$
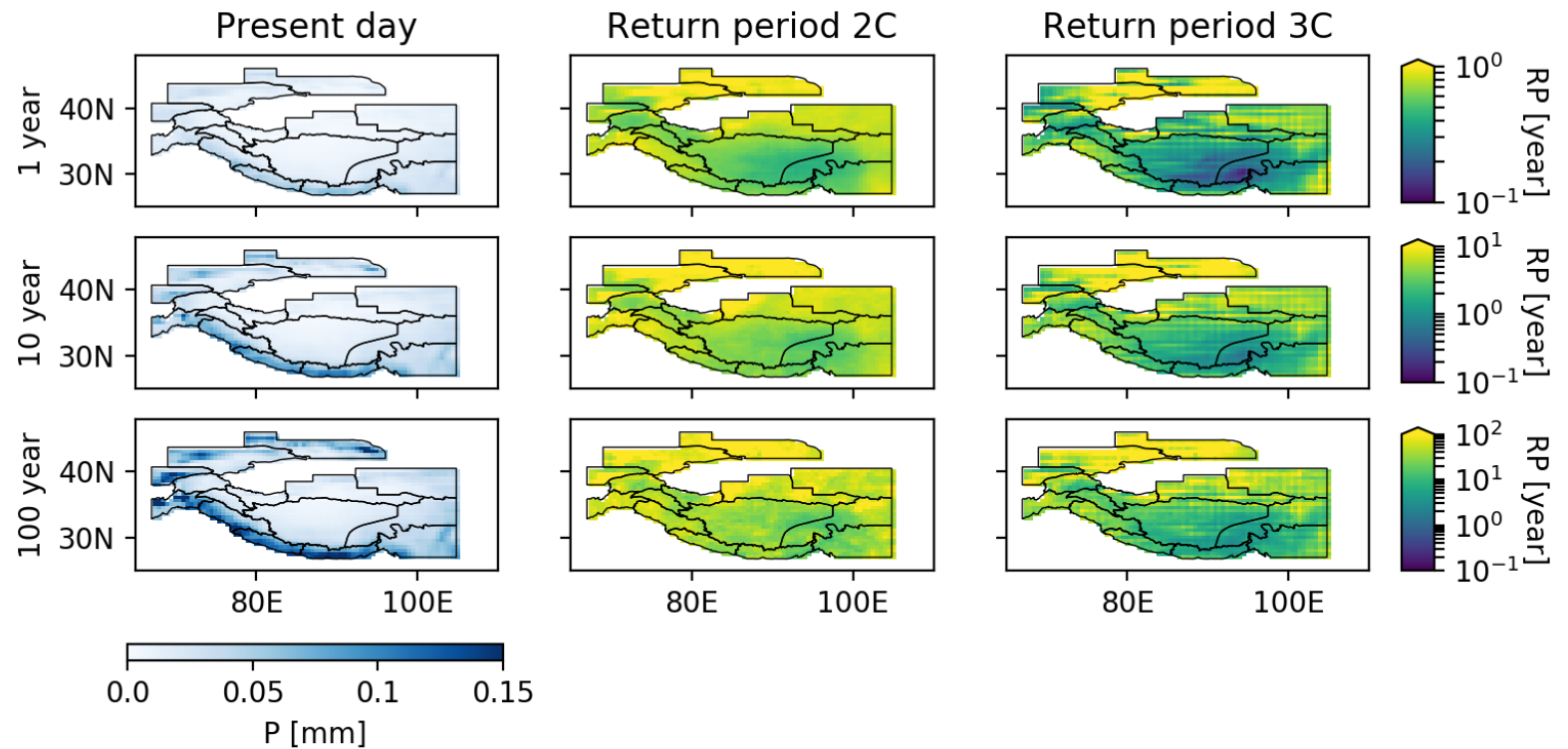

Figure 5.4: Daily averaged temperature and daily precipitation sums for different return periods (1,10 and 100 years) for present day climate (left panels) and its new return periods (RP) in a $2 \mathrm{C}$ (middle panels) and $3 \mathrm{C}$ warmer world (right panels). Please note the different colorbars for the new return periods. 
a $3 C$ warmer world 1:35 years, whereas in the Karakoram ( $3 \mathrm{~mm} \mathrm{day}^{-1}$ ) 1:19 years and in East Himalaya $\left(0.11 \mathrm{~mm} \mathrm{day}^{-1}\right)$ 1:8 years.

Overall, changes in return periods of precipitation extremes are largely homogeneous in a $2 \mathrm{C}$ warmer world, while regional differences are large in a $3 \mathrm{C}$ warmer world. This indicates that changes in return periods of temperature and precipitation are not linearly correlated with global temperature rise. For example, the change in return periods of temperature extremes in the south-western regions are only marginally affected in a $2 \mathrm{C}$ warmer world, while in a $3 \mathrm{C}$ warmer world those are heavily affected. As a consequence, this inhomogeneity will also lead to different regional changes in the number of natural hazards of for example landslides and flash floods. Detailed information of return periods is needed for an adequate prediction of extreme river discharge and likely has large consequences for the occurrence of floods and the production of hydropower.

\subsubsection{Mountain relevant climate indicators.}

Climate indicators reveal specific effects of global warming and can be used to study the regional sensitivity (of the cryosphere) to climate change. In Figure 5.5 changes in several mountain climate indicators, which are proxies for natural hazards and cryospheric change are shown for HMA.

The positive degree day (PDD) sum (Figure 5.5A) is a proxy for glacier melt and shows largest changes at the margins of HMA. It is interesting that relatively low-lying areas such as the southern part of HMA and Tien Shan show the strongest increasing trend. The snow-albedo effect can be of great importance in those areas, as strongest temperature changes are often found near the $0^{\circ} \mathrm{C}$ isotherm (Pepin and Lundquist, 2008).

Snowfall drives glacier accumulation (Figure 5.5B) and will decrease throughout HMA in a warmer world. Two effects are at play: a decrease in solid precipitation due to increasing temperatures and an increase in precipitation by the increased moisture holding capacity of the air at higher temperatures. The decrease in solid precipitation (Figure 5.5B) indicates that on a yearly basis the temperature effect is larger than the associated increase in total precipitation. The amount of solid precipitation (Figure 5.5B) is largest in the western regions, while largest changes can be found along the southern margin of the Himalayas. In the Karakoram, West Kunlun and Pamir regions minor changes are projected, which is in agreement with previous findings on the Karakoram anomaly (e.g. Farinotti et al., 2020). We note that the spatial resolution of EC-Earth is 
insufficient to capture valley-scale processes, such as small-scale orographically forced precipitation, which is important for the distribution of temperature, precipitation and wind over short horizontal distances in mountainous terrain (Bonekamp et al., 2018).

Pre-monsoon precipitation (Figure 5.5C) is expected to increase most in Central and East Himalaya, indicating an earlier onset of the monsoon. Changes are moderate in a $2 \mathrm{C}$ warmer world, while in a $3 \mathrm{C}$ warmer world a clear distinction is visible between the south-eastern regions (East Himalaya and Hengduan Shan and Southern Tibet) and the other regions. This is in correspondence with observed increases in pre-monsoon precipitation during last decades (Brunello et al., 2019).

Monsoon precipitation (Figure 5.5D) is gradually intensifying in a $2 \mathrm{C}$ warmer world, while in a $3 \mathrm{C}$ warmer world a more heterogeneous pattern is visible, with distinct maxima in the Hindu Kush and East Tien Shan. The post monsoon precipitation changes (Figure 5.5E) are largest in the north-western regions in a $2 \mathrm{C}$ warmer world, while in a $3 \mathrm{C}$ warmer world also in changes in East Himalaya, Hengduan Shan and South Tibet are substantial. Precipitation will increase in (pre- and post-) monsoon.

The change in the $95^{\text {th }}$ percentile of temperature (Figure $5.5 \mathrm{~F}$ ) will be largely homogeneous in a 2C warmer world, but spatially variable in a $3 \mathrm{C}$ warmer world. The pattern of the present day temperature extremes is similar compared to the pattern of PDD, however the changes are not. Extreme temperatures change most in moderate temperature regimes (e.g. southern flanks of the Himalayas and Tien Shan) and change least in areas with high temperature extremes (e.g. Hissar alay, Tien Shan). Interesting is the projected decline in temperature extremes in East and West Kunlun Shan, where also glaciers with stable or positive mass balance are found (Brun et al., 2017).

Extreme precipitation (Figure 5.5G) increases absolutely the most in monsoon regions, and agrees with the intensification of the monsoon circulation (Figure 5.5D). The monsoon intensification and monsoon region expansion also result in an increase in events where extreme temperature and extreme precipitation coincide (Figure $5.5 \mathrm{H}$ ). Regions outside the monsoondominated areas generally receive their precipitation extremes in winter and their temperature extremes in summer. As a result, compound events are less common outside monsoondominated regions and therefore also less likely to change. 

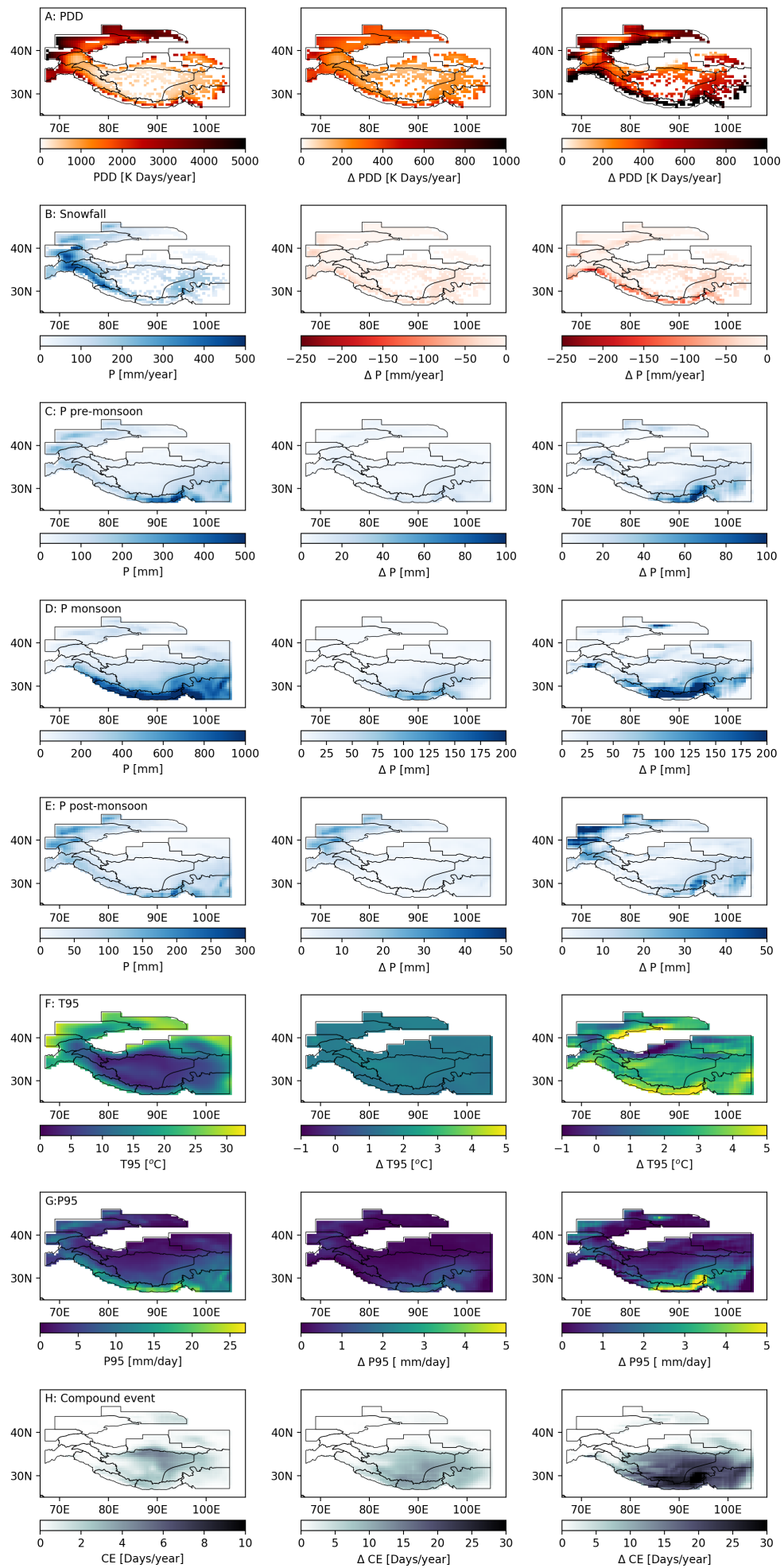

Figure 5.5: The different climate indicators for present day climate (left panels) and the anomaly of the $2 \mathrm{C}$ (middle panels) and $3 \mathrm{C}$ (right panels) warmer world compared to present day climate. Positive degree days and solid precipitation are only shown for glacier and/or snow covered areas for at least one month a year. Panel $A=$ positive degree days, $B=$ snowfall, $C, D, E=$ precipitation in pre-monsoon, monsoon and post-monsoon, $F$ and $G=95^{\text {th }}$ percentile of temperature and precipitation, $\mathrm{H}=$ compound events ( $95^{\text {th }}$ percentile of temperature and precipitation). 

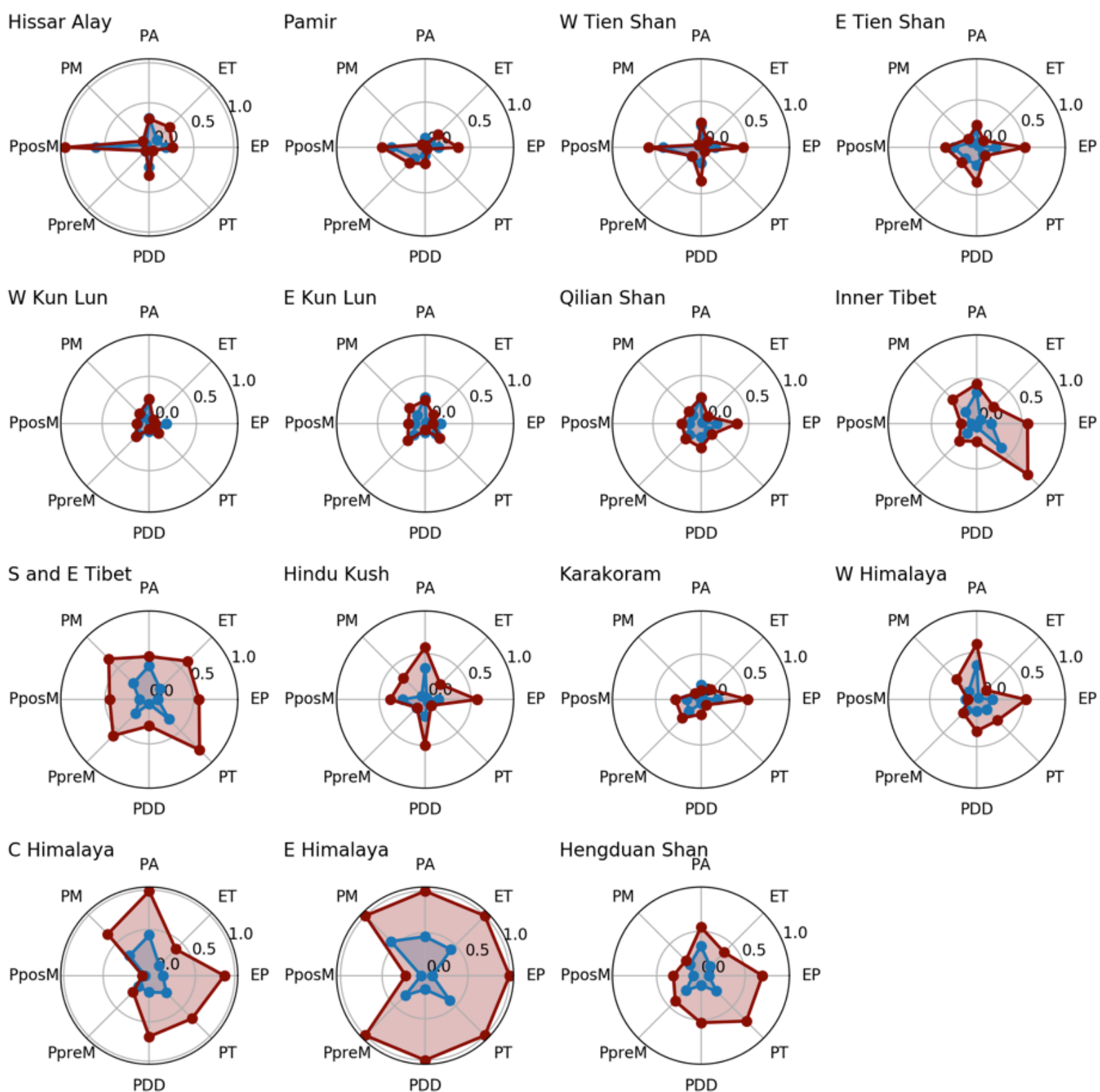

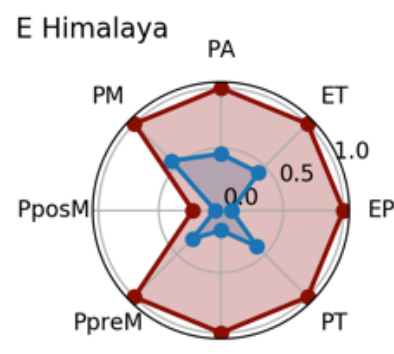

PDD Hengduan Shan

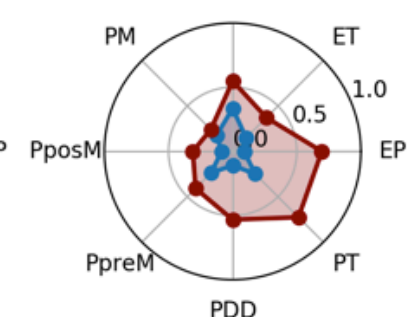

Figure 5.6: Regional summary of change in climate indicators compared to present day, normalized by the 3 degrees warmer world. Each climate indicator is normalized by the maximum regional value: a value of 1 for a specific region and climate indicator means this climate indicator

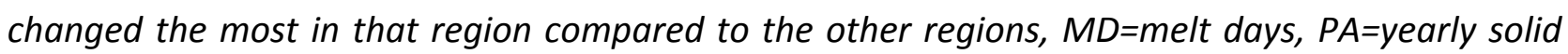
precipitation sum, PpreM=precipitation during pre-monsoon, $P M=$ monsoon precipitation, Ppos $M=$ precipitation during post-monsoon, $P D D=$ positive degree days, $E P=e x t r e m e$ precipitation (P95), ET extreme temperature (T95), PT=compound event when both precipitation and temperature exceed the present day 95\% percentile. The climate indicator change between $2 \mathrm{C}$ and present day is indicated in blue, the change between $3 \mathrm{C}$ and present day in red. Data are aggregated using all cells in a region, except for PDD and PA, where only glacier and/or snowcovered (at least one month a year) cells are considered. 
Our results are in accordance with Jury et al. (2019), who downscaled a climate model ensemble in order to assess the model uncertainty in 2-m temperature, positive degree day, accumulated precipitation and precipitation rate. They also found a decrease in solid precipitation, increase in monsoon precipitation and a PDD increase in lower elevated areas.

East Himalaya shows the strongest changes in all climate indicators, except the post-monsoon precipitation (Figure 5.6). Other regions with large changes are Tibet, C Himalaya, E Himalaya, Hindu Kush and Hengduan Shan. The Karakoram, Qilian Shan and East and West Kun Lun are regions with the least change. We also observe that climate indicators changes are non-linear. For example in East Himalaya, the post-monsoon precipitation increases only marginally, while the extreme precipitation increase is large. Also the boreal summer precipitation in the Pamir did decrease in a $3 \mathrm{C}$ warmer world compared to a $2 \mathrm{C}$ warmer world. This non-linear effect can indicate tipping point behaviour in the climate system, located between $2 \mathrm{C}$ and $3 \mathrm{C}$.

\subsubsection{DT sensitivity per region for the relevant indicators}

In Hengduan Shan and East Himalaya the pre-monsoon, monsoon and post-monsoon precipitation indicators change similarly, while in Central and West Himalaya the pre-monsoon precipitation changes more than the post-monsoon precipitation. In the $2 \mathrm{C}$ warmer world, changes in precipitation indicators are similar between the regions, while in a $3 \mathrm{C}$ warmer world changes become more distinct between the regions. Largest changes can be found in the monsoon-dominated areas and indicates that shifts in large-scale monsoon circulation are a key driver in this part of HMA.

Not all regions show a similar sensitivity to the regional temperature increase. For all climate indicators the spatial heterogeneity in temperature change is lower in the $2 \mathrm{C}$ warmer world than in a $3 C$ warmer world (Figure 5.7). In general, our results show that the climate indicators are positively correlated with the regional temperature increase. Only solid precipitation has a negative correlation with temperature. Lutz et al. (2018) found a linear relationship for similar climate indicators for downstream areas (Indus, Ganges, Brahmaputra).

Monsoon precipitation changes the most of the precipitation indicators. Note that the monsoon precipitation is a precipitation sum over four months, while the pre-monsoon and post-monsoon precipitation is accumulated over two months. The monsoon precipitation (+26 $\mathrm{mm} \mathrm{K}^{-1}$ or $5.4 \% \mathrm{~K}^{-}$

$\left.{ }^{1}\right)$ and pre monsoon (+6 $\mathrm{mm} \mathrm{K}^{-1}$ or $\left.2.0 \% \mathrm{~K}^{-1}\right)$ precipitation show a clear relation with different warming rates, while the post-monsoon precipitation shows a less clear and weaker signal ( $1 \mathrm{~mm}$ 

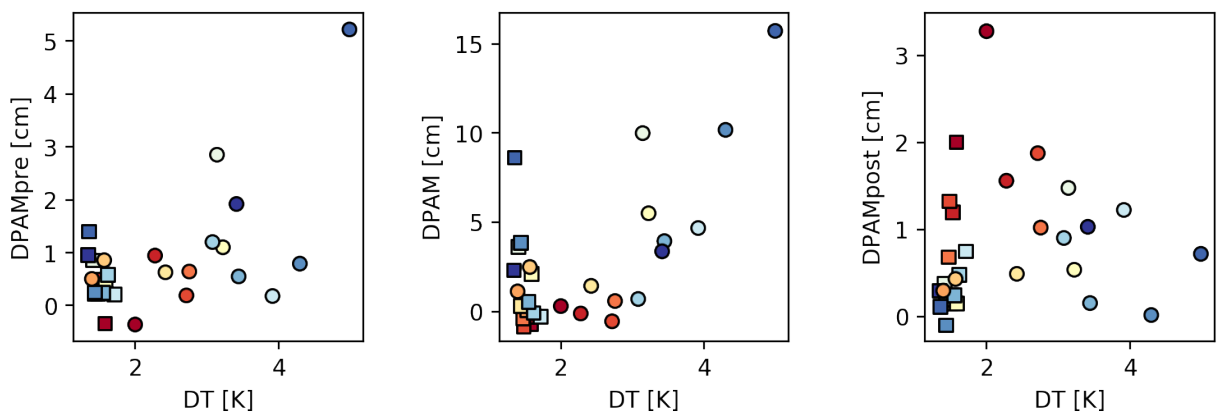

$\square \quad 2 C$
$0 \quad 3 C$
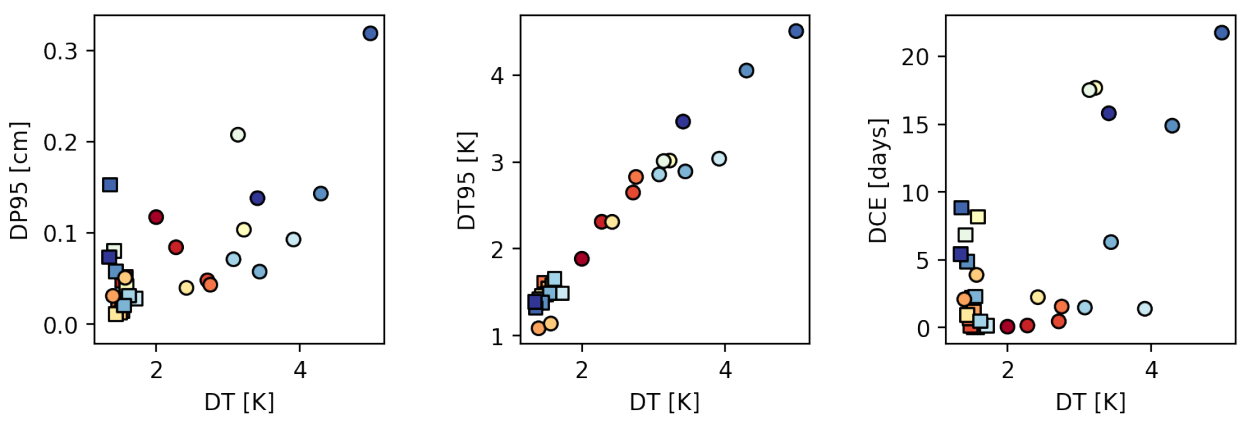

Hengduan Shan

E Himalaya

C Himalaya

W Himalaya

Karakoram

- Hindu Kush

$S$ and $E$ Tibet

- Inner Tibet

- Qilian Shan

E Kun Lun

- W Kun Lun

E Tien Shan

W Tien Shan

Pamir

- Hissar Alay
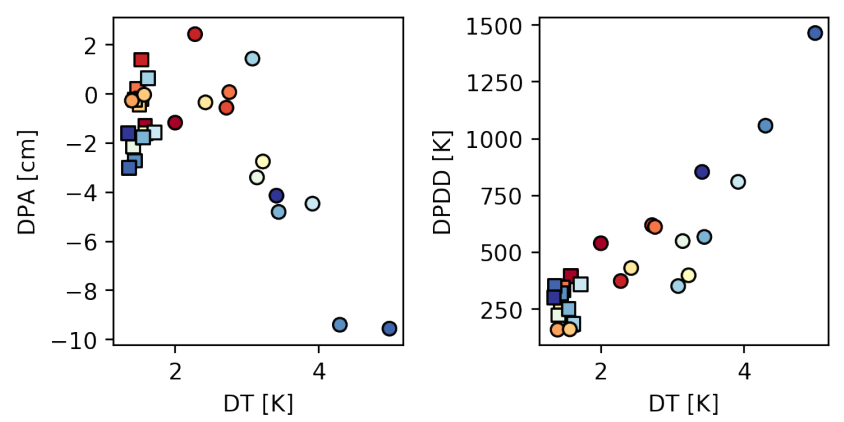

Figure 5.7: Regional climate indicators as a function of the change in average temperature for snow and glacier cells only. The squares denote the $2 \mathrm{C}$ warmer world and the dots a $3 \mathrm{C}$ warmer world. The difference in temperature between the $2 \mathrm{C}$ and $3 \mathrm{C}$ warmer world compared to present day is indicated on the $x$-axis (DT) and the difference in climate indicators on the y-axis: DPAMpre=precipitation during pre-monsoon, DPAM=monsoon precipitation, DPAMpost=postmonsoon precipitation, $D P 95=95^{\text {th }}$ percentile of precipitation, DT95 $=95^{\text {th }}$ percentile of temperature, DCE=compound events (when both precipitation and temperature exceed the present day 95\% percentile, DPA=solid precipitation, DPDD=positive degree days. 
$\mathrm{K}^{-1}$ or $-0.5 \% \mathrm{~K}^{-1}$ ). The significance of these relations is hard to quantify as the temperature differences are small in a $2 \mathrm{C}$ world and the number of regions are low.

When we assume a linear relation between change in regional temperature and the climate indicators in Figure 5.7, precipitation extremes are projected to increase with $0.5 \mathrm{~mm} \mathrm{~K}^{-1}$, temperature extremes with $0.87 \mathrm{~K} \mathrm{~K}^{-1}$ and resulting compound events with 3.9 days $\mathrm{K}^{-1}$, with strongest changes in the south-eastern part of HMA. Compound events are important for flooding, as those are indicative of periods where extreme rainfall coincides with periods of extreme melt. Accumulated solid precipitation is expected to decrease $\left(-1.9 \mathrm{~cm} \mathrm{~K}^{-1}\right)$, with strongest decreases in the Himalaya and Hindu Kush. The positive degree days are expected to increase with 256 days $\mathrm{K}^{-1}$ per degree warming.

\subsection{Conclusion}

In this study we have quantified projected changes in extreme weather events and climate indicators in High Mountain Asia due to global climate changes. To this end, we used three large model ensembles of the EC-Earth model with 2000 simulation years in each ensemble (present day climate and in a $2 \mathrm{C}$ and $3 \mathrm{C}$ warmer world). The most important benefit of large ensemble modelling is that extreme events are explicitly modelled, so no assumptions on tail behaviour of the distributions are required, and that results therefore have greater precision when analysing extreme events in HMA.

Using global climate model data to assess changes in mountainous climate is challenging, as the resolution is too coarse to resolve the complex topography and as a result resolving valley scale dynamics is generally not possible (Cannon et al., 2017; Bonekamp et al., 2018). However, GCMs allow us to generate large ensembles as used in this study due to their relatively low computational costs. Despite its coarse resolution, such an analysis provides key insights in how future extremes and mountain specific weather indicators may change at the large scale that would otherwise not be available.

Our results show that temperature and precipitation will not change uniformly. There are strong seasonal and regional differences between a $2 \mathrm{C}$ and $3 \mathrm{C}$ warmer world. Temperature will increase the most in Eastern HMA (Hindu Kush, Himalayas, Hengduan Shan, Tibet), while precipitation changes follow a more erratic trend. Winters in the Himalayas will be dryer, while wetter in other regions. Summers in the Tien Shan, Hissar Allay and Pamir regions will be dryer, while wetter in the rest of HMA. Elevation dependent warming in EC-Earth is only observed in the southern 
regions of HMA, and not in other regions. This would indicate elevation dependent warming is region specific and not solely an elevation-dependent effect.

The return periods of extreme temperature and precipitation events decrease in a warmer climate, and low-frequent events change more than less frequent events. The 1:100 years temperature events in present day climate will occur approximately yearly in a $2 \mathrm{C}$ warmer world (with a hot spot in Eastern Himalaya), and multi-yearly in a $3 \mathrm{C}$ warmer world in southern and central regions. Return periods of precipitation events show a similar spatial pattern as for temperature events but its absolute return period is considerably less. Precipitation changes are also notable in higher elevated regions such as the Pamir and Karakoram likely due to the increased moisture holding capacity of the atmosphere in combination with the high altitude climate.

We show that the global temperature rise has a large influence on the mountain-specific climate indicators in HMA. The increase in positive degree days and decrease in solid precipitation will lead to more negative glacier mass balances, with largest effects in the Himalaya and Hengduan Shan regions. A $2 \mathrm{C}$ warmer world shows a rather homogeneous response, while distinct differences between regions are present in a $3 \mathrm{C}$ warmer world. This observation can indicate a non-linear acceleration in the regional climate system.

Differences between wet and dry seasons are amplified in monsoon-dominated regions by a dryer winter and wetter monsoon period in the future compared to present-day climate. Precipitation amounts will decrease in pre-monsoon in Hissay Alley, West Tien Shan, Hindu Kush and West and Central Himalaya, which will have large impact on the water availability during the growing season in downstream regions.

Extreme temperature and precipitation are projected to increase the most in the Himalayas, southern part of Tien Shan and western regions. Compound events however are projected to increase most in monsoon-dominated areas, since temperature and precipitation extremes coincide.

Overall, largest changes in climate indicators can be found in regions that are densely populated such as the Hindu Kush and Himalaya. East Himalaya is out far the most affected region, where 7 out of 8 climate indicators change the most, indicating climate change impacts this region the most. 
The increase in weather extremes will affect the number and intensity of natural hazards and will increase the exposure to these hazards for all mountain communities' inhabitants directly. Our results are of great importance for climate change adaptation strategies in HMA and future research into the changes in meteorological and hydrological extremes in HMA is of key importance. Future research should focus on making the explicit link between climate model derived changes in extremes and impact models of natural hazards. This approach has been initiated for landslides in HMA (Kirschbaum et al., 2020), but a full probabilistic approach using large ensemble modelling would be a logical and much needed next step.

\section{Acknowledgements}

This project has received funding from the European Research Council (ERC) under the European Union Horizon 2020 Research and Innovation Program (Grant Agreement No. 676819) and Netherlands Organization for Scientific Research under the Innovational Research Incentives Scheme VIDI (Grant Agreement No. 016.181.308). N.W. acknowledges funding by NWO 016.Veni.181.049. KW acknowledges the HiWAVES3 project for which funding was supplied by the Netherlands Organisation of Scientific Research (NWO) under Grant Number ALWCL.2016.2. Supercomputing resources were financially supported by NWO and provided by SURFsara (www.surfsara.nl) on the Cartesius cluster. 


\section{6}

\section{Synthesis}

The main objective of this thesis is to advance the knowledge on high-altitude climate dynamics from micro to synoptic scales, with a special focus on high-altitude precipitation and the

interaction between the atmosphere, the extreme topography, the land surface and the cryosphere.

The specific research questions addressed are:

1. How do turbulent fluxes drive the energy exchange on debris-covered glaciers?

2. What is the orography-climate interaction at catchment scale?

3. What are the meteorological drivers of the Karakoram anomaly?

4. How does climate change influence the (regional) meteorological extremes in HMA?

These questions are answered by analysing a variety of cases at different resolutions - using a variety of model codes. The MicroHH model code is used for turbulent resolving simulations to investigate turbulent fluxes on a debris-covered glacier. The WRF model code is used to investigate the effect of surface boundary conditions and to perform a climate assessment for the Central Himalayas and Karakoram region. Lastly, a large ensemble of the EC-EARTH model runs is used to investigate weather extremes in High Mountain Asia at different climates.

In this chapter I will synthesize the research questions and main findings of this thesis. I will end by touching upon the key remaining challenges and provide recommendations for further research. 


\subsection{How do turbulent fluxes drive the energy exchange on debris-covered glaciers?}

The melt dynamics of debris-covered glaciers are still largely unknown. At the larger scale the contribution of debris-covered glaciers to the total runoff, and their response to climate change, is uncertain. On a smaller scale, many of the physical properties of these glaciers are still unidentified (i.e. debris thickness, moisture content, surface roughness; Fyffe et al., 2014) and the contribution of sub-glacial channels to the total melt is not understood (Benn et al., 2017). The limited understanding of basic physical properties, and the high spatial heterogeneity of these glaciers, hinders the development of accurate melt estimates by models (Collier et al., 2014; Giese et al., 2019).

Another knowledge gap is the interplay between the debris-covered glacier surface and the atmosphere. Steiner et al. (2018) investigated the validity of the commonly used bulk methods above Lirung glacier by comparing those with measurements of the surface energy balance. They found that bulk methods have the tendency to overestimate the latent heat flux due to the drying character of the debris and also because bulk methods assume full saturation.

In Chapter 2, the impact of surface properties (surface roughness, surface temperature and surface moisture) of debris on the spatial distribution of small-scale meteorological variables such as wind fields, moisture and temperature, and subsequently the turbulent fluxes and conductive heat flux, is investigated for the Lirung Glacier (Nepal) using a direct numerical simulation (DNS) model with a spatial resolution of $\sim 1 \mathrm{~m}$.

In coarse resolution models (debris-covered) glaciers are often represented by a given surface temperature, roughness and water availability. In this study I showed that heterogeneous surface conditions lead to a higher spatial variability of turbulent fluxes when compared to homogeneous surface conditions. The variability of the turbulent fluxes can result in a feedback effect that eventually results in the hummocky terrain typical for debris-covered tongues in the Himalaya, and in extreme situations can result in the formation of cliffs and ponds in such depressions where melt was accelerated.

Our results show that turbulent fluxes can decrease the energy available for melt at the debris surface by $40 \%$ and act as a sink of energy, while on ice cliffs turbulent fluxes enhance energy available for melt by $51 \%$ and are a contributor to melt. In combination with a low albedo this causes ice cliffs to become melt hot spots. Unfortunately our study is representative for only a small time window of one hour. However, the importance of turbulent fluxes for the conductive 
heat flux for a total melt season has been quantified by Steiner et al. (2018), who estimated the reduction of melt by turbulent fluxes to be $17 \%$ at the debris-atmosphere interface. Our results are novel and do open possibilities to investigate small-scale processes on debris-covered glaciers such as the temporal evolution of ponds and ice cliffs. Multi-day simulations could provide new insights of small-scale atmospheric processes in complex terrain. Essential for such highresolution studies are accurate boundary conditions.

For further investigation of melt dynamics of sub-debris melt, MicroHH can be coupled to a energy balance model (i.e. Reid and Brock, 2010). A current limitation of this method is that spatially variable variables (debris thickness, thermal conductivity, density and heat capacity of the debris layer) are needed for a correct estimate of glacier melt. Progress is made in estimating these properties indirectly. Debris thickness has been estimated by means of surface temperature measurements from space, although these are still very uncertain (Rounce et al., 2018).

The high spatial variability of small-scale meteorological variables suggests that point based station observations cannot be simply extrapolated to an entire glacier and should be reconsidered in future studies for a better estimation of glacier melt in High Mountain Asia. In Chapter 2 the first high-resolution study is undertaken for a debris-covered glacier. This investigates the effects of debris on meteorological variables using a turbulence-resolving model. This study improves our process-understanding of debris-glacier melt, and from this to our understanding of the current contribution of debris glacier melt to river discharge and how this will change in future.

This study provides insight only into the surface energy balance for a small part of a debriscovered glacier. In order to determine the glacier-wide effects this model should be run for the whole glacier, and eventually also for other glaciers to demonstrate that results are scalable. This is not straightforward in MicroHH, as the atmospheric forcing should be taken as variable in space. The effects of the surrounding terrain should also be incorporated in the model. This problem can be overcome by using sufficient spin-up time, however this would increase computational requirements tremendously. Another problem is that for longer time periods constant surface boundary conditions (e.g. surface temperature; as used in Chapter 2) no longer represent the situation accurately and should best be updated regularly (i.e. hourly). In practice this means that subsequent additional measurements of the spatial surface temperature would 
be needed, or at the least assumptions of the evolution of the surface temperature should be included.

In Chapter 2 I noted the dependency of model outcomes on the atmospheric stability prescribed by the boundary conditions. The stability is prescribed by the initial atmospheric profiles in MicroHH and needs to be of high quality to represent the atmospheric state correctly. Initially I used ERA-Interim profiles for all variables and downscaled the lower atmospheric levels to that of the AWS-measured value. However, this gave incorrect profiles (sign and incorrect inversion layers) which had large consequences for the results of the turbulent fluxes. This observation puts stress on the need for high-resolution atmospheric input variables to simulate correct results. In order to obtain these it would be interesting to measure, besides surface variables, also basic variables $(T, q, U)$ in the atmosphere. I performed some tests in the field with atmospheric sensors attached to a drone and kite; these proved promising. A disadvantage of this method is that it is time consuming and can only be performed at specific times when people are in the field. Another option in seeking to retrieve high-resolution input variables is to run WRF at sub-kilometre scale and downscale the coarse resolution data to a higher resolution.

Currently UAVs play an important role in the retrieval of spatially stationary variables such as grain size distribution and surface roughness length (Rossini et al., 2018; Westoby et al., 2015; Van Woerkom et al., 2019). UAVs can also play a role in measuring atmospheric variables (Knuth and Cassano, 2014). However, for continuous atmospheric measurements the role of highresolution satellite sensors is more promising.

\subsection{Orographic-climate interactions at the catchment-scale}

Gridded meteorological datasets are frequently used but these provide a poor representation of precipitation in the Himalayas because of their relatively low spatial resolution and the associated representation of the complex topography. In Chapter 3 I showed that increasing the model spatial resolution contributes to more realistic amounts and patterns of precipitation in complex terrain. This is because more orographically forced precipitation is modelled at higher elevations than in the coarser domains. Modest improvements were observed when the resolution was increased to $500 \mathrm{~m}$. This suggests that a sub-kilometre grid spacing may more accurately resolve catchment-scale meteorological variability and therefore the resulting glacio-hydrological changes. Our results further elucidate the performance of WRF at high resolution and demonstrate the importance of accurate surface boundary conditions and spin-up time for simulating precipitation. 
Future studies can use these high-resolution insights to validate coarse resolution models. Highresolution models could have limited value for certain processes and applications. Future research should therefore investigate whether the time and costs are worth the extra information that is obtained by high-resolution modelling. Hybrid options are also a possibility one could for example add one high-resolution member in an ensemble or include a highresolution run as part of the sensitivity tests.

In Chapter 3 I showed that the effect of land use has a large impact on near-surface meteorological variables. Precipitation amounts differ for investigated cases by $10 \%$ in summer, placing an emphasis on the need for correct surface boundary conditions in future simulations. UAV's or high-resolution satellite sensors can play an important role in retrieving correct land use coverages in future.

\subsection{Meteorological drivers of the Karakoram anomaly}

Drivers of the Karakoram anomaly are poorly understood due to the low number of observations in this region and given that satellite data sets have problems measuring correct precipitation amounts at high altitudes. In Chapter 4 I quantified the meteorological drivers of the glacier mass balances in the Karakoram and central Himalaya to understand the underlying atmospheric mechanisms of the Karakoram anomaly. Two catchments in contrasting climatic regions are modelled with the numerical atmospheric model WRF for three years at a high resolution $\left(1 \mathrm{~km}^{2}\right)$ : one in the central Himalaya (Langtang) and one in the Karakoram (Shimshal). Our results show that the accumulation and melt dynamics of both regions are distinctly different in terms of (i) the seasonality and altitudinal distribution of snowfall and (ii) the surface energy balance components. I conclude that glacier mass balances in the Karakoram are more sensitive to longwave radiation from clouds, and that summer snow events are important drivers of the surface energy balance because of their albedo effect. I show that understanding glacier mass balance anomalies requires quantification and insight into subtle shifts in the energy balance and accumulation regimes at high altitude. I also show that summer snow events reset the glacier albedo, decreasing the energy available for melt. As this effect occurs during the summer monsoon, it follows that an enhanced monsoon circulation (Chapter 5) can benefit glaciers in the Karakoram.

In Chapter $4 \mathrm{I}$ also propose a new method for categorization of precipitation events to determine whether the monsoon circulation drives an event or not. This method focuses on the integrated moisture flux and wind direction in the Karakoram region, and in two source areas, in order to determine the origin of the precipitation event. With this method it can be determined whether a 
precipitation event is either monsoon or westerly driven. This quantification is important when addressing the effects of increased future monsoon circulation to glaciers in the Karakoram.

This is the first multi-year high-resolution comparative atmospheric modelling study in High Mountain Asia and provides unique insight into catchment-scale atmospheric processes as drivers for glacier behaviour. I show that net radiation is the main driver of snow and glacier melt and that the main contributors to the net radiation differ per region. Our findings could have important consequences for how glaciers are treated in (climate) models. Glacier ablation is now often represented as a direct consequence of air temperature (i.e. degree day model). However I show that the surface energy balance of a glacier is a leading function in glacier melt. This would imply that glaciers could also melt in cold climates if, for example, incoming solar radiation is high.

The climatic contrast presented in this study is based on two catchments and the results are a direct example of the problems in scalability of location-generated results. Feedbacks and processes in a monsoon-dominated climate are for example not directly transferable to those in winter dominated precipitation areas. Future research should investigate whether the findings presented in Chapter 4 can also be found in the surrounding catchments of Langtang and Shimshal.

In Chapter 4 the results of a three-year simulation are presented; this is unique at a spatial resolution of 1 kilometre. It would be interesting to study multi-decadal trends in the surface energy balance to investigate the atmospheric cause(s) of the anomalous behaviour of glaciers in the Karakoram region. Results of the three-year simulation show that the surface albedo has a large influence on the glacier surface energy balance and is highly sensitive to summer snow events. Longer simulations should demonstrate whether there has been a positive trend in summer precipitation events over past decades. This quantification of monsoon events could be achieved using the new categorization method presented in Chapter 4 . Another option would be to quantify monsoon events using new cloud-computing platforms that integrate data availability and computational power, such as the Google Earth Engine.

A further interesting point for future research would be to investigate the direct and indirect effects of rain with regard to glacier accumulation and ablation processes. Normally these effects are assumed to be negligible (Greuell and Smeets, 2001; Hock and Holmgren, 2005), however rainfall amounts are high in monsoon-dominated areas and can have a profound impact on the 
surface energy balance (Fitzpatrick et al., 2017; Reid and Brock, 2010). Besides the direct energy transfer to the glacier, precipitation also affects the microstructure of snow and therefore the surface albedo (Lehning et al., 2002; Niwano et al., 2012). Additionally, precipitation increases the liquid water content of the snowpack and affects the energy redistribution in the ice, influencing daily melt and refreezing cycles. Research into these effects of precipitation would help to unravel the different glacier responses observed in various climates.

\subsection{Climate change impacts on meteorological extremes}

Weather extremes are hard to quantify with current modelling techniques due to short observation periods and statistical assumptions on the distribution of these extremes, which is uncertain when extrapolating to the future. In Chapter 5 I quantified changes in extreme weather events and climate indicators in High Mountain Asia in a $2^{\circ} \mathrm{C}$ and $3^{\circ} \mathrm{C}$ warmer world, using the large ensemble method. Three large model ensembles of the EC-Earth model with 2000 simulation years in each ensemble were used: one ensemble using present-day climate and then two more - in a $2^{\circ} \mathrm{C}$ and $3^{\circ} \mathrm{C}$ warmer world. With these large ensembles it is possible to analyse the occurrence and changes in extreme weather events without the need of extrapolation or statistical methods, since extreme events are explicitly modelled. This results in greater precision when analysing extreme events in HMA compared to other methods.

A benefit of large ensemble modelling is the ability to directly infer events with very high return periods of temperature and precipitation. I show that the magnitude and return periods of rare events ( 1 in 100 year) change more than more frequent events (1:1 year) in a warmer climate. Return periods of precipitation events show a similar spatial pattern to those of temperature events, but with the absolute change in return period significantly less.

These results also show that temperature and precipitation change non-uniformly with temperature. Where for a $2{ }^{\circ} \mathrm{C}$ warmer world responses are reasonably homogenous, a $3{ }^{\circ} \mathrm{C}$ warmer world shows large differences between regions. Extreme temperature and precipitation are projected to increase the most in the Himalayas, South Tien Shan and Western regions. Compound events however are projected to increase most in monsoon-dominated areas, since temperature and precipitation extremes coincide. Secondly, I show that global temperature rise has a large influence on the mountain-specific climate indicators in HMA. Indicators I investigated are positive degree days, accumulated precipitation, (pre- and post-) monsoon precipitation, extreme temperature, extreme precipitation and compound events. The most heavily affected region is East Himalaya, where changes in 7 out of 8 investigated climate indicators are largest for High Mountain Asia. 
The increase in weather extremes will affect the number and intensity of natural hazards and will increase the exposure to these hazards for all mountain communities' inhabitants directly. Our results are of great importance for climate change adaptation strategies in HMA and will support further research into the changes in meteorological and hydrological extremes in HMA. Future research is needed to unravel the differences between various model ensembles to better estimate the model uncertainty in our projections. This research should focus on the actual quantification of the increase in number and intensity of natural hazards.

Ideally there will be more large ensembles of different climate models in the future and will it be possible to incorporate model uncertainty in statistical analyses. It is critical that the set-up of these large ensembles should be standardised as far as possible given the time and effort it takes to generate them.

Additionally, climate risk information should be coupled to the occurrence of natural hazards such as landslides and floods. Kirschbaum et al. (2020), for example, coupled satellite- and GCMderived precipitation data to a global landslide model. The next step would be to include the information from a large ensemble in this framework (i.e. ensemble used in Chapter 4; van der Wiel et al., 2019). The projected changes in large-scale extreme weather can then be used to improve hazard and risk projections. This will improve climate change adaptation strategies.

\subsection{Recommendations and outlook}

\subsubsection{Observations versus models}

The question whether observations always outperform datasets and models is debatable. Observations are most generally considered to be the truth, and a mismatch between model results and observations are most usually attributed to model errors. However, observations do not always outperform models. In Chapter 2 for example I investigated the effects of homogeneous surface conditions derived from a point measurement compared to heterogeneous surface conditions. I showed that large differences in outcomes exist between the two approaches. Additionally, there may be errors in the processing of the data or observation stations may be badly sited or have technical errors (McCabe et al., 2017).

A main limitation of in-situ point-observations is that they only measure variables at one location. In homogeneous areas such as extensive grasslands the in-situ observation can be representative of its larger area while in mountainous terrain these point observations simply cannot be 
representative of the wider surroundings (as I have also shown in Chapter 2). For example, one measurement in a valley does not mirror the conditions at the valley entrance and at the highest point of the valley. Similarly, a measurement in a village does not represent the conditions above a glacier. Additionally, observation stations often do not met the conditions required by the fabricators. Data quality can therefore not be guaranteed; problems with measuring solid precipitation are also well known (Rasmussen et al., 2012). To overcome the limitation that an observation only gives point-information, multiple observations can be interpolated in space to retrieve a spatial 'measured' field. The results are however subject to interpolation errors and dependent on the chosen interpolation technique (Ossa-Moreno et al., 2018).

Observations from satellites can also be used to complement in-situ measurements. These satellite data cover large areas, however with a coarse resolution and often have large biases, especially in highly heterogeneous terrain (Immerzeel et al., 2015). Satellite products are often calibrated against ground observations. However, as these in-situ observations are often located in areas of lower elevation, corrected satellite products can be biased towards lower-elevation climates.

The conclusion is that I should not blindly trust observations and automatically label models as the culprit, as models can provide spatial insights were observations are scarce, non-existent, or simply impossible. Atmospheric modelling can be a great addition to current observational techniques such as remote sensing and point measurement. So, for example, modelling tools can be used to determine the best locations for the siting of measurement stations and thus be of great value in the planning and design of measurement campaigns. Models can also be used as spatio-temporal interpolators between observations using e.g. data-assimilation methods (Evensen, 2009). The need for observations remains high, as these are needed in models as boundary conditions. There is no single approach and both models and observations will continue to be required in future.

\subsubsection{Small-scale process understanding}

In Chapter 2 I determined the contribution of turbulent fluxes to the surface energy balance on a part of a debris-covered glacier. This was the first time a turbulence-resolving model has been applied to a debris-covered glacier. As this method is shown to be successful it would be interesting to 1 ) enlarge the domain to determine the effect of turbulent fluxes on a larger scale; and 2) to couple the DNS model to a surface energy balance model to determine the energy that would reach the ice/debris interface, as this drives the total melt of debris-covered glaciers. 
Current unknowns are the spatially variable debris thickness, moisture content, and conductivity. Future research would benefit from an accurate representation of these variables.

Future research should focus on fundamental improvements to existing models rather than on increasing the number of models and approaches. Secondly, input data sets should be improved in quality and resolution in order to meet the increased model resolution. This can be achieved by using drones for smaller areas or by the higher-resolution satellite sensors that can be expected and accessed in future. Additionally, there are great opportunities in retrieving 3D observations (wind, wind direction, humidity and pressure; Knuth and Cassano, 2014), and turbulent fluxes with an UAV (Reineman et al., 2013).

In order to overcome the problem of sparse observations, observations and relationships are often scaled to larger areas and other climates, despite the fact that these are often not directly transferable to these different environments. In Chapter 2 I showed that DNS is a useful tool in the investigation of small-scale processes (i.e. ice cliffs and ponds) on glacier surfaces, which eventually can be used to derive or refine parameterizations for coarser-resolution models.

\subsubsection{Computational advances}

Increasing computational power allows model users to increase the spatial resolution of their simulations. Such high-resolution models can serve two purposes: as an operational model or as a validation tool for coarser models. To determine the performance of current relatively coarse resolutions it would be interesting to compare these results to a higher-resolution model. For example, one can run a LES for a whole catchment and compare these results to those of a catchment-scale model such as WRF. If such simulation shows that the coarser resolution provides enough information when compared to a higher resolution model, time and computational power can be saved in subsequent simulations.

Due to the increase in computational power large ensemble modelling is currently possible (Chapter 5) and adds valuable information about the uncertainty of modelling results and possible changes in magnitude and frequency of extreme events. However, those large ensembles are still rare and usually based on a single model. In order to also cover model uncertainty, multi-model large ensembles should be analysed. Considering the effort it takes to make such a large ensemble (computational, time and data management), it would be beneficial to use the same set up and assumptions for each future large ensemble. Only then does comparison between large ensembles become possible, and ensembles can be used constructively in inter-comparison studies. 


\subsubsection{High-resolution insights in coarser resolution models}

One of the main challenges is to translate high-resolution feedbacks into coarse-resolution models and how to achieve that. Examples are clouds and snow processes. It is currently not computationally feasible to run large areas at very high resolution, and in order to treat smallscale processes over large areas they need to be parameterized in coarse resolution models. Parameterizations used in coarse resolution models can be derived from high-resolution models (see 6.5.2), observations, or fundamental relations and are therefore key in coarse resolution models. A problem is that high-resolution parameterizations are not directly scalable in space and time, since they are made for a certain resolution range (such as the occurrence of clouds and turbulence) and need to be handled with care (Beven, 1995). In Chapters 2 and 3 I show that short duration and high-resolution simulations can be used to understand small-scale sub-grid processes. By comparing these high-resolution insights to coarse resolution models parameterizations can be developed.

Current model development often focuses either on increasing the spatial resolution or including more complexity in existing models. However, considerable improvements can be made in the fundamental understanding of small-scales processes and responses (i.e. sub surface soil, snow processes, sublimation and evaporation), as these are fundamental for large-scale patterns. This would also prevent the inclusion of more uncertainty to the model rather than adding detailed information (Orth et al., 2015).

A next step would be to determine how these processes can be included in coarser resolution models. Machine and deep learning can be used for a better understanding and representation of small-scale processes in the hydrological cycle. This approach can be applied to very highresolution model results to learn from these simulations. This can be done by downscaling or finding statistical links between results of high and coarse resolution outputs (Holmstrom et al., 2016; Krasnopolsky and Fox-Rabinovitz, 2006). At a later stage a machine-learned algorithm could be incorporated in a coarser climate or hydrological model to obtain a more accurate and computationally less expensive model. As with current parameterizations people should be careful when applying the algorithms in a changing climate as the process behaviour may not persist into the future. However, with information from machine and deep learning, the current parameterizations can be revisited for refined spatial resolutions.

\subsubsection{Integrated approach}

This thesis provides new insights into high-altitude climate dynamics and its interaction with the cryosphere at various scales. It uses interdisciplinary methods from the fields of atmospheric and 
cryospheric sciences in order to fill the gap between those two fields. A suite of different atmospheric models is used to overcome the scale gap between individual glaciers and HMA as a whole. Results from finer-scale models are used (Chapters 2-4) to obtain insights into the nature of high-resolution processes that are usually parameterized in coarser resolution models.

The coupling between the atmosphere and ice-interface should be the first focus of future research. The atmosphere drives cryospheric changes since the surface energy balance and precipitation drive glacier accumulation and ablation. Fully coupled models including the feedback from the ice to atmosphere at high resolution are needed to truly resolve the complex response of the cryosphere to atmospheric perturbations. Satellite products can be used to identify regions of change. However, in order to understand the underlying processes, coupled atmosphere-cryosphere models are needed. Moreover, cryospheric change itself impacts the lower atmosphere and therefore the micro and meso-climate. Coupled atmosphere-cryosphere models may therefore be key to our understanding and prediction of cryospheric change under a warming climate.

A more interactive approach to solve cryospheric problems is required. The atmosphere and cryosphere are dynamically coupled and feedbacks vary across regions and climates (Chapter 4). This indicates that simplified relations derived at one location cannot be transferred to other regions without consideration of the climatic differences. There are many feedbacks present in the climate system that should be represented in more detail. The increased need for a more integrated approach is also in line with the increasing model complexity that is generally observed today. A better integration between the disciplines of meteorology, glaciology and hydrology is considered to be essential in future research.

It is difficult to link different disciplines as the development of most available models is usually led by one single discipline, and the processes related to the primary objective of that study tend to be best represented. The processes and feedbacks of the secondary discipline are often treated as static input fields or boundary conditions. For example, in atmospheric models cryospheric features are often simplified (glacier is a static land use option), while in glacier models the atmospheric forcing is often reduced in complexity (daily or even seasonally averaged values as forcing).

Future research would benefit from fully integrated models and I argue for increasing effort in developing these. A good step forward would be to couple models interactively to increase model 
complexity in the correct manner (i.e. Collier et al., 2013). At a later stage more refined parameterizations, or explicit modelling of processes, can be implemented - if computational power allows it. Fully coupled models need to resolve various scales, and a full understanding of processes and their interaction with other processes is required. The first step is therefore to understand small-scale processes and feedbacks across different spatial scales. The second step would be to integrate these small-scale processes as parameterizations in coarser resolution models.

This two-way coupled model approach (e.g. glacier surface temperature as affected by air temperature, and vice versa) would give a better representation of reality and would reveal interactions which could not have been studied with one-way modelling. Secondly, these integrated models can give insight into the importance of individual components in the larger system by performing various sensitivity tests. This insight is very valuable as it determines the focus of further model development.

In this thesis four case studies are presented and, for all their range and variety, give only a glimpse of what can be achieved with atmospheric modelling. Advances in atmospheric modelling are shown to play an important role in improving the understanding of the water cycle in high altitudes and complex terrain. As one example, precipitation is the main input and yet also the main unknown in the hydrological cycle in High Mountain Asia (Immerzeel et al., 2015). Improving our understanding of the current climate would be a major step forward when it comes to making adequate projections in future, and good projections are all the more necessary as we face a rapidly changing climate. 


\section{Appendix A}

This appendix presents the most relevant results of a sensitivity study to the Reynolds number. With this analysis we demonstrate that the results in the main text do not change when halving the Reynolds number. To provide an intuitive insight into this, Figure A1 shows the computed surface sensible and latent heat fluxes for both simulations. This figure clearly demonstrates nearly identical patterns and magnitudes of the surface fluxes. The similarity can also be understood from scaling arguments. Over a rough surface, the wind-driven surface fluxes can be approximated as:

$$
\begin{aligned}
& L H F=\rho \cdot L_{v} \cdot c_{d q} \cdot\left(u-u_{0}\right) \cdot\left(q-q_{0}\right), \\
& S H F=\rho \cdot c_{p} \cdot c_{d h} \cdot\left(u-u_{0}\right) \cdot\left(T-T_{0}\right),
\end{aligned}
$$

where $\rho$ is the air density, $c_{p}$ specific heat, $C_{d h}$ and $C_{d q}$ the exchange coefficient for heat and moisture respectively, $\mathrm{u}$ the wind speed, $\mathrm{u}_{0}$ the wind speed at the surface, $\mathrm{T}$ the temperature and $T_{0}$ the temperature at the surface, $L_{v}$ the latent heat of vaporization, $q$ the specific humidity and $q_{0}$ the specific humidity at the surface. In our case both simulations have the same boundary
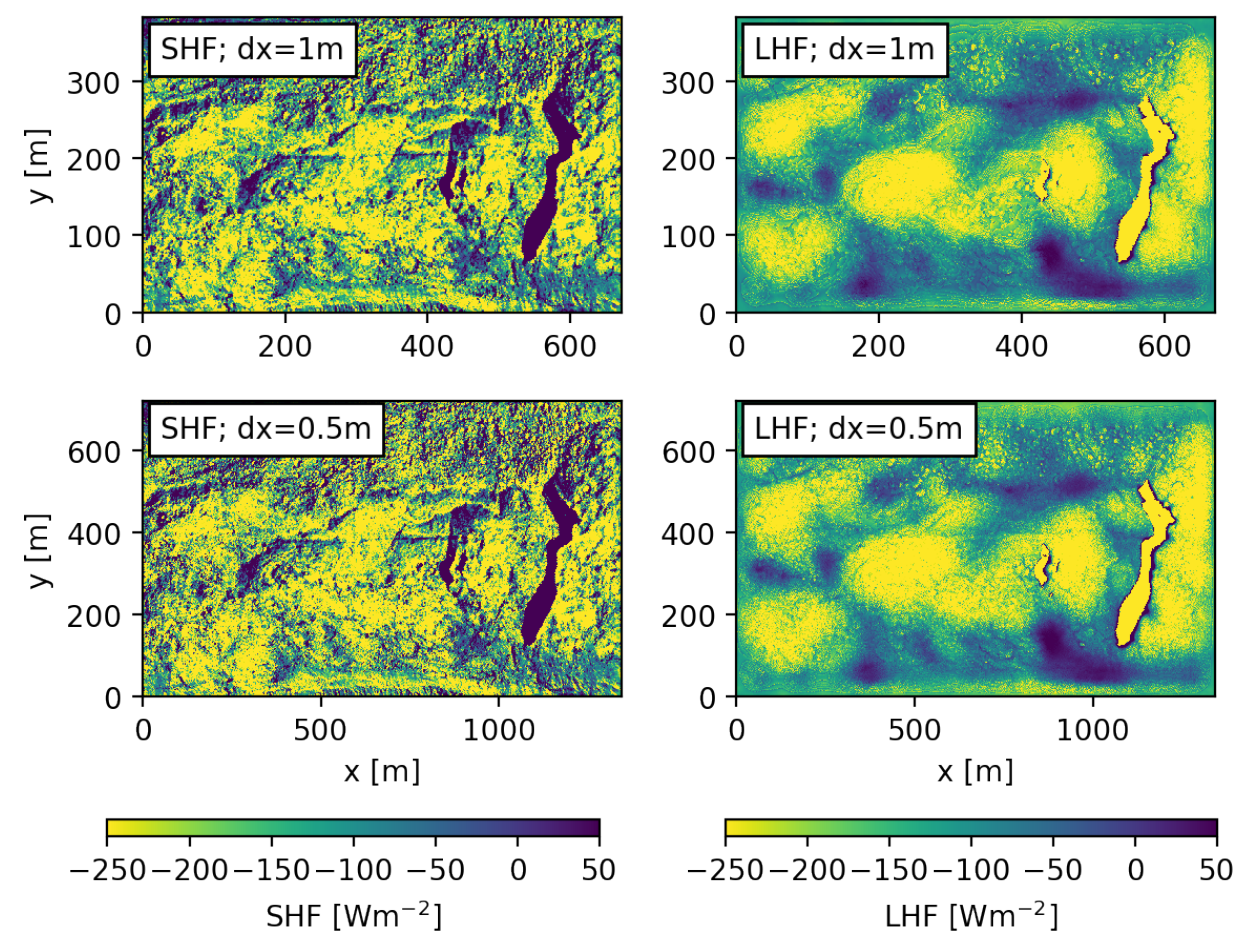

Figure A1: The averaged sensible (left panels) and latent heat flux (right panels) for the REAL experiment with a viscosity of $0.2 \mathrm{~m}^{2} \mathrm{~s}^{-1}\left(d x=1 \mathrm{~m}\right.$; upper panels) and with viscosity of $0.11 \mathrm{~m}^{2} \mathrm{~s}^{-1}$ $(d x=0.5 \mathrm{~m} ;$ lower panels). 
conditions for temperature and humidity, and resolve nearly identical atmospheric fields (Figure A2). As atmospheric profiles are identical, the only place where low Reynolds number effects could manifest is via $C_{d h}$ and $C_{d q}$, and therefore in the magnitude of the surface fluxes, yet Figure A1 shows that this is not the case.

Further proof of the independence of the bulk quantities (profiles of means and variances) can be found in the streamwise spectra of specific humidity (Figure A3). The additional variance that is resolved in wavenumbers $>11$ does not contribute significantly to the total variance. This can be visually inferred from Figure $A 3$, as the total variance is the area under the graph, and the newly added variance is invisible to the eye.
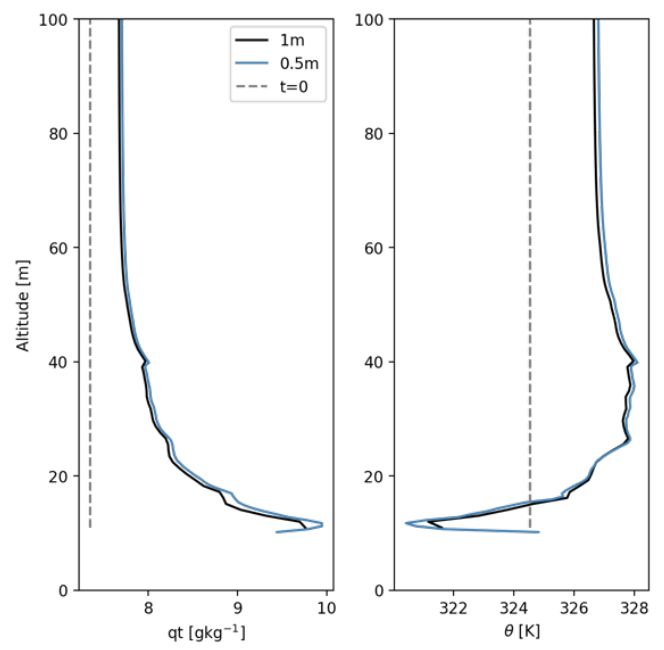

Figure A2: Total specific humidity (left) potential temperature (right) profiles for the REAL experiment with $d x=1 \mathrm{~m}$ (black), $d x=0.5 \mathrm{~m}$ (blue) averaged over the simulation hour and their initial profiles at $t=0$ (grey).

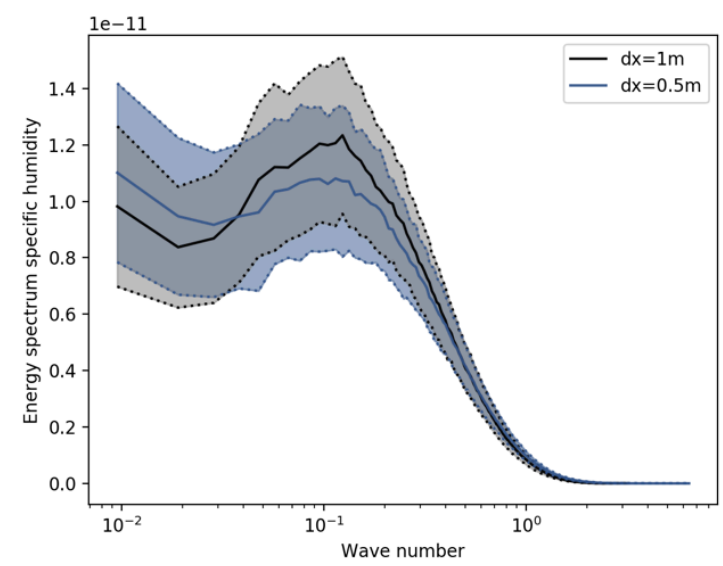

Figure A3: Energy spectrum for the total specific humidity at 65 metres above lowest point of the topography, averaged over the simulation hour. Shading indicates one standard deviation. The vertical axis is pre-multiplied with the wavenumber. 


\section{Appendix B}
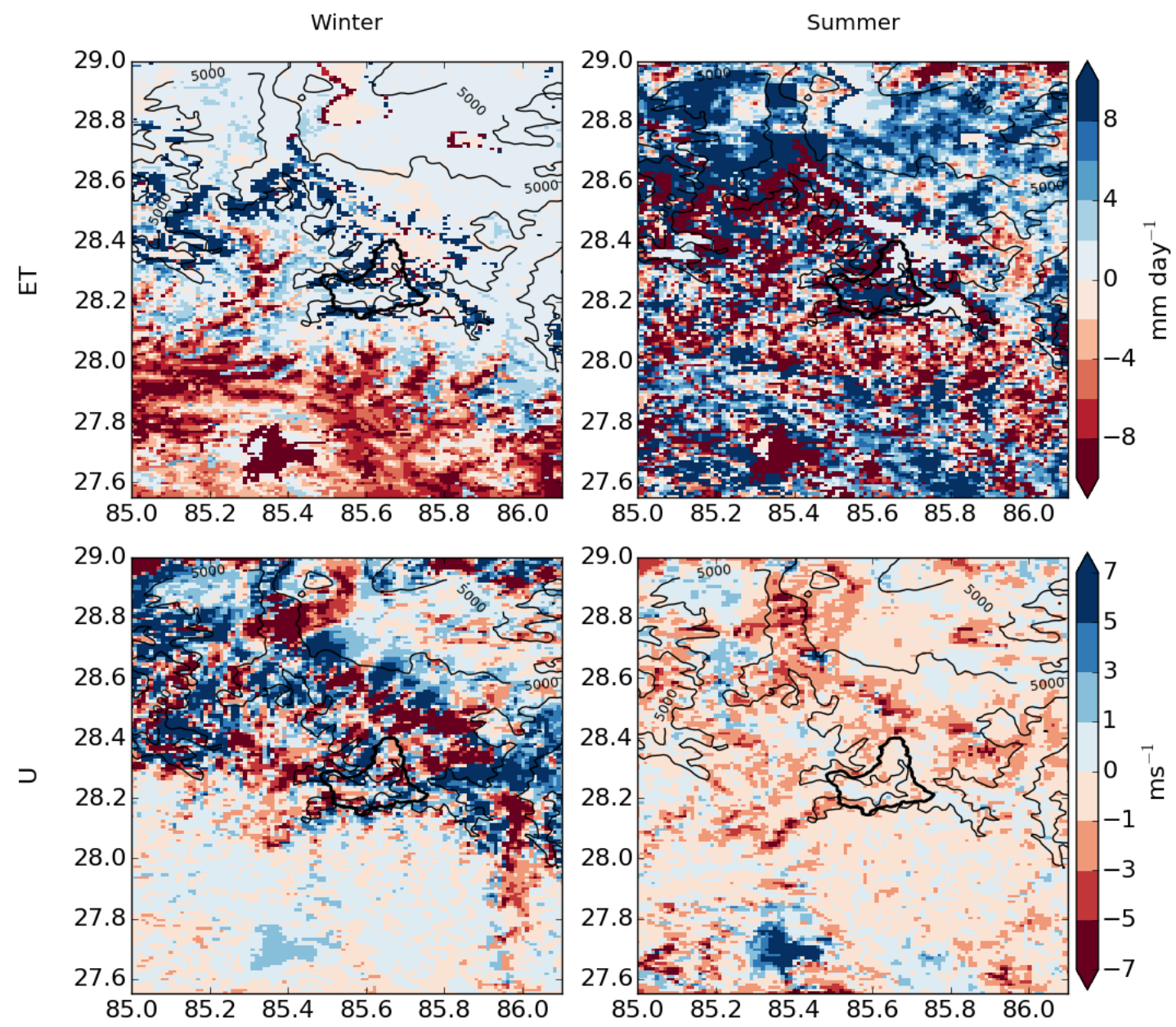

Figure B1: The effect of the FAO landuse (the difference between the model results using FAO and default landuse) on the averaged surface moisture flux per day (upper panels) and averaged wind speed per hour (lower panels) for the winter (left panels) and summer (right panels) period. The thick black contour indicates the catchment outline and the thin black lines indicates the altitude of 5000 meter. 


\section{Appendix C}
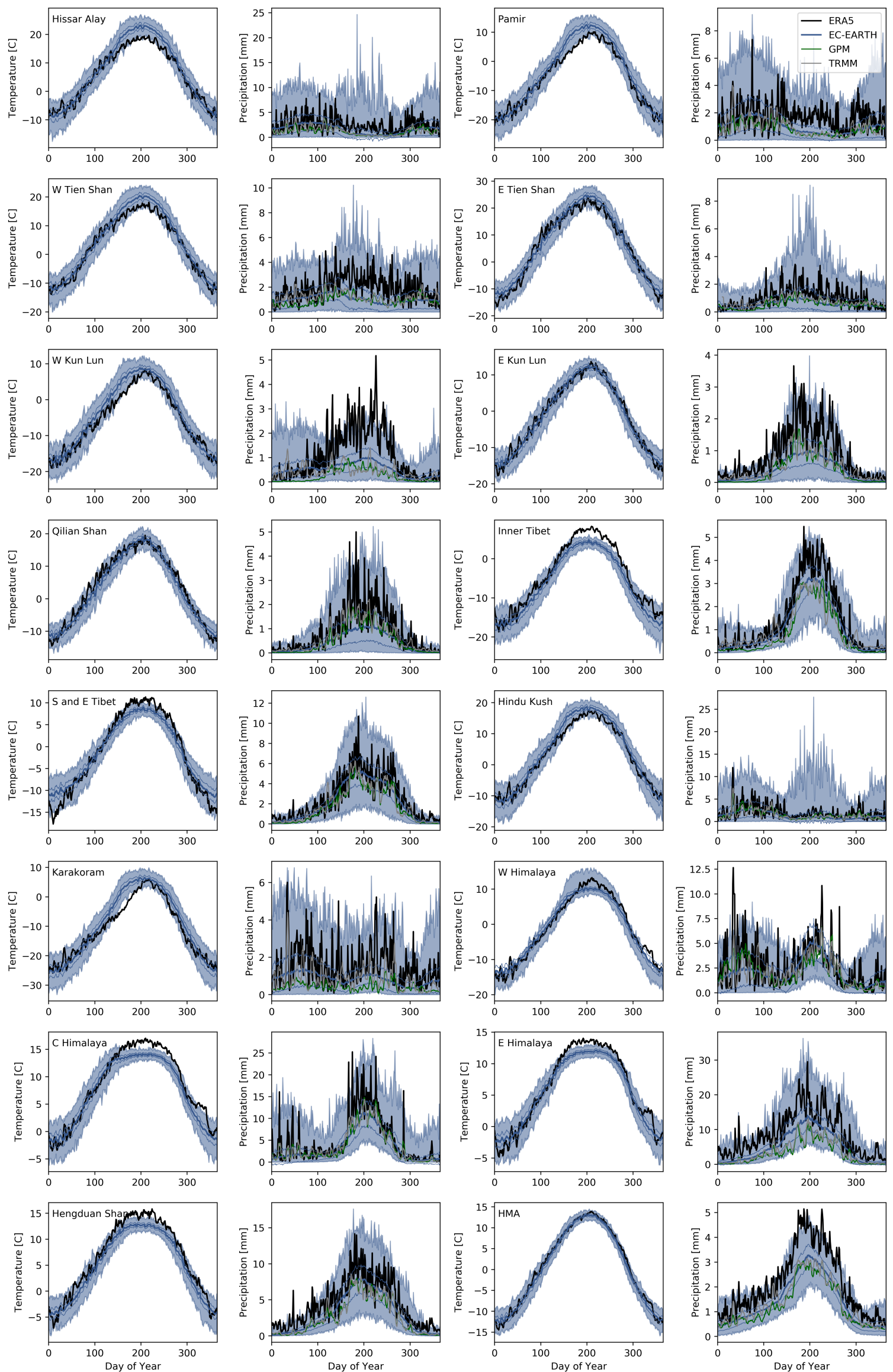

Figure C1: As Figure 5.1 but now for individual regions. 

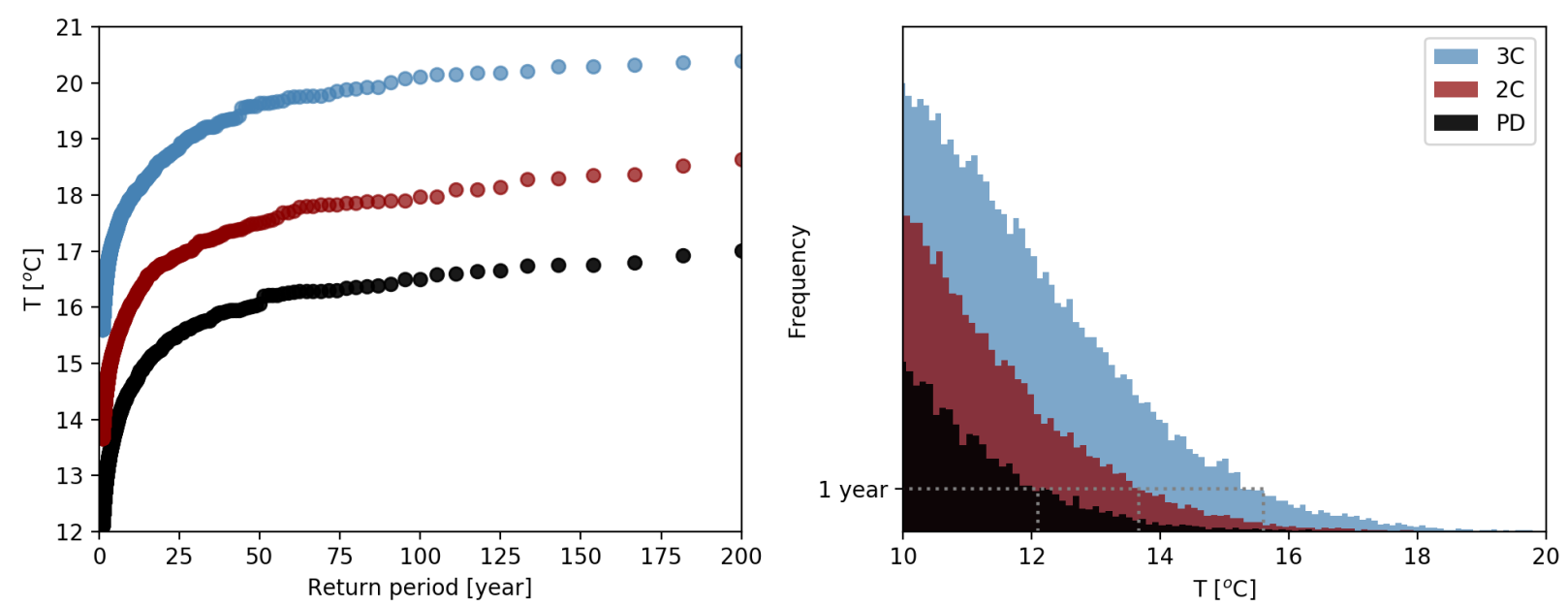

Figure C2: The empirical distribution estimate of daily averaged temperature for all events occurring more than once a year (left; only events with return period $>1$ year are plotted) and the tail of the distribution of all average daily temperature (right) both for 1 pixel (90.25E 30.25N). The gray dotted line indicates the 1 year event in different climates and makes clear the $3 \mathrm{C}$ world (blue) extremes are located almost completely out of present day extremes range (black). The severe increase in daily averaged temperature is a result of the average temperature distribution in different climates. 

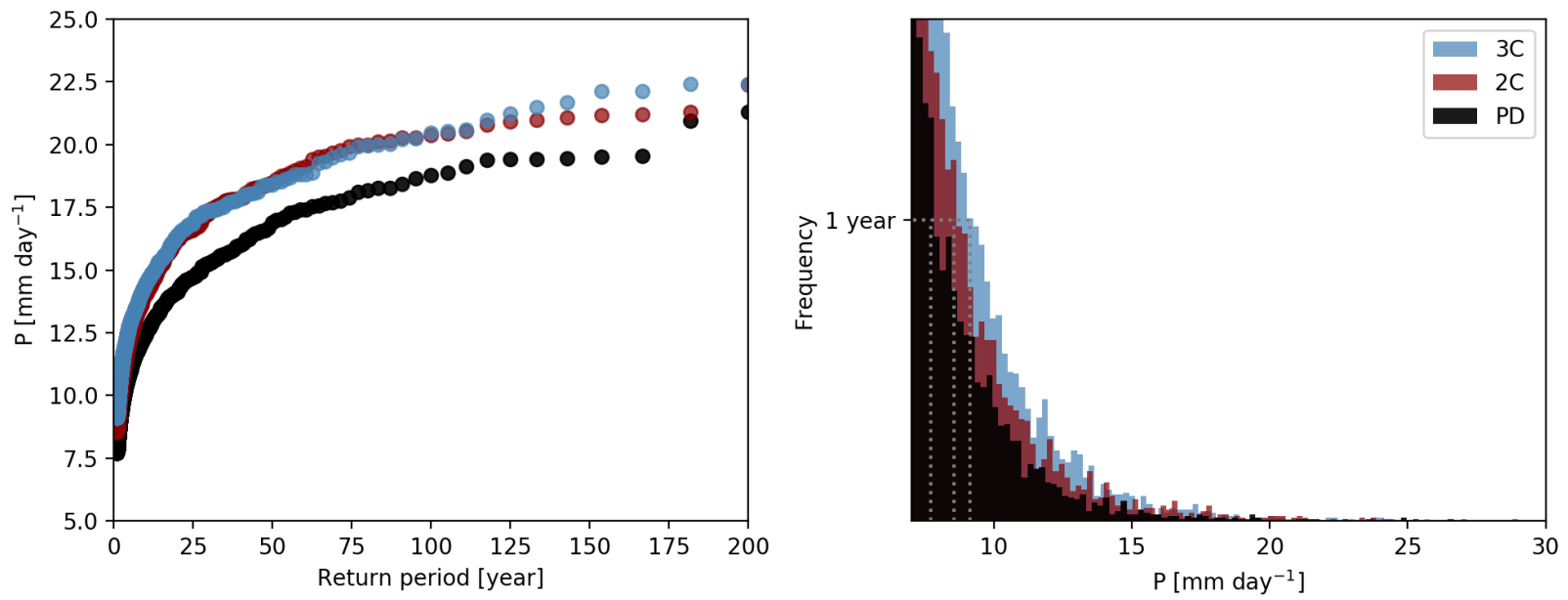

Figure C3: As C2, however now for daily precipitation sums. 


\section{Bibliography}

Ahlers, G., Grossmann, S. and Lohse, D.: Heat transfer and large scale dynamics in turbulent Rayleigh-Bénard convection, Rev. Mod. Phys., 81(2), 503-538, doi:10.1103/RevModPhys.81.503, 2009.

Allen, M. R. and Ingram, W. J.: Constraints on future changes in climate and the hydrologic cycle, Nature, doi:10.1038/nature01092, 2002.

Andermann, C., Bonnet, S. and Gloaguen, R.: Evaluation of precipitation data sets along the Himalayan front, Geochemistry, Geophys. Geosystems, 12(7), doi:10.1029/2011GC003513, 2011.

Anderson, B. and MacKintosh, A.: Controls on mass balance sensitivity of maritime glaciers in the Southern Alps, New Zealand: The role of debris cover, J. Geophys. Res. Earth Surf., 117(1), 1-15, doi:10.1029/2011JF002064, 2012.

Anderson, L. S. and Anderson, R. S.: Modeling debris-covered glaciers: Response to steady debris deposition, Cryosphere, doi:10.5194/tc-10-1105-2016, 2016.

Ansorge, C. and Mellado, J. P.: Analyses of external and global intermittency in the logarithmic layer of Ekman flow, J. Fluid Mech., doi:10.1017/jfm.2016.534, 2016.

Arakawa, A.: The cumulus parameterization problem: Past, present, and future, J. Clim., doi:10.1175/15200442(2004)017<2493:RATCPP>2.0.CO;2, 2004.

Archer, C. L. and Caldeira, K.: Historical trends in the jet streams, Geophys. Res. Lett., 35(8), doi:10.1029/2008GL033614, 2008.

Arnold, D., Morton, D., Schicker, I., Seibert, P., Rotach, M. W., Horvath, K., Dudhia, J., Satomura, T., Müller, M., Zängl, G. and others: High resolution modelling in complex terrain: report on the HiRCoT 2012 Workshop, Vienna, 21-23 February 2012, Institut für Meteorologie, Department Wasser-Atmosphäre-Umwelt, Univ. f. Bodenkultur., 2012.

Axelsen, S. L. and Dop, H.: Large-eddy simulation of katabatic winds. Part 1: Comparison with observations, Acta Geophys., doi:10.2478/s11600-009-0041-6, 2009.

Axelsen, S. L. and van Dop, H.: Large-Eddy simulation of katabatic winds. Part 2: Sensitivity study and comparison with analytical models., 2009.

Aznar-Siguan, G. and Bresch, D. N.: CLIMADA v1: A global weather and climate risk assessment platform, Geosci. Model Dev., 12, 3085-3097, doi:10.5194/gmd-12-3085-2019, 2019.

Baral, P., Kayastha, R. B., Immerzeel, W. W., Pradhananga, N. S., Bhattarai, B. C., Shahi, S., Galos, S., Springer, C., Joshi, S. P. and Mool, P. K.: Preliminary results of mass-balance observations of Yala Glacier and analysis of temperature and precipitation gradients in Langtang Valley, Nepal, Ann. Glaciol., 55(66), 9-14, doi:10.3189/2014AoG66A106, 2014.

Barros, A. P., Kim, G., Williams, E. and Nesbitt, S. W.: Probing orographic controls in the Himalayas during the monsoon using satellite imagery, Nat. Hazards Earth Syst. Sci., doi:10.5194/nhess-4-29-2004, 2004.

Benn, D., Thompson, S., Gulley, J., Mertes, J., Luckman, A. and Nicholson, L.: Structure and evolution of the drainage system of a Himalayan debris-covered glacier, and its relationship with patterns of mass loss, Cryosphere, 11, 2247-2264, doi:10.5194/tc-11-2247-2017, 2017.

Benn, D. I., Bolch, T., Hands, K., Gulley, J., Luckman, A., Nicholson, L. I., Quincey, D., Thompson, S., Toumi, R. and Wiseman, S.: Response of debris-covered glaciers in the Mount Everest region to recent warming, and implications for outburst flood hazards, Earth-Science Rev., doi:10.1016/j.earscirev.2012.03.008, 2012.

Beven, K.: Linking parameters across scales: Subgrid parameterizations and scale dependent hydrological models, Hydrol. Process., 9(5-6), 507-525, doi:10.1002/hyp.3360090504, 1995.

Biemans, H., Siderius, C., Lutz, A. F., Nepal, S., Ahmad, B., Hassan, T., von Bloh, W., Wijngaard, R. R., Wester, P., Shrestha, A. B. and Immerzeel, W. W.: Importance of snow and glacier meltwater for agriculture on the Indo-Gangetic Plain, Nat. Sustain., doi:10.1038/s41893-019-0305-3, 2019.

Boer, G. J.: Climate change and the regulation of the surface moisture and energy budgets, Clim. Dyn., doi:10.1007/BF00198617, 1993.

Bolch, T., Kulkarni, A., Kääb, A., Huggel, C., Paul, F., Cogley, J. G., Frey, H., Kargel, J. S., Fujita, K., Scheel, M., Bajracharya, S. and Stoffel, M.: The state and fate of himalayan glaciers, Science (80-. )., doi:10.1126/science.1215828, 2012.

Bolch, T., Pieczonka, T., Mukherjee, K. and Shea, J.: Brief communication: Glaciers in the Hunza catchment (Karakoram) have been nearly in balance since the 1970s, Cryosphere, doi:10.5194/tc-11-531-2017, 2017.

Bonekamp, P. N. J., Collier, E. and Immerzeel, W. W.: The impact of spatial resolution, landuse and spin-up time on resolving spatial precipitation patterns in the Himalayas, J. Hydrometeorol., 19(10), 1565-1591, doi:10.1175/JHM-D-17-0212.1, 2018.

Bonekamp, P. N. J., de Kok, R. J., Collier, E. and Immerzeel, W. W.: Contrasting Meteorological Drivers of the Glacier Mass Balance Between the Karakoram and Central Himalaya, Front. Earth Sci., 7(June), 1-14, doi:10.3389/feart.2019.00107, 2019.

Bookhagen, B. and Burbank, D. W.: Toward a complete Himalayan hydrological budget: Spatiotemporal distribution of snowmelt and rainfall and their impact on river discharge, J. Geophys. Res. Earth Surf., 115(3), 1-25, doi:10.1029/2009JF001426, 2010.

Bowden, J. H., Nolte, C. G. and Otte, T. L.: Simulating the impact of the large-scale circulation on the 2-m temperature and precipitation climatology, Clim. Dyn., 40(7-8), 1903-1920, doi:10.1007/s00382-012-1440-y, 2013.

Brun, F., Buri, P., Miles, E. S., Wagnon, P., Steiner, J., Berthier, E., Ragettli, S., Kraaijenbrink, P., Immerzeel, W. W. and Pellicciotti, F.: Quantifying volume loss from ice cliffs on debris-covered glaciers using high-resolution terrestrial and aerial photogrammetry, J. Glaciol., 62(234), 684-695, doi:10.1017/jog.2016.54, 2016.

Brun, F., Berthier, E., Wagnon, P., Kääb, A. and Treichler, D.: A spatially resolved estimate of High Mountain Asia glacier mass 
balances from 2000 to 2016, Nat. Geosci., 10(9), 668, doi:10.1038/ngeo2999, 2017.

Brun, F., Berthier, E., Wagnon, P., Kaäb, A. and Treichler, D.: Correction: A spatially resolved estimate of High Mountain Asia glacier mass balances from 2000 to 2016 (Nature Geoscience DOI: 10.1038/ngeo2999), Nat. Geosci., 11(7), 543, doi:10.1038/s41561-018-0171-z, 2018a.

Brun, F., Wagnon, P., Berthier, E., Shea, J. M., Immerzeel, W. W., Kraaijenbrink, D. A., Vincent, C., Reverchon, C., Shrestha, D. and Arnaud, Y.: Ice cliff contribution to the tongue-wide ablation of Changri Nup Glacier, Nepal, Central Himalaya, Cryosph. Discuss., 12(11), 3439-3457, doi:10.5194/tc-12-3439-2018, 2018b.

Brunello, C. F., Andermann, C., Helle, G., Comiti, F., Tonon, G., Tiwari, A. and Hovius, N.: Hydroclimatic seasonality recorded by tree ring $\delta 180$ signature across a Himalayan altitudinal transect, Earth Planet. Sci. Lett., doi:10.1016/j.epsl.2019.04.030, 2019.

Buizza, R., Miller, M. and Palmer, T. N.: Stochastic representation of model uncertainties in the ECMWF Ensemble Prediction System, Q. J. R. Meteorol. Soc., doi:10.1256/smsqj.56005, 1999.

Buri, P. and Pellicciotti, F.: Aspect controls the survival of ice cliffs on debris-covered glaciers, Proc. Natl. Acad. Sci., 115(17), 4369-4374, doi:10.1073/pnas.1713892115, 2018.

Buri, P., Pellicciotti, F., Steiner, J. F., Miles, E. S. and Immerzeel, W. W.: A grid-based model of backwasting of supraglacial ice cliffs on debris-covered glaciers, Ann. Glaciol., 57(71), 199-211, doi:10.3189/2016AoG71A059, 2016 a.

Buri, P., Miles, E. S., Steiner, J. F., Immerzeel, W. W., Wagnon, P. and Pellicciotti, F.: A physically based 3-D model of ice cliff evolution over debris-covered glaciers, J. Geophys. Res. Earth Surf., 121, 2471-2493, doi:10.1002/2016JF004039, $2016 \mathrm{~b}$.

Cannon, F., Carvalho, L. M. V, Jones, C. and Norris, J.: Winter westerly disturbance dynamics and precipitation in the western Himalaya and Karakoram: a wave-tracking approach, Theor. Appl. Climatol., 125(1-2), 27-44, doi:10.1007/s00704-0151489-8, 2016.

Cannon, F., Carvalho, L. M. V., Jones, C., Norris, J., Bookhagen, B. and Kiladis, G. N.: Effects of Topographic Smoothing on the Simulation of Winter Precipitation in High Mountain Asia, J. Geophys. Res., 122(3), 1456-1474, doi:10.1002/2016JD026038, 2017.

Cheng, F.-Y., Hsu, Y.-C., Lin, P.-L. and Lin, T.-H.: Investigation of the effects of different land use and land cover patterns on mesoscale meteorological simulations in the Taiwan area, J. Appl. Meteorol. Climatol., 52(3), 570-587, 2013.

Christensen, J. H., Hewitson, B., Busuioc, A., Chen, A., Gao, X., Held, I., Jones, R., Kolli, R. ., Kwon, W. ., Laprise, R., Rueda, V., Mearns, L., Menéndez, C. G., Röisänen, J., Rinke, A., Sarr, A. and Whetton, P.: Climate Change 2007: Regional Climate Projections., 2007

Christensen, J. H., Kumar, K. K., Aldrian, E., An, S.-I., Cavalcanti, I. F. A., Castro, M. de, Dong, W., Goswami, P., Hall, A., Kanyanga, J. K., Kitoh, A., Kossin, J., Lau, N.-C., Renwick, J., Stephenson, D. B., Xie, S.-P. and Zhou, T.: Climate change 2013 the physical science basis: Working Group I contribution to the fifth assessment report of the intergovernmental panel on climate change, in Climate Change 2013 the Physical Science Basis: Working Group I Contribution to the Fifth Assessment Report of the Intergovernmental Panel on Climate Change. [Stocker, T.F., D. Qin, G.-K. Plattner, M. Tignor, S.K. Allen, J. Boschung, A. Nauels, Y. Xia, V., Cambridge, United Kingdom and New York, NY, USA., 2013.

Collier, E. and Immerzeel, W. W.: High-resolution modeling of atmospheric dynamics in the Nepalese Himalaya, J. Geophys. Res. Atmos., 120(19), 9882-9896, doi:10.1002/2015JD023266, 2015.

Collier, E., Mölg, T., Maussion, F., Scherer, D., Mayer, C. and Bush, A. B. G.: High-resolution interactive modelling of the mountain glacier-atmosphere interface: An application over the Karakoram, Cryosphere, 7(3), 779-795, doi:10.5194/tc-7-7792013, 2013.

Collier, E., Nicholson, L. I., Brock, B. W., Maussion, F., Essery, R. and Bush, A. B. G.: Representing moisture fluxes and phase changes in glacier debris cover using a reservoir approach, Cryosph., 8(4), 1429-1444, doi:10.5194/tc-8-1429-2014, 2014.

Collier, E., Maussion, F., Nicholson, L. I., Mölg, T., Immerzeel, W. W. and Bush, A. B. G.: Impact of debris cover on glacier ablation and atmosphere-glacier feedbacks in the Karakoram, Cryosphere, 9(4), 1617-1632, doi:10.5194/tc-9-1617-2015, 2015.

Copernicus: Quality of ERA-Interim and comparison with other datasets: precipitation, [online] Available from: https://climate.copernicus.eu/quality-era-interim-and-comparison-other-datasets-precipitation (Accessed 27 March 2020), 2017.

Copernicus Climate Change Service (C3S): ERA5: Fifth generation of ECMWF atmospheric reanalyses of the global climate. Copernicus Climate Change Service Climate Data Store (CDS), [online] Available from: https://cds.climate.copernicus.eu/cdsapp\#!/home, 2017.

Cuffey, K. M. and Paterson, W. S. B.: The physics of glaciers, Academic Press., 2010.

Dadic, R., Mott, R., Lehning, M. and Burlando, P.: Wind influence on snow depth distribution and accumulation over glaciers, J. Geophys. Res. Earth Surf., 115(1), 1-8, doi:10.1029/2009JF001261, 2010.

Dai, A.: Precipitation characteristics in eighteen coupled climate models, J. Clim., doi:10.1175/JCLI3884.1, 2006.

Dee, D. P., Uppala, S. M., Simmons, A. J., Berrisford, P., Poli, P., Kobayashi, S., Andrae, U., Balmaseda, M. A., Balsamo, G., Bauer, P., Bechtold, P., Beljaars, A. C. M., Berg, L. Van De, Bidlot, J., Bormann, N., Delsol, C., Dragani, R., Fuentes, M., Geer, A. J. and Dee, D. P.: The ERA-Interim reanalysis : configuration and performance of the data assimilation system, , 137(656), 553-597, doi:10.1002/qj.828, 2011a.

Dee, D. P., Uppala, S. M., Simmons, A. J., Berrisford, P., Poli, P., Kobayashi, S., Andrae, U., Balmaseda, M. A., Balsamo, G., Bauer, P. and others: The ERA-Interim reanalysis: Configuration and performance of the data assimilation system, Q. J. R. Meteorol. Soc., 137(656), 553-597, 2011b.

Defourny, P., Bontemps, S., Lamarche, C., Brockmann, C., Boettcher, M., Wevers, J., Kirches, G. and Santoro, M.: Land Cover CCI PRODUCT USER GUIDE - VERSION 2.0, Esa, doi:10.1080/00223980.1975.9923902, 2017.

Dimitrova, R., Silver, Z., Zsedrovits, T., Hocut, C. M., Leo, L. S., Di, S. and Fernando, H. J. S.: Assessment of Planetary BoundaryLayer Schemes in the Weather Research and Forecasting Mesoscale Model Using MATERHORN Field Data, BoundaryLayer Meteorol., 159(3), 589-609, doi:10.1007/s10546-015-0095-8, 2016. 
Dimotakis, P. E.: The mixing transition in turbulent flows, J. Fluid Mech., doi:10.1017/\$0022112099007946, 2000.

ECMWF: Experts to explore global modelling at resolutions under $10 \mathrm{~km}$, [online] Available from: https://www.ecmwf.int/en/about/media-centre/news/2017/experts-explore-global-modelling-resolutions-under-10-km, 2017.

ECMWF, S. P.: IFS documentation CY40R1 Part IV: Physical Processes, ECMWF:Reading, UK., 2007.

European Centre for Medium-Range Weather Forecasts (ECMWF): ERA5 monthly averaged data on single levels from 1979 to present, ERA5 Mon. averaged data single levels from 1979 to Present, doi:10.24381/cds.f17050d7, 2019.

Evensen, G.: Data assimilation: The ensemble kalman filter, v2 ed., Springer-Verlag Berlin Heidelberg., 2009.

FAO: Land Cover Map, 2017.

Farinotti, D., Immerzeel, W. W., Kok, R. J. De, Quincey, D. J. and Dehecq, A.: Manifestations and mechanisms of the Karakoram glacier Anomaly, Nat. Geosci., 13(January), 8-16, doi:10.1038/s41561-019-0513-5, 2020.

Fedorovich, E. and Shapiro, A.: Structure of numerically simulated katabatic and anabatic flows along steep slopes, Acta Geophys., 57(4), 981-1010, doi:10.2478/s11600-009-0027-4, 2009.

Fitzpatrick, N., Radić, V. and Menounos, B.: Surface energy balance closure and turbulent flux parameterization on a mid-latitude mountain Glacier, Purcell mountains, Canada, Front. Earth Sci., 5(67), doi:10.3389/feart.2017.00067, 2017.

Forsythe, N., Fowler, H. J., Li, X. F., Blenkinsop, S. and Pritchard, D.: Karakoram temperature and glacial melt driven by regional atmospheric circulation variability, Nat. Clim. Chang., 7(9), 664, doi:10.1038/nclimate3361, 2017.

Fowler, H. J. and Archer, D. R.: Hydro-climatological variability in the Upper Indus Basin and implications for water resources, Reg. Hydrol. Impacts Clim. Chang. Assess. Decis. Mak., 295, 131-138, doi:0144-7815\r978-1-901502-08-4, 2005.

Fowler, H. J. and Archer, D. R.: Conflicting signals of climatic change in the upper Indus Basin, J. Clim., doi:10.1175/JCLI3860.1, 2006.

Fyffe, C. L., Reid, T. D., Brock, B. W., Kirkbride, M. P., Diolaiuti, G., Smiraglia, C. and Diotri, F.: A distributed energy-balance melt model of an alpine debris-covered glacier, J. Glaciol., 60(221), 587-602, doi:10.3189/2014JoG13J148, 2014.

Gao, Y., Chen, F., Lettenmaier, D. P., Xu, J., Xiao, L. and Li, X.: Does elevation-dependent warming hold true above $5000 \mathrm{~m}$ elevation? Lessons from the Tibetan Plateau, npj Clim. Atmos. Sci., 9, doi:10.1038/s41612-018-0030-z, 2018.

García-Díez, M., Fernández, J., Fita, L. and Yagüe, C.: Seasonal dependence of WRF model biases and sensitivity to PBL schemes over Europe, Q. J. R. Meteorol. Soc., 139(671), 501-514, 2013.

Gardelle, J., Berthier, E. and Arnaud, Y.: Slight mass gain of Karakoram glaciers in the early twenty-first century, Nat. Geosci., 5(5), 322-325, doi:10.1038/ngeo1450, 2012.

Gardelle, J., Berthier, E., Arnaud, Y. and Kääb, A.: Region-wide glacier mass balances over the Pamir-Karakoram-Himalaya during 1999\&ndash;2011, Cryosphere, doi:10.5194/tc-7-1263-2013, 2013.

Gardner, A. S., Moholdt, G., Cogley, J. G., Wouters, B., Arendt, A. A., Wahr, J., Berthier, E., Hock, R., Pfeffer, W. T., Kaser, G., Ligtenberg, S. R. M., Bolch, T., Sharp, M. J., Hagen, J. O. and Asia, N.: A Reconciled Estimate of Glacier 2003 to 2009, Science (80-. )., 340(6134), 852-957, doi:10.1126/science.1234532, 2013.

Ghosh, S., Luniya, V. and Gupta, A.: Trend analysis of Indian summer monsoon rainfall at different spatial scales, Atmos. Sci. Lett., 10, 285-290, doi:10.1002/asl.235, 2009.

Giese, A.: Heat flow, energy balance, and radar propagation: porous media studies applied to the melt of Changri Nup Glacier, Nepal Himalayas, Doctoral dissertation, Darthmonth College, Hanover, New Hampshire., 2019.

Giese, A., Boone, A., Wagnon, P. and Hawley, R.: Incorporating moisture content in surface energy balance modeling of a debriscovered glacier, , (September), 2019.

Giovannini, L., Antonacci, G., Zardi, D., Laiti, L. and Panziera, L.: Sensitivity of simulated wind speed to spatial resolution over complex terrain, Energy Procedia, 59, 323-329, 2014.

Gleick, P. H.: Water and Conflict: Fresh Water Resources and International Security, Int. Secur., 18(1), 79, doi:10.2307/2539033, 1993.

Goodison, B. E., Louie, P. Y. T. and Yang, D.: WMO solid precipitation measurement intercomparison, World Meteorological Organization Geneva., 1998.

Greuell, W. and Smeets, P.: Variations with elevation in the surface energy balance on the Pasterze (Austria), J. Geophys. Res. Atmos., 106, 31717-31727, doi:10.1029/2001JD900127, 2001.

Groisman, P. Y. and Legates, D. R.: The accuracy of United States precipitation data, Bull. - Am. Meteorol. Soc., 75, 215-227, doi:10.1175/1520-0477(1994)075<0215:TAOUSP>2.0.CO;2, 1994.

Groos, A. R., Mayer, C., Smiraglia, C., Diolaiuti, G. and Lambrecht, A.: A first attempt to model region-wide glacier surface mass balances in the Karakoram: Findings and future challenges, Geogr. Fis. e Din. Quat., 40(2), 137-159, doi:10.4461/GFDQ2017.40.10, 2017.

Hall, D. K. and Riggs, G. A.: MODIS/Terra Snow Cover Monthly L3 Global 0.05Deg CMG, Version 6., Boulder, Colorado, USA., 2015. Hauser, M., Gudmundsson, L., Orth, R., Jézéquel, A., Haustein, K., Vautard, R., van Oldenborgh, G. J., Wilcox, L. and Seneviratne, S. I.: Methods and Model Dependency of Extreme Event Attribution: The 2015 European Drought, Earth's Futur., Earth's $\mathrm{Fu}(5), 1034-1043$, doi:10.1002/2017EF000612, 2017.

Hazeleger, W., Wang, X., Severijns, C., Ştefănescu, S., Bintanja, R., Sterl, A., Wyser, K., Semmler, T., Yang, S., van den Hurk, B., van Noije, T., van der Linden, E. and van der Wiel, K.: EC-Earth V2.2: Description and validation of a new seamless earth system prediction model, Clim. Dyn., 39(11), 2611-2629, doi:10.1007/s00382-011-1228-5, 2012.

Hazeleger, W., Van Den Hurk, B. J. J. M., Min, E., Van Oldenborgh, G. J., Petersen, A. C., Stainforth, D. A., Vasileiadou, E. and Smith, L. A.: Tales of future weather, Nat. Clim. Chang., doi:10.1038/nclimate2450, 2015.

Heerwaarden, C. C. van, Mellado, J. P. and de Lozar, A.: Scaling laws for the heterogeneously heated free convective boundary layer, J. Atmos. Sci., 71, 3975-4000, doi:10.1175/JAS-D-13-0383.1, 2014.

Heerwaarden, C. C. Van and Mellado, J. P.: Growth and decay of a convective boundary layer over a surface with a constant temperature, J. Atmos. Sci., doi:10.1175/JAS-D-15-0315.1, 2016. 
Heerwaarden, C. C. Van, Stratum, B. J. H. Van, Heus, T., Gibbs, J. A. and Fedorovich, E.: MicroHH 1.0 : a computational fluid dynamics code for direct numerical simulation and large-eddy simulation of atmospheric boundary layer flows, Geosci. Model Dev., 10, 3145-3165, doi:https://doi.org/10.5194/gmd-10-3145-2017, 2017.

Held, I. M. and Soden, B. J.: Robust responses of the hydrological cycle to global warming, J. Clim., doi:10.1175/JCLI3990.1, 2006.

Hewitt, K.: Altitudinal organization of Karakoram geomorphic processes and depositional environments., edited by S. J. Jr, Routledge, New York., 2002.

Hewitt, K.: The Karakoram Anomaly? Glacier Expansion and the 'Elevation Effect,' Karakoram Himalaya, Mt. Res. Dev., 25(4), 332-340, doi:10.1659/0276-4741(2005)025[0332:TKAGEA]2.0.CO;2, 2005

Hiyama, T., Asai, K., Kolesnikov, A. B., Gagarin, L. A. and Shepelev, V. V.: Estimation of the residence time of permafrost groundwater in the middle of the Lena River basin, eastern Siberia, Environ. Res. Lett., 8(3), doi:10.1088/17489326/8/3/035040, 2013.

Hock, R. and Holmgren, B.: A distributed surface energy-balance model for complex topography and its application to Storglaciären, Sweden, J. Glaciol., 51(172), 25-36, doi:10.3189/172756505781829566, 2005

Hoke, J. E. and Anthes, R. A.: The Initialization of Numerical Models by a Dynamic-Initialization Technique, Mon. Weather Rev., 104, 1551-1556, doi:10.1175/1520-0493(1976)104<1551:tionmb>2.0.co;2, 1976.

Holmstrom, M., Liu, D. and Vo, C.: Machine Learning Applied to Weather Forecasting, Meteorol. Appl., Dec, 2016.

Hong, S.-Y. and Dudhia, J.: Next-Generation Numerical Weather Prediction: Bridging Parameterization, Explicit Clouds, and Large Eddies, Bull. Am. Meteorol. Soc., 93(1), ES6-ES9, doi:10.1175/2011BAMS3224.1, 2012.

Hong, S.-Y., Noh, Y. and Dudhia, J.: A New Vertical Diffusion Package with an Explicit Treatment of Entrainment Processes, Mon. Weather Rev., 134(9), 2318-2341, doi:10.1175/MWR3199.1, 2006.

Horvath, K., Koracin, D., Vellore, R., Jiang, J. and Belu, R.: Sub-kilometer dynamical downscaling of near-surface winds in complex terrain using WRF and MM5 mesoscale models, J. Geophys. Res. Atmos., 117(D11), 2012.

Hu, X.-M., Nielsen-Gammon, J. W. and Zhang, F.: Evaluation of three planetary boundary layer schemes in the WRF model, J. Appl. Meteorol. Climatol., 49(9), 1831-1844, 2010.

Huffman, G., Bolvin, D. T., Braithwaite, D., Hsu, K., Joyce, R. and Xie, P.: NASA Global Precipitation Measurement (GPM) Integrated Multi-satellitE Retrievals for GPM (IMERG), version 4.4., 2014.

Huffman, G. J., Adler, R. F., Bolvin, D. T., Gu, G., Nelkin, E. J., Bowman, K. P., Hong, Y., Stocker, E. F. and Wolff, D. B.: The TRMM Multisatellite Precipitation Analysis (TMPA): Quasi-global, multiyear, combined-sensor precipitation estimates at fine scales, J. Hydrometeorol., 8, 38-55, doi:10.1175/JHM560.1, 2007.

Huss, M. and Hock, R.: Global-scale hydrological response to future glacier mass loss, Nat. Clim. Chang., doi:10.1038/s41558-0170049-x, 2018.

lacono, M. J., Delamere, J. S., Mlawer, E. J., Shephard, M. W., Clough, S. A. and Collins, W. D.: Radiative forcing by long-lived greenhouse gases: Calculations with the AER radiative transfer models, J. Geophys. Res. Atmos., 113(13), doi:10.1029/2008JD009944, 2008.

Immerzeel, W. W., Van Beek, L. P. H. and Bierkens, M. F. P.: Climate change will affect the Asian water towers, Science (80-. )., 328(5984), 1382-1385, 2010

Immerzeel, W. W., Pellicciotti, F. and Bierkens, M. F. P.: Rising river flows throughout the twenty-first century in two Himalayan glacierized watersheds, Nat. Geosci., doi:10.1038/ngeo1896, 2013.

Immerzeel, W. W., Kraaijenbrink, P. D. A., Shea, J. M., Shrestha, A. B., Pellicciotti, F., Bierkens, M. F. P. and de Jong, S. M.: Highresolution monitoring of Himalayan glacier dynamics using unmanned aerial vehicles, Remote Sens. Environ., 150, 93103, doi:10.1016/j.rse.2014.04.025, 2014a.

Immerzeel, W. W., Petersen, L., Ragettli, S. and Pellicciotti, F.: The importance of observed gradients of air temperature and precipitation for modeling runoff from a glacierized watershed in the Nepalese Himalayas, Water Resour. Res., doi:10.1002/2013WR014506, 2014b.

Immerzeel, W. W., Wanders, N., Lutz, A. F., Shea, J. M. and Bierkens, M. F. P.: Reconciling high-altitude precipitation in the upper Indus basin with glacier mass balances and runoff, Hydrol. Earth Syst. Sci., 19(11), 4673-4687, doi:10.5194/hess-19-46732015, 2015.

Immerzeel, W. W., Lutz, A. F., Andrade, M., Bahl, A., Biemans, H., Bolch, T., Hyde, S., Brumby, S., Davies, B. J., Elmore, A. C., Emmer, A., Feng, M., Fernández, A., Haritashya, U., Kargel, J. S., Koppes, M., Kraaijenbrink, P. D. A., Kulkarni, A. V., Mayewski, P. A., Nepal, S., Pacheco, P., Painter, T. H., Pellicciotti, F., Rajaram, H., Rupper, S., Sinisalo, A., Shrestha, A. B., Viviroli, D., Wada, Y., Xiao, C., Yao, T. and Baillie, J. E. M.: Importance and vulnerability of the world's water towers, Nature, 577(7790), 364-369, doi:10.1038/s41586-019-1822-y, 2020.

Iturrizaga, L.: The valley of Shimshall - A geographical portrait of a remote high mountain settlement and its pastures with reference to environmental habitat conditions in the North-West Karakorum (Pakistan), GeoJournal, 42(2-3), 303-328, doi:10.1023/A:1006869406576, 1997.

Jacob, T., Wahr, J., Pfeffer, W. T. and Swenson, S.: Recent contributions of glaciers and ice caps to sea level rise, Nature, 482(7386), 514, doi:10.1038/nature10847, 2012.

James, R., Washington, R., Schleussner, C. F., Rogelj, J. and Conway, D.: Characterizing half-a-degree difference: a review of methods for identifying regional climate responses to global warming targets, Wiley Interdiscip. Rev. Clim. Chang., doi:10.1002/wcc.457, 2017.

Jankov, I., Gallus Jr, W. A., Segal, M. and Koch, S. E.: Influence of initial conditions on the WRF--ARW model QPF response to physical parameterization changes, Weather Forecast., 22(3), 501-519, 2007.

Jin, J., Miller, N. L. and Schlegel, N.: Sensitivity study of four land surface schemes in the WRF model, Adv. Meteorol., $2010,2010$.

Jury, M. W., Mendlik, T., Tani, S., Truhetz, H., Maraun, D., Immerzeel, W. W. and Lutz, A. F.: Climate projections for glacier change modelling over the Himalayas, Int. J. Climatol., doi:10.1002/joc.6298, 2019.

Kääb, A., Berthier, E., Nuth, C., Gardelle, J. and Arnaud, Y.: Contrasting patterns of early twenty-first-century glacier mass change 
in the Himalayas, Nature, doi:10.1038/nature11324, 2012.

Kääb, A., Treichler, D., Nuth, C. and Berthier, E.: Brief Communication: Contending estimates of 2003-2008 glacier mass balance over the Pamir-Karakoram-Himalaya, Cryosphere, 9(2), 557-564, doi:10.5194/tc-9-557-2015, 2015.

Kain, J. S.: The Kain-Fritsch Convective Parameterization: An Update, J. Appl. Meteorol., 43(1), 170-181, doi:10.1175/15200450(2004)043<0170:TKCPAU>2.0.CO;2, 2004.

Kapnick, S. B., Delworth, T. L., Ashfaq, M., Malyshev, S. and Milly, P. C. D.: Snowfall less sensitive to warming in Karakoram than in Himalayas due to a unique seasonal cycle, Nat. Geosci., 7(11), 834-840, doi:10.1038/ngeo2269, 2014.

Kapos, V., Rhind, J., Edwards, M., Ravilious, C., Price, M. F. and Butt, N.: Developing a map of the world's mountain forests., in Forests in sustainable mountain development: a state of knowledge report for 2000. Task Force on Forests in Sustainable Mountain Development., 2000.

Kirschbaum, D., Kapnick, S. B., Stanlet, T. and Pascale, S.: Changes in Extreme Precipitation and Landslides over High Mountain Asia, Geophys. Res. Lett., 47, doi:10.1029/2019GL085347, 2020.

Kleczek, M. A., Steeneveld, G.-J. and Holtslag, A. A. M.: Evaluation of the weather research and forecasting mesoscale model for GABLS3: impact of boundary-layer schemes, boundary conditions and spin-up, Boundary-layer Meteorol., 152(2), 213243, 2014.

Knuth, S. L. and Cassano, J. J.: Estimating sensible and latent heat fluxes using the integral method from in situ aircraft measurements, J. Atmos. Ocean. Technol., doi:10.1175/JTECH-D-14-00008.1, 2014.

de Kok, R. J., Tuinenburg, O. A., Bonekamp, P. N. J. and Immerzeel, W. W.: Irrigation as a Potential Driver for Anomalous Glacier Behavior in High Mountain Asia, Geophys. Res. Lett., 45(4), 2047-2054, doi:10.1002/2017GL076158, 2018.

Kotlarski, S., Jacob, D., Podzun, R. and Paul, F.: Representing glaciers in a regional climate model, Clim. Dyn., 34, 27-46, doi:10.1007/s00382-009-0685-6, 2010.

Kraaijenbrink, P. D. A., Shea, J. M. M., Pellicciotti, F., De Jong, S. M., Immerzeel, W. W., Jong, S. M. D. and Immerzeel, W. W. W.: Object-based analysis of unmanned aerial vehicle imagery to map and characterise surface features on a debris-covered glacier, Remote Sens. Environ., 186, 581-595, doi:10.1016/j.rse.2016.09.013, 2016.

Kraaijenbrink, P. D. A., Bierkens, M. F. P., Lutz, A. F. and Immerzeel, W. W.: Impact of a global temperature rise of 1.5 degrees Celsius on Asia's glaciers, Nature, doi:10.1038/nature23878, 2017a.

Kraaijenbrink, P. D. A., Shea, J. M., Litt, M., Steiner, J. F., Treichler, D., Koch, I. and Immerzeel, W. W.: Mapping surface temperatures on a debris-covered glacier with an unmanned aerial vehicle, Front. Earth Sci., 6, doi:10.3389/feart.2018.00064, 2018.

Krasnopolsky, V. M. and Fox-Rabinovitz, M. S.: Complex hybrid models combining deterministic and machine learning components for numerical climate modeling and weather prediction, Neural Networks, 19(2), 122-134, doi:10.1016/j.neunet.2006.01.002, 2006.

Krishna Kumar, K., Patwardhan, S. K., Kulkarni, A., Kamala, K., Koteswara Rao, K. and Jones, R.: Simulated projections for summer monsoon climate over India by a high-resolution regional climate model (PRECIS), Curr. Sci., 2011.

Kuang, X. and Zhang, Y.: Seasonal variation of the East Asian Subtropical Westerly Jet and its association with the heating field over East Asia, Adv. Atmos. Sci., 22, 831-840, 2005.

Lambert, S. J.: The effect of enhanced greenhouse warming on winter cyclone frequencies and strengths, J. Clim., 8, 1447-1452, doi:10.1175/1520-0442(1995)008<1447:teoegw>2.0.co;2, 1995.

Lau, K. M. and Yang, S.: Climatology and interannual variability of the Southeast Asian summer monsoon, Adv. Atmos. Sci., 14(2), 141-162, doi:10.1007/s00376-997-0016-y, 1997.

Lehning, M., Bartelt, P., Brown, B., Fierz, C. and Satyawali, P.: A physical SNOWPACK model for the Swiss avalanche warning Part II. Snow microstructure, Cold Reg. Sci. Technol., 35(3), 147-167, doi:10.1016/S0165-232X(02)00073-3, 2002.

Lejeune, Y., Bertrand, J. M., Wagnon, P. and Morin, S.: A physically based model of the year-round surface energy and mass balance of debris-covered glaciers, J. Glaciol., doi:10.3189/2013JoG12J149, 2013.

Li, J., Wu, Z., Jiang, Z. and He, J.: Can global warming strengthen the East Asian summer monsoon?, J. Clim., 23, 6696-6705, doi:10.1175/2010JCLI3434.1, 2010.

Liu, J. and Chen, R.: Discriminating types of precipitation in Qilian Mountains, Tibetan Plateau, J. Hydrol. Reg. Stud., 5, 20-32, 2016.

Liu, X. and Chen, B.: Climatic warming in the Tibetan Plateau during recent decades, Int. J. Climatol., doi:10.1002/10970088(20001130)20:14<1729::AID-JOC556>3.0.CO;2-Y, 2000.

Liu, Y., Warner, T. T., Astling, E. G., Bowers, J. F., Davis, C. A., Halvorson, S. F., Rife, D. L., Sheu, R.-S., Swerdlin, S. P. and Xu, M.: The operational mesogamma-scale analysis and forecast system of the US Army test and evaluation command. Part II: Interrange comparison of the accuracy of model analyses and forecasts, J. Appl. Meteorol. Climatol., 47(4), 1093-1104, 2008.

Loveland, T. R., Reed, B. C., Ohlen, D. O., Brown, J. F., Zhu, Z., Yang, L. and Merchant, J. W.: Development of a global land cover characteristics database and IGBP DISCover from $1 \mathrm{~km}$ AVHRR data, Int. J. Remote Sens., 21(6-7), 1303-1330, doi:10.1080/014311600210191, 2000.

Lundqvist, J. and Falkenmark, M.: Towards Hydrosolidarity: Focus on the upstream-downstream conflicts of interests, Int. Water Resour. Assoc., 25(2), 168-171, doi:10.1080/02508060008686814, 2000.

Lutz, A. F., Immerzeel, W. W., Shrestha, A. B. and Bierkens, M. F. P.: Consistent increase in High Asia's runoff due to increasing glacier melt and precipitation, Nat. Clim. Chang., 4(7), 587-592, doi:10.1038/nclimate2237, 2014.

Lutz, A. F., Immerzeel, W. W., Kraaijenbrink, P. D. A., Shrestha, A. B. and Bierkens, M. F. P.: Climate Change Impacts on the Upper Indus Hydrology : Sources, Shifts and Extremes, , (November), doi:10.1371/journal.pone.0165630, $2016 \mathrm{a}$.

Lutz, A. F., Maat, W., Biemans, H. and Shrestha, A. B.: Selecting representative climate models for climate change impact studies : an advanced envelope-based selection approach, Int. J. ofClimatology Publ., doi:10.1002/joc.4608, $2016 \mathrm{~b}$.

Lutz, A. F., Maat, H. W., Wijngaard, R. R., Biemans, H., Syed, A. and Shrestha, A. B.: South Asian river basins in a $1.5^{\circ} \mathrm{C}$ warmer 
world, Reg. Environ. Chang., (November), doi:10.1007/s10113-018-1433-4, 2018.

Lutz, A. F. F., Immerzeel, W. W. W., Gobiet, A., Pellicciotti, F. and Bierkens, M. F. P. F. P.: Comparison of climate change signals in CMIP3 and CMIP5 multi-model ensembles and implications for Central Asian glaciers, Hydrol. Earth Syst. Sci., 17(9), 3661-3677, doi:10.5194/hess-17-3661-2013, 2013.

Maraun, D., Wetterhall, F., Ireson, A. M., Chandler, R. E., Kendon, E. J., Widmann, M., Brienen, S., Rust, H. W., Sauter, T., Themel, M., Venema, V. K. C., Chun, K. P., Goodess, C. M., Jones, R. G., Onof, C., Vrac, M. and Thiele-Eich, I.: Precipitation downscaling under climate change: Recent developments to bridge the gap between dynamical models and the end user, Rev. Geophys., doi:10.1029/2009RG000314, 2010.

Markus, T.: UU - Geosciences, Communicatie and marketing - Kartografie, 2020.

Marzeion, B., Cogley, J. G., Richter, K. and Parkes, D.: Attribution of Past Glacier Mass Loss to Anthropogenic and Natural Climate Forcing, Science (80-. )., 2014.

Maussion, F., Scherer, D., Finkelnburg, R., Richters, J., Yang, W. and Yao, T.: WRF simulation of a precipitation event over the Tibetan Plateau, China-an assessment using remote sensing and ground observations, Hydrol. Earth Syst. Sci., 15(6), 1795, 2011.

Maussion, F., Scherer, D., Mölg, T., Collier, E., Curio, J. and Finkelnburg, R.: Precipitation seasonality and variability over the Tibetan Plateau as resolved by the high Asia reanalysis, J. Clim., 27(5), 1910-1927, doi:10.1175/JCLI-D-13-00282.1, 2014.

Mayer, C., Lambrecht, A., Oerter, H., Schwikowski, M., Vuillermoz, E., Frank, N. and Diolaiuti, G.: Accumulation Studies at a High Elevation Glacier Site in Central Karakoram, Adv. Meteorol., 2014(September), doi:10.1155/2014/215162, 2014.

McCabe, M. F., Rodell, M., Alsdorf, D. E., Miralles, D. G., Uijlenhoet, R., Wagner, W., Lucieer, A., Houborg, R., Verhoest, N. E. C., Franz, T. E., Shi, J., Gao, H. and Wood, E. F.: The future of Earth observation in hydrology, Hydrol. Earth Syst. Sci., 21(7), 3879-3914, doi:10.5194/hess-21-3879-2017, 2017.

McCarthy, M., Pritchard, H., Willis, I. and King, E.: Ground-penetrating radar measurements of debris thickness on Lirung Glacier, Nepal, J. Glaciol., 63(239), 543-555, doi:10.1017/jog.2017.18, 2017.

Mellado, J. P.: Direct numerical simulation of free convection over a heated plate, J. Fluid Mech., 712, 418-450, doi:10.1017/jfm.2012.428, 2012.

Mihalcea, C., Mayer, C., Diolaiuti, G., D’Agata, C., Smiraglia, C., Lambrecht, A., Vuillermoz, E. and Tartari, G.: Spatial distribution of debris thickness and melting from remote-sensing and meteorological data, at debris-covered Baltoro glacier, Karakoram, Pakistan, in Annals of Glaciology., 2008.

Miles, E. S., Pellicciotti, F., Willis, I. C., Steiner, J. F., Buri, P. and Arnold, N. S.: Refined energy-balance modelling of a supraglacial pond, Langtang Khola, Nepal, Ann. Glaciol., 57(71), 29-40, doi:10.3189/2016AoG71A421, 2016.

Miles, E. S., Steiner, J. F. and Brun, F.: Highly variable aerodynamic roughness length (z0) for a hummocky debris-covered glacier, J. Geophys. Res. Atmos., 122(16), 8447-8466, doi:10.1002/2017JD026510, 2017a.

Miles, E. S., Steiner, J., Willis, I., Buri, P., Immerzeel, W. W., Chesnokova, A. and Pellicciotti, F.: Pond Dynamics and SupraglacialEnglacial Connectivity on Debris-Covered Lirung Glacier, Nepal, Front. Earth Sci., doi:10.3389/feart.2017.00069, 2017b.

Miles, E. S., Willis, I., Buri, P., Steiner, J. F., Arnold, N. S. and Pellicciotti, F.: Surface Pond Energy Absorption Across Four Himalayan Glaciers Accounts for 1/8 of Total Catchment Ice Loss, Geophys. Res. Lett., doi:10.1029/2018GL079678, 2018.

Moin, P. and Mahesh, K.: DIRECT NUMERICAL SIMULATION: A Tool in Turbulence Research, Annu. Rev. Fluid Mech., doi:10.1146/annurev.fluid.30.1.539, 1998.

Mölg, T. and Kaser, G.: A new approach to resolving climate-cryosphere relations: Downscaling climate dynamics to glacier-scale mass and energy balance without statistical scale linking, J. Geophys. Res. Atmos., 116(16), 1-13, doi:10.1029/2011JD015669, 2011.

Morrison, H., Thompson, G. and Tatarskii, V.: Impact of Cloud Microphysics on the Development of Trailing Stratiform Precipitation in a Simulated Squall Line: Comparison of One- and Two-Moment Schemes, Mon. Weather Rev., 137(3), 991-1007, doi:10.1175/2008MWR2556.1, 2009.

Moser, R. D., Kim, J. and Mansour, N. N.: Direct numerical simulation of turbulent channel flow up to Ret=590, Phys. Fluids, doi:10.1063/1.869966, 1999.

Mott, R., Daniels, M. and Lehning, M.: Atmospheric Flow Development and Associated Changes in Turbulent Sensible Heat Flux over a Patchy Mountain Snow Cover, J. Hydrometeorol., 16(3), 1315-1340, doi:10.1175/jhm-d-14-0036.1, 2014.

Nadeau, D. F., Pardyjak, E. R., Higgins, C. W., Huwald, H. and Parlange, M. B.: Flow during the evening transition over steep Alpine slopes, Q. J. R. Meteorol. Soc., doi:10.1002/qj.1985, 2013.

Nanditha, J., van der Wiel, K., Bhatia, U., Stone, D., Selton, F. and Mishra, V.: A seven-fold rise in the probability of exceeding the observed hottest summer in India in a $2{ }^{\circ} \mathrm{C}$ warmer world, Environ. Res. Lett., 15(4), 1-12, doi:10.1088/17489326/ab7555, 2020.

National_Geographic: Perpetual planet, [online] Available from: https://www.nationalgeographic.com/environment/perpetualplanet/ (Accessed 20 April 2020), 2019.

Nicholson, L. and Benn, D. I.: Calculating ice melt beneath a debris layer using meteorological data, J. Glaciol., 52(178), 463-470, doi:10.3189/172756506781828584, 2006.

Nicholson, L. and Benn, D. I.: Properties of natural supraglacial debris in relation to modelling sub-debris ice ablation, Earth Surf. Process. Landforms, 38(5), 490-501, doi:10.1002/esp.3299, 2012.

Niu, G.-Y., Yang, Z.-L., Mitchell, K. E., Chen, F., Ek, M. B., Barlage, M., Kumar, A., Manning, K., Niyogi, D., Rosero, E. and others: The community Noah land surface model with multiparameterization options (Noah-MP): 1. Model description and evaluation with local-scale measurements, J. Geophys. Res. Atmos., 116(D12), 2011a.

Niu, G. Y., Yang, Z. L., Mitchell, K. E., Chen, F., Ek, M. B., Barlage, M., Kumar, A., Manning, K., Niyogi, D., Rosero, E., Tewari, M. and Xia, Y.: The community Noah land surface model with multiparameterization options (Noah-MP): 1. Model description and evaluation with local-scale measurements, J. Geophys. Res. Atmos., 116(12), 1-19, doi:10.1029/2010JD015139, 2011b. 
Niwano, M., Aoki, T., Kuchiki, K., Hosaka, M. and Kodama, Y.: Snow Metamorphism and Albedo Process (SMAP) model for climate studies: Model validation using meteorological and snow impurity data measured at Sapporo, Japan, J. Geophys. Res. Earth Surf., 117(F3), 1-18, doi:10.1029/2011JF002239, 2012.

Norris, J., Carvalho, L. M. V, Jones, C., Cannon, F., Bookhagen, B., Palazzi, E. and Tahir, A. A.: The spatiotemporal variability of precipitation over the Himalaya: evaluation of one-year WRF model simulation, Clim. Dyn., 49(5-6), 2179-2204, 2017.

Norris, J., Carvalho, L. M. V., Jones, C. and Cannon, F.: Deciphering the contrasting climatic trends between the central Himalaya and Karakoram with 36 years of WRF simulations, Clim. Dyn., 0(0), 1-22, doi:10.1007/s00382-018-4133-3, 2018.

Nuimura, T., Fujita, K. and Sakai, A.: Downwasting of the debris-covered area of Lirung Glacier in Langtang Valley, Nepal Himalaya, from 1974 to 2010, Quat. Int., doi:10.1016/j.quaint.2017.06.066, 2017.

Ochoa, A., Pineda, L., Crespo, P. and Willems, P.: Evaluation of TRMM 3 B42 precipitation estimates and WRF retrospective precipitation simulation over the Pacific--Andean region of Ecuador and Peru, Hydrol. Earth Syst. Sci., 18(8), 3179, 2014.

Orr, A., Listowski, C., Couttet, M., Collier, E., Immerzeel, W., Deb, P. and Bannister, D.: Sensitivity of simulated summer monsoonal precipitation in Langtang Valley, Himalaya to cloud microphysics schemes in WRF, J. Geophys. Res. Atmos., 2017.

Orth, R., Staudinger, M., Seneviratne, S. I., Seibert, J. and Zappa, M.: Does model performance improve with complexity? A case study with three hydrological models, J. Hydrol., 523, 147-159, doi:10.1016/j.jhydrol.2015.01.044, 2015.

Ossa-Moreno, J., Keir, G., McIntyre, N., Cameletti, M. and Rivera, D.: Comparison of approaches to interpolating climate observations in steep terrains with low-density gauging networks, Hydrol. Earth Syst. Sci. Discuss., doi:10.5194/hess2018-505, 2018.

Östrem, G.: Ice Melting under a Thin Layer of Moraine, and the Existence of Ice Cores in Moraine Ridges, Geogr. Ann., 41(4), 228-230, doi:10.1080/20014422.1959.11907953, 1959.

Palazzi, E., Von Hardenberg, J. and Provenzale, A.: Precipitation in the hindu-kush karakoram himalaya: Observations and future scenarios, J. Geophys. Res. Atmos., 118(1), 85-100, doi:10.1029/2012JD018697, 2013.

Palazzi, E., von Hardenberg, J., Terzago, S. and Provenzale, A.: Precipitation in the Karakoram-Himalaya: a CMIP5 view, Clim. Dyn., doi:10.1007/s00382-014-2341-z, 2015.

Palazzi, E., Mortarini, L., Terzago, S. and von Hardenberg, J.: Elevation-dependent warming in global climate model simulations at high spatial resolution, Clim. Dyn., 52(5-6), 2685-2702, doi:10.1007/s00382-018-4287-z, 2019.

Papalexiou, S. M. and Montanari, A.: Global and Regional Increase of Precipitation Extremes Under Global Warming, Water Resour. Res., 55(6), 4901-4914, doi:10.1029/2018WR024067, 2019.

Paulson, C. A.: The Mathematical Representation of Wind Speed and Temperature Profiles in the Unstable Atmospheric Surface Layer, J. Appl. Meteorol., 9(6), 857-861, doi:10.1175/1520-0450(1970)009<0857:TMROWS>2.0.CO;2, 1970.

Pellicciotti, F., Stephan, C., Miles, E., Herreid, S., Immerzeel, W. W. and Bolch, T.: Mass-balance changes of the debris-covered glaciers in the Langtang Himalaya, Nepal, from 1974 to 1999, J. Glaciol., 61(226), 373-386, doi:10.3189/2015JoG13J237, 2015.

Pepin, N., Bradley, R. S., Diaz, H. F., Baraer, M., Caceres, E. B., Forsythe, N., Fowler, H., Greenwood, G., Hashmi, M. Z., Liu, X. D., Miller, J. R., Ning, L., Ohmura, A., Palazzi, E., Rangwala, I., Schöner, W., Severskiy, I., Shahgedanova, M., Wang, M. B., Williamson, S. N. and Yang, D. Q.: Elevation-dependent warming in mountain regions of the world, Nat. Clim. Chang., doi:10.1038/nclimate2563, 2015.

Pepin, N. C. and Lundquist, J. D.: Temperature trends at high elevations: Patterns across the globe, Geophys. Res. Lett., 35(14), 1-6, doi:10.1029/2008GL034026, 2008.

Planet Team: Planet Application Program Interface: In Space for Life on Earth, [online] Available from: https://www.planet.com (Accessed 7 January 2018), 2017.

Potter, E. R., Orr, A., Willis, I. C., Bannister, D. and Salerno, F.: Dynamical Drivers of the Local Wind Regime in a Himalayan Valley, J. Geophys. Res. Atmos., 123(23), 13,186-13,202, doi:10.1029/2018JD029427, 2018.

Pritchard, H. D.: Asia's shrinking glaciers protect large populations from drought stress, Nature, 569, 649-654, doi:10.1038/s41586-019-1240-1, 2019.

$\mathrm{Pu}, \mathrm{Z}$., Xu, L. and Salomonson, V. V.: MODIS/Terra observed seasonal variations of snow cover over the Tibetan Plateau, Geophys. Res. Lett., 34(6), doi:10.1029/2007GL029262, 2007.

Qiu, J.: China: The third pole, Nature, 454, 393-396, doi:10.1038/454393a, 2008.

Qiu, Y., Fu, B., Wang, J. and Chen, L.: Spatial variability of soil moisture content and its relation to environmental indices in a semi-arid gully catchment of the Loess Plateau, China, J. Arid Environ., doi:10.1006/jare.2001.0828, 2001.

Ragettli, S., Pellicciotti, F., Bordoy, R. and Immerzeel, W. W.: Sources of uncertainty in modeling the glaciohydrological response of a Karakoram watershed to climate change, Water Resour. Res., 49(9), 6048-6066, doi:10.1002/wrcr.20450, 2013.

Ragettli, S., Bolch, T. and Pellicciotti, F.: Heterogeneous glacier thinning patterns over the last 40 years in Langtang Himal, Nepal, Cryosphere, 10, 2075-2097, doi:10.5194/tc-10-2075-2016, 2016.

Rangwala, I., Sinsky, E. and Miller, J. R.: Variability in projected elevation dependent warming in boreal midlatitude winter in CMIP5 climate models and its potential drivers, Clim. Dyn., 46(6-8), 2115-2122, doi:10.1007/s00382-015-2692-0, 2016.

Rasmussen, R., Liu, C., Ikeda, K., Gochis, D., Yates, D., Chen, F., Tewari, M., Barlage, M., Dudhia, J., Yu, W. and others: Highresolution coupled climate runoff simulations of seasonal snowfall over Colorado: a process study of current and warmer climate, J. Clim., 24(12), 3015-3048, 2011.

Rasmussen, R., Baker, B., Kochendorfer, J., Meyers, T., Landolt, S., Fischer, A. P., Black, J., Thériault, J. M., Kucera, P., Gochis, D., Smith, C., Nitu, R., Hall, M., Ikeda, K. and Gutmann, E.: How well are we measuring snow: The NOAA/FAA/NCAR winter precipitation test bed, Bull. Am. Meteorol. Soc., 93(6), 811-829, doi:10.1175/BAMS-D-11-00052.1, 2012.

Reid, T. and Brock, B.: An energy-balance model for debris-covered glaciers including heat conduction through the debris layer, J. Glaciol., 56(199), 903-916, 2010a.

Reid, T. D. and Brock, B. W.: An energy-balance model for debris-covered glaciers including heat conduction through the debris 
layer, J. Glaciol., 56(199), 903-916, doi:10.3189/002214310794457218, $2010 \mathrm{~b}$.

Reid, T. D. and Brock, B. W.: Assessing ice-cliff backwasting and its contribution to total ablation of debris-covered Miage glacier, Mont Blanc massif, Italy, J. Glaciol., 60(219), 3-13, doi:10.3189/2014JoG13J045, 2014.

Reineman, B. D., Lenain, L., Statom, N. M. and Melville, K. K.: Development and testing of instrumentation for UAV-based flux measurements within terrestrial and marine atmospheric boundary layers, J. Atmos. Ocean. Technol., doi:10.1175/JTECH-D-12-00176.1, 2013.

Reinert, D. and Wirth, V.: A new large-eddy simulation model for simulating air flow and warm clouds above highly complex terrain. Part II: The moist model and its application to banner clouds, Boundary-layer Meteorol., 133(1), 113-136, 2009.

RGI Consortium: Randolph Glacier Inventory - A Dataset of Global Glacier Outlines: Version 6.0: Technical Report, Global Land Ice Measurements from Space, Colorado, USA., 2017.

Robins, N. S. and Fergusson, J.: Groundwater scarcity and conflict - managing hotspots, Earth Perspect., doi:10.1186/2194-64341-6, 2014.

Rodell, M., Houser, P. R., Jambor, U., Gottschalck, J., Mitchell, K., Meng, C. J., Arsenault, K., Cosgrove, B., Radakovich, J., Bosilovich, M., Entin, J. K., Walker, J. P., Lohmann, D. and Toll, D.: The Global Land Data Assimilation System, Bull. Am. Meteorol. Soc., 85(3), 381-394, doi:10.1175/BAMS-85-3-381, 2004.

Román-Cascón, C., Steeneveld, G. J., Yagüe, C., Sastre, M., Arrillaga, J. A. and Maqueda, G.: Forecasting radiation fog at climatologically contrasting sites: evaluation of statistical methods and WRF, Q. J. R. Meteorol. Soc., 142(695), 10481063, 2016.

Rossini, M., Di Mauro, B., Garzonio, R., Baccolo, G., Cavallini, G., Mattavelli, M., De Amicis, M. and Colombo, R.: Rapid melting dynamics of an alpine glacier with repeated UAV photogrammetry, Geomorphology, 304, 159-172, doi:10.1016/j.geomorph.2017.12.039, 2018.

Rounce, D. R., Quincey, D. J. and McKinney, D. C.: Debris-covered energy balance model for Imja-Lhotse Shar Glacier in the Everest region of Nepal, Cryosph., 9(3), 3503-3540, doi:10.5194/tcd-9-3503-2015, 2015.

Rounce, D. R., King, O., McCarthy, M., Shean, D. E. and Salerno, F.: Quantifying Debris Thickness of Debris-Covered Glaciers in the Everest Region of Nepal Through Inversion of a Subdebris Melt Model, J. Geophys. Res. Earth Surf., 123(5), 1094-1115, doi:10.1029/2017JF004395, 2018.

Rousseau, D.: A new skill score for the evaluation of yes/no forecasts, in WMO Symposium on Probabilistic and Statistical methods in weather forecasting, pp. 8--12., 1980.

Sakai, A. and Fujita, K.: Contrasting glacier responses to recent climate change in high-mountain Asia, Sci. Rep., 7(1), 1-8, doi:10.1046/j.1365-8711.1999.02268.x, 2017.

Sakai, A., Takeuchi, N., Fujita, K. and Nakawo, M.: Role of supraglacial ponds in the ablation process of a debris-covered glacier in the Nepal Himalayas, Debris-covered glaciers, (265), 119-130, 2000.

Sakai, A., Nakawo, M. and Fujita, K.: Distribution Characteristics and Energy Balance of Ice Cliffs on Debris-Covered Glaciers, Nepal Himalaya, Arctic, Antarct. Alp. Res., 34, 12/19, doi:10.2307/1552503, 2002.

Salerno, F., Guyennon, N., Thakuri, S., Viviano, G., Romano, E., Vuillermoz, E., Cristofanelli, P., Stocchi, P., Agrillo, G., Ma, Y. and Tartari, G.: Weak precipitation, warm winters and springs impact glaciers of south slopes of Mt. Everest (central Himalaya) in the last 2 decades (1994-2013), Cryosphere, 9, 1229-1247, doi:10.5194/tc-9-1229-2015, 2015.

Sauter, T. and Galos, S. P.: Effects of local advection on the spatial sensible heat flux variation on a mountain glacier, Cryosphere, 10(6), 2887-2905, doi:10.5194/tc-10-2887-2016, 2016.

Schultz, M. P. and Flack, K. A.: Reynolds-number scaling of turbulent channel flow, in International Symposium on Turbulence and Shear Flow Phenomena, TSFP 2013., 2013.

Sharmila, S., Joseph, S., Sahai, A. K., Abhilash, S. and Chattopadhyay, R.: Future projection of Indian summer monsoon variability under climate change scenario: An assessment from CMIP5 climate models, Glob. Planet. Change, doi:10.1016/j.gloplacha.2014.11.004, 2015.

Shea, J. M., Immerzeel, W. W., Wagnon, P., Vincent, C. and Bajracharya, S.: Modelling glacier change in the Everest region, Nepal Himalaya, Cryosphere, doi:10.5194/tc-9-1105-2015, 2015.

Skamarock, W. C.: Evaluating mesoscale NWP models using kinetic energy spectra, Mon. Weather Rev., 132(12), 3019-3032, 2004.

Skamarock, W. C. and Klemp, J. B.: A time-split nonhydrostatic atmospheric model for weather research and forecasting applications, J. Comput. Phys., 227(7), 3465-3485, 2008.

Skamarock, W. C., Klemp, J. B., Dudhi, J., Gill, D. O., Barker, D. M., Duda, M. G., Huang, X.-Y., Wang, W. and Powers, J. G.: A Description of the Advanced Research WRF Version 3, Tech. Rep., (June), 113, doi:10.5065/D6DZ069T, 2008.

Spalart, P. R.: Detached-Eddy Simulation, Annu. Rev. Fluid Mech., doi:10.1146/annurev.fluid.010908.165130, 2009.

Steeneveld, G. J., Mauritsen, T., De Bruijn, E. I. F., de Arellano, J., Svensson, G. and Holtslag, A. A. M.: Evaluation of limited-area models for the representation of the diurnal cycle and contrasting nights in CASES-99, J. Appl. Meteorol. Climatol., 47(3), 869-887, 2008.

Steiner, J. F. and Pellicciotti, F.: Variability of air temperature over a debris-covered glacier in the Nepalese Himalaya, Ann. Glaciol., doi:10.3189/2016aog71a066, 2016.

Steiner, J. F., Pellicciotti, F., Buri, P., Miles, E. S., Immerzeel, W. W. and Reid, T. D.: Modelling ice-cliff backwasting on a debriscovered glacier in the Nepalese Himalaya, J. Glaciol., 61(229), 889-907, doi:10.3189/2015jog14j194, 2015.

Steiner, J. F., Litt, M., Stigter, E. E., Shea, J., Bierkens, M. F. P. and Immerzeel, W. W.: The Importance of Turbulent Fluxes in the Surface Energy Balance of a Debris-Covered Glacier in the Himalayas, Front. Earth Sci., 6(October), 1-18, doi:10.3389/feart.2018.00144, 2018.

Steiner, J. F., Buri, P., Miles, E. S., Ragettli, S. and Pellicciotti, F.: Supraglacial ice cliffs and ponds on debris-covered glaciers: Spatio-temporal distribution and characteristics, J. Glaciol., doi:10.1017/jog.2019.40, 2019.

Stephens, G. L. and Ellis, T. D.: Controls of global-mean precipitation increases in global warming GCM experiments, J. Clim., 21, 
6141-6154, doi:10.1175/2008JCLI2144.1, 2008.

Stevens, B. and Bony, S.: What are climate models missing?, Science (80-. )., doi:10.1126/science.1237554, 2013.

Stigter, E. E., Litt, M., Steiner, J. F., Bonekamp, P. N. J., Shea, J. M. and Immerzeel, W. W.: The Importance of Snow Sublimation on a Himalayan Glacier, , 6(August), 1-16, doi:10.3389/feart.2018.00108, 2018.

Syed, F. S., Giorgi, F., Pal, J. S. and King, M. P.: Effect of remote forcings on the winter precipitation of central southwest Asia part 1: Observations, Theor. Appl. Climatol., 86(1-4), 147-160, doi:10.1007/s00704-005-0217-1, 2006.

Talbot, C., Bou-Zeid, E. and Smith, J.: Nested mesoscale large-eddy simulations with WRF: performance in real test cases, J. Hydrometeorol., 13(5), 1421-1441, 2012.

Tariq, S., Mahmood, A. and Rasul, G.: Temperature and Precipitation : GLOF Triggering Indicators in Gilgit-Baltistan , Pakistan, Pakistan J. Meteorol., 10(20), 39-56, 2014.

Taylor, K. E., Stouffer, R. J. and Meehl, G. A.: An overview of CMIP5 and the experiment design, Bull. Am. Meteorol. Soc., 93(4), 485-498, doi:10.1175/BAMS-D-11-00094.1, 2012.

Thériault, J. M., Rasmussen, R., Ikeda, K. and Landolt, S.: Dependence of snow gauge collection efficiency on snowflake characteristics, J. Appl. Meteorol. Climatol., 51(4), 745-762, 2012.

Trenberth, K. E.: Changes in precipitation with climate change, Clim. Res., 47, 123-138, doi:10.3354/cr00953, 2011.

Trenberth, K. E., Dai, A., Rasmussen, R. M. and Parsons, D. B.: The changing character of precipitation, Bull. Am. Meteorol. Soc., doi:10.1175/BAMS-84-9-1205, 2003.

Trenberth, K. E., Fasullo, J. T. and Shepherd, T. G.: Attribution of climate extreme events, Nat. Clim. Chang., 5(8), 725-730, doi:10.1038/nclimate2657, 2015.

Tseng, Y. H. and Ferziger, J. H.: A ghost-cell immersed boundary method for flow in complex geometry, J. Comput. Phys., doi:10.1016/j.jcp.2003.07.024, 2003.

Tuinenburg, O. A., Hutjes, R. W. A. and Kabat, P.: The fate of evaporated water from the Ganges basin, J. Geophys. Res. Atmos., 117(1), 1-17, doi:10.1029/2011JD016221, 2012.

Twomey, S.: Aerosols, clouds and radiation, Atmos. Environ. Part A, Gen. Top., 25(11), 2435-2442, doi:10.1016/09601686(91)90159-5, 1991.

Umphrey, C., DeLeon, R. and Senocak, I.: Direct Numerical Simulation of Turbulent Katabatic Slope Flows with an ImmersedBoundary Method, Boundary-Layer Meteorol., doi:10.1007/s10546-017-0252-3, 2017.

Viviroli, D., Dürr, H. H., Messerli, B., Meybeck, M. and Weingartner, R.: Mountains of the world, water towers for humanity: Typology, mapping, and global significance, Water Resour. Res., 43(W07447), doi:10.1029/2006WR005653, 2007.

Vos, F., Rodriguez, J., Below, R. and D, G.-S.: Annual Disaster Statistical Review 2009 The numbers and trends, Brussels., 2010.

Wang, C., Wilson, D., Haack, T., Clark, P., Lean, H. and Marshall, R.: Effects of initial and boundary conditions of mesoscale models on simulated atmospheric refractivity, J. Appl. Meteorol. Climatol., 51(1), 115-132, 2012.

De Wekker, S. F. J., Kossmann, M., Knievel, J. C., Giovannini, L., Gutmann, E. D. and Zardi, D.: Meteorological applications benefiting from an improved understanding of atmospheric exchange processes over mountains, Atmosphere (Basel)., 9, 1-23, doi:10.3390/atmos9100371, 2018.

Wester, P., Mishra, A., Mukherji, A. and Bhakta Shrestha, A.: The Hindu Kush Himalaya Assessment-Mountains, Climate Change, Sustainability and People, Cham: Springer Nature Switzerland AG., 2019.

Westoby, M. J., Dunning, S. A., Woodward, J., Hein, A. S., Marrero, S. M., Winter, K. and Sugden, D. E.: Instruments and methods: Sedimentological characterization of Antarctic moraines using uavs and Structure-from-Motion photogrammetry, J. Glaciol., 61(230), 1088-1102, doi:10.3189/2015JoG15J086, 2015.

Whiteman, C. D.: Mountain meteorology: fundamentals and applications, Oxford University Press., 2000.

van der Wiel, K., Wanders, N., Selten, F. M. and Bierkens, M. F. P.: Added value of large ensemble simulations for assessing extreme river discharge in a 2 ○ C warmer world, Geophys. Res. Lett., (46), 2093-2102, doi:10.1029/2019GL081967, 2019.

Wijngaard, R. R., Biemans, H., Friedrich Lutz, A., Bhakta Shrestha, A., Wester, P. and Willem Immerzeel, W.: Climate change vs. socio-economic development: Understanding the future South Asian water gap, Hydrol. Earth Syst. Sci., doi:10.5194/hess-22-6297-2018, 2018.

Winiger, M., Gumpert, M. and Yamout, H.: Karakorum-Hindukush-western Himalaya: Assessing high-altitude water resources, Hydrol. Process., 19(12), 2329-2338, doi:10.1002/hyp.5887, 2005.

Van Woerkom, T., Steiner, J. F., Kraaijenbrink, P. D. A., Miles, E. S. and Immerzeel, W. W.: Sediment supply from lateral moraines to a debris-covered glacier in the Himalaya, Earth Surf. Dyn., 7(2), 411-427, doi:10.5194/esurf-7-411-2019, 2019.

Wyngaard, J. C.: Toward numerical modeling in the "Terra Incognita," J. Atmos. Sci., 61(14), 1816-1826, 2004.

Yao, J., Gu, L., Han, H., Wang, Y. and Liu, S.: The surface energy budget on the debris-covered Koxkar Glacier in China, Environ. Earth Sci., doi:10.1007/s12665-014-3350-2, 2014.

Yao, T., Thompson, L. G., Mosbrugger, V., Zhang, F., Ma, Y., Luo, T., Xu, B., Yang, X., Joswiak, D. R., Wang, W. and others: Third pole environment (TPE), Environ. Dev., 3, 52-64, 2012.

Zängl, G.: An Improved Method for Computing Horizontal Diffusion in a Sigma-Coordinate Model and Its Application to Simulations over Mountainous Topography, Mon. Weather Rev., 130(5), 1423-1432, doi:10.1175/15200493(2002)130<1423:AIMFCH>2.0.CO;2, 2002.

Zardi, D. and Whiteman, C. D.: Diurnal Mountain Wind Systems., 2013.

Zhang, H., Pu, Z. and Zhang, X.: Examination of errors in near-surface temperature and wind from WRF numerical simulations in regions of complex terrain, Weather Forecast., 28(3), 893-914, 2013. 


\section{Acknowledgements}

I would like to start with Walter, who I am grateful to for giving me the opportunity to climb the big mountain called PhD. Thanks for giving me the opportunity to do what I wanted and for the freedom to fladder around a bit. Thanks for always making time in your busy schedule, your new ideas and for motivating me at the right times. The fieldwork to Langtang is -literally and symbolically- a highlight of my PhD. Let's plan a mountainbike adventure after my PhD defence, as before will be a bit tricky ;) It was great to have you as daily supervisor from which I learnt to be an independent researcher. You where always critical, and gave me the right push to go more in depth or spend more time on something. Marc, thank you for your suggestions, reviewing and commenting on my thesis; it improved my thesis a lot. I really liked working with you and also enjoyed your presence in the field, especially when you managed to save the third generator in Kyanging (in contrast to the first two).

Jakob, Emmy, we started our journey together and thanks for being around. Unfortunately after all those years you still not managed to get me enthusiastic for bouldering. Emmy, you were my partner in crime during this journey. I can say after those four years we know each other inside out as we shared our ups and downs together. Our conversations were always very valuable, so let's continue our nice chats and maybe do some occasional running when we are up to it. Jakob, your comments always make me laugh and your sarcasm is definitely not misplaced in the Dutch culture. Thanks to you I was always up to date of all new papers in our field. And -of course- I would like to thank the rest of the Mountain Hydrology team: Philip, Remco, Arthur, Fanny, René, Max, Sanita for the wonderful chats, lunch breaks and valuable insights in your lives.

Niko, thanks for dragging me out the office with your improvised cowbell-imitation. Thanks for the fun lunch walks and tea breaks, I can learn a lot from your positivism. Marjolein, although only for me the first half and for you the last half of your PhD, thanks for being around and teach me tons of zelfspot. I like your enthusiasm and was always eager to hear about your adventures -especially on Mondays after the weekend-.

I want to thank all my co-authors of all the publications featured in this thesis. In particular Emily who learned me tons about the WRF model and Chiel who gave me a glimpse of a whole another field of meteorology that I wasn't aware of. Thanks all for your expertise and valuable comments. It definitely helped improving the thesis. 
Amy, when we met 15 years ago we could not have imagined who we are today; thanks for all your gezelligheid and our well spend numerous tea-hours. And of course the players from boundary layers toppers Eef, Nadia en René. We all started our PhD roughly at the same time, however all at other places. Although not very regularly, I am very happy to have you around.

Fleur en Ronald, although on the other side of the world, you where always up to date to -in my view- not always very interesting stuff. Thank you for your patience and willingness to listen to real-life PhD struggles and being there when I needed you. Thanks for your unconditional support and the back-to-earth mentality when I -just sometimes- overthink issues too much. Mama en Piet; you were always eager to know what I was doing and how the whole process was going. Every milestone was followed closely, and celebrated accordingly. Papa, Pepijn and Anouk, thanks for always believing in me and for your unconditional love. Atty en Rudi, thank you for your interest and support along the way!

Martin, almost 9 years together and we have survived some obstacles along the way. Without your support I would not have been the person who I am today. Thanks for always believing in me, having (a lot of) patience and putting things in perspective when needed. Thanks for letting me grumpy when I needed to. Let's keep having fun coming years and start planning some new (tropical) adventures. Let's start this new period in our lives as doctors! 


\section{About the Author}

Pleun Bonekamp obtained her bachelor Soil, Water and Atmosphere with a minor in Physics of the Climate System at Wageningen University in 2014. She continued the master Meteorology, Physical Oceanography and Climate at the IMAU, Utrecht University including an eight-month internship at the KNMI, where she gathered a physical background and understanding in various climate processes. She started as a PhD candidate in 2016 to unravel processes in the atmosphere-cryosphere interface at different scales. Her interests lie in the interdisciplinary research between the atmosphere, cryosphere, larger-scale climate and its social impact. Over the years she gained experience with different (atmospheric) models and big data ( 1 TB) analysis in different programming languages and operating systems. As part of her PhD she attended several (international) conferences and joined the Karthaus Summerschool, which is famous for its cryospheric content. She joined fieldwork to the Nepalese Himalayas up to 5300 $m$ altitude with the international Mountain Hydrology group in spring 2017. Pleun gained teaching experience during various bachelor and master courses over the years $1+700$ hours teaching), first as student assistant at Wageningen University and later as part of her PhD at Utrecht University. She gave (guest) lectures, developed practicals and supervised master students with their thesis.

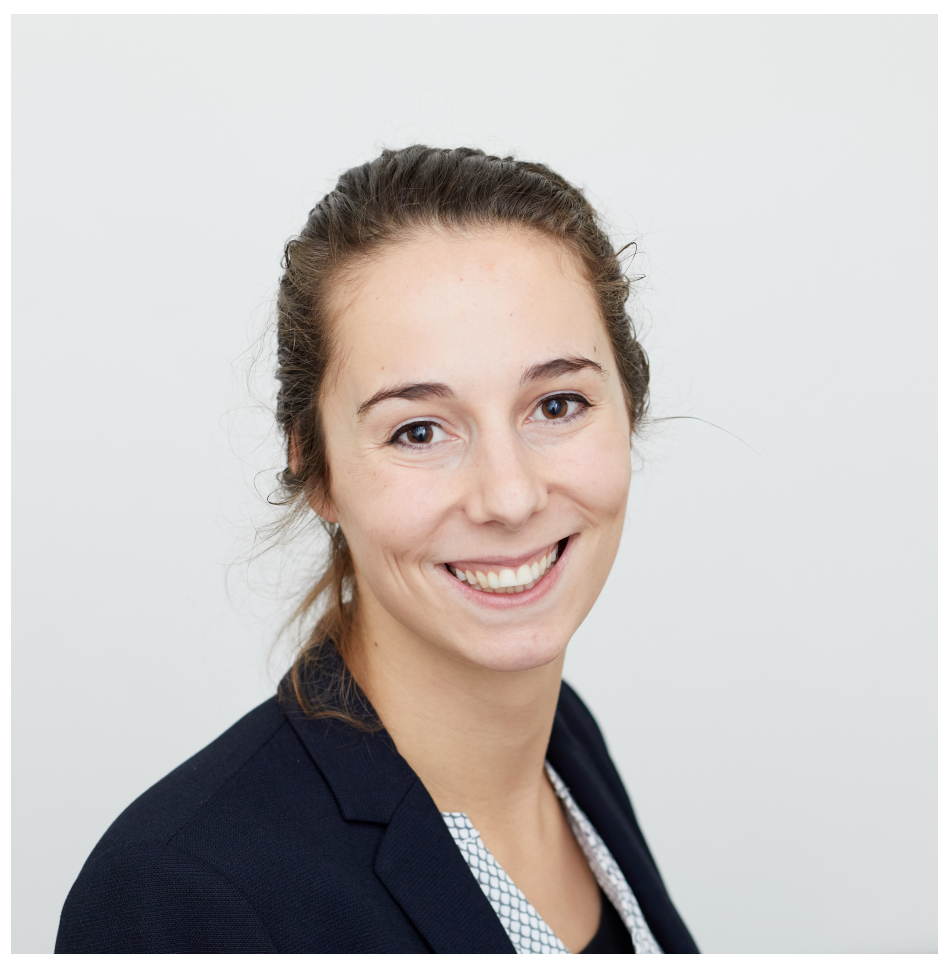




\section{List of publications}

First author publications

Bonekamp P.N.J., Wanders N., van der Wiel K., Lutz A.F., Immerzeel W.W. (2020), Using large ensemble modelling to derive future changes in a 2 and $3 C$ warmer world in High Mountain Asia, International Journal of Climatology, 1-16, doi:10.1002/joc.6742

Bonekamp P.N.J., van Heerwaarden C.C., Steiner J.F., Immerzeel W.W. (2020), Using 3D turbulence-resolving simulations to understand the impact of surface properties on the energy balance of a debris-covered glacier, The Cryosphere, 14, 5, 1611-1632, doi: $10.5194 /$ tc-14-1611-2020

Bonekamp P.N.J., de Kok R.J., Collier E., Immerzeel W.W. (2019), Contrasting meteorological drivers of the glacier mass balance between the Karakoram and central Himalaya, Frontiers in Earth Science, 7, 107, doi: 10.3389/feart.2019.00107

Bonekamp P.N.J., Collier E., Immerzeel W.W. (2018). The Impact of Spatial Resolution, Land Use, and Spinup Time on Resolving Spatial Precipitation Patterns in the Himalayas, Journal of Hydrometeorology, 19 (10), 1565-1581, doi: 10.1175/JHM-D-17-0212.1

\section{Co-authored publications}

De Kok R.J., Kraaijenbrink P.D.A., Tuinenburg O.A., Bonekamp P.N.J, Immerzeel W.W., (2020) Towards understanding the pattern of glacier mass balances in High Mountain Asia using regional climate modelling, The Cryosphere, 14, 3215-3234, doi:10.5194/tc-14-3215-2020

Litt M., Bonekamp P.N.J., Immerzeel W.W., Precipitation downscaling over the Himalayas using the linear theory of orographic precipitation (in prep)

De Kok R.J., Tuinenburg O.A., Bonekamp, P.N.J., Immerzeel W.W. (2018). Irrigation as a Potential Driver for Anomalous Glacier Behavior in High Mountain Asia, Geophysical Research Letters, 45 (4), 2047-2054, doi: 10.1002/2017GL076158

Stigter E.E., Litt M.H.V., Steiner J.F., Bonekamp, P.N.J., Shea, J.M., Bierkens M.F.P., Immerzeel W.W. (2018). The importance of snow sublimation on a Himalayan glacier. Frontiers in Earth Science, Cryosphere, 6 (108), doi: 10.3389/feart.2018.00108 


\section{Selected conference abstracts}

EGU 2020 Vienna: Bonekamp P.N.J., Wanders N., van der Wiel K., Lutz A.F., and Immerzeel W.W., Shifts in in High-Mountain Asia's mountain-specific climate indicators derived with large ensemble modelling (4-05-2020; digital poster)

IUGG 2019 Montreal: Bonekamp P.N.J., van Heerwaarden C.C., Immerzeel W.W., Inhomogeneous spatial effects of debris properties to surface meteorological variables resolved by large eddy simulation modeling (11-7-2019)

AGU 2018 Washington: Bonekamp P.N.J., Immerzeel W.W., de Kok R.J., Collier E, Differences in meteorological conditions between the Karakoram and the Himalayas and their potential impact on the glacier mass balance (13-12-2018)

EGU 2018 Vienna: Bonekamp P.N.J., Immerzeel W.W., de Kok R.J., Collier E. Local contrasting weather dynamics as a potential control of the Karakoram anomaly, (12.04.2018)

AGU 2017 New Orleans: Bonekamp P.N.J., Collier E., Immerzeel W.W., The impact of spatial resolution on resolving spatial precipitation patterns in the Himalayas, (11.12.2017)

EGU 2017 Vienna: Bonekamp P.N.J., Collier E., Immerzeel W.W., High-resolution atmospheric modeling over complex terrain: the effects of spatial resolution and land use in WRF in the Nepalese Himalaya, (23.04.2017) 


\section{Extra activities:}

- PhD council /PhD representative department of physical geography (2019-2020)

- Part of Young Women of Geosciences (YWOG) (2019-2020)

- Course scientific writing (2019)

- Co-developing course, giving guest lectures, practical guidance in course Hydrology and Climate (GEO4-4423; 2017,2018,2019).

- Involved in teaching in Climate systems and Adaptation (GEO4-2327) and Mens en Landschap (GEO2-4210; 2018,2019)

- Guest lecturer for Honours Trajectum Utrecht (2019)

- Master thesis supervision of Elissavet Antonopoulou (2019)

- High-altitude medical training by Dr. Emmanuel Cauchy (2018)

- Involved in making a group documentary and a personal video about my research (2018)

- Workshop Google Earth Engine (2018)

- Karthaus Summerschool 2017

- Course scientific integrity (2017)

- The impacts of spatial resolution on resolving spatial precipitation patterns in complex terrain (invited talk), P.N.J. Bonekamp, Boussinesq event, 26th October 2017, Delft. 
